\title{
The health of our soils
}

\section{Toward sustainable agriculture in Canada}

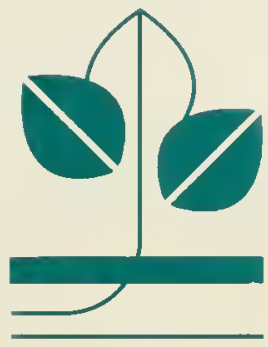




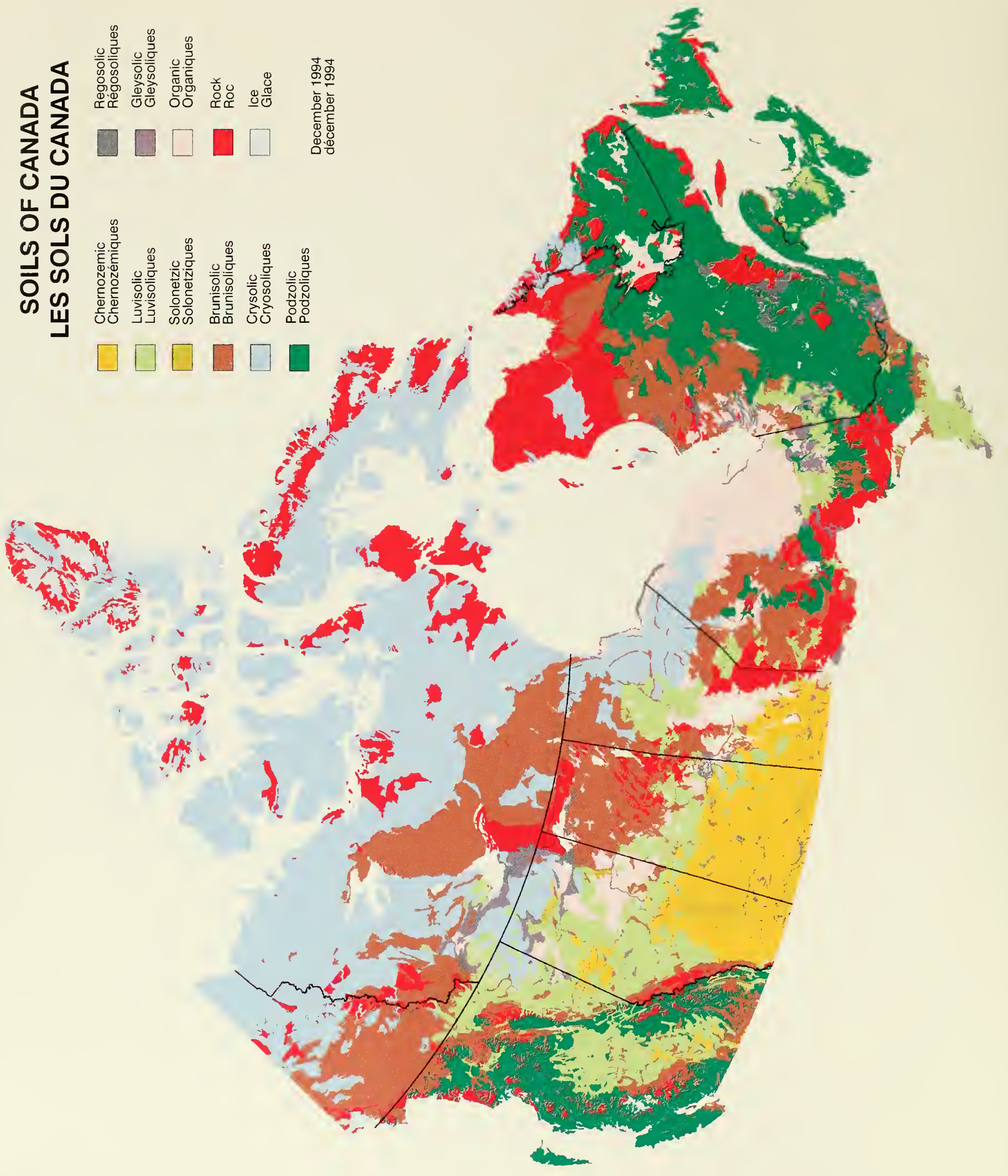




\section{The Health of Our Soils}

Toward sustainable agriculture in Canada 
Digitized by the Internet Archive in 2012 with funding from

Agriculture and Agri-Food Canada - Agriculture et Agroalimentaire Canada 


\section{The Health of Our Soils}

Toward sustainable agriculture in Canada

D.F. Acton and L.J. Gregorich (editors)

Centre for Land and Biological Resources Research

Research Branch

Agriculture and Agri-Food Canada

Publication 1906/E

1995

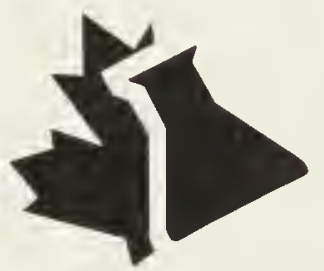

Centre for Land and Biological Resources Research Centre de recherches sur les terres et les ressources biologiques 
Available from

Centre for Land and Biological Resources Research

Research Branch, Agriculture and Agri-Food Canada

K.W. Neatby Building, Central Experimental Farm

Ottawa, ON K1A 0C6

Catalog No. A53-1906/1995E

ISBN 0-660-15947-3

\section{Canadian Cataloguing in Publication Data}

The health of our soils : toward sustainable

agriculture in Canada / D.F. Acton and L. J. Gregorich, editors.--

(Publication ; 1906/E)

Issued also in French under title: La santé de nos sols.

Cat no. A53-1906/1995E

ISBN 0-660-15947-3

1. Soils--Canada--Quality. 2. Soil degradation--

Canada. I. Acton, D. F. (Donald F.) II.

Gregorich, L. J. III. Centre for Land and

Biological Resources Research (Canada) IV.

Canada. Agriculture and Agri-Food Canada. V.

Series: Publication (Canada. Agriculture and

Agri-Food Canada); 1906/E.

S625.C3H42 $1995 \quad 631.4^{\prime} 971 \quad$ C95-982001-9

Cette publication est disponible en français sous le titre

La santé de nos sols : vers une agriculture durable au Canada

Science Writer: L.J. Gregorich

Staff Designer: Judy McCarthy

Staff Editor: Jane T. Buckley 


\section{Contents}

Executive summary (D.F. Actor/L.J. Gregorich) Xi

Introduction (L.J. Gregorich)

1. Understanding soil health (D.F. Acton/L.J. Gregorich) 5

2. Developments and effects of farming in Canada (D.F. Acton) 11

3. A geographical framework for assessing soil quality (K.B. MacDornald et al.) 19

4. Benchmark sites for monitoring soil quality (C. Wang et al.) 31

5. Changes in soil organic matter (E.G. Gregorich et al.) 41

6. Changes in soil structure (G.C. Topp et al.) 51

7. Erosion (G.J. Wall et al.) 61

8. Salinization of soil (R.G. Eilers et al.) 77

9. Contamination of agricultural soils (M.D. Webber/S.S. Singh) 87

10. Agrochemical entry into groundwater (W.D. Reynolds et al.) 97

Summary (L.J. Gregorich/D.F. Acton) 111

Glossary $\quad 121$

Additional reading 129

$\begin{array}{ll}\text { Author affiliations } & 133\end{array}$

$\begin{array}{ll}\text { Acknowledgments } & 137\end{array}$

Map: Terrestrial ecozones of Canada $\quad$ (inside back cover) 


\section{Citation}

D.F. Acton and L.J. Gregorich (eds.) 1995. The health of our soils-toward sustainable agriculture in Canada. Centre for Land and Biological Resources Research, Research Branch. Agriculture and Agri-Food Canada, Ottawa, Ont. xiv + 138 pp.

Each chapter can be cited as follows:

[Name(s) of chapter author(s)]. 1995. [Chapter heading]. Pages [. . .]-[. . .] in

D.F. Acton and L.J. Gregorich (eds.) The health of our soils-toward sustainable agriculture in Canada. Centre for Land and Biological Resources Research, Research Branch, Agriculture and Agri-Food Canada, Ottawa, Ont. 


\section{Foreword}

Soil degradation is the most serious threat to the agricultural industry in the long term. This statement does not diminish the facts of the current economic crisis in some sectors of agriculture, but economic problems are cyclical in nature, and it is to be hoped that the present problems will be managed satisfactorily in the near future. On the other hand, soil degradation is with us today, and will be with us tomorrow, next year, and forever. Unless we are vigilant, we shall lose the competitiveness of our agricultural ind ustry in the next few years. The health of the agricultural industry depends on both the quantity and the health of the soil.

Soil degradation is not just a problem in isolated areas of our nation. Degradation takes place in every agricultural area of Canada, be it through wind erosion, water erosion, acidification, salinization, loss of organic matter, or urban encroachment for residential, commercial, or public use.

Since the Senate report of 1984, Soil at risk: Canada's eroding future, there has been a much greater awareness of what soil degradation is and how it affects soils and the agricultural industry. The report spurred some action to alleviate the problem. I stated in 1984 that unless action was taken quickly, we would lose a major portion of our agricultural lands in 100 years. Since then, many forms of conservation have taken place, allowing that time period to be extended, but not by enough. Let there be no mistake-there is a finite amount of productive agricultural land and without proper care of this most valuable resource, we shall lose the capability of feeding ourselves in the not too distant future.

In a discussion of the problems of urban encroachment on our agricultural lands, the mayor of a community bent on expanding the boundaries of his municipality asked the question: "How much land are we going to require for agriculture for the next 100 years?" I was shocked with the question. My reply was that I can estimate how much land is required for residential housing or commercial development for the next 100 years but that no one can ask me how much agricultural land we need for the next 100 years, because we need it forever.

I am very pleased with this new report, The licalth of out soils-toward sustainable agriculture in Canada. This report is a valuable and timely addition to the understanding of the subject of soil degradation. It indicates how much has been done to protect our soils, but also how much more remains to be done. 


\section{Preface}

Much has been written and said to describe the health of soils in Canada's farming regions. During the past 15 years, several groups and agencies, including the Science Council of Canada; the Standing Senate Committee on Agriculture, Fisheries, and Forestry; federal and provincial departments of agriculture; universities; and nongovernment agencies, such as the Agricultural Institute of Canada, have reported on soil quality. These reports have differed in outlook, style, content, scientific validity and methods, and interpretations. All identified major concerns about soil degradation, but neither individually nor together do they thoroughly assess soil quality in Canada. Recent research on soil quality has questioned some of their findings. Many experts now dispute or qualify the reported extent and degree of soil degradation in Canada, its economic and environmental cost, and the effects of land use and management practices.

Early reports on soil quality successfully raised concern about the effects of soil degradation on the sustainable production of high-quality food, the careless use of land and certain farming practices, and the likely environmental damage. If the 1980s were the decade of awareness, when the plight of Canada's agricultural soils became well known, then the 1990s are the decade of healing, with the focus on finding ways to measure and improve soil quality. The danger that soil degradation is merely an emotional rhetoric rather than a measurable condition is beginning to pass.

Finding that there existed no acceptable way for tracking the health of Canada's agricultural lands, a joint committee of federal and provincial agriculture ministers recommended in the 1986 National Agriculture Strategy that monitoring of soil and water resources be included in future agricultural plans. As a result, the Federal Government started the National Soil Conservation Program to monitor soil quality in Canada and to establish whether degradation of agricultural soils is increasing or decreasing.

The Research Branch of Agriculture Canada made the Centre for Land and Biological Resources Research responsible for developing and coordinating a national program to monitor soil quality. After many sessions involving federal and provincial governments, universities, and the private sector, the Soil Quality Evaluation Program (SQEP) was approved as the first phase of monitoring soil quality in Canada. The program's goal was to develop a national capability to assess soil and associated environmental quality, as well as the effects of land use and management practices on these qualities. Armed with this knowledge, farmers, extension advisers, policy makers, and the public can then work to safeguard and preserve Canada's agricultural lands for future generations. 
This book presents some of the early signs of soil health and associated water quality observed in the SQEP and related activities across the country. Aldo Leopold, noted American ecologist and conservationist, many years ago suggested that "the marvelous advances in agricultural technology are improvements in the pump rather than the well" and that "acre for acre, they have barely sufficed to offset the sinking level of fertility." The authors of this document report on current efforts to measure the "water in the well" and comment on whether "improvements in the pump" are really improvements after all.

Leopold also said that in searching for high ideals it is important not necessarily to achieve, but to strive for that ideal. The ideal for which we are striving is to develop precise measures of soil health and environmental quality for all agricultural soils in Canada. This work is an important step toward that ideal-one that will significantly improve our ability to effectively use and preserve Canada's valuable soil resources. 


\title{
Executive Summary
}

\author{
D.F. Acton and L.J. Gregorich
}

\section{Introduction}

- Soil supports the growth of most food and fibre and contributes to the well-being of Canadians and economic stability.

- Healthy soil, an essential component of a healthy environment, is the foundation upon which sustainable agriculture is built.

- Soil health, also called soil quality, is defined in agricultural terms as the soil's fitness to support crop growth without becoming degraded or otherwise harming the environment.

- Health of Canada's agricultural soils is portrayed by presenting key findings of recent research on

- soil organic matter and soil structure

- processes that degrade soil, including erosion, salinization, and chemical contamination

- groundwater contamination

- the role of land use and management practices in degrading, maintaining, or improving soil quality.

\section{Geographical framework to assess soil quality}

- Potential and actual farmland is compared in the Prairie Provinces and southern Ontario: all the good and much of the marginal farmland is already in production.

- Soil health has been widely assessed using newly developed indexes for soil quality and susceptibility to change.

- Areas of potentially declining soil quality include arid and saline regions on the prairies, especially those under summerfallow, and areas of intensive cropping, especially of row crops, in southern Ontario.

- Conservation tillage is used extensively on more than $60 \%$ of prairie farmland and more than $40 \%$ of southern Ontario farmland.

- Soil quality is limited by both soil-landscape conditions and land use and management conditions in $2.4 \%$ of farmland on the prairies and $7.3 \%$ in southern Ontario. 


\section{Benchmark system}

- Twenty-three benchmark sites were set up across Canada in 1989 to monitor soil quality under representative farming systems and landscape conditions.

- Regular measurements are made of soil properties to determine effects of land use and management practices.

- Baseline data sets will be completed for all sites in 1995; resampling has begun, yielding the first measurements of effects of soil degradation.

\section{Soil organic matter}

- Soil organic matter losses of 15-30\% since initial cultivation have been measured on uneroded soils (compared to earlier estimates of 50-70\%).

- Most loss occurs during the first 10 years; without erosion, levels drop quickly to about $80 \%$ of the original and then stabilize; with erosion, levels may drop more quickly and not level off even after 70 years.

- Levels have been maintained or increased in some Canadian croplands because of conservation practices that reduce erosion and increase the amount of organic matter added to soil.

\section{Soil structure}

- Structural deterioration is associated with soils that are fine-textured, wet, low in organic matter, and eroded.

- Soil compaction is a significant problem in all agricultural regions except the prairies, where structure is inherently good.

- Soil structure improves with increased soil organic matter and decreased erosion; beneficial practices include conservation tillage, residue management, extending crop rotations with forages, and using erosion controls.

\section{Erosion}

- Twenty percent of Canada's agricultural land is at high-to-severe risk of inherent (bare soil) water erosion, especially areas of intensive row-cropping, but under 1991 management practices 16\% of the cultivated land in Ontario and 5\% on the prairies is at this risk level; the overall risk of water erosion in Canada has decreased by at least $11 \%$ since 1981 because of conservation practices.

- Thirty-six percent of the prairies is at high-to-severe risk of inherent (bare soil) wind erosion, but under 1991 management practices less than $5 \%$ of the cultivated land on the prairies is at this risk level; the overall risk of wind erosion in Canada has decreased by at least $7 \%$ since 1981 because of changed cropping practices and tillage systems.

- Erosion control practices include conservation tillage, residue management, extending crop rotations, interseeding, growing winter cover crops, planting shelterbelts, stripcropping, contour cultivation, and restructuring landscape (terraces, diversions, and grassed waterways). 


\section{Salinization}

- Sixty-two percent of farmland in the Prairie Provinces has less than $1 \%$ of area affected by salinity; $36 \%$ has $1-15 \%$ affected; $2 \%$ has more than $15 \%$ affected.

- Sixty-six percent of farmland in the Prairie Provinces has low risk of increasing salinity (salinization) under 1991 management practices; 27\% has moderate risk; 7\% has high risk.

- Risk of increasing salinity decreased by $19 \%$ in Manitoba since 1981, probably because of conservation practices (conversion to permanent cover and extending crop rotations).

\section{Soil contamination}

- Pesticide contamination of soil is not a serious problem in Canada; local elevated levels are attributed to pesticide use either during the previous growing season or prior to the ban on certain persistent pesticides in the 1970s.

- Nonpesticide organic contaminants occasionally detected are readily degraded and not thought to pose risk.

- Heavy metal contaminants are of most concern because they persist and may enter the human food chain; their levels must be controlled.

- Land application is an acceptable way to manage sewage sludge provided guidelines respecting heavy metal loading are followed; the need for guidelines respecting organic chemical loading is currently under review.

\section{Agrochemicals in groundwater}

- Nitrate entry into groundwater is ubiquitous in Canada; levels are usually below the safe limit, but areas of intensive agriculture are prone to levels above the safe limit, including south coastal British Columbia, the Maritime Provinces, and areas under heavy manure application or irrigation.

- Pesticide concentrations in groundwater are almost always below safe limits, mainly because of the use of less-persistent, more-specific pesticides than in the past.

- Bacterial entry into groundwater usually results from liquid manure being applied to soil; bacterial entry into wells is usually from point-source leakage (e.g., manure piles).

- Agrochemical leaching can be reduced by balancing fertilizer application with crop needs, regulating the amounts applied to soil, refining agrochemical application and irrigation methods, improving fertilizer and pesticide composition, and adopting integrated pest management. 


\section{Summary}

- Some Canadian agricultural soils are improving in health and becoming less susceptible to erosion and other damaging forces, mainly because of increased use of conservation farming methods over the past 10 years.

- The general trend is a small one overall and does not apply to all soils.

- Further maintenance and improvement of agricultural soil health depends on selecting appropriate land use and management practices.

- New government policy for soil conservation is needed, aimed at achieving sustainable agriculture and built on the understanding that agro-ecosystems are part of the broader environment.

- Soil management programs are best designed at the farm level, integrating management practices to suit specific, local soil needs. 


\title{
Introduction
}

\author{
L.J. Gregorich
}

Most people know that they need clean air and clean water to stay healthy. Fewer people realize that their well-being also depends on the health of another component of our environment-the soil. Soil supports the growth of most of our food and fibre, so its productivity is a major factor in the economies of Canada and other nations. But it also has a much broader role globally. Soil acts as a filter, cleaning air and water. It exchanges gases with the atmosphere and thus influences global climate. Soil receives organic wastes and recycles their nutrients back to plants; it also holds and breaks down some toxic wastes. Because soil plays such a key role in world health, economies, and environmental stability, we must conserve it and use it in a sustainable manner.
This soil of ours, this precious heritage, what an unobtrusive existence it leads! ... To the rich soil let us give the credit due. The soil is the reservoir of life.

J.A. Toogood Our Soil and Water

\section{Sustainable agriculture}

Sustainable agriculture is a way of farming that can be carried out for generations to come. This long-term approach to agriculture combines efficient production with the wise stewardship of the earth's resources. It is hoped that, over time, sustainable agriculture will do the following:

- meet human needs for food and fibre

- protect the natural resource base and prevent the degradation of soil and water quality

- use nonrenezuable resources efficiently

- use natural biological cycles and controls

- assure the economic survival of farming and the well-being of farmers and their families.

The most important link between farming practices and sustainable agriculture is the health, or quality, of our agricultural soils (Fig. 0-1). If soil becomes degraded, more resources in terms of time, money, energy, and chemicals will be needed to produce less-abundant crops of a lower quality, and the goals of sustainable agriculture will not be met. On the other hand, if soil degradation is reversed and soil health is maintained or improved by using appropriate farming methods, sustainable agriculture can be a reality.

\section{The health of Canada's agricultural soils}

Most producers know from experience that you cannot keep taking a crop off year after year without also investing back into the land. But, since the 1950s, the pressure on farmers to produce more and more food, to meet their costs of production, and to 
STRATEGY

Conservation Farming

Crop rotations

Residue management

Conservation tillage

Erosion control

Permanent cover

Reduced fallow

Organic recycling

Integrated pest management

Water management
GOAL

Sustainable Agriculture

LINK

Good-quality food

Realistic ccop yields

Environmental health

Soil health Energy conservation

Natural resource conservation

Economic viability

Safety

(After Parr et al. 1992)

Figure 0-1 Soil health links conservation farming to sustainable agriculture.

Sustainable development is that which meets the needs and aspirations of the present without compromising the ability of future generations to meet their own needs.

World Council on Economic

Development Our Common Future maintain an urban standard of living has in many cases outweighed the importance of caring for the soil. Crop yiclds have increased over the past 20 years, but both the soil and the environment have suffered.

Soil begins to change as soon as it is "broken" and converted from a natural state to one suitable for agriculture.

Farming introduces a new system of plant growth that changes the soil's balance of water, organic matter, and nutrients and exposes it to greater wind and water erosion. Some tillage and cropping methods break down the structure of the soil, which causes compaction and promotes greater erosion and soil salinity in some locales. Other farming practices, such as liming acid soils, draining waterlogged soils, and removing stones, improve soils from their natural state.

Agricultural activity also contributes to broader environmental degradation. As soil health declines, more fertilizer and pesticides may be needed to maintain acceptable crop production. However, poor soils are less able to hold and use these chemicals, which often find their way into surface water and groundwater. Unhealthy soils are also less effective in the role of gas exchange and maintaining air quality.

\section{Objectives of this report}

Ten years ago reports warned of the environmental, economic, and human health disaster that could result from the degradation of Canada's agricultural soils. But in what condition do we find Canada's agricultural soils today? Are soils really decreasing in quality and, if so, what measures have been taken to reverse soil degradation and to build our soils back up?

We begin to answer these questions by presenting recent findings of Canadian research on soil quality. We look at agricultural activity in an environmental context and focus on farming systems as the main vehicle for halting soil degradation, and maintaining or improving soil health. Our objectives are

- to define soil health and to identify and describe the factors contributing to it

- to identify and describe the main problems of soil degradation found in Canada

- to assess the present status of soil health in Canada

- to examine trends in soil health over the past 10 years

- to predict future trends in soil health

- to suggest solutions to problems of soil degradation. 


\section{Reporting scope, methods, and reliability}

In this report we describe soil health in rain-fed, cultivated agricultural land. We do not consider the health of soils in forest, recreational, or urban lands, nor in agricultural rangeland. Little attention is given to soils under irrigation. Although we address soil health from an environmental perspective, air quality is not considered and surface water quality is not discussed in detail.

Although the goal of the report is to provide a national picture of soil health, research results are most abundant for the Prairie Provinces and Ontario. We do not address all themes in all regions and do not examine soil health in Newfoundland or the Territories, regions with relatively little agricultural land.

Most of the studies presented here provide "windows" through which we can view aspects of soil health at specific sites in Canada. The loss of soil organic matter and the deterioration of soil structure exemplify degradative processes that we examine using this approach. Where possible, broader assessments provide a picture of soil quality across a larger geographical area, such as an agricultural region.

In some cases, we portray soil health by assessing the risk that it will change. Such risk assessment depends heavily on existing knowledge of the ways in which soils become degraded in response to pressures such as wind and water erosion and salinization. We made every attempt to use the best data and the most reliable simulation models and other mathematical treatments available. However, our knowledge of soil degradative processes is incomplete and our ability to predict their effects needs continual refinement.

Information describing land-use and management practices for all the soils in the various agricultural regions of Canada is also incomplete and is subject to the type of errors associated with survey data. For example, the reliability of information on land use and management practices from the Census of Agriculture depends to a large extent on whether respondents interpreted the census questions in the intended way.

We cannot report on some parts of the soilquality monitoring program in full at this time. In particular, the national benchmarks system is in its early years, and we confine ourselves to describing the system and giving examples of preliminary monitoring data. Other ongoing studies will continue to produce a clearer picture of changes in soil health as more field data are collected and as computer simulation models are validated and refined for Canadian soils.

\section{Reading the report}

Our report is in three parts. Chapters 1 to 4 introduce the reader to the concept of soil health in agriculture. Chapters 5 to 10 present recent research findings on topics related to soil degradation. The summary offers a systematic approach to assessing and conserving soil quality.

Although we have written each chapter to stand alone (each may be cited as an individual document for which the correct citation is given on page vi), the reader will benefit most from reading the entire report. If this is not possible, the highlights at the beginning of each chapter capture the main points of interest.

We intend this report to be understood by people who are not scientists. However, we have not avoided technical words and concepts completely. These words are italicized and defined. The glossary at the end of the report lists all words treated in this way, as well as other helpful definitions. 


\title{
Understanding Soil Health
}

\author{
D.F. Acton and L.J. Gregorich
}

\section{Highlights}

- Soil health is an indicator of environmental health and, like human health, provides an overall picture of the condition of many properties and processes; the terms soil health and soil quality can be used interchangeably.

- Soil health or quality is the soil's fitness to support crop growth without resulting in soil degradation or otherwise harming the environment.

- Soil quality changes slowly because of natural processes, such as weathering, and more rapidly under human activity; land use and farming practices may change soil quality for the better or for the worse.

- Soil health deteriorates mainly through erosion by wind and water, loss of organic matter, breakdown of soil structure, salinization, and chemical contamination.

\section{Introduction}

Soils are used for many purposes, such as road and building construction, waste disposal, and crop production. The most practical definitions of soil quality relate to the soil's function, or what it does. The definition of soil health commonly used by agriculturalists has emphasized soil productivity - a healthy soil produces abundant, high-quality crops. But, over the past 10 years, our thinking about agriculture has shifted. We no longer see it as a closed operation, but rather as part of a much-broader ecological system, which interacts with, and affects other parts of, the system. We need a new definition of soil health that goes beyond productivity and connects with the environment as a whole. To that end, we define soil health for agriculture as the soil's fitness to support crop growth withont resulting in soil degradation or otherwise harming the environment.

The terms soil health and soil quality can be used interchangeably. Soil health is the term commonly used by producers and by the popular press. Soil quality is the term favoured by researchers and used most often in scientific writing. Some writers have attempted to join the terms by referring to soil health/quality. We prefer to use both terms to mean the same thing in the remainder of the report.
The thin layer of soil covering the earth's surface represents the difference between survival and extinction for most terrestrial life.

John W. Doran and Timothy B. Parkin Defining and Assessing Soil Quality 
In many ways, soil quality is one measure of ecosystem health. Conserving soil quality means protecting the full range of ecological services high-quality soils provide.

Sandra S. Batie and Craig A. Cox Soil and Water Quality: An Agenda for Agriculture

\section{Assessing soil quality}

Human health is a composite picture of the condition of the body's various parts and functions. We assess human health by looking at many factors (including physical function, mental capacity, and emotional well-being) and by forming an overall sense of how the body and mind are working. In the same way, soil quality is a composite picture of the state of the soil's many physical, chemical, and biological properties and of the processes that interact to determine this quality. Furthermore, as human health varies from person to person, soil health varies among soil types. Some soils have poor inherent (natural) quality and are not fit for crop production.

Just as we have no single measure of human health, we have no single measure of soil quality. Although soil quality cannot be measured directly, it can be inferred or estimated, both by measuring specific soil properties (such as $\mathrm{pH}$ or organic matter content) and by observing soil conditions (such as fertility, structure, and erodibility).

Soil researchers have recently recognized the need for a reliable and systematic way to assess soil quality. One promising possibility is to develop a soil quality index - a report card that documents a soil's health condition and provides a way to monitor that condition over time and to predict the effects of farming practices. The index would include measurements of certain soil properties, functions, and conditions that provide useful indicators of soil quality (see box). Work is currently under way in several countries to identify suitable soil quality indicators and to develop efficient, reliable methods with which to measure them.

\section{Elements of soil quality}

The three main functions of soil are to provide a medium for plant growth, to regulate and partition water flow through the environment, and to serve as an environmental buffer. A soil's chemical, physical, and biological properties work together to make a soil fit to perform these functions.

\section{Plant growth}

A good-quality soil is both tillable and fertile. It yields good-quality crops because it

- provides a suitable medium for seed germination and root growth (including the absence of unsuitable chemical conditions, such as acidity or salinity, that are harmful to plant growth)

- supplies a balance of nutrients to plants

- receives, stores, and releases moisture for plant use

- supports a community of microorganisms that recycle nutrients through decomposition and help plants to resist disease.

\section{Water regulation and partitioning}

Water entering the soil as either rain or melting snow has several fates. It can soak into the soil, to be stored or taken up by plants. It can percolate down through the soil and enter the groundwater. If it fails to penetrate the soil, it can move along the soil surface as runoff.

Depending on the amount of precipitation received, a good-quality soil stores enough water to promote optimal crop growth. It allows only a limited amount of water either to run off the soil surface, carrying away soil sediments, or to seep below the root zone into the ground water.

\section{Environmental buffer}

A good-quality soil can accept and hold nutrients and release them as required by plants. To some extent, it can also break down harmful compounds into substances that are nontoxic to plants and animals and do not pollute surface water and groundwater. However, soil has a limited ability to perform this function and should not be expected to repair the damage of chemical contamination caused by human activity. 


\section{Changing soil quality}

The inherent or natural quality of a soil is determined by the geological materials and soil formation processes (such as chemical and physical weathering) that combine to produce it. The characteristics of a natural soil can be changed by human activities, including land use and farming practices. Decline in inherent soil quality can occur because of erosion, loss of organic matter, compaction, desertification, and other degradative processes. On the other hand, soil quality can be maintained or even improved by regularly adding organic material, using conservation tillage, rotating crops, and growing legumes, among other practices.

\section{Effects of land use and management practices}

Agricultural land use refers to the type of farming activity that takes place on an area of land. Examples of agricultural land use include pasture and cultivation of forage crops, cereals, oilseeds, berry fruits, or vegetables. Defining land use also considers whether crops are grown under natural rainfall or irrigation. In general, the more that a specific land use disturbs the land's natural ecology, the greater its effects on soil quality.

Management practices are methods that a farmer uses to tend the land, cultivate a crop, or care for livestock. On pasture lands, these practices include animal stocking, rotational grazing, weed control, and protecting vegetation along water courses. On cultivated lands, management practices include crop selection and rotation, tillage methods, residue management, traffic management, use of fertilizers and other nutritional amendments, pest control, and water management.

Crops that provide high-density and continuous ground cover offer greater protection against erosion than rowcropping systems or systems that include extensive use of cultivated fallow. Minimal tillage for weed control or seedbed preparation alters soil structure less and

\section{Producers describe soil health}

Producers generally describe soil health subjectively, using words related to how the soil looks, feels, and smells. Asked in a U.S. survey to describe healthy soils, producers said that they

- are deeper and darker

- easier to plow

- work up more easily in the spring

- sponge up and hold more water

- dry out sooner

- break down crop residues more rapidaly in the fall

- have higher organic matter and less erosion

- have greater numbers and more varieties of earthworms

- have a sweet, fresh-air smell.

They also observed that, on healthy soils,

- fuel costs are way down

- there is less wear and tear on machinery

- the tractor pulls more easily

- less fertilizer is required

- crop yields are higher

- there is a greater variety of weeds

- there are fewer problems with insects and disease

- the feed-crops produced are of better quality, and veterinary bills of animals eating this feed are lower.

(L.J. Gregorich)

maintains crop residues better than moreintensive tillage. Systems that return plant nutrients at the rate of their removal by crops help maintain soil tilth and cover, which protect against erosion. Reduced use of pesticides on erodible soils or use of pesticides along with effective measures for crosion control reduces the risk of contaminating surface water. Systems that reduce the use of pesticides on highly permeable soils reduce the risk of contaminating groundwater. 


\section{Processes that reduce soil quality}

Wind and water erosion, loss of organic matter, breakdown of soil structure, salinization, and chemical contamination-all processes that affect soil quality (Fig. 1-1) are accelerated by inappropriate land use

\section{Soil quality indicators}

An indicator is a factor that indicates or helps to define the condition of a larger system. For example, your blood pressure and heart rate are indicators of your general health.

Soil quality indicators are properties, functions, or conditions that point to a soil's general health. These factors may be directly related to the soil, or they may be related to something that is affected by the soil, such as crops and water. Some factors that may be useful as indicators of soil quality are

Soil

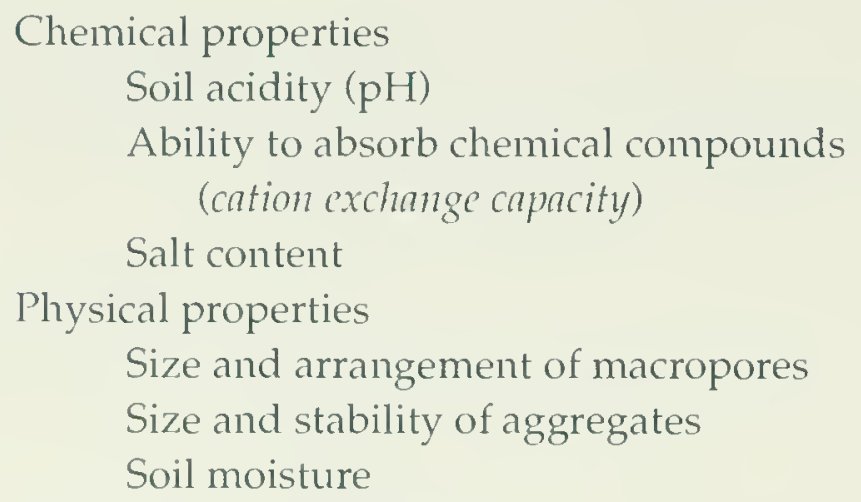

Surface water quality

Groundwater quality.

and management practices. These processes reduce the soil's ability to grow crops and to maintain a healthy environment.

\section{Erosion}

Erosion is a process that removes and redistributes soil. Although some erosion takes place gradually, most results from extreme weather events, such as a windstorm or a heavy rainfall.

Both wind and water erosion remove topsoil, which is the soil layer best fitted to support life. Loss of all or part of this surface layer impairs the soil's ability to produce a crop by reducing its fertility and its ability to accept and store water and air. The materials removed may be redeposited in some nearby leeward or low-lying area with little or no apparent consequence to the environment at that locale. In some areas, however, the materials are transported to streams, rivers, and lakeseven to oceans-which may considerably affect the water quality in these areas.

Each further loss of topsoil compounds the effects of erosion, so the soil increasingly loses its ability to produce crops and to regulate and partition the flow of water in the environment. As soil fertility declines, lost nutrients are often replaced by applying fertilizer, and the chance of nutrient loading in the runoff during subsequent erosion events increases.

Protecting the soil against erosion usually involves keeping it covered with crops or crop residues. Using methods such as conservation tillage and residue management, green manuring, continuous cropping, and winter cover-cropping helps to maintain soil cover.

\section{Loss of organic matter}

Loss of soil organic matter is usually related to the loss of topsoil through erosion. Organic matter is also lost by microbial oxidation, in which soil microorganisms use organic matter in the soil as a food source during their normal 
metabolism. Management practices that add little organic matter to the soil or increase the rates of organic matter decomposition (such as summerfallowing and excess tillage) lead to reduced levels of organic matter in the soil.

Because organic matter is rich in nitrogen, phosphorus, and other nutrients, loss of soil organic matter reduces a soil's fertility and its capacity to produce crops. Organic matter holds more water per unit weight than mineral matter and is needed for a well-aggregated soil structure. Its loss also reduces the soil's capacity to accept, store, and release water for plant growth.

\section{Changes in soil structure}

Changes in soil structure affect soil quality in many ways. Pore space in the soil is important as a pathway for water entering the soil, a storehouse and provider of soil water and air to the plant, and a conduit for water leaving the soil.
High-quality soils have many pores of various sizes and shapes, with varying continuity. Farming practices that increase the rate of erosion, break down soil aggregates, or reduce soil pore space (compact the soil) are the most common means of modifying soil structure. A breakdown of soil structure reduces the soil's capacity to produce crops, which in turn affects its capacity to regulate and partition water flow through the environment.

\section{Salinization}

Soil salinity (an excess of salts in the soil) reduces the soil's capacity to produce crops by restricting the amount of water the plant can withdraw from the soil. Crops respond to increasing salinity in much the same way as they do to increasing drought stresseven though water is present in the soil, the plant responds as though the soil were dry or nearly dry.

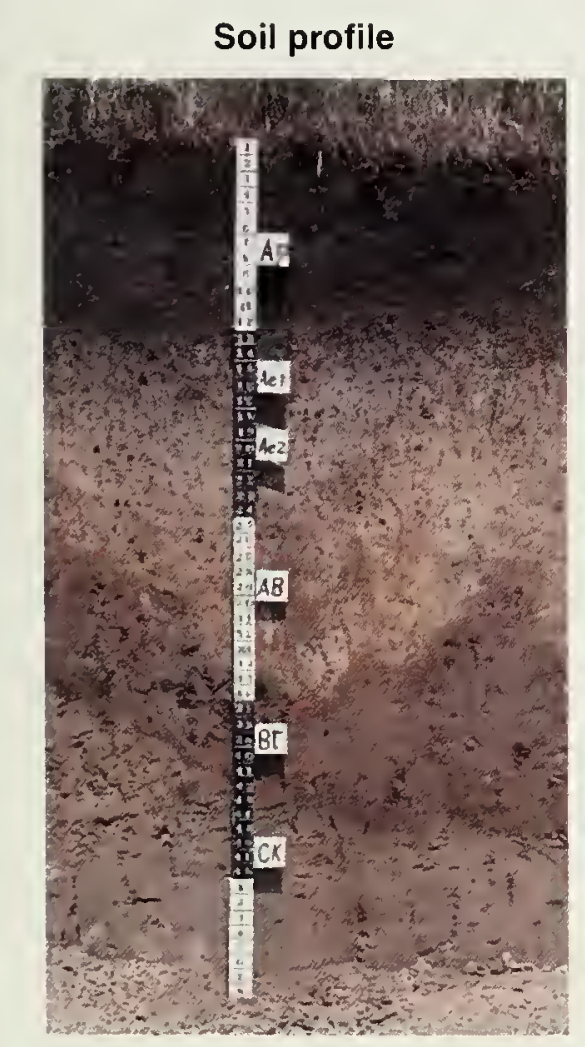

Soil profile

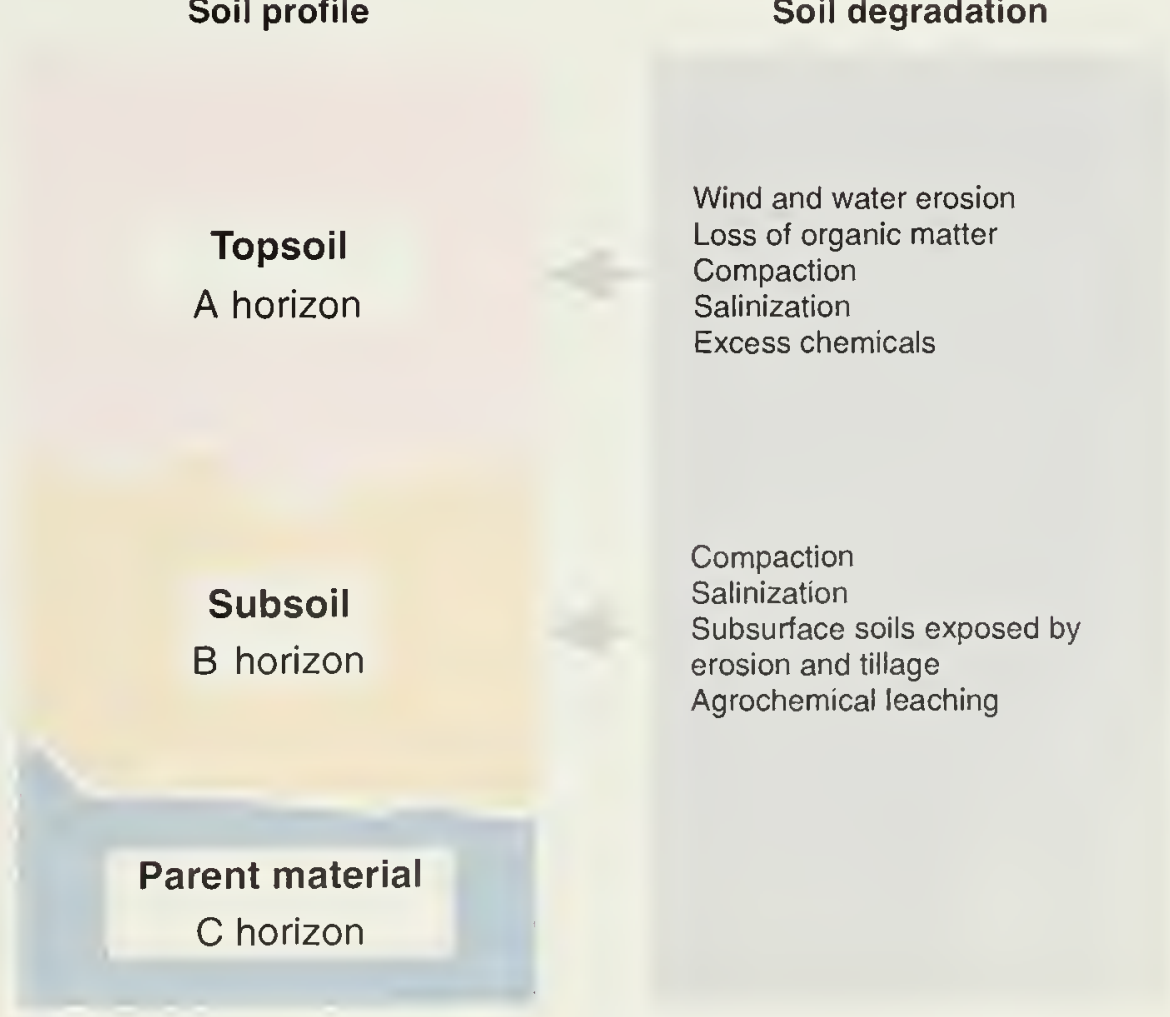

Topsoil doesn't need to be bulldozed, paved over, or washed away to lose its productivity. If it is mismanaged, or polluted, it can lose many of the natural soil properties that directly contribute to plant growth or the soil's capability to respond to agricultural management.

R. Neil Sampson Farmland or Wasteland: A Time to Choose

Figure 1-1 Degradation problems throughout the soil profile. 


\section{Agri-environmental indicator project}

Agriculture and Agri-Food Canada's (AAFC) agri-environmental indicator project, begun in 1993, is designed to

- improve our understanding of the nature, extent, and location of environmental risks and benefits related to primary agriculture

- track the progress of the agri-food sector toward environmentally sustainable agriculture

- facilitate the design and targeting of agri-environmental strategies, policies, and programs.

This project works from a framework that shows the cyclical relationship among farming practices, environmental conditions, productivity, and policy.

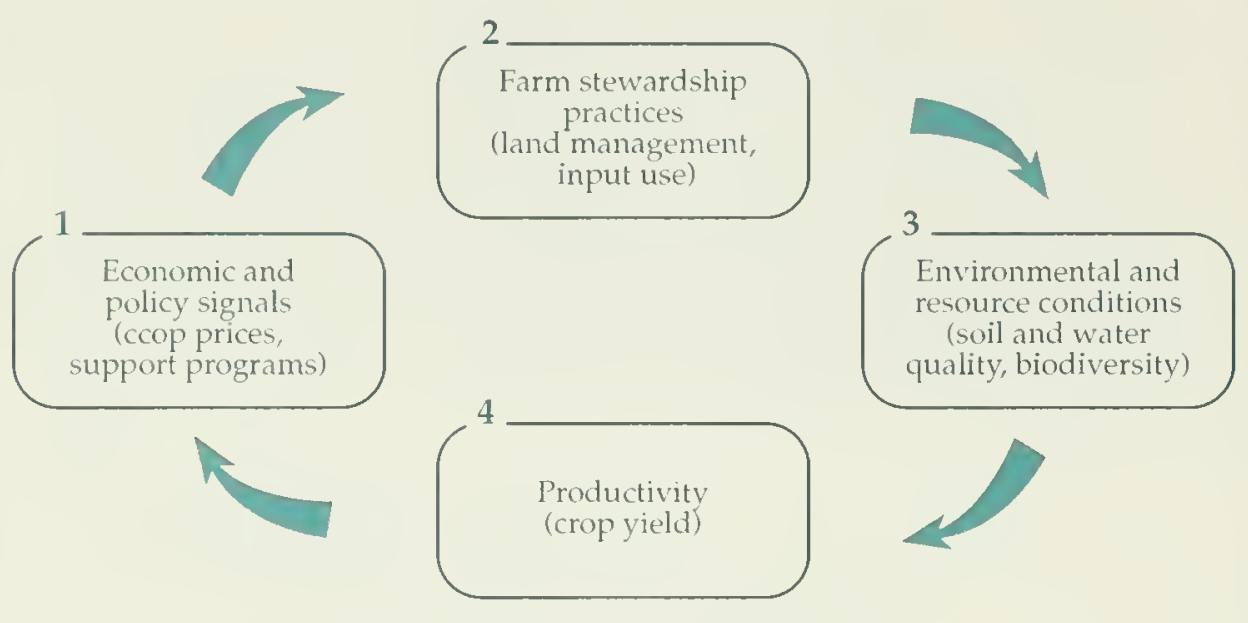

The stewardship-state-productivity framework.

An agri-environmental indicator is a measure of change either in the state of environmental resources used or affected by agriculture, or in farming activities that affect the state of these resources.

Six comprehensive performance indicators and their subcomponents have been identified. Each indicator is linked to an agri-environmental issue and a corresponding performance objective. Results for one of these indicators-soil degradation risk-are presented in this report as soil organic matter change, erosion, and salinization of soil (see chapters 5, 7, and 8 ).

Other indicators have been identified for the issues of water quality, agroecosystem biodiversity, climatic change, farm resource management, and production efficiency. All the indicators relate, directly or indirectly, to soil quality and soil management.
Soil salinity is mainly controlled by geological and climatic factors. However, any change in the hydrologic (water) cycle, such as results from draining or flooding low-lying areas, changing the shape of the land's surface, or increasing or reducing vegetative growth, can affect soil salinity.

\section{Agrochemical contamination}

Agricultural land can become contaminated in many ways, including atmospheric deposition of industrial wastes and direct application of agricultural chemicals, municipal waste, or irrigation water containing salts or chemicals. Here, we consider only soil contamination that results from adding agrochemicals (agricultural chemicals). These chemicals are used in crop production to improve nutrient levels in the soil (fertilizers) and to reduce damage of the crop by pests (pesticides). Unused chemicals may remain in the soil as soil contaminants or become water contaminants by entering surface waters through runoff or groundwater through leaching. Management practices that involve either adding fertilizer (particularly nitrogen) beyond the requirements of the crop or heavily applying certain pesticides on highly permeable soils have the greatest potential to exceed the soil's capacity to act as an environmental buffer.

\section{Environmental health}

Soil health is a key component of environmental health. The findings on soil quality presented in the following chapters are a valuable addition to the information needed to assess the environmental effects of agriculture and to monitor the progress toward sustainable agriculture in Canada (see box). 


\section{Development and Effects of Farming in Canada}

D.F. Acton

\section{Highlights}

- Only 5\% of Canada's vast terrain is suited to agriculture, and much of this area is threatened by urbanization, soil degradation, or both.

- The many types of farming systems found throughout the country reflect differences in ecological conditions (ecozones), land settlement and development policy, and markets.

- The main cause of the degradation of Canada's agricultural soils is the move from small, low-mechanized mixed farms to larger, highly mechanized farms growing monocultures.

- British Columbia's mild climate permits a thriving agriculture in the south; intensive farming on moist soils in the lower mainland may cause loss of soil fertility, compaction, and agrochemical contamination of groundwater.

- The naturally high fertility of soils has made the Prairie Provinces very productive for agriculture for more than 100 years; soil quality may be reduced by wind and water erosion, salinization, and local acidification.

- Central Canada is one of the country's leading agricultural regions; soils may be degraded through compaction, acidification, and erosion; the quality of waters linked to agricultural systems may be reduced by the entry of agrochemicals.

- More than 200 years of agriculture in the Atlantic Provinces has resulted in serious soil degradation in some areas of intense row-cropping, seen in the loss of organic matter and fertility, structural degradation, compaction, and erosion.

\section{Introduction}

Canada is the second largest country in the world, but only $5 \%$ (about 46 million hectares) of its land can be used for crop production. Only one-half of this area is considered prime agricultural land.

During the past two decades, the total area of farmland (all land for crops, grazing and pasture, summerfallow, buildings and barnyards, bush, slough, and marshes, etc.) has remained relatively constant and the area of improved cropland (the sum of cropland, summerfallow, and improved pasture) has levelled off (Table 2-1). Over this period, the composition of improved cropland has changed, with a steady increase in the area of cropland (the total area on which field crops, fruits, vegetables, nursery products, and sod are grown) and
The grower of trees, the gardener, the man born to farming, whose hands reach into the ground and sprout, to him the soil is a divine drug. He enters into death yearly, and comes back rejoicing.

Wendell Berry, poem: "The Man Born to Farming" 
Table 2-1 The use of farmland in Canada, 1971-1991

\begin{tabular}{|c|c|c|c|c|c|}
\hline Land use (million ha) & 1971 & 1976 & 1981 & 1986 & 1991 \\
\hline Total farmland & 68.7 & 68.4 & 65.9 & 67.8 & 67.8 \\
\hline Cropland & 27.8 & 28.3 & 31.0 & 33.2 & 33.5 \\
\hline Summerfallow & 10.8 & 10.9 & 9.7 & 8.5 & 7.9 \\
\hline Improved pasture ${ }^{a}$ & 4.1 & 4.1 & 4.4 & 3.6 & 4.1 \\
\hline Improved cropland & 42.7 & 43.3 & 45.1 & 45.3 & 45.5 \\
\hline $\begin{array}{l}\text { Improved cropland as a } \\
\text { percentage of total farmland }\end{array}$ & 62.2 & 63.3 & 68.4 & 66.8 & 67.1 \\
\hline
\end{tabular}

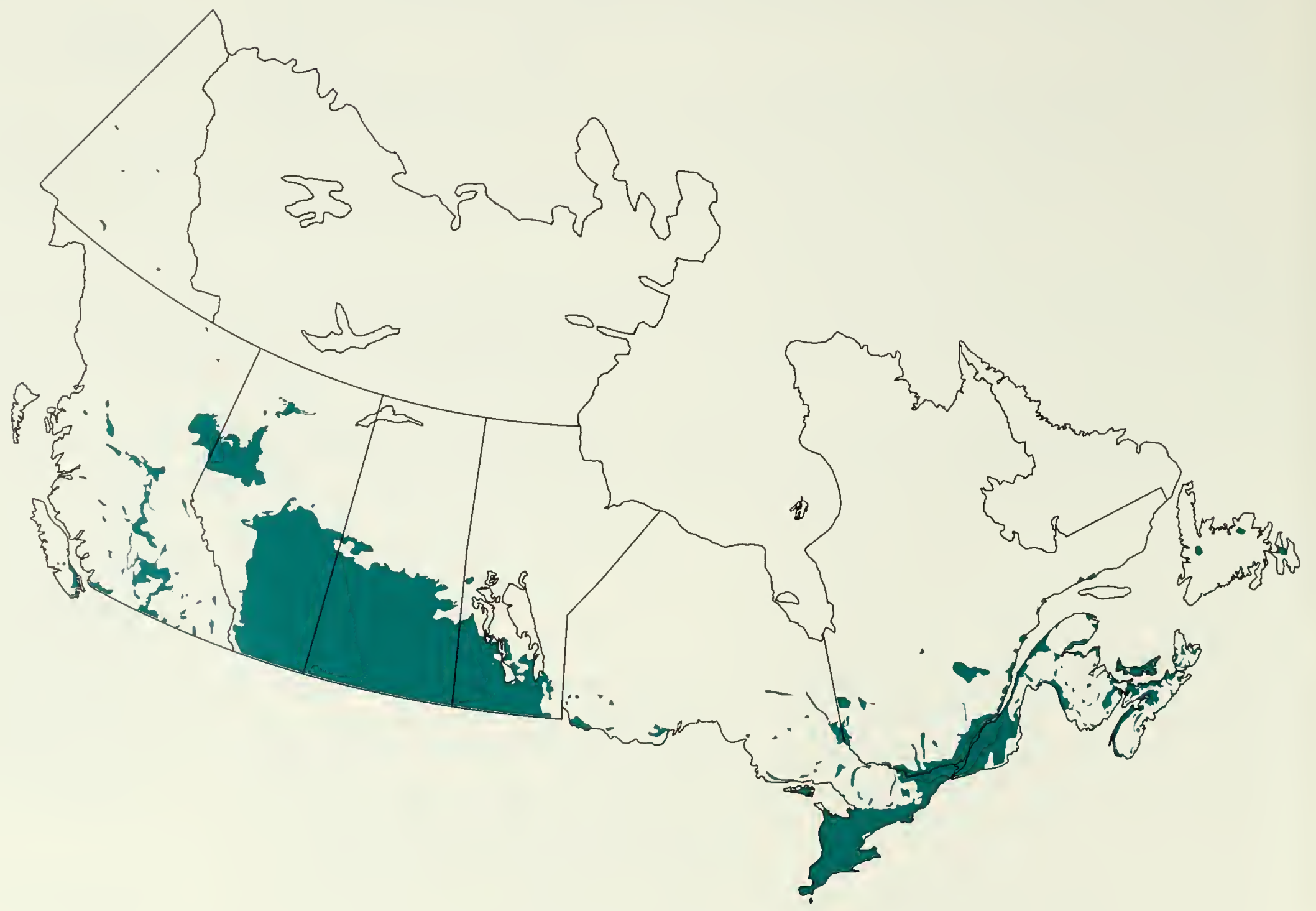

Figure 2-1 Agricultural areas of Canada. 
a steady decrease in the area of summerfallow (land that is not cropped for at least 1 year). These trends suggest that we are approaching or have approached the upper limit of farmland development in Canada. They also suggest that the amount of farmland that can be used for crop production may have peaked and that any further increases in cropland area must come mainly from a change in land use (for example, by further reducing the amount of land in summerfallow). Also, cropland area is continually threatened by conversion to urban and other uses.

Canada's agricultural lands, representing about 293000 farms, stretch from coast to coast across the southern quarter of the country (Fig. 2-1). Widely diverse farming systems have developed throughout Canada in response to land settlement and development policy, markets, and ecological conditions, among other factors.

The ecological conditions of Canada's lands have been used to define ecozones-areas that have distinct climate, vegetation, geology, and soils (see map inside back cover). In this chapter, ecozones are used as the framework to describe

- ecological conditions (geology and soil, climate, and vegetation)

- the history of agricultural development

- the general nature of farming today

- the effect of development and current farming practices on soils and the broader environment.

\section{British Columbia}

British Columbia is a large province, but improved cropland comprises only about 900000 hectares. The most important agricultural lands, excluding the Peace River region considered later with the Prairie Provinces, occur in the Pacific Maritime ecozone and in the the Montane Cordillera ecozone. Many of these areas do not have particularly good agricultural soils, but the mild climate allows these lands to be some of the most productive in Canada.

\section{Alternative agriculture}

Most alternative agriculturalists believe that the standard of living currently enjoyed in the western world is incompatible with sustainable agriculture. But who are these people, and what makes them different?

Long before mainstream agriculturalists conceded that standard farming practices often caused soil degradation, a small group of thinkers and researchers saw the connections between healthy soils, healthy food, and healthy people. The new school of thought that they spawned became known as alternative agriculture, which made a major departure from the attitudes and practices common in agriculture.

Traditional agriculture, driven by the economy, has as its hidden code "bigger is better" - using more resources to produce moreabundant crops of higher quality to make more money. In contrast, alternative agriculture, driven by ecology, has as its code "balance is better"-making careful use of renewable resources to produce realistic yields of crops of acceptable quality to make just enough money.

Alternative agriculture sees people as one component in a large ecological system. Their need for food, fibre, and fuel must balance with the earth's ability to produce these commodities without being depleted and degraded. The goals of alternative agriculture are then simple: to produce enough food and fibre for all the world's peoples, to make farming a reasonable livelihood, and to do all this while protecting and conserving the earth's precious resources.

This way of thinking, once perceived as "on the fringe," is now beginning to penetrate the major agricultural research agencies in the world's developed countries. Although one may reject the spiritual foundations on which alternative agriculture is built, it cannot be denied that human activity has its best results when carried out according to nature's rules.

(J.F. Dormanr, AAFC, Lethbridge, Alta.)

The Pacific Maritime ecozone has a mild coastal climate and includes the land margin along the entire Pacific coast of British Columbia; here mountainous land is cut through by many fjords and glacial valleys and bordered by coastal plains along the ocean. This area's most highly productive agricultural soils are found in the lowlands of the Fraser Valley and the southeastern tip of Vancouver Island. In the lower mainland region, peaty soils 
(Gleysolic and Organic soils) are common in the alluvial plains (floodplains) and peatcovered wetlands; reddish brown, slightly to moderately acidic soils (Brunisols) are found on the sandy-to-loamy outwash and glacial till in the nearby hills. Brmmisolic soils also predominate on the colluvinum (material at the base of slopes or cliffs) and glacial deposits of the Nanaimo lowland on Vancouver Island.

The Montane Cordillera ecozone covers most of southern British Columbia, where the climate is mild and relatively dry. Rugged mountains ring several major interior plains composed mainly of moraine and, to some degree, fluvial (river) and lacustrine (lake) deposits. Luvisols and Brunisols are the most common soils in the plains, except in the lower valley floor of the southern plains, where dark-coloured soils (Chernozemic soils) are most common. Agriculture takes place mainly in the valleys: areas are improved for rangeland or cropped to grains; row crops and hay are grown where water is available for irrigation; and orchards and vineyards are common in the southern valleys.

Throughout the 20th century, the total area of farmland and cropland has increased steadily in many parts of British Columbia. At the same time, much prime agricultural land has been lost to urban expansion in the lower mainland-Nanaimo lowland areas and in the southern valleys of the Montane Cordillera ecozone. Most farms in this province are small and intensively worked and may be subject to the following problems of soil degradation:

- soil compaction and ponding of water in winter and early spring, resulting from high water tables (especially in alluvial lowland soils of the lower mainland region, where horticultural and orchard crops are grown and dairy farming is common)

- erosion of soils formed from glacial till capped with silt (especially where row crops and berry fruits are grown on sloping land in areas where most of the annual rainfall comes outside the growing season)
- loss of productivity as soils deteriorate (particularly organic or peat soils, which gradually decompose and subside)

- agrochemical contamination of surface water and groundwater (especially in areas such as the lower mainland where intensive cultivation involves much fertilization, heavy applications of manure from high-density livestock operations, and irrigation).

\section{Prairie Provinces}

Most agriculture in the Prairie Provinces takes place in the Prairie ecozone. This zone is composed mainly of semiarid grasslands and subhumid aspen parkland, but large farming areas also occur in the southern part of the cool, subhumid, aspen forests of the Boreal Plain ecozone, which extends from the Peace River region of British Columbia to central Manitoba.

The surface of the nearly level-to-rolling landscape of the Prairie and Boreal Plain ecozones consists mainly of hummmocky (hilly) morainal (glacial) deposits and gently undulating fluvial and lacustrine deposits. The relatively high natural fertility and good moisture-holding capacity of many of the soils (Chernozemic soils) of the Prairie ecozone make this area highly productive for crops. The relatively flat topography is good for highly mechanized farming, and the relatively long growing season permits the growth of hard spring wheats, including durum, as well as other cereals, pulse crops, and oilseeds. More hilly and sandier areas are suited to beef-cattle ranching. The Luvisolic soils of the Boreal Plain ecozone are more acidic and lower in fertility than those of the Prairie ecozone. A shorter growing season often limits crop production to shortseason cereals, such as barley, cool-season oilseeds, such as canola, and forage crops.

Most of the land settlement in the Prairie and Boreal Plain ecozones occurred between 1900 and 1913, although some farming took place along rivers 100 years earlier. Land was generally made available for settlement based on its location rather than its suitability for agriculture, and settlers introduced 
farming methods that were better suited to the moist conditions found in eastern Canada and Europe.

When first broken from native grass, organic-rich prairie soils are fertile and fairly resistant to wind erosion. Good soil fertility, a relatively moist climate in the early 1900s, and the development of adapted wheat varieties resulted in good crops in those early years. By the 1920s, inappropriate farming methods and drought had combined to produce serious problems with soil erosion and low crop yields; some farms were abandoned in the driest regions. Droughts, devastating soil erosion, and the economic depression of the 1930s resulted in widespread abandonment of farms, even in the moist Dark Brozun soil zone of Alberta and Saskatchewan. Although suitable methods for dryland farming were developed in the 1940s and 1950s, soil health continued to deteriorate, especially in areas where much of the land was summerfallowed.

Since the 1950s, the number of prairie farms has decreased. In Saskatchewan, for example, the number of farms dropped from 112000 in 1951 to 60000 today. During this period, prairie agriculture has been

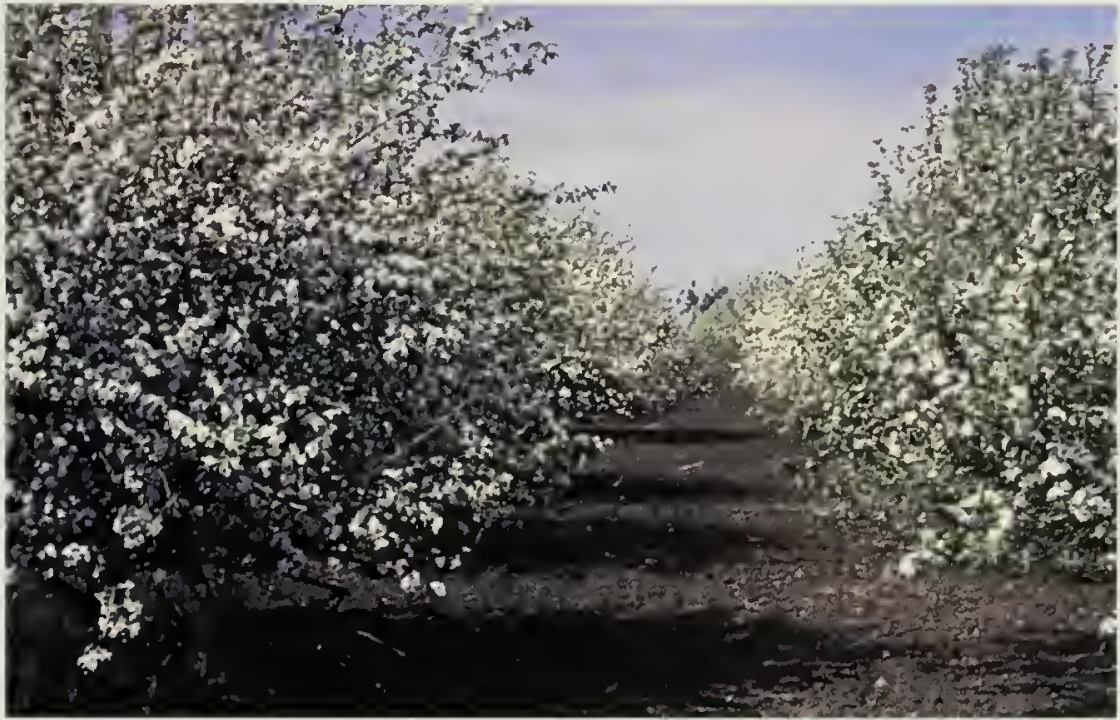

Orchard in British Colmubia.

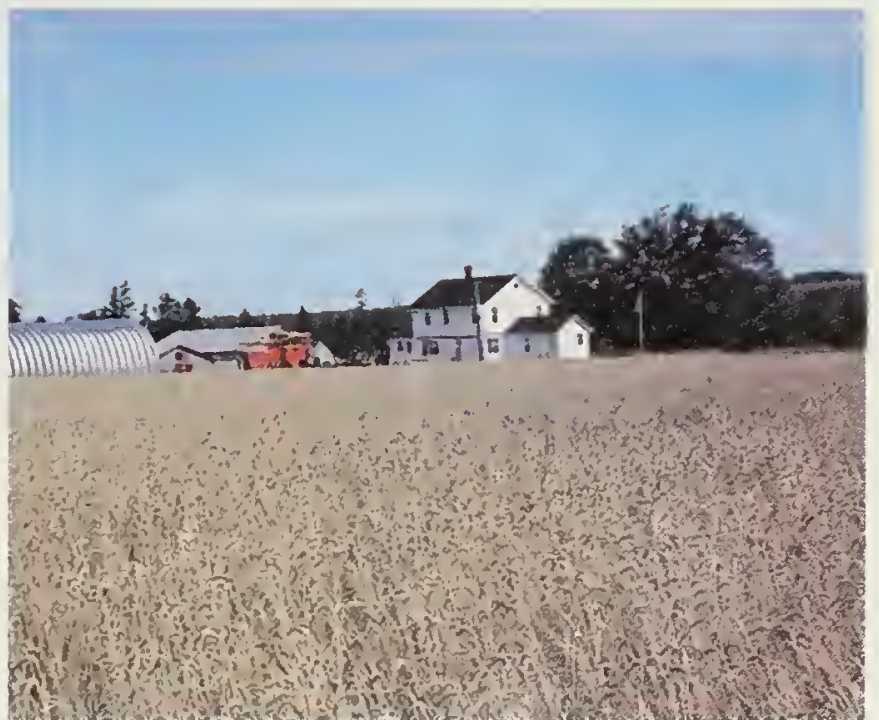

Grain field in the prairies.

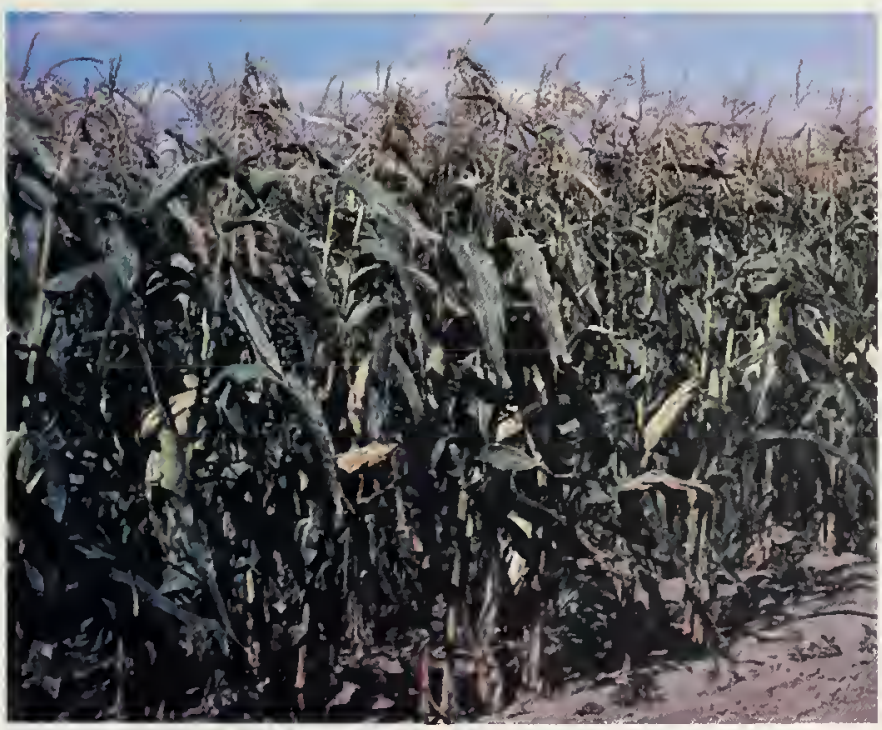

Corn ficld in Ontario.

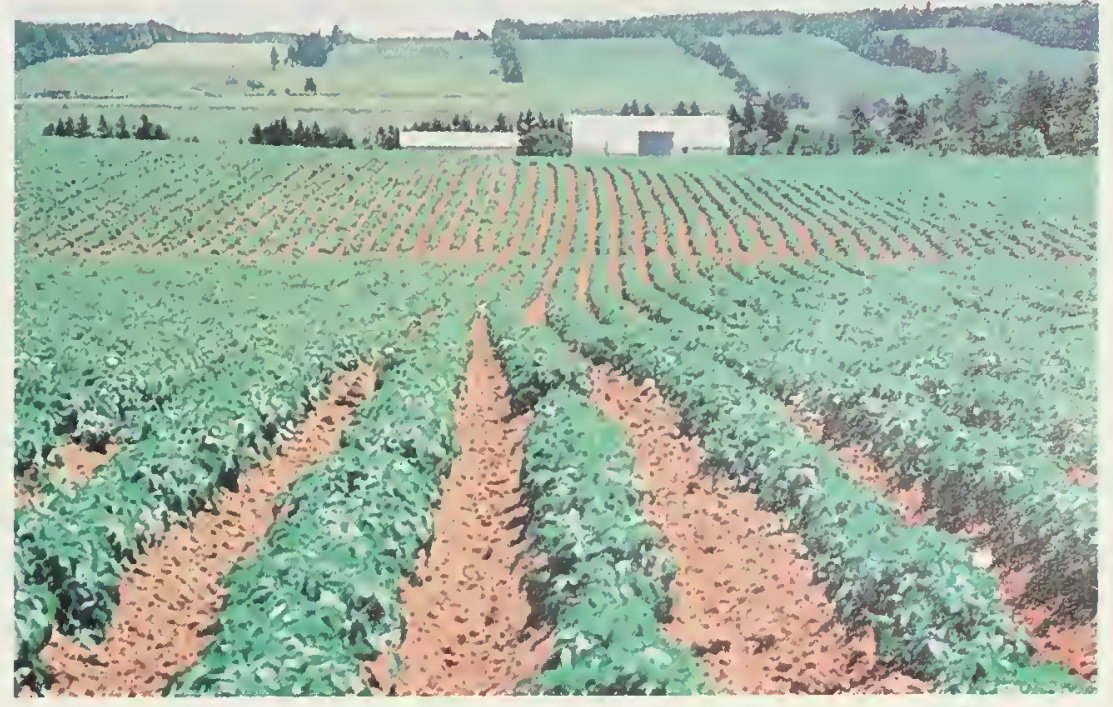

Potato field in the Maritines. 
Farmers are the source of the nutrients we all need every day to stay alive, let alone thrive. What they do on the lands they till affects the health and well-being of all the world's people.

John Haberen Rodale Institute characterized by more crops and better crop varieties, better crop yields, increased use of chemical inputs (fertilizer and pesticides), and larger, more-mechanized farms. At the same time, the following problems of soil degradation have continued:

- moderate to severe wind erosion, affecting nearly $20 \%$ of the improved farmland (most common in dry, windy areas using summerfallow, but also occurring in the moister regions, particularly where soils are cultivated intensively for crops such as potatoes and canola)

- water erosion, particularly on hilly and sloping land in the moist Black and Gray soil zones

- soil salinity (most common in the semiarid part of the Prairie ecozone and present in this region before agricultural development; agriculture has increased the area of salinized land)

- soil acidity (a natural feature of soils developed under forest but increased by acidic precipitation and the continued application of nitrogen fertilizers elsewhere).

Farms in the Prairie ecozone account for about $80 \%$ of the herbicides used in Canada. There appear to be no significant negative effects from long-term application of herbicides to prairie land, but continued research and monitoring are required.

\section{Central Canada}

Most agriculture in Ontario and Quebec takes place in the St. Lawrence lowlands and the triangle of land in southern Ontario bordered by the Great Lakes. Most of this area falls within the Mixed Wood ecozone, which has a relatively humid and temperate-to-warm climate. The land is characterized by level-to-rolling landscapes with a variety of morainal, marine (sea) and lacustrine deposits that were once covered by a deciduous hardwood forest with species such as maple and beech. The upland soils are leached and somewhat acidic (Podzols, Luvisols, and Brunisols), but surface soils in the south are granular and fairly fertile. Much of the farmland is level and clayey, employing tile drainage to relieve the original wet conditions of the soils (Gleysols).

This region produces about $40 \%$ of Canada's farm income. High-value crops are grown on most farmland, including corn, beans, and a variety of specialty crops. The more-rolling landscapes support a large dairy industry.

Pockets of agriculture extend into northern Ontario and Quebec, in the Boreal Shield ecozone. The cooler climate in this area generally limits farming to livestock production. Some farming takes place on poorly drained soils (Gleysolic and Organic soils) formed in belts of lacustrine clays in the Abitibi, Lac Saint-Jean, and Lake of the Woods regions. There are also sizable areas of farming on sandy, acid soils (Podzols) along valleys and gently sloping plains extending from the Laurentian Highlands in Quebec to the Thunder Bay-Quetico region of western Ontario.

Agricultural development in the Mixed Wood Plain and Boreal Shield ecozones expanded rapidly during European settlement of the area in the late-18th to mid19 th centuries. Farms were small and efficient, producing livestock and dairy products and a variety of crops. The early 1950s saw a move toward larger, morespecialized farms. The area of improved farmland, which had remained constant at about 5.3 million hectares from 1921 to 1951 , declined to 4.3 million hectares by 1976 . The reduction was greatest in Quebec, where the improved farmland area dropped from 3.6 million hectares to 2.2 million hectares during that period.

Deteriorating soil health has always been part of farming in the Mixed Wood Plain and Boreal Shield ecozones of central Canada. Forest clearance and agricultural land use during the 19th century accelerated soil erosion and exhausted the soils. The small, mixed farms that emerged in the early 
20th century reduced soil erosion by using sod-based rotations and livestock management practices. However, the shift from growing small grains and forages in rotation to growing row crops in monoculture has resulted in increasing soil erosion today because of declining soil organic matter levels and deteriorating soil structure. Water quality has also declined. Other signs of soil degradation in these ecozones include

- compaction of soils in the Lake Erie and St. Lawrence lowlands, particularly where soils are cropped to corn every year (poorly drained clayey soils are the most seriously affected)

- acidification of soils in the Mixed Wood Plain ecozone because of the humid climate, high rates of fertilization, and inputs of acid precipitation

- pollution of the Great Lakes by phosphorus coming from fertilizers and livestock wastes

- contamination of groundwater by nitrate below porous, sandy soils, such as those used to grow tobacco and potatoes.

\section{Atlantic Provinces}

The agricultural land of Atlantic Canada lies mostly in the Atlantic Maritime ecozone and, to some extent, in the Boreal Shield ecozone (Newfoundland). The climate is both humid and temperate. The area has much hilly land, including extensions of the Appalachians. Soils have formed on morainal deposits and, to a much smaller extent, on marine and fluvial deposits. The native vegetation was a mixed coniferous and deciduous forest that included species such as maple and spruce. The soils are strongly leached and acidic (Podzols) and generally have a loamy texture. Dense subsoils that impede drainage are common. Farming takes place mainly on the rolling coastal lowlands but also on river terraces and peatlands in some provinces.
Agricultural development in these ecozones began in the early 17 th century as subsistence farming for societies based mainly on fishing and forestry. By the late 19th century, food was being produced for export. Small farms, mainly based on dairying and livestock, also grew turnips, carrots, and potatoes as cash crops. Crop rotations included forages, small grains, vegetables, and potatoes. Orchards developed mainly in the Annapolis Valley in Nova Scotia. Agriculture of this kind had little negative effect on soil or water, provided that the land was suitable for agricultural production and the people had some farming skills.

Following World War II, many people lived on the land but didn't farm it. There was an ample supply of vegetables and dairy and meat products at reasonable prices, and most people had off-farm employment. The area of improved cropland declined by $55 \%$ between 1951 and 1986, except in Newfoundland where improved cropland increased by 20\% between 1961 and 1986 . Farms became fewer. However, the remaining farms were larger and were used for more-intensive production that depended on large machinery and substantial inputs of agrochemicals.

The main types of soil degradation seen in these ecozones today are soil erosion by water and degraded soil structure caused by tillage and traffic. The practice of continuous row-cropping without adequate crop rotation has also degraded soils by depleting soil organic matter and causing structural instability, fertility problems, and accelerated water erosion. Severe water erosion has taken place in the New Brunswick potato belt, in Prince Edward Island, and in some areas of Nova Scotia. Soil acidification and surface and groundwater contamination are concerns in areas where crops and livestock are farmed intensely. In areas where forested land is still being cleared for agriculture (New Brunswick and Newfoundland), land-clearing practices often
Numerous problems lie before us, but the day may not be too far off when scientists who have been studying natural ecosystems will begin to talk to farmers as equals, and when farmers and scientists will join together in the common task of learning how to live decently on the land surface of the planet and make a deccnt living while doing it.

Wes Jackson Alters of Unheton Stone 
result in soil degradation. The potential for severe wind erosion is high in Prince

Edward Island, where most of the land is cultivated and strong ocean winds prevail.

Increasingly complex agricultural technology has masked the extent to which soil has become degraded in the Atlantic
Provinces. Many observers believe that soil degradation has reached the point at which fertilizers and other chemicals cannot reverse the depression of crop yields and quality. The effects of soil degradation are no longer confined to annual losses in income of individual farms but actually threaten the economy of crop production in some areas. 


\title{
A Geographical Framework for Assessing Soil Quality
}

\author{
K.B. MacDonald, W.R. Fraser, F. Wang, and G.W. Lelyk
}

\section{Highlights}

- A comparison of estimates of potential and actual agricultural land in the Prairie Provinces shows that all good land and much marginal land is already in production.

- A new tool, the index of inherent soil quality (ISQ), was developed to assess inherent soil quality based on broad-scale soil, landscape, and climatic information.

- An index of soil quality susceptibility (SQS) was developed to identify agricultural areas that are at risk of declining soil quality because of various land use and management practices.

- Most agricultural land in the Prairie Provinces is classified as good using the ISQ; limitations to crop production in this region are associated with areas that are dry or saline; areas most vulnerable to declining soil quality are those under intensive summerfallow.

- Considerable area of southern Ontario is at risk of declining soil quality because of intensive cropping, especially of row crops; between 1981 and 1991, the area of Ontario farmland under intense cultivation increased and the area under conservation tillage increased; many Ontario soils have low levels of organic matter.

- Broad-scale geographical assessment of soil quality allows areas to be targeted for further study and produces a baseline against which to make future comparisons; interpretations from these assessments are limited by the level of detail of the databases and the wide span of time between samplings.

\section{Introduction}

As a starting point for looking at the health of Canada's agricultural soils, it is helpful to have a general picture of the inherent (natural) quality of these soils, as well as some of the forces that cause this quality to change. This chapter presents a framework for developing just such a picture.

Detailed assessments of soil quality usually involve measuring soil properties and processes at specific field sites. In contrast, a broad assessment examines soil quality generalized over large areas. We used broad-scale information on soil, landscapes, and climate, derived from Soil Landscapes of Canada, to produce a general picture of inherent soil quality. We then superimposed generalized information about farming practices, taken from the Census of Agriculture, to identify areas where soil quality may decline over time under these practices.
A land ethic, then, reflects the existence o an ecological conscience, and this in turn reflects conviction of individual responsibility for the health of the land. Health is the capacity for self-renewal. Conservation is our effort to understand and preserve this capacity. 
This broad approach to soil quality is useful in targeting areas where soil health is in question and should be looked at more closely. However, interpretation of the data is limited not only by the large land area and type of data used, but also by the 5 year spans between data collections by Statistics Canada in the Census of Agriculture.

Our geographical picture of soil quality focusses on Canada's two largest regions of crop production, the Prairie Provinces and southern Ontario. We estimate

\section{Steps in soil quality assessment}

Assessing soil quality involves five simple steps. These steps are followed for areas as small as a field-site or as large as a country. They can be carried out intuitively and subjectively by farmers or systematically by researchers using sophisticated models and information systems. They are as follows:

1) Estimate the inherent soil quality for one or more specific soil functions, using land resource information (e.g., a deep, well-drained soil with adequate capacity to retain and supply nutrients is well suited for crop production and to retain and degrade toxic materials).

2) Estimate the physical conditions placing land at risk of declining quality, using topographic and land resource information (e.g., steep slopes and silty surface textures make the soil susceptible to water erosion).

3) Estimate the human-made conditions causing soil to be at risk of decreasing quality, using land use and management information and trends (e.g., intensive row-cropping up and down the slope makes water erosion and loss of soil organic matter more likely).

4) Combine the information from steps 1-3 over time to predict changes in land resource quality

a) subjectively

b) by monitoring and recording new land resource data

c) by using computer models that simulate processes of soil degradation, along with historical and representative climate data.

5) Reevaluate, in the future, the quality of soil under a specified use by using land-resource estimates.

(K.B. MacDonald, AAFC, Guelph, Ont.)
- potential and actual supply of land for agricultural use (Prairie Provinces)

- inherent soil quality (Prairie Provinces and southern Ontario)

- areas at risk of declining soil quality (Prairie Provinces and southern Ontario)

- trends in land use and management practices that affect soil quality (southern Ontario).

\section{Land for agriculture}

\section{Potential land supply}

A limited area of Canada has climatic and soil conditions suitable for crop production, particularly of annual crops. These two factors, climate and soil, were used to establish where and how much land potentially suitable for crop production exists in the Prairie Provinces (Table 3-1).

Cropping is considered possible only where there are at least 1050 effective growing degree days (a measure of heat energy available for crop production) and where soil is of adequate quality. In this assessment soil quality was rated using an index of inherent soil quality (ISQ; described later in this section).

\section{Actual land use}

Two sources of information were used to estimate actual land use:

1) satellite images obtained in 1989, which can determine land use at a resolution of 1 square kilometre and are limited to general classification of the land use or land cover; and

2) 1991 Census of Agriculture, which provides much more detailed information about land cover, but this information is generalized for areas as large as 10-250 square kilometres.

About one-third of the total land area of the Prairie Provinces meets minimum soil and climatic requirements for agriculture, and about one-quarter has potential for annual cropping (an ISQ rating better than poor; Table 3-1). Potential farmland is larger than 
Table 3-1 Land resources of the Prairie Provinces

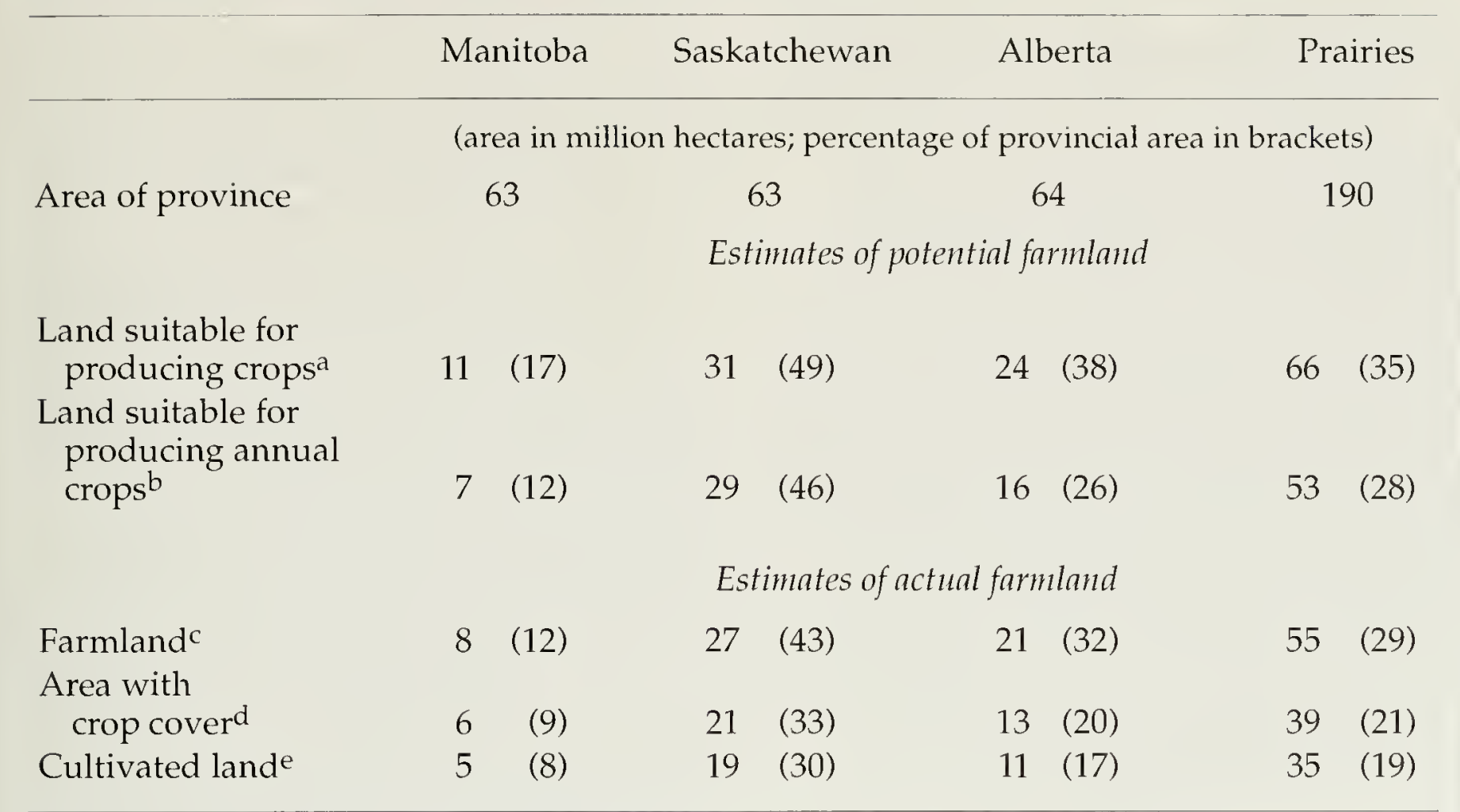

a Based on climate and minimum ISQ requirements.

$\mathrm{b}$ With ISQ rating better than poor.

c All land on a farm, including that used for crops, grazing and pasture, summerfallow, buildings and barnyards, bush, sloughs, marshes, etc.; from 1991 Census of Agriculture.

d From satellite measurements of land cover of cropland.

e Land used for crops and summerfallow; from 1991 Census of Agriculture.

actual farmland, as determined by the agriculture census, because it includes some areas occupied by competing uses (such as national and provincial parks, forests, and military reserves), as well as areas of rangeland. Only about one-fifth of the area of the Prairie Provinces is currently cultivated.

\section{Inherent soil quality}

We developed an index of inherent soil quality (ISQ), which ranks soils according to four elements that determine their ability to produce crops, as follows:

- soil porosity (providing air and water for biological processes)

- nutrient retention (retaining plant nutrients)

- physical rooting conditions (promoting root growth as a result of certain physical characteristics)
- chemical rooting conditions (promoting root growth as a result of certain chemical characteristics).

Data for these four elements came from existing land resource inventories. Each ISQ element was rated at one of four levels (good, good to moderate, moderate to poor, poor). Areas with the most restrictive ISQ rating (poor) are best-suited for perennial crops, such as forages, and for grazing. Areas with ISQ ratings better than poor are suitable for annual crops.

Inherent soil quality ratings can be used to assess the status of soil quality and to make comparisons between regions. Note that, because they are based on information collected over a number of years, these ratings do not provide a current "snapshot" of soil health but rather give an overall impression of a soil's capacity to produce crops. 
Each soil is an individual body of nature, possessing its own character, life history, and powers to support plants and animals.

Hans Jenny Meeting the Expectations of the Land
Specific ISQ ratings, however, can be used to determine soil health by interpreting the possible effects of degradative processes. For example, the loss of 1 centimetre of soil by erosion is much more serious on a shallow soil with a thin layer of fertile topsoil than on a deep soil with a thick fertile topsoil. In some cases it will be important to maintain the quality of soils with moderate ISQ ratings, because any further decline will make them unsuitable for annual cultivation. In other cases it will be more important to maintain the quality of the best lands, to ensure maximum response to additional inputs, such as fertilizer, to the soil. In this section, the four ISQ elements are rated and mapped both individually and together to assess soil quality in the Prairie Provinces.

\section{Soil porosity}

The amount and size of pore space in the soil determines

- how well the soil drains excess moisture and provides air to plant roots

- how much water is stored and made available to growing plants, depending on annual precipitation.

In each case, the most limiting of these two factors was used to determine the ISQ for this element.

Most of the subhumid region in the Prairie Provinces is rated good for this ISQ element (Fig. 3-1A). Areas that have a lower rating for this ISQ element include

- the Red River Plain area of Manitoba, where soil is unable to supply adequate air to crop roots, particularly in the spring and during wet years

- areas that receive limited precipitation during the growing season, such as southwestern Saskatchewan

- areas dominated by coarse soils, which have limited capacity to store water.

\section{Nutrient retention}

Most plant nutrients are supplied from the surface layer of the soil. The capacity of a soil to retain and supply nutrients depends on the storage capacity of the soil (cation exchange capacity). This property is controlled by the amount and type of clay and organic matter in the soil. Figure 3-1B shows the ISQ element rating the relative ability of soil to retain materials in the surface. Much of the cropland in the Prairie Provinces is rated good for this ISQ element. The areas that rate lower have a substantial proportion of soils of coarse texture or low organic matter content, or both, in the surface layer.

This element indicates the extent to which fertilizers and pesticides remain where they are applied and promote crop production. It also indicates how well the soil retains and breaks down waste materials, such as compost and sewage shidge.

\section{Physical rooting conditions}

There is a limited range of soil conditions under which crops are most productive. Ideal physical rooting conditions include a soil structure that provides optimum water and air for the plant (not too compacted), and soil firmness sufficient to support the plant and permit management traffic but not great enough to hinder root development and penetration of the soil. Figure 3$1 C$ shows the physical rooting conditions of soil related to the cultivation of annual crops. These conditions are not thought to restrict crop production in the Prairie Provinces. Lower ratings are caused in some areas where the following are found:

- shallow soils, which restrict root growth

- surface crusting (in northern soils)

- pans (dense soil layers, which form a barrier to roots)

- soil deterioration resulting from loss of organic matter. 


\section{Chemical rooting conditions}

Chemical rooting conditions may be both natural and altered by humans. The range of chemical conditions conducive to the growth of agricultural crops in general includes a $\mathrm{pH}$ in the range of $6-8$ and relatively low levels of soluble salts. Figure $3-1 D$ shows the locations and levels of natural chemical conditions for a general range of grain and oilseed crops. Restrictive areas in the southern porion of the Prairie Provinces reflect the presence of soils with high salt content. Salts are most restrictive where they are found at the surface and somewhat less where they occur in the deeper soil layers. In the northern regions, low soil $\mathrm{pH}$ limits plant growth.

\section{Identifying areas at risk of declining soil health}

Soil health is the state or condition of soil properties and processes at a certain time. Soil health can change over time as the inherent properties of the soil, described above, are altered by the natural effects of climate and soil landscape, as well as by human activity (land use and management practices).

Identifying agricultural areas that are at risk of declining soil health should ideally be based on validated computer models that simulate soil degradation using actual field measurements, but these models and the databases (collection of data) needed to run them are not yet available. Instead, we developed an index of soil quality susceptibility (SQS) based on soil-landscape and census information, to locate areas that are at risk of soil degradation. Factors (various landscape conditions, soil characteristics, and land use and management practices) and actual threshold values (points at which a change in soil quality is likely to occur) were selected on the basis of their importance in soil-modifying processes, as well as the information available about them.

\section{Role of databases in geographical assessment of soil quality}

In today's world, a wide range of agricultural assessments is demanded for purposes such as meeting the requirements of international agreements related to agricultural and environmental stewardship (General Agreement on Tariffs and Trade and North America Free Trade Agreement). In the past, experts who carried out broad regional and national assessments of land quality (for example, the Canada Land Inventory) relied on their personal knowledge to make adjustments for gaps in the data and inconsistencies between geographical areas. But current assessments must be carried out in a documented, reproducible way. The ISQ (inherent soil quality) and SQS (soil quality susceptibility) procedures are examples of how advances in our knowledge, ability to handle data, and technology can be used to meet current and future needs for land-quality assessment.

Statistics Canada has collected census data for many years but has only recently made the information available in computerized formats. Satellite imagery characterizing land cover is also a recent innovation. Land resource information has been collected for many years, but the content and level of detail varies greatly. With the development of the National Soil Data Base in Agriculture and Agri-Food Canada's Centre for Land and Biological Resources Research, the land resource databases have been standardized. The Soil Landscapes of Canada map series contains land resource information in a consistent format and content for all of Canada.

The ISQ assessment of soil quality status and SQS assessment of the potential for change in soil quality constitute one of the first uses of Soil Landscapes of Canada data. Data from various sources were combined and analyzed in a computerized geographic information system (GIS) to produce analyses at the broad regional level. Although expert opinion was required to develop the system, it is now open to critical review and can be modified as new information becomes available. Also, because the system uses standard data formats from the National Soil Data Base, it can be used for more detailed assessments of soil quality and susceptibility to change by using more detailed land resource and land use information. 


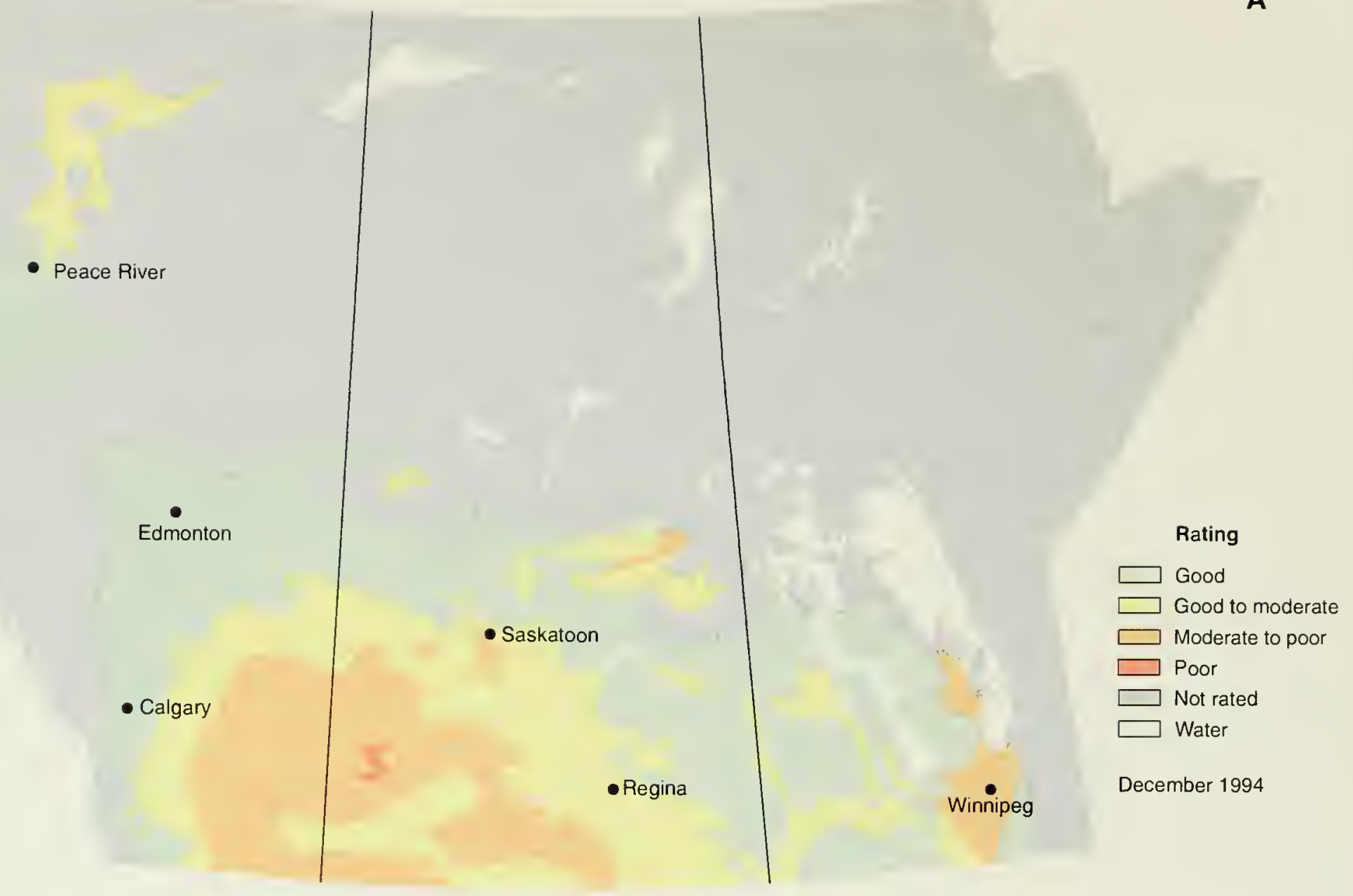

- Peace River

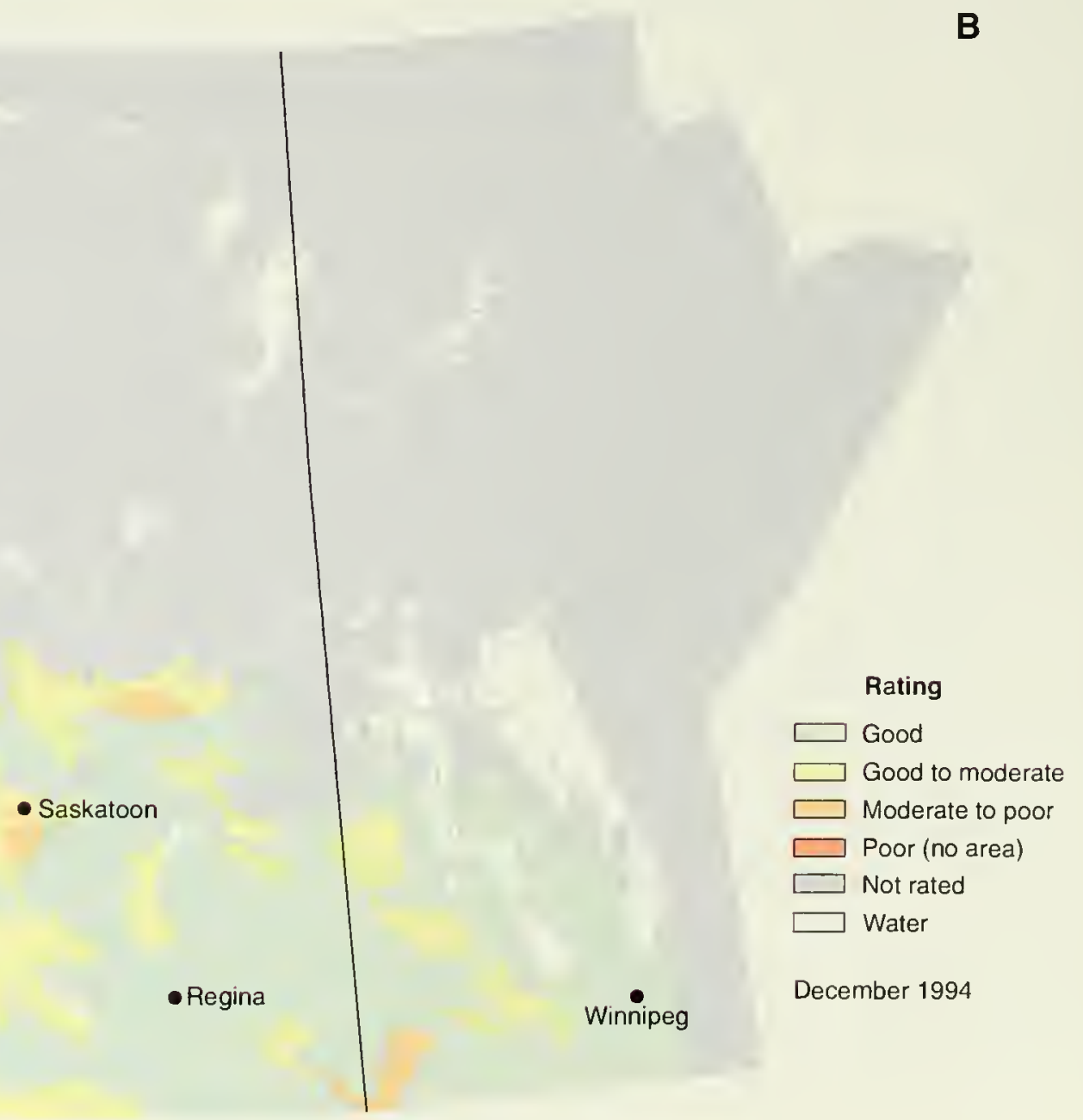

Figure 3-1 Inherent soil quality (ISQ) in the prairies.

A) Soil porosity for crop production; $B$ ) Nutrient retention for crop production. 
- Peace River

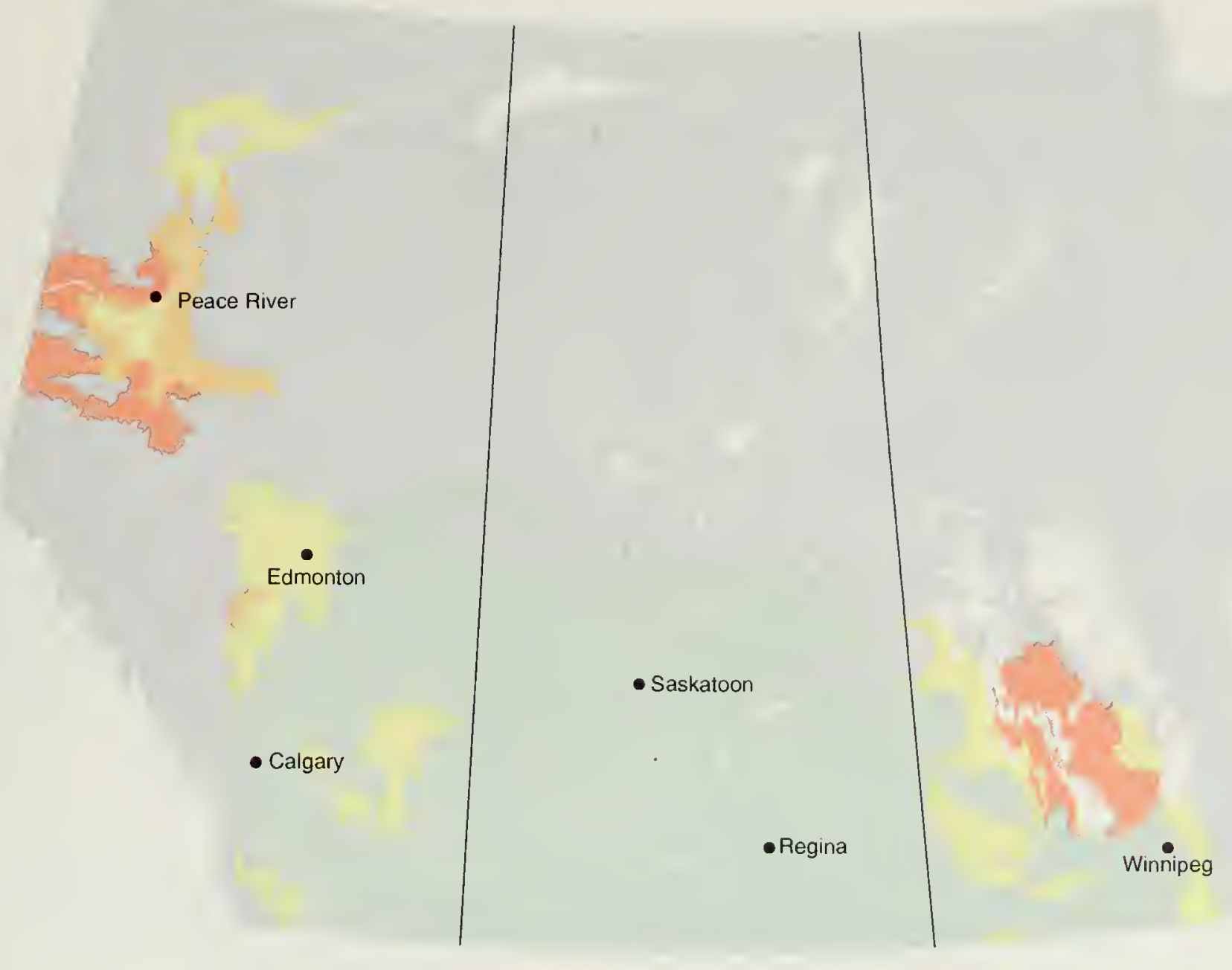

C

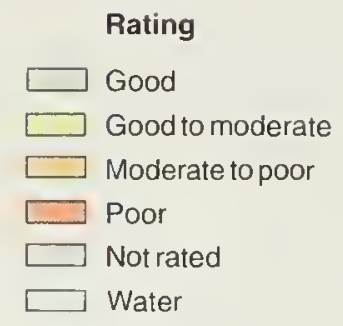

December 1994

D

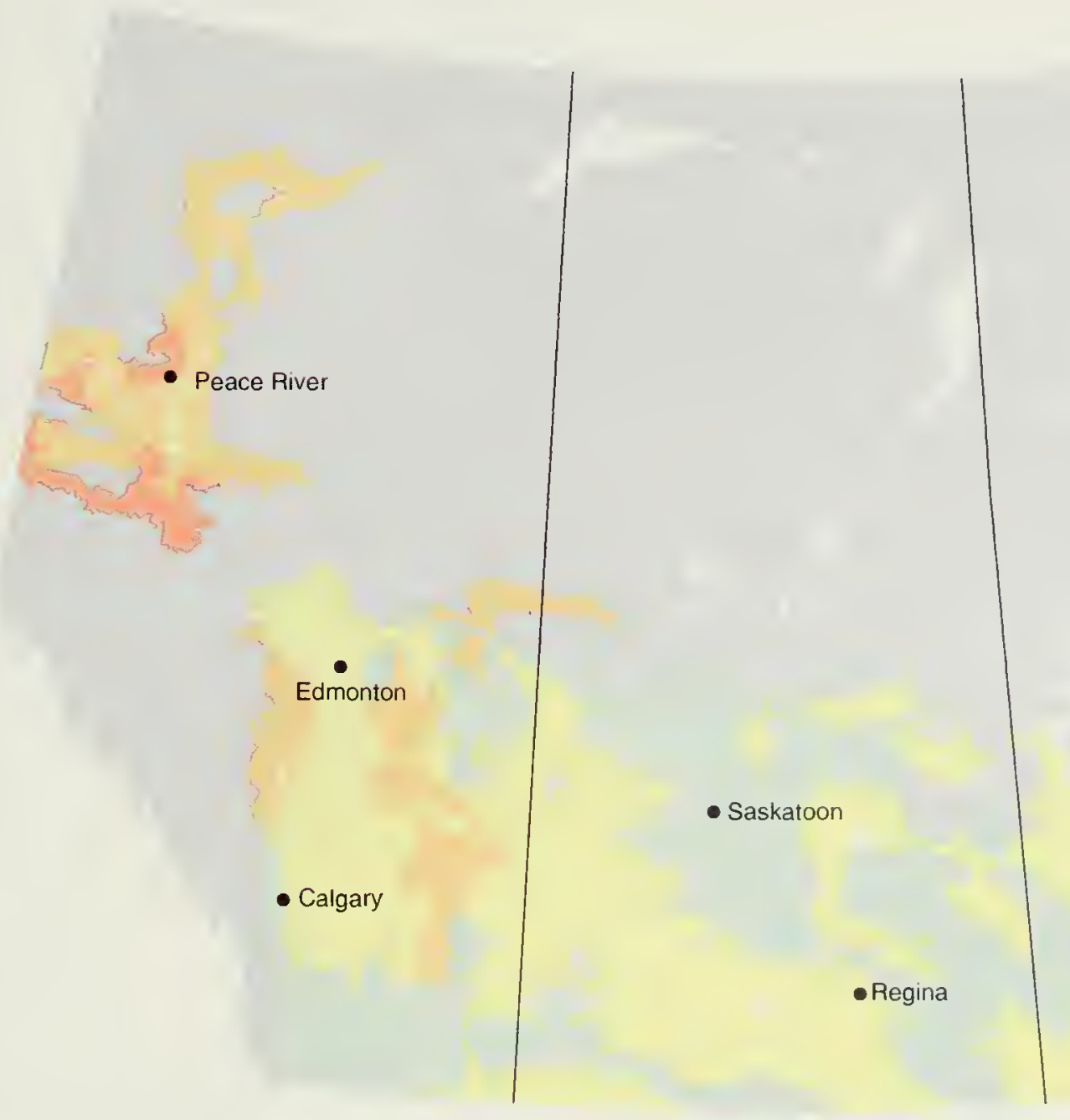

Figure 3-1 Inherent soil quality (ISQ) in the prairies.

C) Physical rooting conditions for crop production; $D$ ) Chemical rooting conditions for crop production. 


\section{Soil and landscape conditions}

Erosion is a process that contributes to the deterioration of soil health through the loss of soil material, both mineral and organic. Fine-textured soils are particularly vulnerable to erosion, especially on sloping land. The factors used to identify areas that are vulnerable to erosion were

- slope steepness (a slope of more than 9\% was chosen as the threshold)

- surface texture of the soil (silty soils were selected as the most vulnerable)

- organic matter levels in the top layer of soil (organic matter levels of less than $2 \%$, based on organic carbon levels of $1 \%$ or less).
In Figure 3-2, areas where these conditions exist (Prairie Provinces and southern Ontario) are mapped on a background showing inherent soil quality (represented by the most limiting of the four ISQ elements, since a soil is only as good as its greatest weakness allows). Areas that are most susceptible to declining soil quality are those where more than one of the study factors apply, especially where the inherent soil quality is poor. Proportionately less land is at risk of declining soil quality because of soil and landscape features in the Prairie Provinces than in southern Ontario, which has more than 10 times as much land with less than $2 \%$ soil organic matter (Table 3-2).

Table 3-2 Area of land with various landscape or soil features or under various management practices (as a percentage of total land assessed for inherent soil quality) that may make soil susceptible to a change in quality

$\begin{array}{cc}\text { Prairie } & \text { Southern } \\ \text { Provinces } & \text { Ontario }\end{array}$

Soil and landscape conditions

Slope greater than $9 \%$

High silt content at soil surface

Organic carbon less than $1 \%$ at soil surface

$\begin{array}{rr}14 & 12 \\ 11 & 15 \\ 1 & 11\end{array}$

Land use and managenent conditions

Crop intensity

(more than $70 \%$ of farmland cultivated)

\begin{tabular}{|c|c|c|}
\hline 1991 & 1981 & 1991 \\
\hline 10 & 38 & 41 \\
\hline 12 & - & - \\
\hline- & 16 & 16 \\
\hline 63 & - & 43 \\
\hline
\end{tabular}

Summerfallow

(more than $30 \%$ of farmland)

Row crops

(more than $60 \%$ of cropland)

Conservation tillage

(more than 20\% of seeded area)

Areas $^{\text {a }}$ where conditions of both soil landscape and land use and management indicate susceptibility of soil quality to change

a Areas where at least one of the soil landscape conditions (slope, silt content, or organic carbon level) overlaps with at least one land use or management practice (intensity of cropping, summerfallow, or row-cropping). 


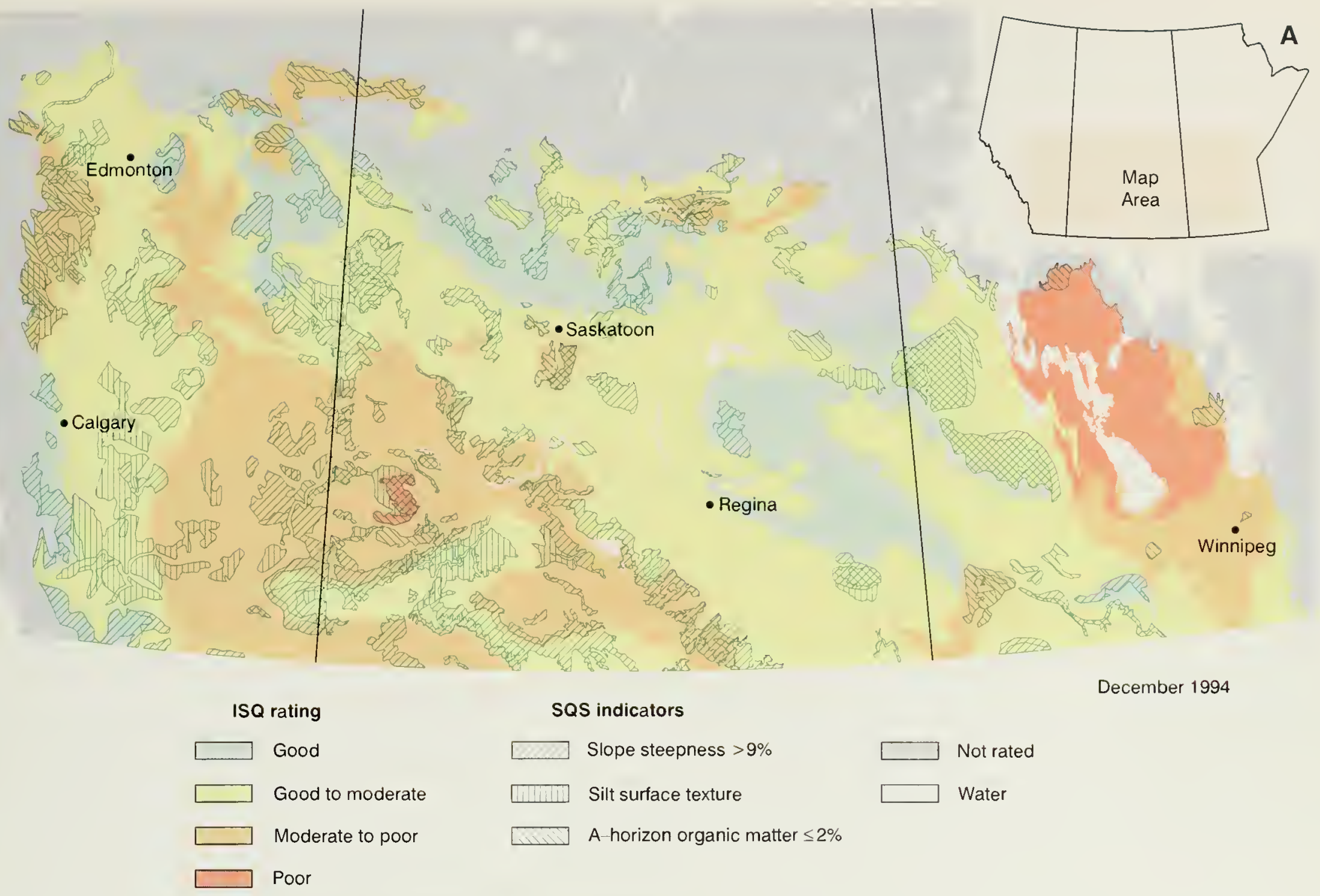

B

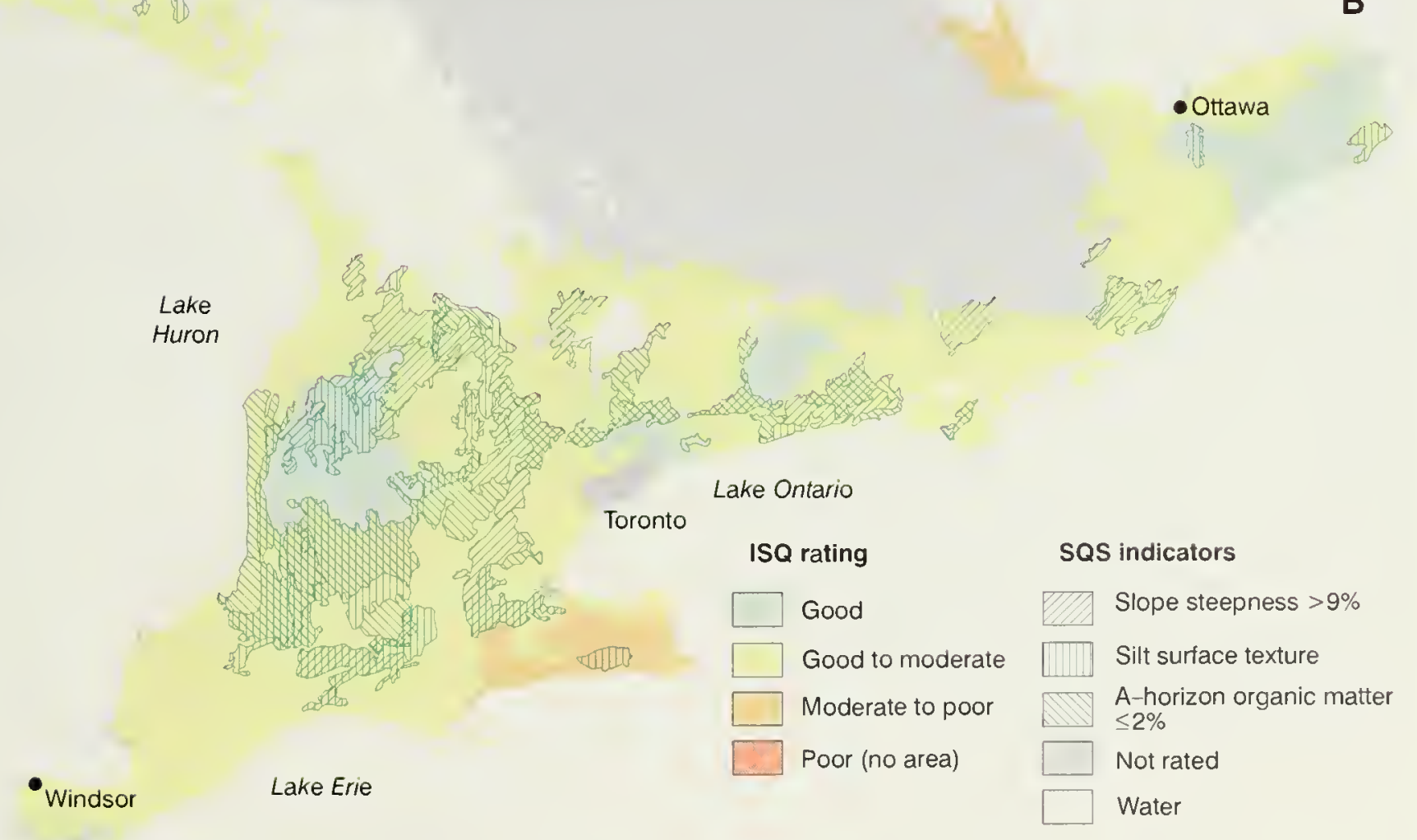

December 1994

Figure 3-2 Areas at risk of declining soil quality because of various soil and landscape conditions.

A) Prairie Provinces; B) Southern Ontario. 
agriculture, overall,

has been and now is many times more sophisticated a venture than space travel could ever become ... partly perhaps because it comes out of living nature and is therefore complex, and partly because more human minds have worked on

ways to generate an assured food supply than on any other task.

Wes Jackson Altars of Unhlewn Stone

\section{Land use and management practices}

Declining soil quality resulting from loss of organic matter is associated with the use of management practices that involve intensive cultivation and exposure of the soil surface, particularly on soils containing low levels of organic matter. We used the following three elements to locate areas where soil quality might decline as a result of land use and management practices:

- cropping intensity (more than $70 \%$ of all farmland is cultivated)

- summerfallow intensity (more than $30 \%$ of all farmland is in summerfallow; Prairie Provinces only)

- row-cropping intensity (more than $60 \%$ of all cropland is row-cropped; southern Ontario only).

In the Prairie Provinces, much of the area where soil and landscape conditions put the soil at risk of declining quality is forest reserve or parkland. Intensive cropping is carried out around Edmonton and north of Calgary in Alberta, in the northeastern part of Saskatchewan's agricultural land, and in southern Manitoba (Fig. 3-3A). These areas generally have soils that rate moderate to high for the ISQ elements capacity to retain nutrients and capacity to supply water and air. Other areas that are vulnerable to declining soil quality are the intensively summerfallowed lands in the arid regions of southern Alberta and southwestern Saskatchewan. These areas often have soils that rate moderate to poor for the ISQ element capacity to supply water and air (Fig. 3-1A). However, because the summerfallow area includes land that is rated good to moderate for this ISQ element, it is possible that soil quality can be improved in these areas by reducing summerfallow. More than $60 \%$ of prairie farmers report using conservation tillage on at least $20 \%$ of their cultivated land (Table 3-2).
In southern Ontario, intensive cropping is carried out in much of the southwestern region and southeast of Ottawa. The Lake Erie lowlands are especially at risk of declining soil quality because of widespread intensive row-cropping (Fig. 3-3B). More than $40 \%$ of farmers in southern Ontario report using conservation tillage on at least $20 \%$ of their cultivated land (Table 3-2).

\section{Trends in land use and management practices}

Land use and management practices are factors affecting soil quality that are both under human control and measurable in the short term. An example of a trend in soil quality resulting from changes in farming practices is shown in Figure 3-4. Table 3-2 compares cropping intensity (expressed as the share of farmland occupied by crops) in southern Ontario in 1981 and 1991. There has been a 3\% increase in cropping intensity over the 10 years, but no change in the proportion of row crops. By 1991, cropping intensity increased in eastern Ontario and decreased north of Lake Erie, and conservation tillage was more widely used. The areas where both soil-landscape and land-use and management thresholds are exceeded are substantial (Table 3-2). These areas should be targeted for more detailed study to determine the actual extent of soil degradation and to develop appropriate management plans. 


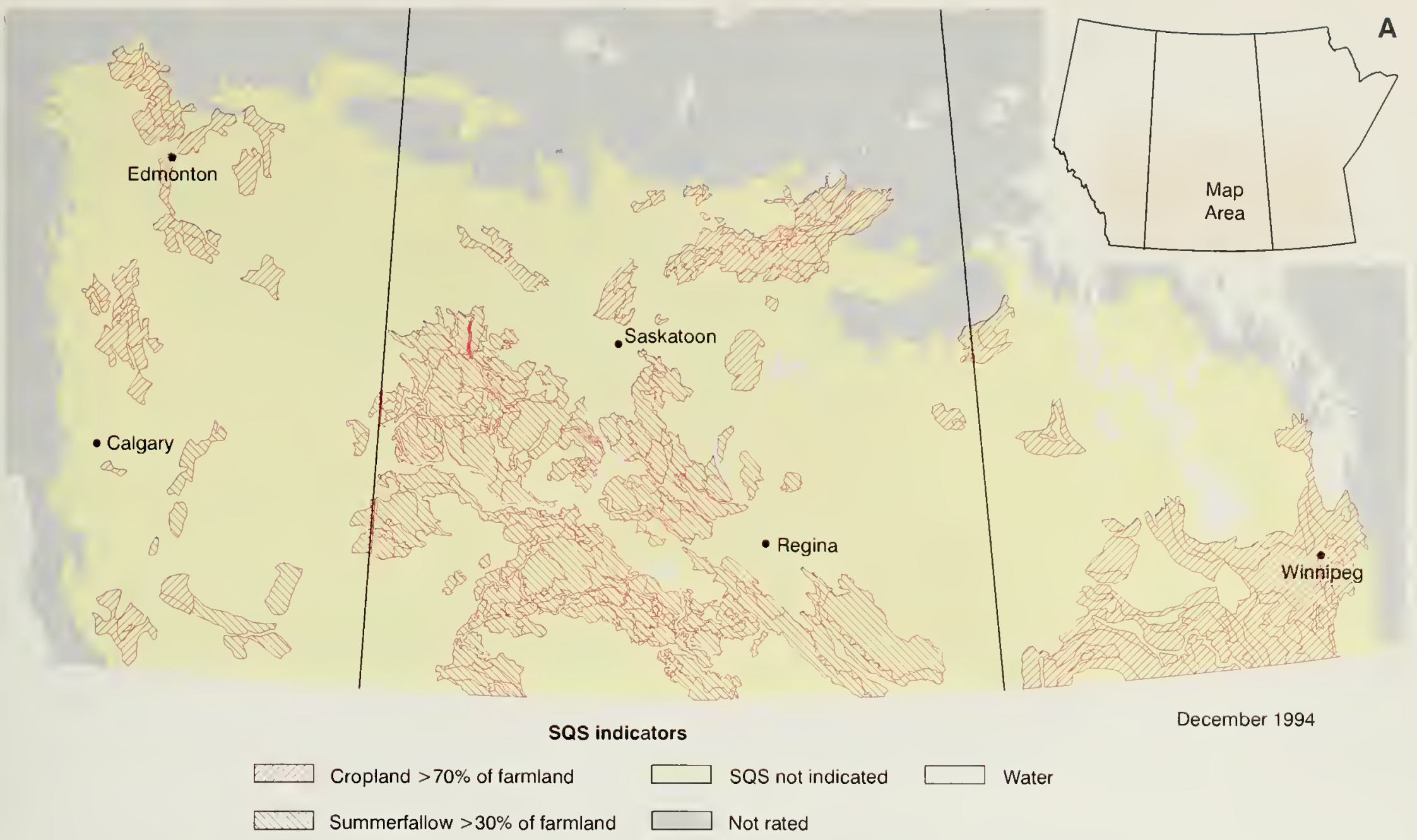

B

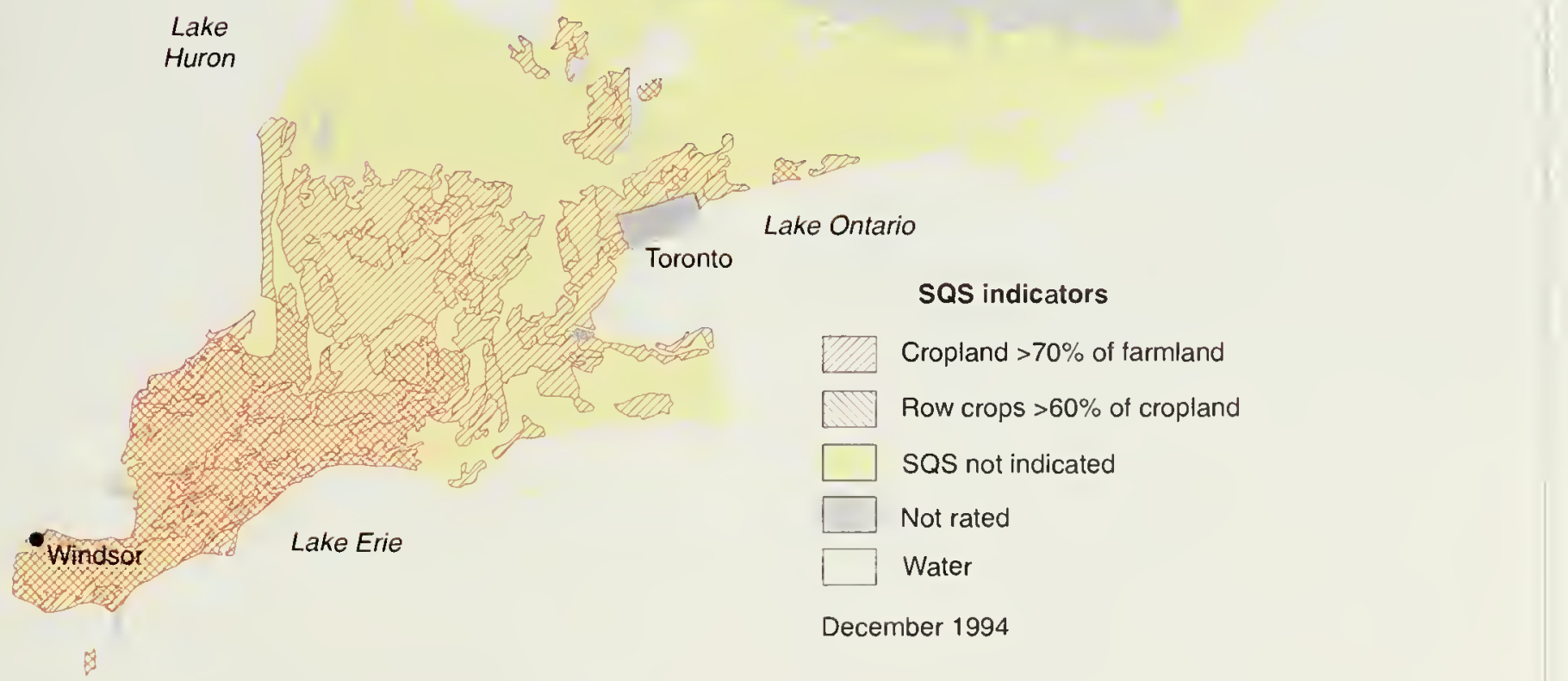

Figure 3-3 Areas at risk of declining soil quality because of various land use and management practices.

A) Prairie Provinces, 1991; B) Southern Ontario, 1991. 
We must remember that knowledge is only in past tense; learning is only in present tense; and prediction is only in future tense. To have sustainable forests [agriculture], we need to be able to know, to learn, and to predict.

Chris Maser The Redesigned Forest

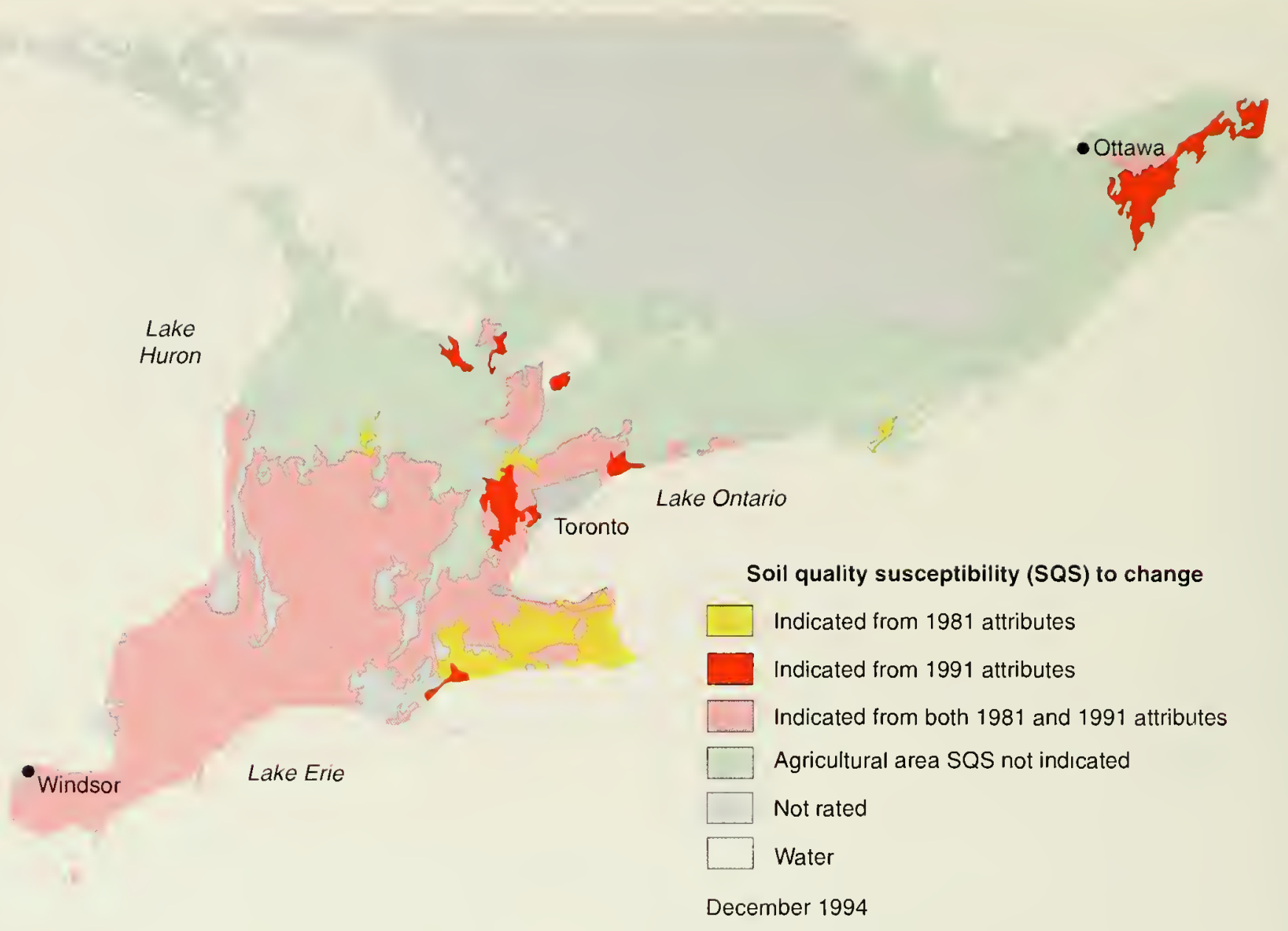

Figure 3-4 Areas in southern Ontario at risk of declining soil quality because of various land use and management practices between 1981 and 1991. (Based on 1981 and 1991 Census of Agriculture.)

\section{Conclusions}

Changes in soil quality are natural and occur everywhere. Processes which degrade soil quality may be accelerated by natural conditions of the soil landscape alone or in association with land use and management practices. It is the job of soil researchers to determine how susceptible soils are to degradation and to identify land use and management practices that contribute to or reverse degradation.
This assessment shows the general relationship between soil quality and land use and management practices, but it cannot definitively analyze the effects of farming on soil quality. As research produces a better understanding of soil quality indicators and the processes of soil degradation, both the parameters (factors chosen for study) and the thresholds of these parameters may be changed in future broad-scale assessment of soil quality. 


\title{
Benchmark Sites for Monitoring Agricultural Soil Quality
}

\author{
C. Wang, L.J. Gregorich, H.W. Rees, B.D. Walker, D.A. Holmstron, E.A. Kenney,
}

D.J. King, L.M. Kozak, W. Michalyna, M.C. Nolin, K.T. Webb, and E.F. Woodrow

\section{Highlights}

- A national benchmark program has been put in place to monitor changes in the health of agricultural soils, especially changes resulting from land use and management practices.

- Baseline data sets include farm history; soil and landform descriptions; and measurements of various chemical, physical, and biological properties of the soil. Several climatic factors are measured daily at eight locations.

- Some soil properties are measured annually. Others are measured every 5 or 10 years, depending on their sensitivity (how quickly they change). Soil properties are classified as sensitive, moderately sensitive, and nonsensitive.

- Baseline data sets for all benchmark sites will be completed in 1995; the first set of resampling data has been collected for 6 out of 23 sites.

- Early results of the program allow some conclusions about effects of farming practices on soil health.

\section{Introduction}

Discussions of sustainable agriculture in Canada have raised questions about the health of our agricultural soils and the effects of farming practices on soil health, including

- How do changes in soil properties affect crop yields?

- Do certain crops and crop rotations degrade soil more than others?

- Does the method of tillage have an effect on soil health?

- Is there enough organic matter in our soils? What can be done to build levels up?

- How serious is the problem of soil erosion? Which farming practices increase or reduce the risk of erosion?
- How widespread is the breakdown of soil structure? How can soil compaction by farm vehicles be reduced?

- When and how should agrochemicals be used? What happens when they accumulate in the soil?

However, the scientific information needed to answer these and other questions in relation to a broad range of agricultural conditions across Canada was generally unavailable. Although studies on various features of soil health were being carried out at several sites across Canada, most of these studies were narrow in scope, focusing on selected soil properties, land uses, and management systems.
There is an urgent need to develop the institutional capability for continuously monitoring and assessing the status or quality of the world's resources.

Parr et al. 1992 


\section{Questions}

What is the health of Canada's agricultural soils?

How do land use and management practices affect soil health?

National soil-quality monitoring program

\section{Results}

- a national network of monitoring sites is established

- a national soil-quality database is produced

- methods of testing and simulating soil health can be validated

- farmers use management practices that conserve soil health

- researchers focus on important soil conservation issues

- decision-makers design policies to protect soil health

- research groups cooperate on soil-quality studies

\section{(L.J. Gregorich)}

What was needed was a system to monitor the quality of agricultural soils all across the country. This system would look at the health of soils under different land uses and farming practices. Over time it would show how soil health changes as a result of climate, landform, and agricultural use.

In January 1988, participants at a national workshop on soil-quality monitoring agreed that we had only a hazy picture of the health of Canada's agricultural soils. It was decided that a national soil-quality monitoring system should be put into place and was agreed to establish agricultural benchmark sites across Canada-sites at which certain soil and environmental characteristics would be measured in a standard way at regular intervals, so that changes could be observed over time.
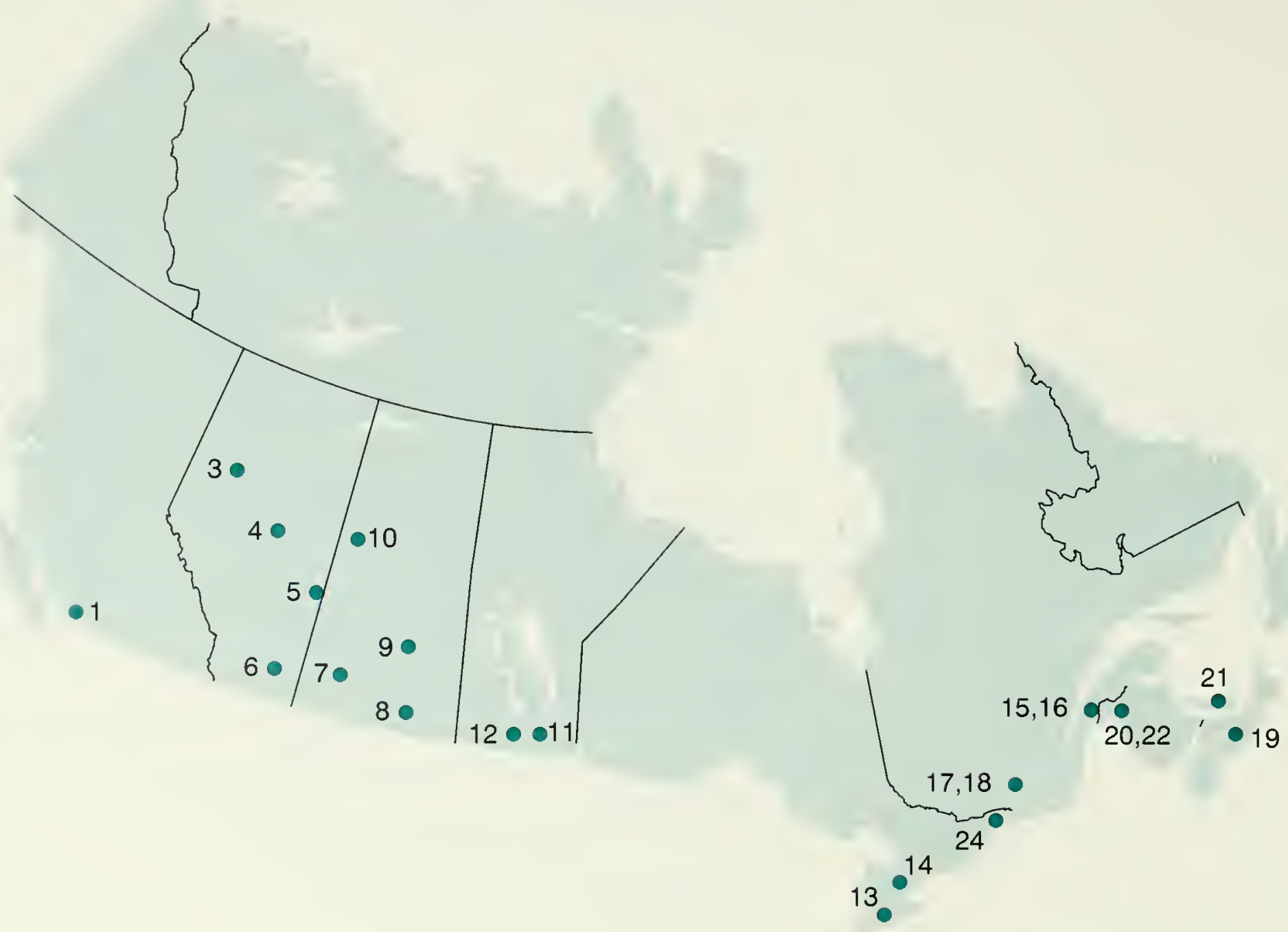
Seven benchmark sites were set up and sampled in eastern Canada in 1989. The National Soil Conservation Program began supporting the project in 1990, and 16 more benchmark sites were selected and sampled by 1993, for a total of 23 sites across Canada (Fig. 4-1). The collection of baseline data sets (the first set of measurements made at each site) will be completed in 1995 . Soil quality will be monitored for at least 10 years after baseline data is collected or until trends in changing soil health become clear.

\section{Objectives of the benchmark system}

The system for benchmark monitoring will allow various soil properties and processes to be measured at specific times and places over the long term. In this way, it will generate periodic "snapshots" of soil health and allow researchers to determine changes in soil health over time and to relate these changes to land use and management practices, as well as other factors.

The main objectives of the benchmark system are to provide

- baseline and resampling data sets for assessing changes in soil health and productivity (soil's ability to produce crops, measured as crop yields) of typical farm production systems

- a way to test and validate simulation models that predict soil degradation and productivity

- a way to evaluate whether farming systems in the major agricultural regions of Canada are sustainable

- a national network of sites that can be used by government and nongovernment groups to conduct cooperative research.

\section{Benchmark sites}

Benchmark sites were selected on the basis of seven factors that were identified by scientists and agricultural workers. The goal was to represent the main landform in
Canada's most important agricultural regions. Benchmark sites were to be made up only of cultivated land and were to represent

- a major soil zone, agricultural region, or both

- a typical landform or a broad textural grouping of soils, or both

- an important farm production system within a region.

They would also

- fit well with provincial agricultural concerns

- show signs of soil degradation or the potential for soil degradation

- cover about 5 to 10 hectares (a small watershed in some cases).

\section{Choosing a benchmark site}

Potato production accounts for more than $20 \%$ of provincial farm cash income in New Brunswick. More than 20000 hectares are planted to potatoes every year in this province and more than 50000 hectares are in a potato rotation.

The stability of the potato industry depends on the quality of potato-producing soils. Degraded soils are usually more susceptible to climatic extremes, such as drought and intense rainfall, which can cause large variations in potato production from year to year and unbalance an already volatile industry.

Land used for potato production is especially susceptible to soil degradation caused by water erosion and soil compaction. Water erosion costs farmers an estimated $\$ 10-12$ million every year, and compaction costs them an estimated $\$ 1$ million (based on 1986 dollars).

Benchmark Site 20 is located about $5 \mathrm{~km}$ southeast of Grand Falls in Victoria County in northwestern New Brunswick. It has a mid-temperate climate and is dominated by Podzolic soils of morainal origin. This site was chosen because it typifies land under potato production in this region. The 4.3-hectare site, located on a commercial farm, is farmed intensively for seed potatoes using a potato-grain rotation. The farming practices include conventional tillage, fertilization with a commercial fertilizer, and application of pesticides. 
Emphasis was placed on the first four points, so that monitoring results could be used to evaluate as many similar land forms and farming systems as possible over as broad an area as possible within each agricultural region.

\section{Baseline data sets}

To observe changes in soil quality over time and area, one must begin by establishing a set of baseline data. This set of observations, made at the start of the monitoring period,

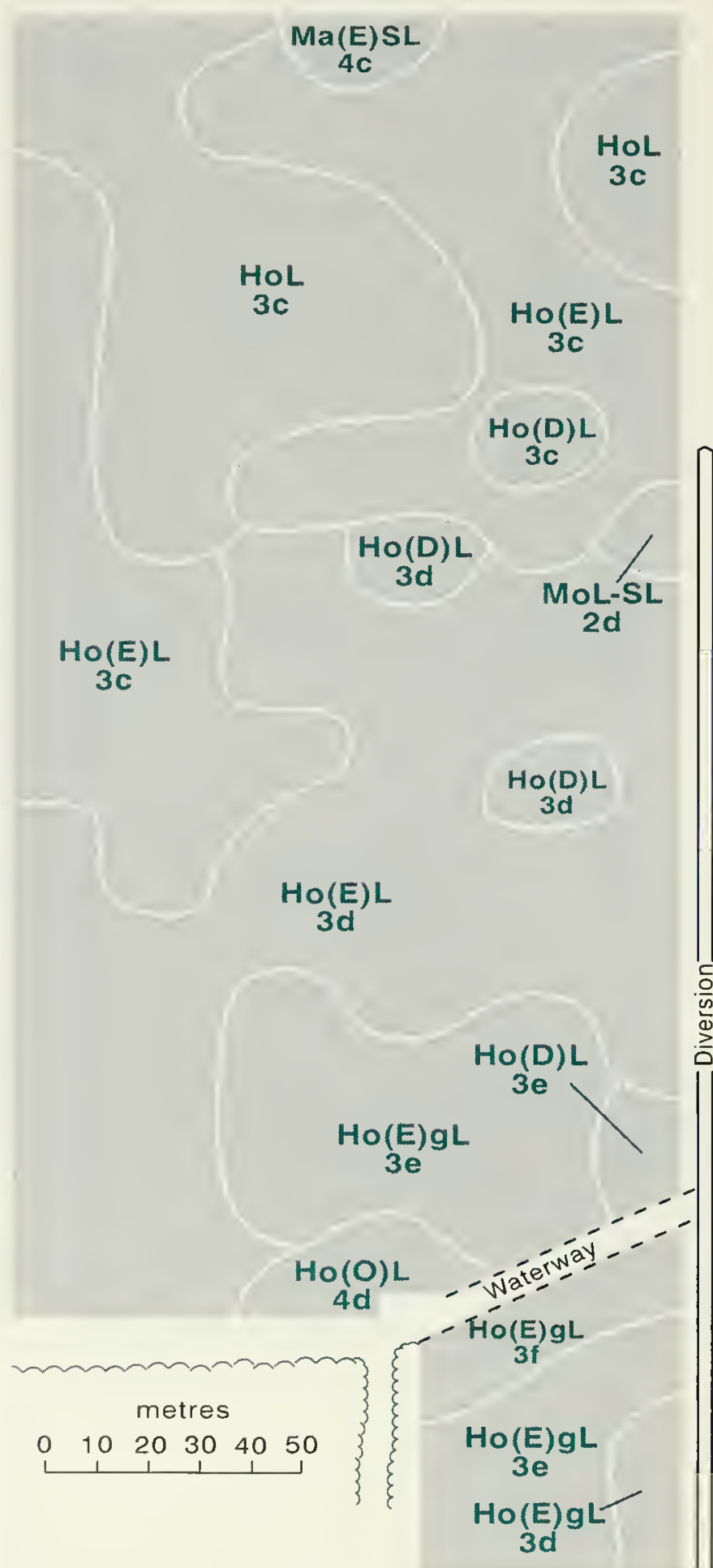

serves as the reference point against which to compare all future observations.

\section{Farm history database}

A farm history was recorded for each benchmark site, based on an interview with the farmer. Three types of information were collected:

1) site identification (including legal and ecological descriptions);

2) site history (including land acquisition; first cultivation; land management in the

\section{Figure 4-2}

\section{A soil map, showing the types of soil found at Site 20, in New Brunswick. \\ Legend}

\section{Soil association:}

Ho Holmesville

Ma Maliseet

Mo Monquart

\section{Phase:}

D Depth (the thickness of the material over the compact layer is $50-100 \mathrm{~cm}$ )

E Eroded (the B horizon has completely disappeared)

O Overwash (the Ap horizon is more than 1.5 times thicker than average)

Surface texture:

gL Gravelly loam

L Loam

SL Sandy loam

\section{Drainage:}

2 Well drained

3 Moderately well drained

4 Mainly well drained and moderately well drained, but with some imperfectly drained

\section{Slope:}

c $2-5 \%$

d $5-9 \%$

e $\quad 9-15 \%$

f $\quad 15-30 \%$ 
early years; major changes in farming practices; crop rotation; tillage system; crop yields and quality; use of commercial fertilizers, organic fertilizers and soil conditioners, and chemical pesticides or herbicides; drainage improvement; and degradation problems); and

3) current cropping and tillage practices (including crop rotation system; tillage, crop management, and harvesting methods; and an inventory of farm machinery).

\section{Soil and relief maps}

The following were drawn for each site:

- a map of the types of soil (Fig. 4-2) found over the entire benchmark site, at a scale of 1:2000 or larger, using observations from at least 40 inspection points

- a map of the surface relief (Fig. 4-3A) of the benchmark site, constructed from elevations (relative height of the ground surface) measured at about 100 selected points.
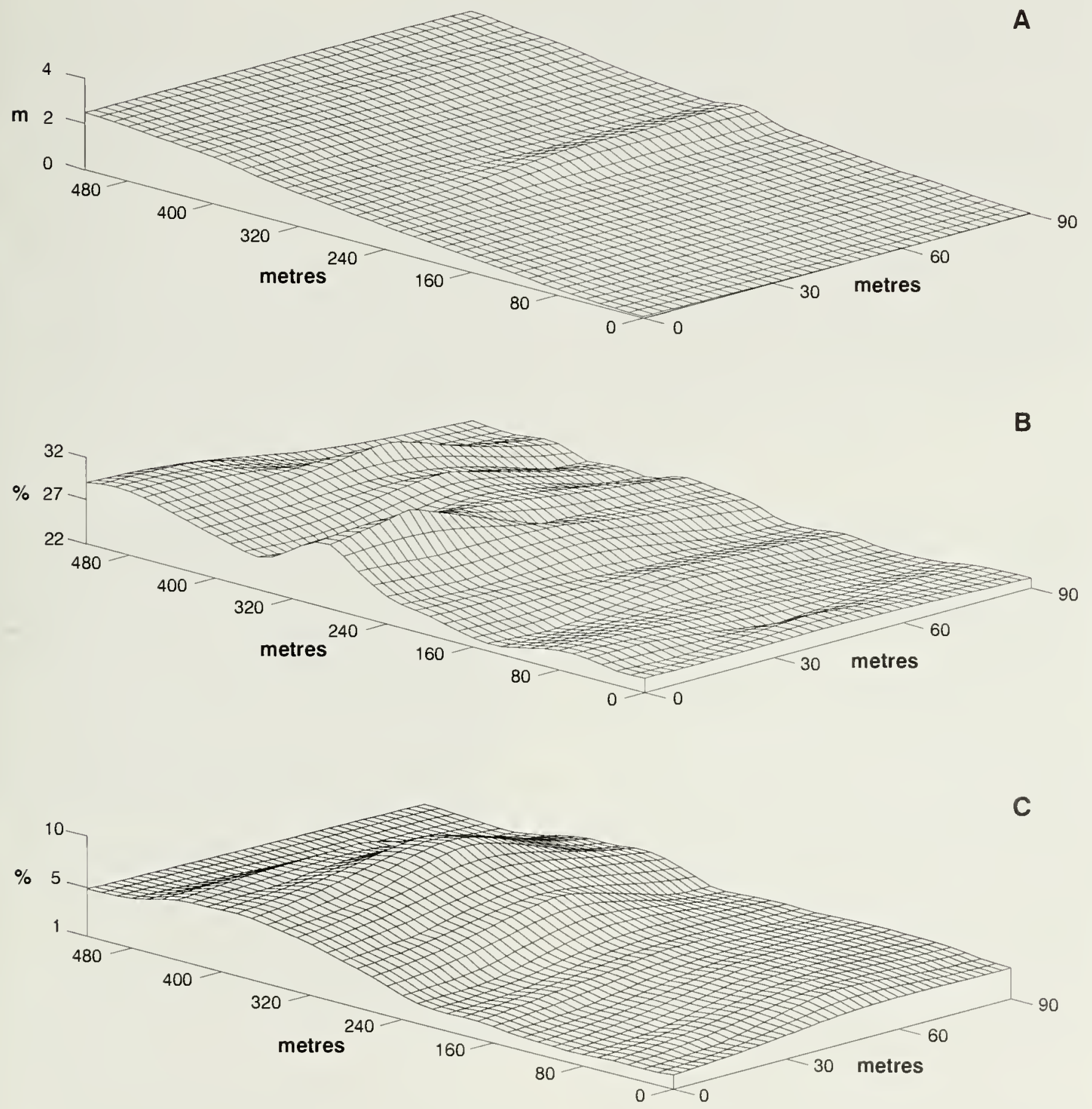

Figure 4-3 Properties of Site 18, in Quebec.

A) Surface relief; $B$ ) Soil moisture content in topsoil; C) Organic matter content in topsoil. 
Information provided by the relief map can be used to display landforms, such as ridges and gullies, and drainage direction. It provides the background for overlaying other soil and landform features. It also allows strategic sampling points to be located for future resampling.

\section{Soil sampling}

Three types of samples are taken as follows:

- samples of all the major layers in the two most representative soils found on the benchmark site

- 60-100 loose soil-surface samples, taken at selected points throughout the benchmark site (to establish baseline data for the site)

- 60-100 loose soil-surface samples, taken at selected points throughout the benchmark site to assess soil redistribution, using analytical methods involving cesium.

A portion of each loose sample is stored in a soil archive (collection) so that more testing is possible in the future.

\section{Soil properties}

A number of chemical, physical, biological, and mineralogical properties of soil were identified at the 1988 soil-quality workshop as key elements of a baseline data set. These properties were classified into the following categories (Table 4-1):

- sensitive properties, which could change significantly in less than 10 years

- moderately sensitive properties, which are likely to change over decades

- nonsensitive properties, which are not expected to change significantly in 100 years.

The nonsensitive properties, although not expected to change much over the duration of this study, are important properties for assessing the overall soil health of the benchmark sites.

Data sets for some physical and biological properties of soil are collected in the field (Table 4-1). Measuring the saturated and unsaturated hydraulic conductivity outlines the movement of water in the crop-root zone of soil. It also identifies changes in soil

Table 4-1 Soil properties (chemical, physical, biological, and mineralogical) measured at benchmark sites

\section{Sensitive properties ${ }^{1}$}

Soil reaction $(\mathrm{pH})$

Available phosphorus and potassium

Organic carbon

Total nitrogen

Bulk density

Dry-aggregate size distribution

${ }^{137}$ Cesium distribution

Extractable iron and aluminum ${ }^{2}$

Moderately sensitive properties ${ }^{3}$

Cation exchange capacity and exchangeable cations

Carbonates

Soil moisture retention

\section{Nonsensitive properties 4}

Particle-size distribution

Clay mineralogy 5

Total surface area

Total elements (aluminum, calcium, cobalt, chromium, copper, iron, potassium, lithium, magnesium, sodium, nickel, lead, zinc)

Properties measured in the field 6

Saturated hydraulic conductivity Near-saturated hydraulic conductivity Penetrometer reading and soil moisture Electromagnetic ground conductivity ${ }^{7}$ Biopore and root counts Earthworm counts ${ }^{8}$ Crop yields
1 Measured every 5 years.

2 For Podzolic soils only.

Measured every 10 years.

4 Measured only at the beginning of the observation period to establish baseline data.
5 Heavy application of nitrogen and potassium fertilizer may alter some silicate clays and special studies may be needed.

6 Measured in the field annually.

7 Only in areas with potential salinity problems.

8 Except in the Prairie Provinces. 


\section{Sensitive soil properties}

Sensitive soil property

Benefits

Problem

Soil reaction ( $\mathrm{pH}$ or acidity) Crops require a specific $\mathrm{pH}$ range; most grow best in soil with a $\mathrm{pH}$ of $6-8$

\begin{abstract}
Available phosphorus (P)
and potassium $(\mathrm{K})$

Soil organic matter, measured as organic carbon (C)
\end{abstract}

Total nitrogen (N)

Bulk density

Dry-aggregate size distribution

\section{Essential crop nutrients}

Maintains soil structure, holds and supplies plant rutrients and water

Essential crop nutrient

Soils with low bulk density (crumbly soils with good aeration) promote good root growth and good infiltration of water and air

Well-aggregated soils are stable, easy to cultivate, and make a good seedbed
Most crop growth is poor on acid soils (low $\mathrm{pH}$ ) and alkaline soils (high $\mathrm{pH}$ )

Excess $\mathrm{P}$ and $\mathrm{K}$ can contaminate surface water and
groundwater

Loss of soil organic matter may cause lower fertility, structural degradation, and increased risk of erosion

Excess $\mathrm{N}$ can contaminate surface water and
ground water

Soils with high bulk density (compacted, hard soils) have lower infiltration by air and water and increased risk of erosion and further deterioration

Breakdown of aggregates into fine soil particles increases the risk of erosion and loss of soil organic matter

(L.J. Gregorich) structure over the long term. Penetrometer readings provide information about soil strength (soil strength influences plant-root growth, which in turn affects the availability of soil moisture to plants).

Biopores, which are important to the movement of water in water-saturated soils and to soil aeration, include root channels and earthworm holes. Earthworms have an important effect on soil structure; a large population of earthworms produces a better structure by aerating the soil and increases the availability of organic nutrients. Crop yield (quality and quantity of the crop) is affected by many soil properties and processes and is the most visible sign of the health of agricultural soils.

\section{Progress of the study \\ Baseline data sets}

Much baseline information has already been collected at the benchmark sites. Most of the data have been organized and entered into a national benchmark site database (a collection of data). Besides providing valuable information about trends for particular soil properties, the database allows researchers to observe how a particular feature is affected by other characteristics of the soil.

\section{Example 1}

Site 18 in Quebec appears to the casual observer to be a flat field. But, by mapping the contours of the field, we found that the field has a slight slope, and a small ridge extends halfway across it at the mid point (Fig. 4-3A). This ridge, although a small relief feature, clearly affects soil characteristics at this site.

On measuring soil moisture (Fig. 4-3B), we found that the moisture was greatest directly behind, or upslope, from the ridge. The water runoff pattern is also affected; water skirts the ridge and runs to the opposite side of the field downslope, leaving the soil directly below the ridge with a much lower moisture content. Levels of soil organic matter (Fig. 4-3C) were higher behind the ridge, probably because better soil moisture conditions in that location promote better crop growth and higher returns of organic matter to the soil. 
A basic principle in the manufacture of products is that quality cannot be sampled [sic] into a product. ... The analogy to soil quality is that monitoring soil quality cannot change it.

Therefore, sustainable land management requires a deliberate effort to design land management systems that do not degrade the soil.

F.J. Pierce and W.E. Larson Developing Criteria to Evaluate Sustainable Land Management

\section{Example 2}

Site 5 in Alberta (Fig. 4-1) has a hilly surface. Adjacent to the national benchmark site is another agricultural research site, located on native (uncultivated) land. These paired sites provide the opportunity to look directly at the effects of agriculture on native soil. Sampling points are located along a hillslope on both the cultivated (since 1912) and native sites. Soil properties vary widely according to slope position and land use. On the hilltops (crests and upper slopes) of both cultivated and native sites, the topsoil is high in $\mathrm{pH}$ (Fig. 4-4A) and low in organic matter (Fig. 4-4B). On lower slopes and depressions, the topsoil is low in $\mathrm{pH}$ and high in organic matter. Because of soil erosion and thin topsoil, cultivation has brought subsoil material near the surface. Carbonates (which have a high $\mathrm{pH}$, or are alkaline) from the subsoils have been mixed with the plow layer, producing a higher $\mathrm{pH}$
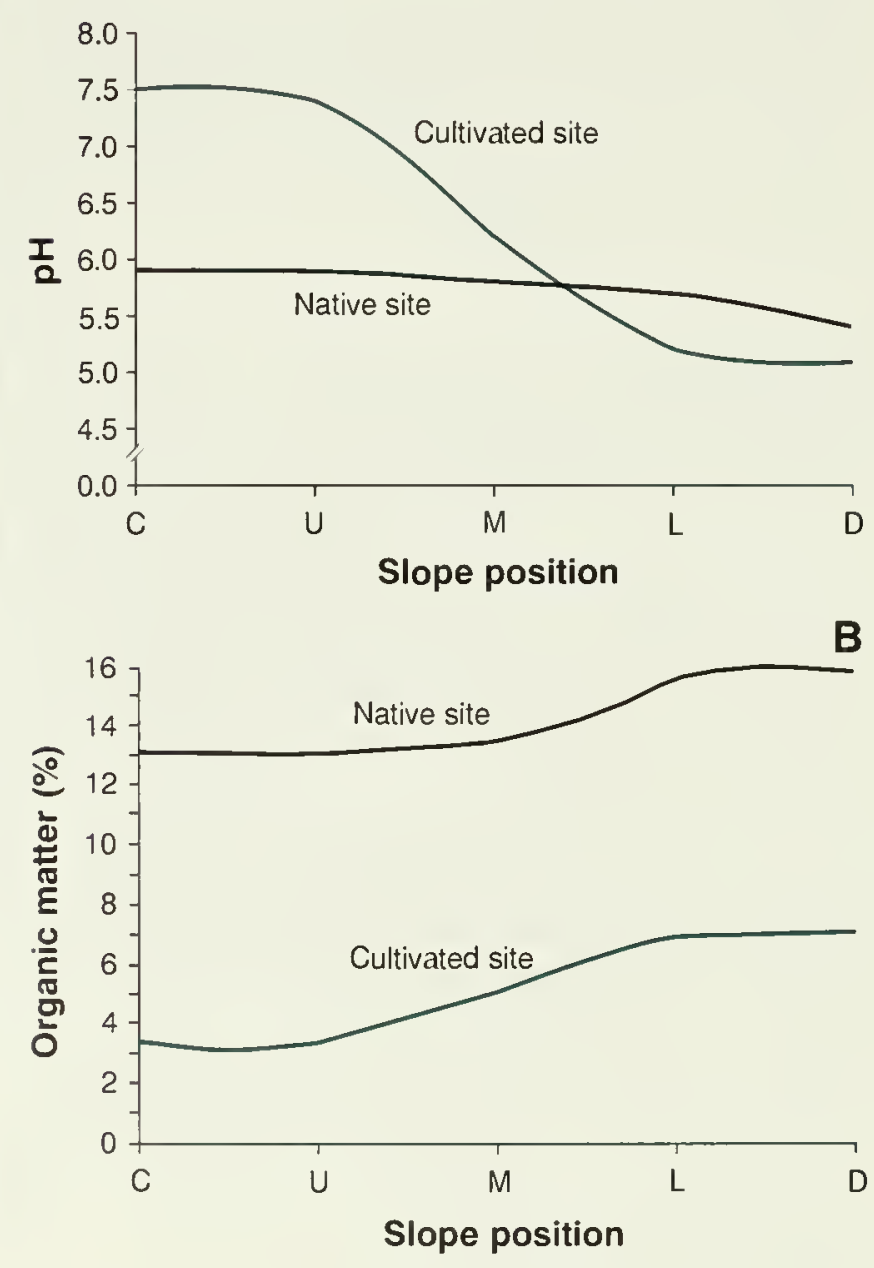

Figure 4-4

Effects of relief at site 5, Alberta, in the plowed layer (about $10 \mathrm{~cm}$ ).

A) $\mathrm{pH}$; B) Organic matter

$\mathrm{C}=$ crest, $\mathrm{U}=$ upper $, \mathrm{M}=\mathrm{mid}, \mathrm{L}=$ lower,

$\mathrm{D}=$ depresion. in hilltop positions. The lack of grass cover on the cultivated slope allows greater runoff of precipitation. This runoff in turn results in more leaching by water on the lower slope, producing a lower $\mathrm{pH}$ in this position on the cultivated site than on the native site.

The organic matter content is much lower on the cultivated site than on the native site (about $25 \%$ on the hilltop and $50 \%$ on the lower slope). Cultivation dilutes and reduces the amount of organic matter that is found naturally in prairie soils; the reduction is greatest at hilltop positions. On hilltops (crests and upperslopes), the topsoil is low in organic matter and nitrogen. On lower slopes and in depressions, levels of organic matter and nitrogen are much higher. (Soil organic matter is discussed more fully in Chapter 5.)

\section{Monitoring and preliminary results}

Soils at each benchmark site are resampled according to the monitoring schedule (see footnotes to Table 4-1) by taking 60-100 loose surface-soil samples at selected points throughout the site. For hilly sites, measurements of soil properties are grouped by their position in the landscape (all the measurements taken at upper-slope positions are combined, as are measurements taken at mid-slope and lower-slope positions). From this grouping we can observe differences in how soil quality changes at different slope positions.

Six benchmark sites were resampled by 1993. Some trends in soil quality were already evident at that time.

\section{Example}

The New Brunswick benchmark sites (Sites 20 and 22, Fig. 4-1) have the same soil type and similar slopes. They are under similar tillage systems, and the crop rotation at both sites is 2 years of potatoes followed by 1 year of grain. (This rotation is not typical in New Brunswick; most rotations are less intensive, such as 1 year of potatoes followed by 1 or more years of grain.) Terraces and grassed waterways are used on Site 22 to prevent soil erosion, whereas Site 20 is cultivated up- and down-slope. 


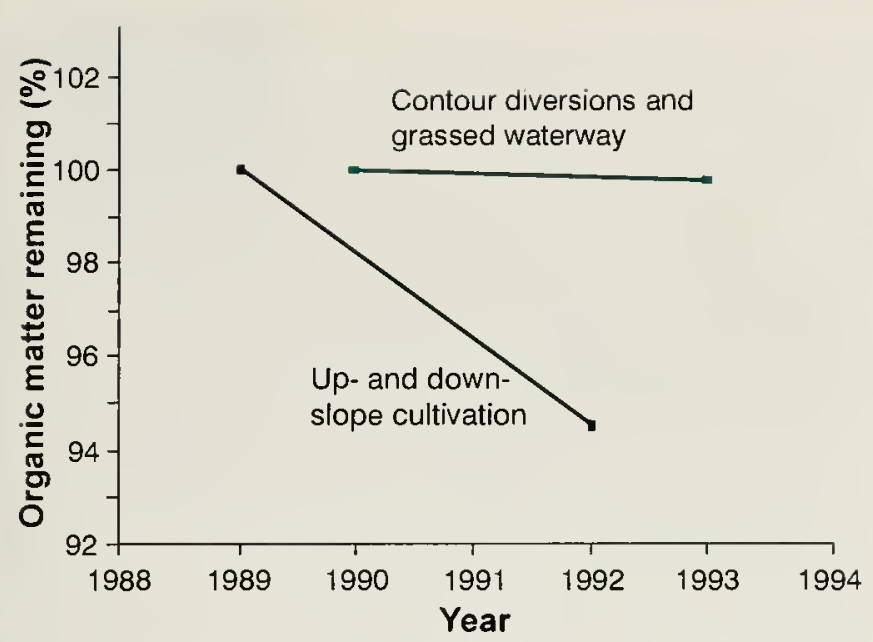

Figure 4-5

Organic matter content of topsoil at two New Brunswick benchmark sites.

A comparison of the baseline and resampling data for these sites (Fig. 4-5) shows that over 3 years there has been little change in the level of soil organic matter at Site 22 , but there has been a $5 \%$ loss on Site 20, 10 to 20 times more than on Site 22. Nearly all erosion on both sites took place during potato production. This result shows the positive effects of erosion controls in reducing the loss of soil organic matter.

On the Prince Edward Island benchmark site (Site 21, Fig. 4-1), potatoes are grown for 1 year, followed by 1 year of grain and 2 years of forage, which is plowed under. The initial level of soil organic matter at this site was lower than at either of the New Brunswick sites, because a previous cropping system had degraded the soil. But, between 1989 and 1993, soil organic matter at this site actually increased slightly as a result of plowing under the forage crop 2 years in a row (this practice puts organic matter and nutrients back into the soil).

A degraded soil may require many years to be restored. On the Prince Edward Island site, the 4-year crop rotation resulted in only a small improvement in soil organic carbon content. This observation shows that it takes less time and effort to maintain healthy soils and prevent soil degradation than to restore a soil that has been degraded.

\section{A benchmark farm family}

Dennis Carter first noticed the signs of soil degradation on his family farm when he was a boy helping his dad. "You know there's a problem when you see soil piled up against the fencelines and or you find gullies in the field because of water erosion," he says. When he was approached in 1990 about having part of his farm serve as a benchmark site (Site 5), Dennis agreed. "I wanted to find out just how much the farm has lost over the years."

Dennis took over the family farm in 1975 and later combined farming with studies at Lakeland Agricultural College. Together with his brother, John, Dennis manages 13 quarters of rolling land near Provost, Alta., in the northern part of the Dark Brown soil zone. They use conventional tillage and a rotation of canolacereal-fallow, typical practices in this farming region.

A small area of virgin prairie still exists on his brother's land. Benchmark researchers have compared measurements of soil properties on that site with those made at the benchmark site on Dennis's farm to find out the effects of 80 years of cultivation on the soil. Their studies show that about $50 \%$ of the soil organic matter remains from the days before cultivation began.

Dennis sees signs of this degradation in the field. Some parts of his land are "harder to work," and when the soil is tilled, "it comes up lumpy, not as mellow." So, three years ago he started pulling some land out of the usual rotation and planting alfalfa, which he sells as forage. He's already noticed a difference in the tilth of soil under this treatment and is talking about using other conservation methods; but he notes that those are usually "a matter of economics-waiting until you have enough money to buy the special equipment you need." But he's hopeful, because he and and his wife, Cheryl, have three young sons that will probably make the Carter place a fourth-generation family farm some day. And they'll need good soil for that.

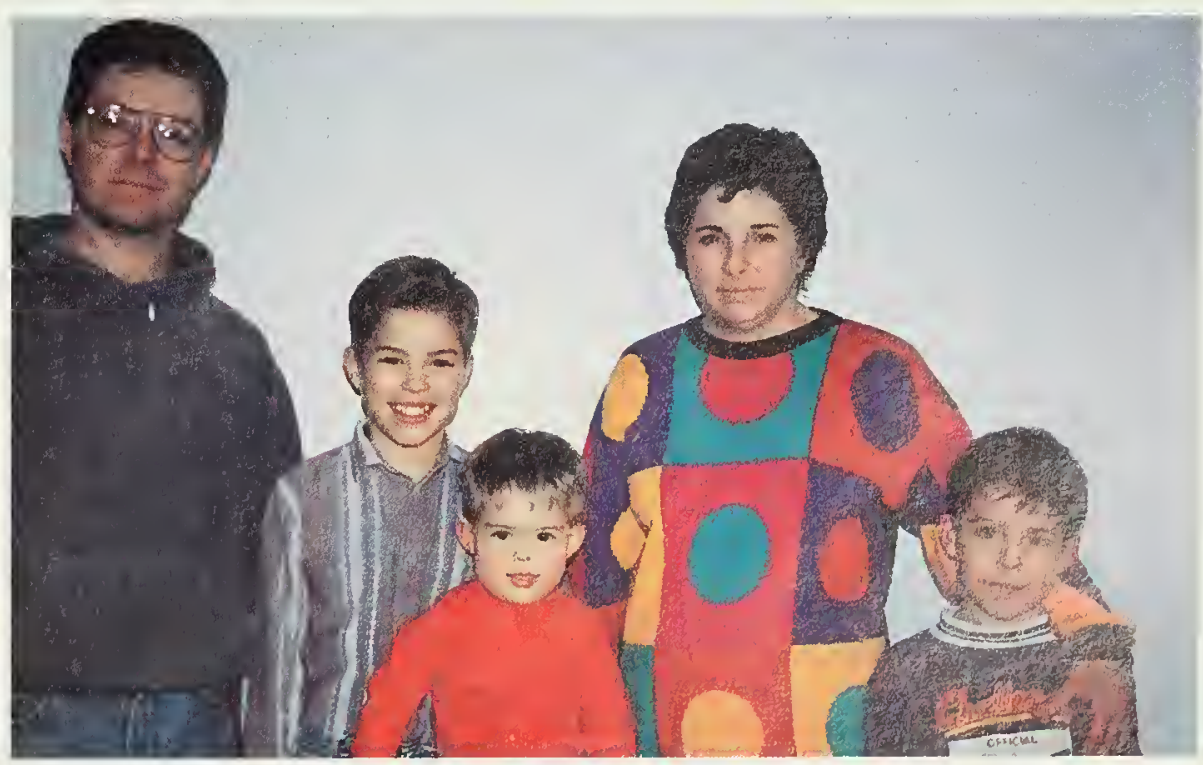

The Carter family: Dennis, Michael 11, Jason 3, Cheryl, and Kevin 8 (L.J. Gregorich) 
Wang et al.

But the care of the earth is our most ancient and most worthy and, after

all, our most pleasing responsibility. To cherish what remains of it, and to foster its renewal, is our only legitimate

hope.

Wendell Berry The Unsettling of America: Culture and Agriculture

\section{The future}

The national benchmark system holds considerable promise for monitoring the health of selected agricultural soils. It not only takes a systematic look at how individual soil properties change over time but also shows how these properties are related to each other and how current farming practices affect soil health. Early findings of the program show that the sensitive soil properties selected for measurement every 5 years are indeed measurable and together provide a good indication of changes in soil health.

At a time when financial resources are limited and research needs are pressing, it makes sense for partners in agricultural research to work together. The benchmark system enables researchers from many agencies to use the database, set up complementary programs, and apply findings to a wider range of sites. 


\title{
Changes in Soil Organic Matter
}

\author{
E.G. Gregorich, D.A. Angers, C.A. Campbell, M.R. Carter, C.F. Drury, \\ B.H. Ellert, P.H. Groenevelt, D.A. Holmstrom, C.M. Monreal, H.W. Rees, \\ R.P. Voroney, and T.J. Vyn
}

\section{Highlights}

- Organic matter is an essential component of soil that stores and supplies plant nutrients, aids water infiltration into the soil, retains carbon, stabilizes the soil and reduces erosion, and controls the effectiveness of pesticides.

- Levels of organic matter in Canada's uneroded agricultural soils have declined by 15-30\% since cultivation began.

- Soil organic matter levels are now being maintained or increased in many Canadian croplands.

- Optimal levels of organic matter for crop production vary with soil type and at present are not well-defined for Canadian soils.

- Soil organic matter increases under farming systems that use both conservation tillage and adequate fertilization and that reduce summerfallow.

- Inputs of crop residues, animal manure, green manure, sewage sludge, wood chips, or peat into the soil increase the organic matter.

\section{Introduction}

Organic matter is anything that is living or was once alive. Soil organic matter includes plant and animal remains in various stages of decomposition, cells and tissues of soil organisms, and substances produced by the soil microbes (Fig. 5-1). Well-decomposed organic matter forms humus-a dark brown, porous, spongy material with a pleasant, earthy smell.

Organic matter is an essential component of soil because it

- holds soil particles together and stabilizes the soil, thus reducing the risk of erosion

- aids crop growth by improving the soil's ability to store and transmit air and water
- stores and supplies many nutrients needed for the growth of plants and soil organisms

- maintains soil in an uncompacted condition, making it easier to work

- retains carbon from the atmosphere

- reduces the negative environmental effects of pesticides, heavy metals, and many other pollutants.

In this chapter we look at the condition of organic matter in Canada's agricultural soils. We also evaluate the effects of farming on soil organic matter and identify practices that degrade or improve soil organic matter.
Land, then, is not merely soil; it is a fountain of energy flowing through a circuit of soils, plants, and animals. Food chains are the living channels which conduct energy upward; death and decay return it to the soil. The circuit is not closed; some energy is dissipated in decay, some is added by absorption from the air, some is stored in soils, peats, and long-lived forests. 


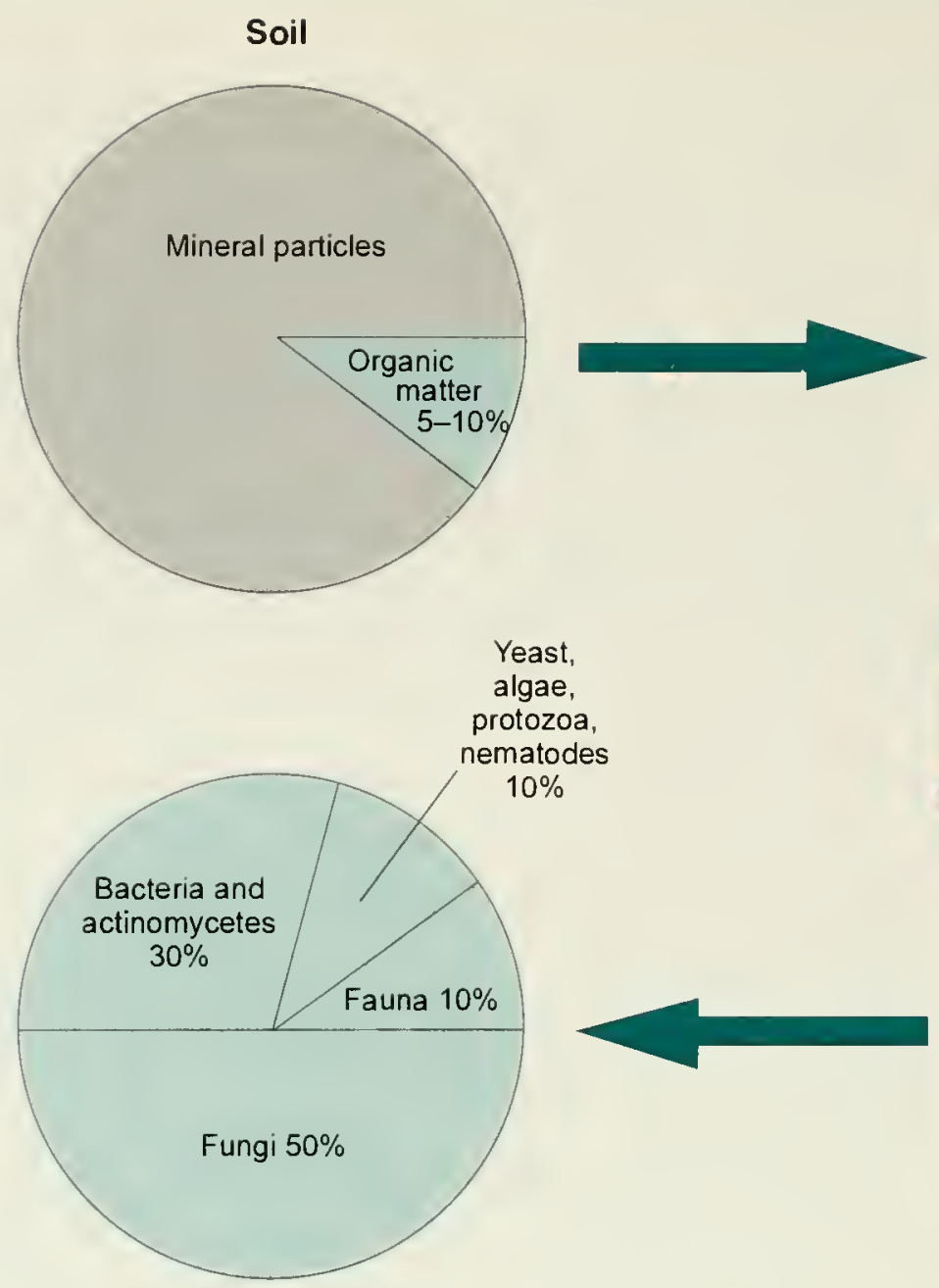

Soil microbial biomass

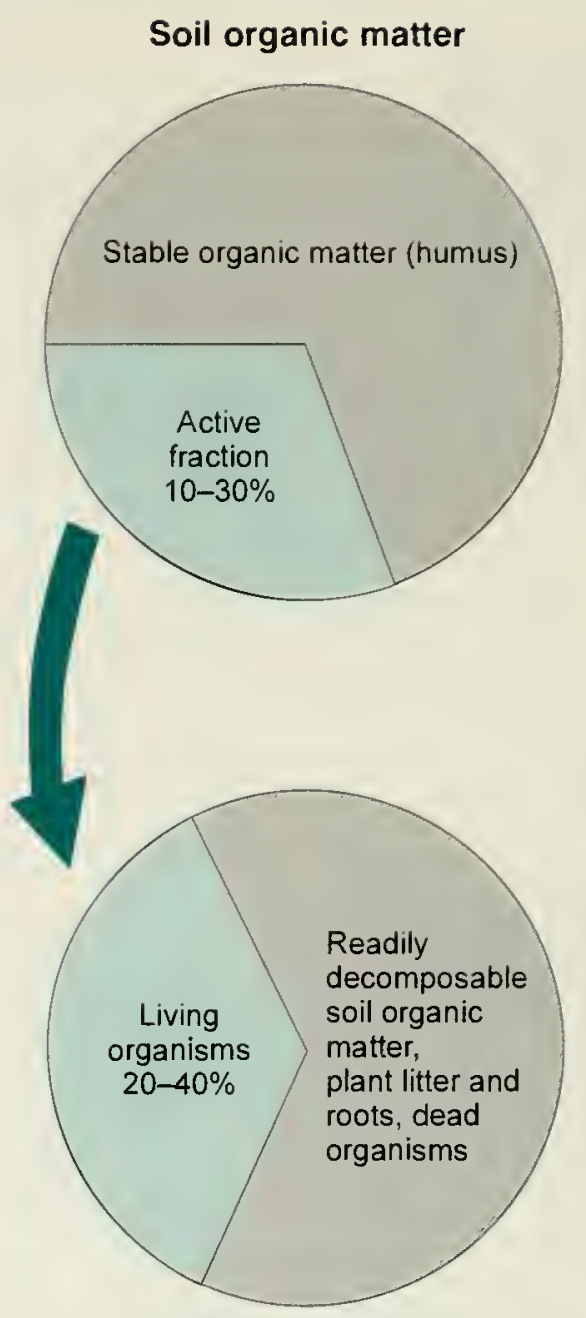

Active organic fraction

Figure 5-1 Composition of soil organic matter.

\section{Composition of soil organic matter}

Soil organic matter is affected by climate, vegetation, parent material (materials from which soils are formed), and topography (landforms), and by land use and farming practices. Carbon is cycled from carbon dioxide in the atmosphere to organic compounds in plants, to organic matter in soil, and back to atmospheric carbon dioxide (Fig. 5-2). Soil organic matter, like the plants and animals from which it derives, is composed of carbon chains and rings to which other atoms are attached. The terms soil organic matter and soil organic carbon are often used interchangeably, because carbon, the key component of organic matter, is readily measured in the laboratory. Although dry, undecayed plant organic matter contains about $40 \%$ carbon, soil organic matter typically contains about $50 \%$ carbon. Soil organic matter also contains about $40 \%$ oxygen, $5 \%$ hydrogen, $4 \%$ nitrogen, and $1 \%$ sulfur.

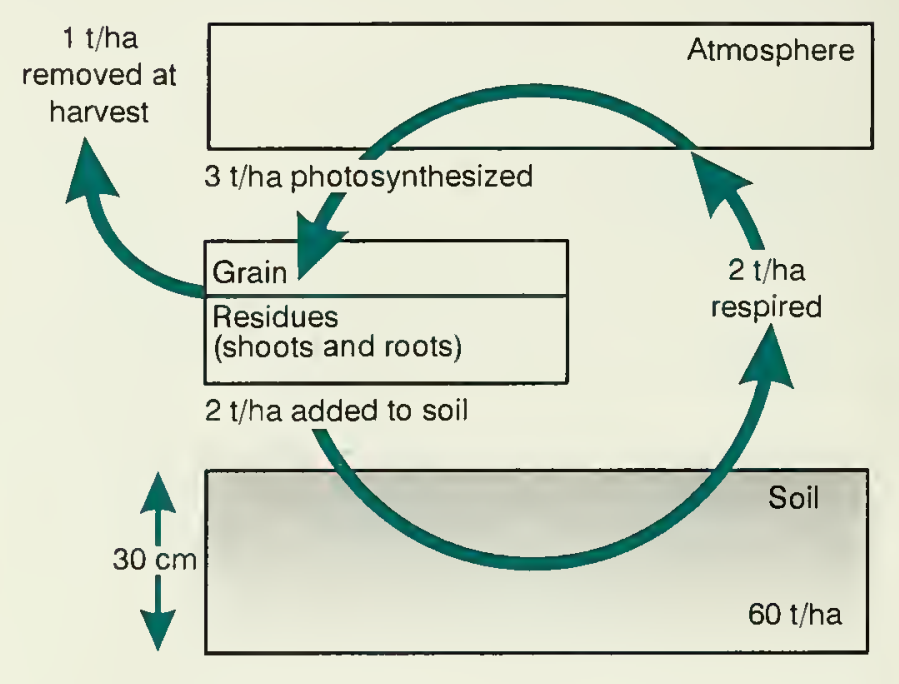

Figure 5-2

The carbon cycle.

Carbon added is balanced by carbon removed for 1 year of spring wheat growing on a Chernozemic soil $(t=$ metric tonne, or $1000 \mathrm{~kg})$. 


\section{Levels of soil organic matter}

The amount of organic matter added to the soil and the amount released or removed from the soil control the content of organic matter in soil. The biological processes of plant growth and organic matter decomposition are the main factors in whether the level of soil organic matter increases, decreases, or remains the same.

The amount of organic carbon in the top 30 centimetres of the soil in nonforest ecosystems is usually much greater than the amount contained in the roots, leaves, and stems of the vegetation (Fig. 5-3). Agricultural soils may contain more than 10 times the amount of carbon found in the crop growing on the soil.

The amount of organic matter in soils varies widely, from 1 to $10 \%$ (total dry weight) in most agricultural soils to more than $90 \%$ in wetlands where peat has accumulated (Fig. 5-4). Chernozemic soils, formed in grassland ecosystems found in the prairies, contain large amounts of organic matter.

They occupy the largest area of improved

\section{The decomposition machine}

The transformation of plant residues into soil organic matter is regulated by three factors: organisms $(\mathrm{O})$, the physical-chemical environment $(P)$, and the quality of residues $(Q)$. These factors act like a valve in the "decomposition machine," determining the rate at which, and the extent to which, residues in the soil decompose.

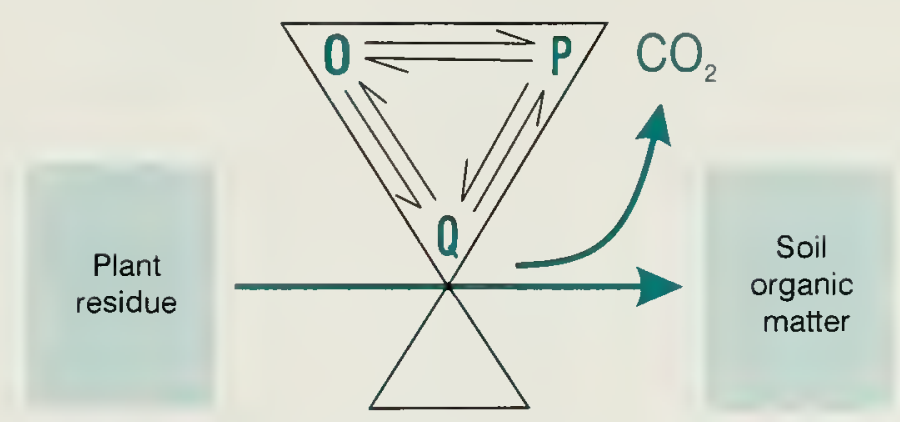

Farming practices can affect one or all of these factors. For example, no-till leaves a large amount of crop residue on the surface, which changes the physical environment by altering the soil's temperature and moisture. The use of leguminous forage plants, such as alfalfa, in rotations changes the quality of the residue added to the soil.

(E.G. Gregorich, AAFC, Ottatua, Ont.)

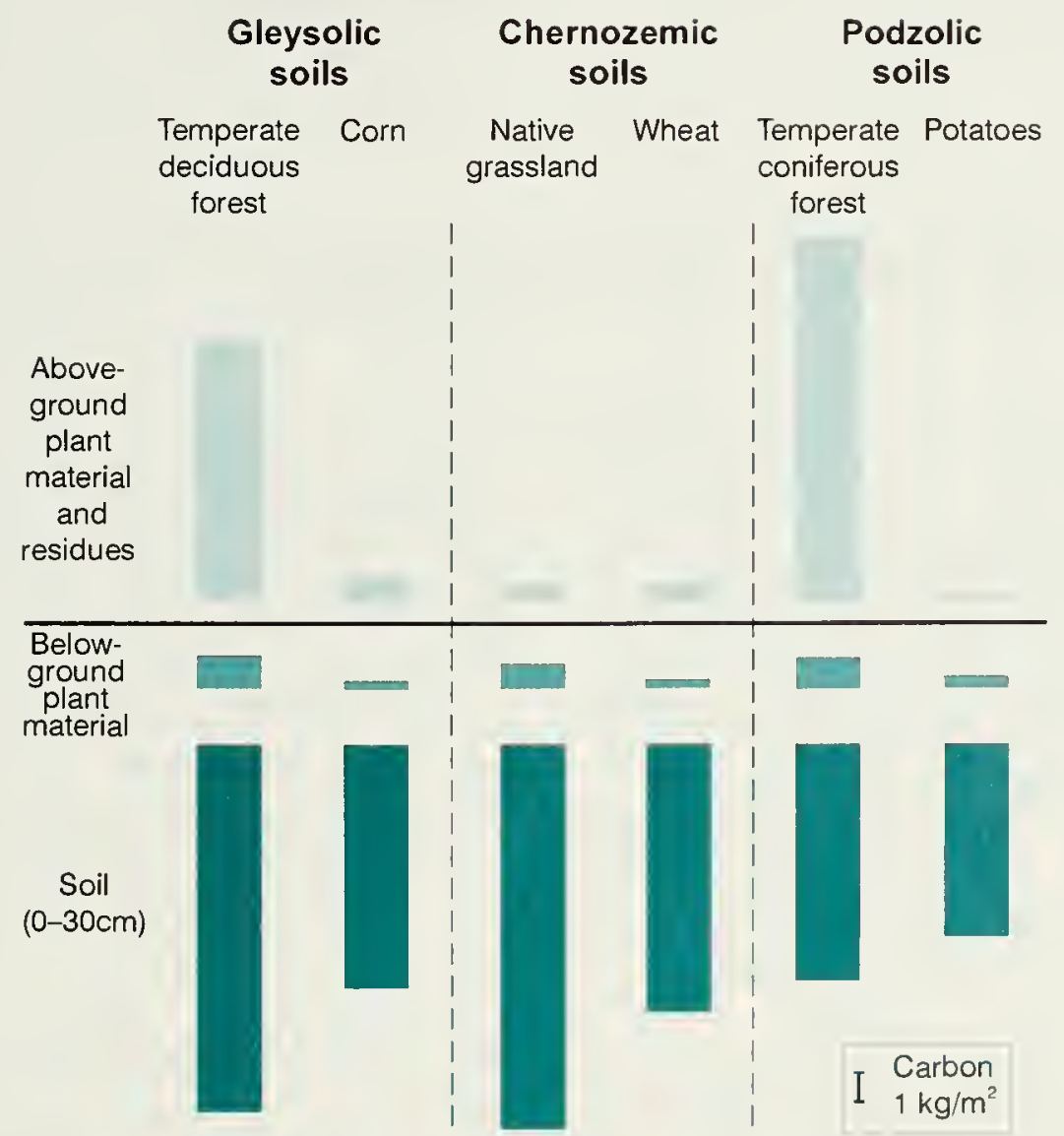

Figure 5-3 Carbon in terrestrial ecosystems.

The amount of carbon in above-ground plant material and residues, roots, and the top $30 \mathrm{~cm}$ of soil in different native and agroecosystems. 


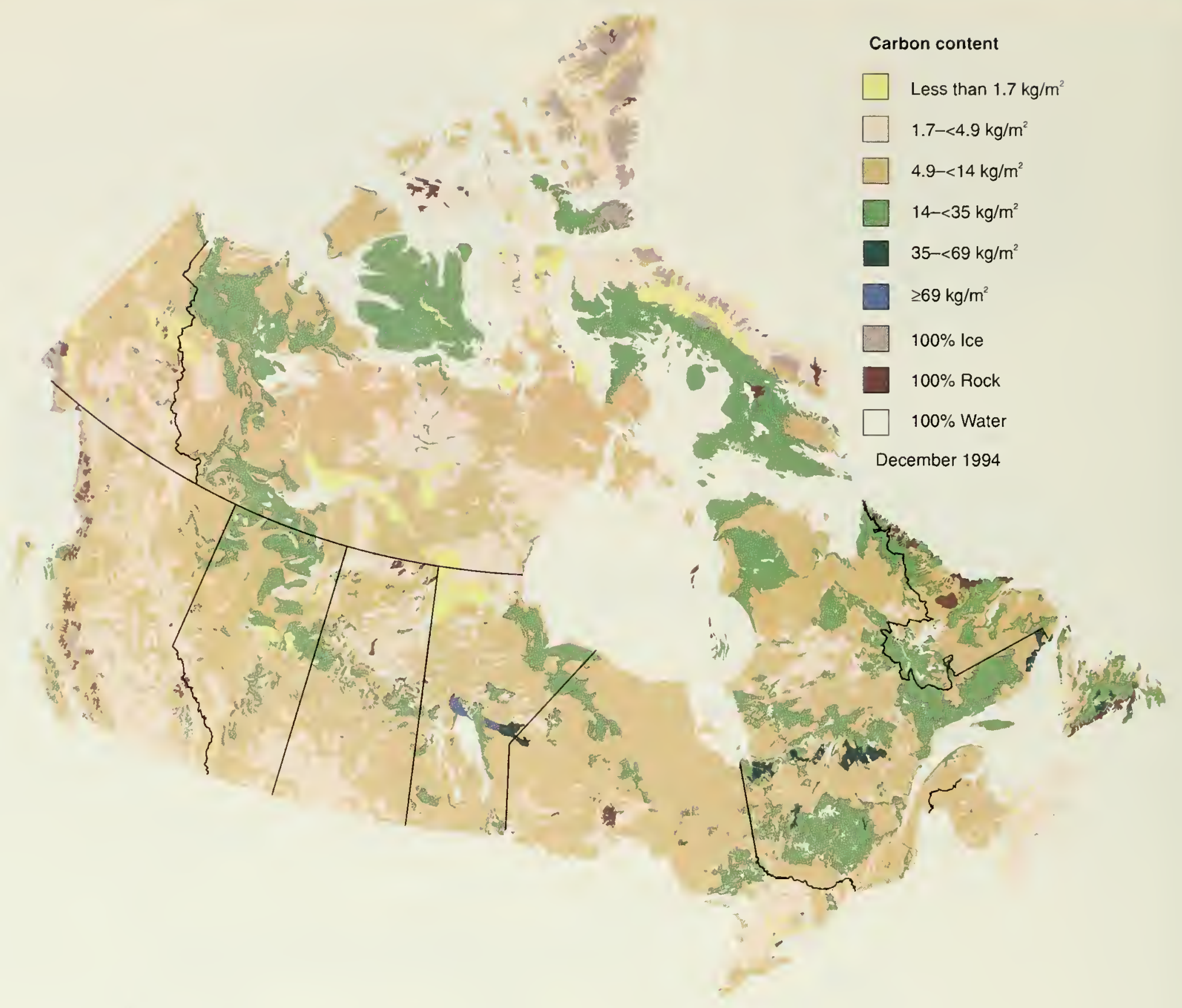

Figure 5-4 Carbon content of surface soils in Canada.

cropland in Canada (see map inside front cover). Soils common to eastern Canada, such as Gleysols (soils formed under conditions of poor drainage) and Podzols (acidic soils formed under trees), also have relatively large amounts of organic matter but do not make up a large share of agricultural land. Organic soils (those found in bogs, fens, and swamps) have the greatest amount of organic matter but occupy only a small area of Canada's cropland.

The optimum organic matter content of a soil depends on local climate, the amount and type of clay material present in the soil, and the soil's intended use. Ideally, in a good-quality soil, all the functions of organic matter listed earlier operate fully. However, soil organic matter alone cannot supply the quantity and balance of nutrients required by crops under intensive production; fertilizer must be added to meet the crop's needs. On the other hand, soil needs optimum amounts of organic matter to maintain its structure and keep it in a tillable condition.

\section{Decline of soil organic matter}

When soil is cultivated to produce crops, especially annual crops, the natural plant-soil system is altered. Harvesting removes much plant material, leaving little to be worked back into the soil to replenish 


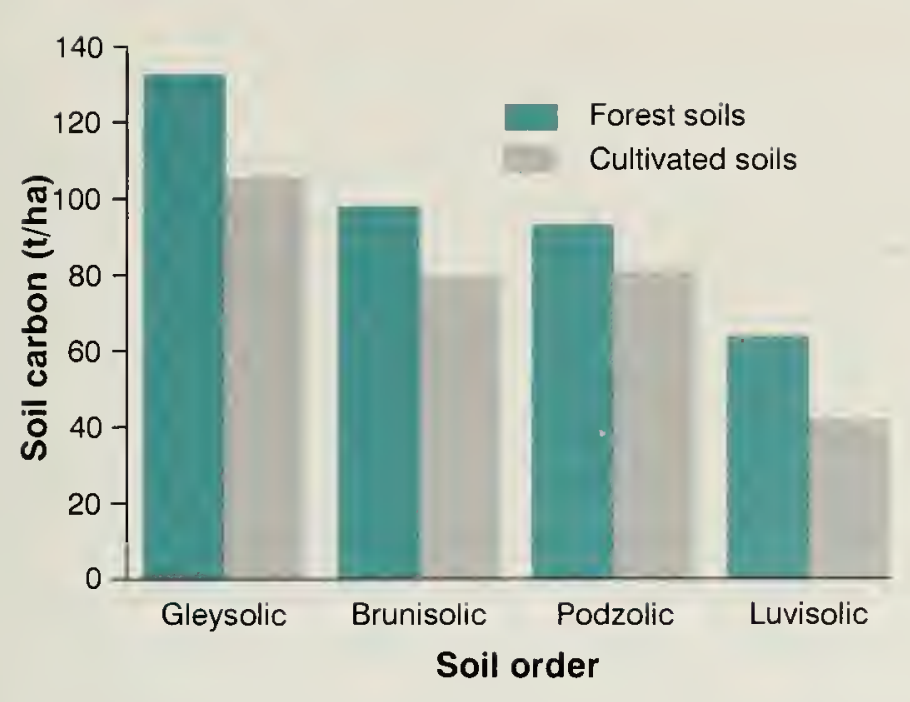

Figure 5-5

Carbon in forest and adjacent cultivated soils in eastern Canada.

the organic matter. Some plants are removed almost completely, leaving little residue. Commercial fertilizers can be added to replace nutrients removed from the soil but they do not directly build up soil organic matter. Rather, they promote plant growth, which in turn results in more residue being returned to the soil. Other materials, such as crop residues, animal manure, green manure (leguminous plants, such as alfalfa and red clover, and grasses), compost, peat, and wood chips must be added to maintain or increase soil organic matter.

When an undisturbed forest or grassland soil is converted to agriculture, soil organic matter levels usually decline (Fig. 5-5). This decline results from

- increased decomposition of existing soil organic matter because of tillage and changes in moisture, aeration, and temperature conditions

- reduced replenishment of soil organic matter by crop residues.

Studies in the 1970s and 1980s focussed on the decline of soil organic matter; some scientists suggested that losses of up to $50-70 \%$ had occurred since virgin land was first cultivated. A recent survey in eastern Canada, carried out under the National Soil Conservation Program (NSCP), suggests these estimates are high; actual losses of soil organic matter since converting virgin land to agriculture are typically only 15-30\%.

\section{What is living in your soil?}

Healthy soil teems with an immense community of living organisms. In fact, a hectare supports about 20000 kilograms of soil organisms, equivalent to the weight of 40 horses. Although they make up only about $5 \%$ of soil organic matter, these organisms are vital to many soil processes. Through their roles in the decomposition cycle, they regulate the flow of energy through the soil, the cycling of nutrients, and the productivity of agroecosystems.

Soil organisms span a wide range in size, from microscopic forms, such as bacteria, fungi, and protozoa, to larger animals, such as insects, worms, and burrowing mammals. The larger organisms assist in decomposition by ingesting plant residues, breaking them into finer particles, and mixing them as waste throughout the moist soil environment. These wastes become food for the microorganisms, which digest the organic matter, releasing plant nutrients and gases, and producing glues that stick the soil mineral particles together to form aggregates.

An active population of soil organisms can be maintained if the soil has a suitable physical environment (adequate moisture and aeration) and is well-supplied with decomposable plant material. Growing crops in rotation, using cover crops, and underseeding crops with legumes are examples of practices that provide an abundance of food-stuffs for a wide range of soil organisms. Conservation tillage also helps to enhance the biodiversity of the community by protecting the soil surface with plant residues and minimizing disturbance of the soil's structure.

(R.P. Voroney, University of Guelph, Guelph, Ont. and E.G. Gregorich, AAFC, Ottnwa, Ont.)

Most of the loss in soil organic matter occurs within 10 years of clearing forest or native grassland; the size of the loss varies according to the type of soil. Losing soil nitrogen may not be as serious as losing soil carbon, because agricultural production usually involves adding nitrogen fertilizers. Adding nitrogen may result in soil-nitrogen levels equal to or greater than those found in natural, undisturbed soils.

\section{Monitoring soil organic matter}

A nationwide system for monitoring soil organic matter was not in place until Agriculture and Agri-Food Canada's benchmark program to monitor soil quality 


\section{Organic matter affects soil structure}

Soil organic matter plays a central role in forming soil aggregates. The polysaccharide content of soil organic matter acts as a glue, holding soil particles together in stable aggregates. Soils with high aggregate stability are more resistant to degradation by erosion and compaction.

As the clay content of a soil increases, it requires a higher content of organic matter to maintain a given level of aggregate formation and stability. For example, a maximum level of aggregate stability was associated with the following clay and organic matter levels in some soils with clay minerals of a similar type:

Clay content (\%)

$\begin{array}{rrrr}10 & 20 & 40 & 50 \\ 3 & 4 & 7 & 9\end{array}$

(M.R. Carter, AAFC, Charlottetoun, P.E.I. and D.A. Angers, AAFC, Sainte-Foy, Que.)

was set up in 1989 (see Chapter 4). This program has delivered baseline data on soil organic matter for 23 benchmark sites across the country and is designed to provide comparative data over 10 years.

Although we lack comprehensive data on soil organic matter across Canada, current information from specific regions of the country suggests general trends for the effects of land use and farming practices on soil organic matter. Evidence shows that soil organic matter levels are being main. tained or increased in many Canadian croplands because of improved manage- ment. For example, long-term cropping experiments in the Prairie Provinces suggest that levels of soil organic matter are holding steady meaning that the amount of organic matter taken out of the soil in the form of crops is replenished by adding crop residues, manure, and commercial fertilizers. As another example, many soils under potato production in Prince Edward Island now have higher levels of soil organic matter than 10 years ago, in part because longer crop rotations have been introduced. These rotations include forages that are plowed under.

\section{Factors affecting soil organic matter}

\section{Tillage}

Conservation tillage is a method designed to keep most crop residue on the soil's surface, where it protects against soil loss caused by erosion and reduces water loss by runoff and evaporation. This type of tillage concentrates organic matter at the soil's surface because crop residues are not mixed into the soil.

A study in Ontario showed that no-till increased organic matter at the soil's surface and throughout the soil profile, compared to soil tilled conventionally with a moldboard plow (Table 5-1). A study in southwestern Saskatchewan looked at changes in soil organic matter on conventionally tilled land that had been in a fallow-wheat rotation with minimal fertilization for 70-80 years and was then converted to a system that grew wheat

Table 5-1 Organic matter at two depths after 18 years of various tillage treatments of Ontario soil under corn

Tillage system

Soil organic matter (tonnes per hectare)

\begin{tabular}{lccc} 
& $0-15 \mathrm{~cm}$ & $15-30 \mathrm{~cm}$ & $0-30 \mathrm{~cm}$ \\
\hline No-till & 86 & 65 & 151 \\
Chisel plow & 73 & 52 & 125 \\
Disc & 74 & 58 & 133 \\
Moldboard plow & 66 & 64 & 130
\end{tabular}




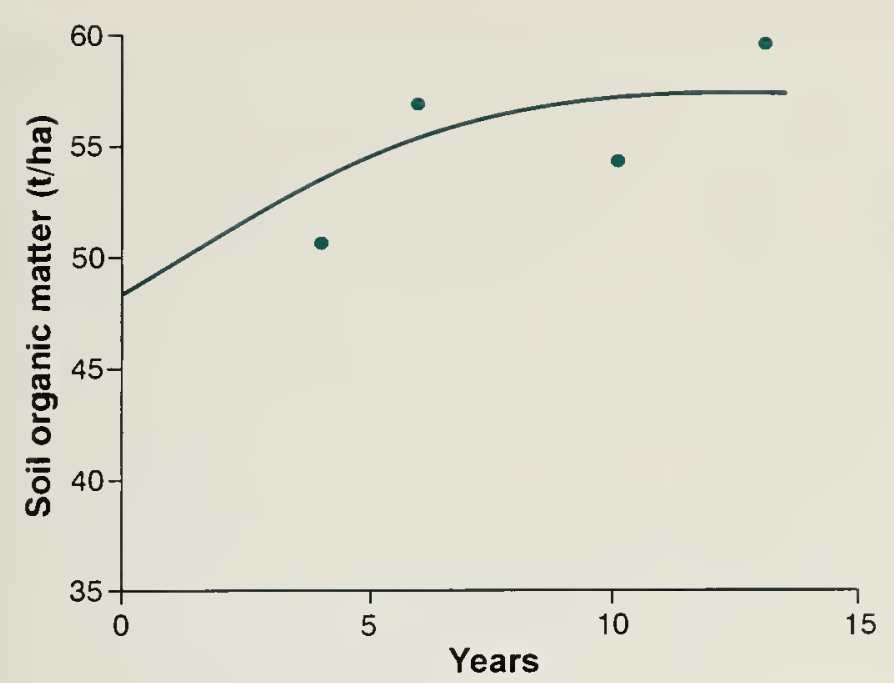

Figure 5-6

Effects of no-till on soil organic matter. Changes in organic matter levels in the top $15 \mathrm{~cm}$ of soil after conversion from a conventionally tilled fallow-wheat rotation to no-till continuous wheat.

every year using conservation tillage and fertilization. Soil organic matter increased steadily during the period of conservation tillage but appears to approach a steady state (Fig. 5-6).

The total amount and the rate of increase in soil organic matter varies throughout Canada according to soil, climate, and farming system used. But systems that use conservation tillage and fertilization help to conserve organic matter in all agricultural soils.

We used a computer simulation model to predict changes in the level of organic matter in the top 15 centimetres of virgin soil subjected to 50 years of conventional tillage, no-till, or no-till plus fertilization with nitrogen at an annual rate of 50 kilograms per hectare. Results show that soil organic matter levels would continue to decline to some steady state under conventional tillage without fertilization; they would decline at a slower rate under no-till without fertilization. In contrast, notill with adequate fertilization would significantly increase soil organic matter over present-day levels, according to the model (Fig. 5-7).

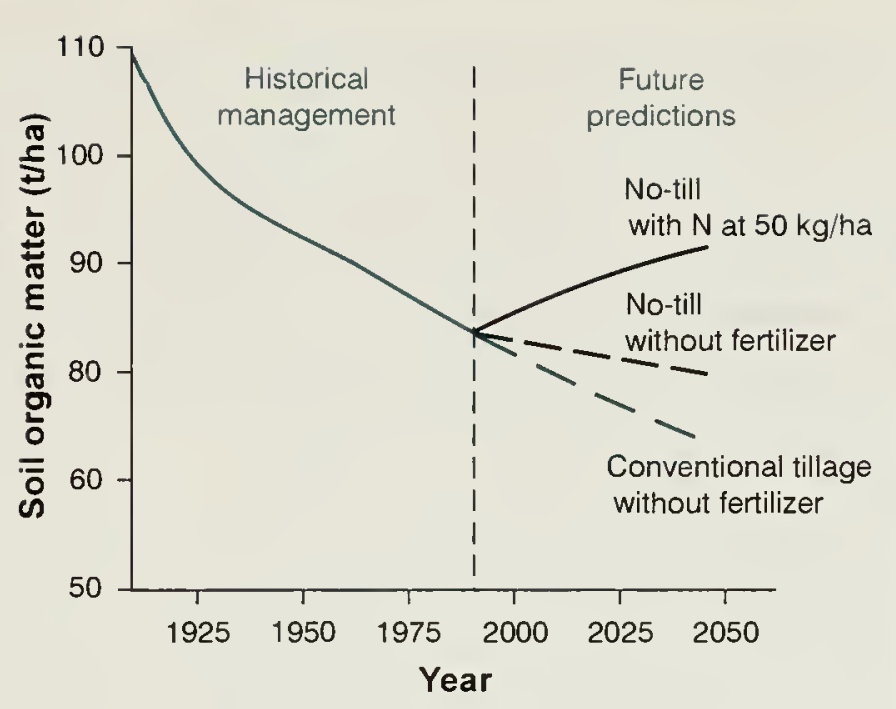

Figure 5-7

Soil organic matter levels under three management practices.

Computer predictions of total levels of organic matter in the top $30 \mathrm{~cm}$ of a prairie soil under no-till with and without fertilizer and under conventional tillage without fertilizer.

\section{Crop rotations}

Crop rotation affects the amount of organic matter in the soil. Forages and legumes have extensive rooting systems that leave large amounts of organic matter in the soil when they die. Fallow periods in rotations have been used in semiarid regions of western Canada to conserve moisture for the succeeding crop. However, fallow (especially when conventionally tilled) exposes the soil to erosion, which reduces the levels of organic matter and creates temperature and moisture conditions that speed up the rate at which soil organic matter decomposes.

Studies in the Prairie Provinces have shown that soils cropped to wheat every year, especially when fertilized, maintain levels of organic matter better than soil under rotations that include fallow (Fig. 5-8). The improvement results from

- more crop residues being returned to the soil each year

- the soil being protected against erosion

- organic matter decomposing slower in cropped soils. 


\section{Atomic differences in carbon}

The most abundant form of carbon in nature has 12 nucleons (12C), but some carbon atoms are heavier because they have 13 nucleons $\left({ }^{13} \mathrm{C}\right)$. The ratio of these two forms of carbon varies slightly among carbon-containing substances. Geologists have used differences in ${ }^{13} \mathrm{C} /{ }^{12} \mathrm{C}$ ratios of sediments and tree rings to identify prehistoric changes in the landscape and climate. Atomic differences have also been used to trace the flow of carbon from plants to grazing animals and meat-eaters.

In 1970, scientists discovered that plants fall into two major groups according to the chemical pathway by which they take up carbon dioxide during photosynthesis. The most common group contains the plants, such as cereals and most trees, that have relatively low ${ }^{13} \mathrm{C} /{ }^{12} \mathrm{C}$ ratios. $\mathrm{C} 4$ plants, including corn, sugar cane, and pigweed, photosynthesize very efficiently and have higher ${ }^{13} \mathrm{C} /{ }^{12} \mathrm{C}$ ratios.

The different carbon ratios in C3 and C4 plants can be used to trace the flow of carbon from plants to soil, since carbon ratios in soil organic matter are very similar to those in the plant material added to the soil. When $\mathrm{C} 3$ plants, such as natural grasses and cereals, are replaced by $\mathrm{C} 4$ plants, such as corn, the ${ }^{13} \mathrm{C} /{ }^{12} \mathrm{C}$ ratio of soil organic matter increases.

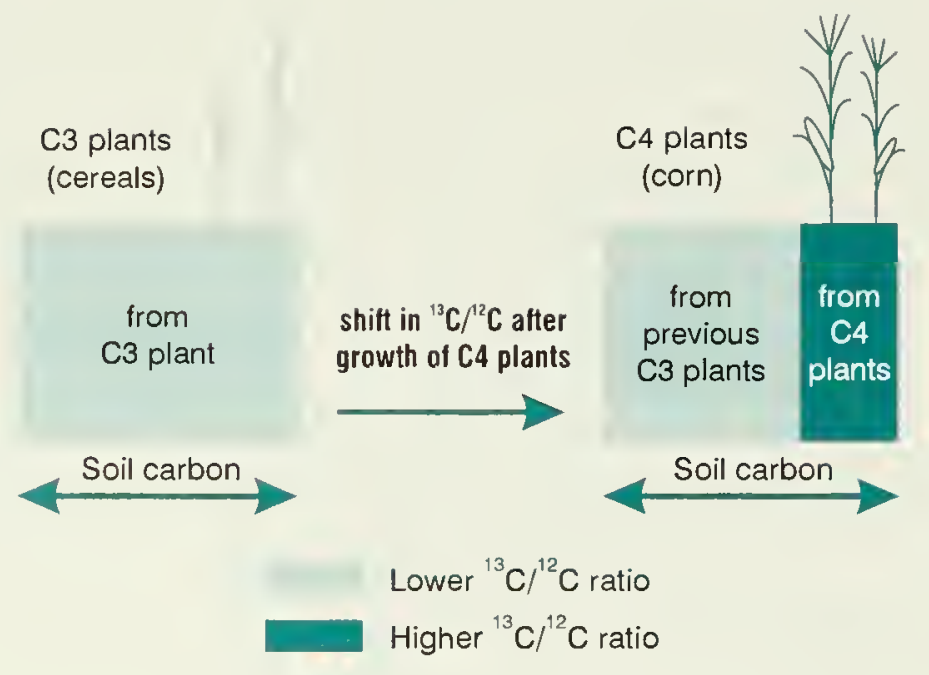

An Alberta study used carbon ratios to distinguish corn-derived carbon from carbon that was present in soils before corn was grown. Results showed that $15 \%$ of soil carbon came from corn tissues and $85 \%$ persisted from previously grown C3 plants, and also that some of the original soil organic matter decomposed rapidly and was replaced by corn residues. This type of information on the relative amounts of decomposable and persistent soil organic matter is useful in choosing farm management systems that sustain organic matter and crop production.

(B.H. Ellert, AAFC, Lethbridge, Alta.)

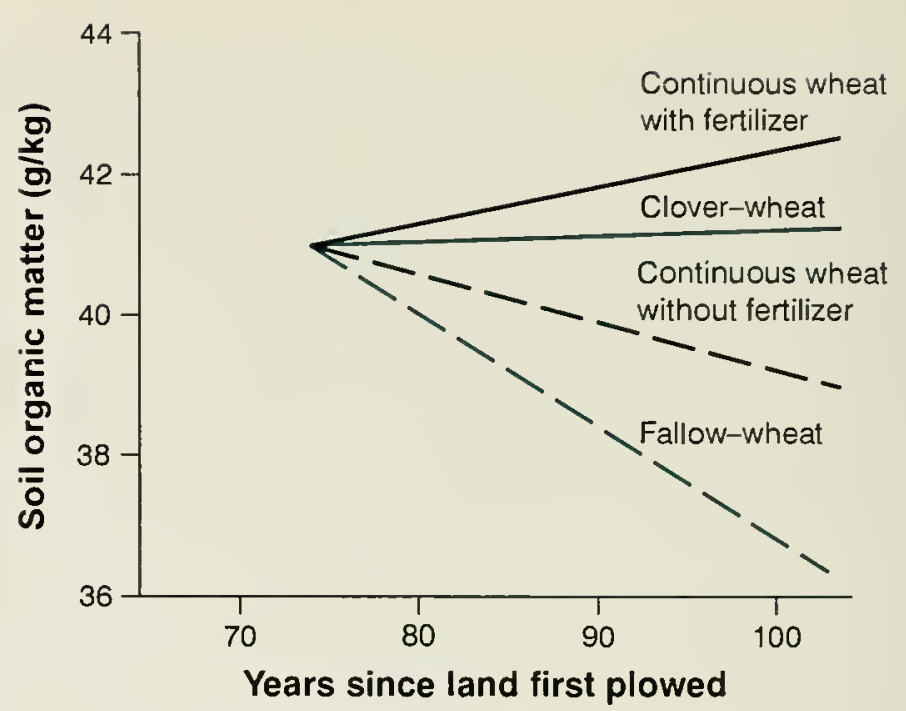

Figure 5-8

Organic matter levels under different crop rotations in prairie soils (after Campbell et al. 1979).

A long-term study of corn grown in Ontario showed the positive effect of fertilization on soil organic matter levels and crop yields, especially when corn was rotated with other crops (Table 5-2). Using forages in rotations works well in Ontario and Quebec, where there is a large livestock industry, but is not as practical where livestock production is limited.

\section{Soil amendments}

Organic matter added to the soil besides crop residues includes compost, manure, sewage sludge, wood chips, and peat. In a long-term study in Alberta, levels of soil organic matter increased steadily over a 50year period when manure was applied to the soil. Without manure, soil organic matter levels declined over the same period (Fig. 5-9). A field study in Ontario showed that adding manure helps prevent the loss of organic matter on severely eroded soils by promoting the formation of aggregates that resist erosion.

\section{Erosion}

Erosion selectively detaches and transports those soil particles richest in organic matter. The organic matter content of a soil decreases over the years with cultivation (Fig. 5-10). Where no erosion occurs, soil 
Table 5-2 Organic matter in the top $20 \mathrm{~cm}$ of soils continuously cropped to corn and under a corn rotation (corn-oats-hay-hay), with and without fertilization, for 31 years in southwestern Ontario

Crop
Soil organic matter

(tonnes per hectare)
Corn grain yield

(tonnes per hectare)
Continuous corn

Fertilized

Unfertilized

Corn in rotation

Fertilized

Unfertilized
97

88

112

88
6.0

1.6

7.8

4.6 organic matter declines quickly and then levels off at about $80 \%$ of the original value (for a loss of about $20 \%$ ). Where severe erosion occurs, levels of soil organic matter may drop much faster and, even after 70 years of cultivation, may not level off.

Soil-quality monitoring at two New Brunswick benchmark sites under intensive potato production (using a potato-potatograin rotation) demonstrates the value of conservation farming practices to control erosion and maintain levels of soil organic

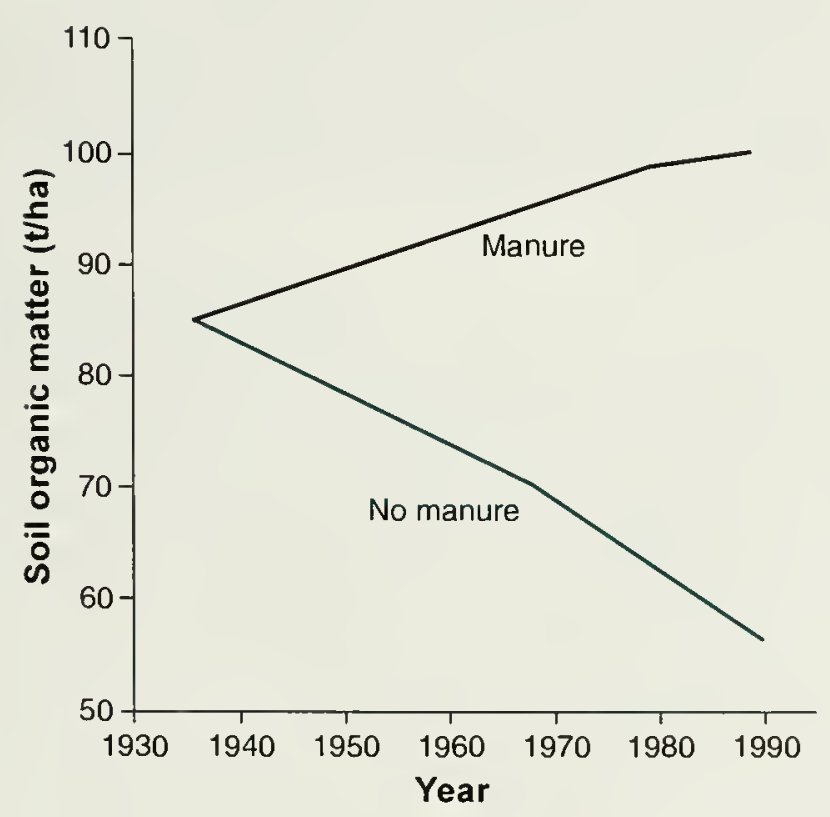

Figure 5-9 years, with and without manure.
Changes in soil organic matter over 50 matter. One site is cultivated up- and down-slope, and the other is under a conservation system (cropped along the contour of the land, with variable grade diversions and a grassed waterway). Under potato production, soil lost from the contour-cropped site was less than $10 \%$ of that lost from the site cultivated up- and down-slope. After 3 years, the soil cultivated up- and down-slope had significantly less organic matter than that under conservation management (see Fig. 4-5 in Chapter 4).
To enrich the earth I have sowed clover and grass to grow and die. I have plowed in the seeds of winter grains and of various legumes, their growth to be plowed in to enrich the earth. I have stirred into the ground the offal and the decay of the growth of past seasons and so mended the earth and made its yield increase.

Wendell Berry Enriching the Earth

\section{Underseeding increases organic inputs}

Barley is currently the main grain crop rotated with potato in New Brunswick. Underseeding (companion planting) with a grass or legume is growing in popularity, with more than $80 \%$ of barley fields in potato-grain rotation being underseeded in 1992.

After the grain is harvested in August, the underseeded grass or legume is allowed to grow until it succumbs to inclement weather. Underseeding barley with Lemtal ryegrass increased organic inputs into the soil by more than $90 \%$, making the year in grain production a net humus supplier rather than a potential humus depletor. 
The action begins when roots decay and aboveground residues break down, and the released nutrients begin their downward tumble through soil catacombs to start all over again.

Wes Jackson Altars of Unhewon Stone

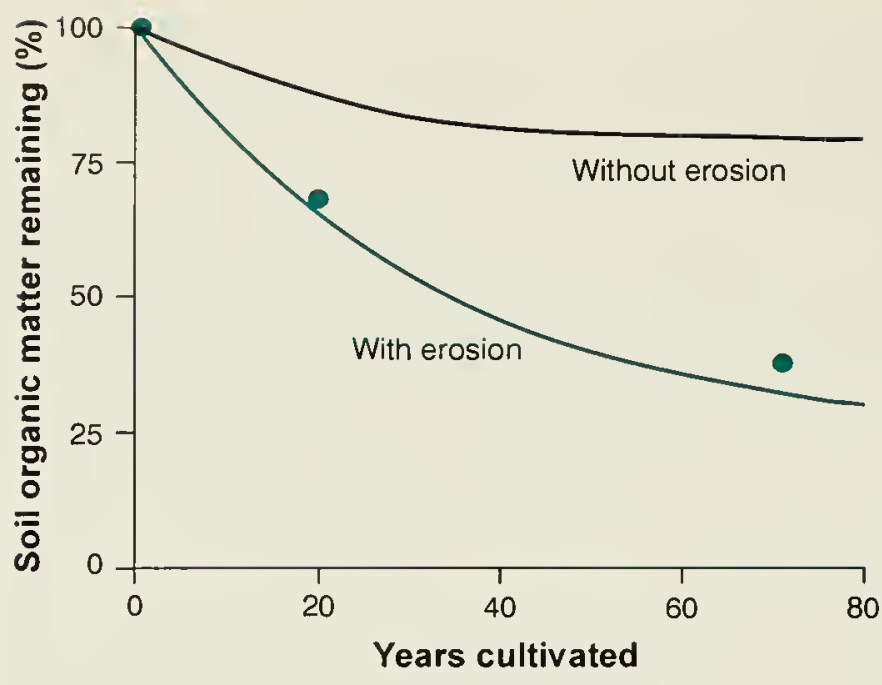

Figure 5-10

Effects of erosion on soil organic matter.

Simulated and observed $(\cdot)$ effects of erosion on organic matter levels in soil to $30 \mathrm{~cm}$ over 70 years.

Highly erodible soils benefit from conservation tillage methods that disturb the soil as little as possible; no-till disturbs the soil the least. No-till (direct seeding) leaves crop residues on the soil surface, where they protect the soil from erosion by wind, rain, and the runoff of melted snow.

\section{Conclusions}

Organic matter is essential for maintaining a soil's ability to produce crops economically and to resist degradation. Systematic monitoring of soil organic matter is now under way in Canada. Considerable research in the past 10-20 years has resulted in a good understanding of the effects of land use and management practices on types and levels of organic matter.

Although some organic matter has been lost from soils since they were first converted to agriculture, the loss is not nearly as high as was thought in the early 1980s. Research shows that certain farming practices stabilize and may even increase levels of soil organic matter by increasing inputs of organic matter into the soil and reducing the loss of organic matter from the soil.

Since the 1980s, government programs have encouraged farmers to adopt conservation farming practices. Practices that increase organic matter inputs into the soil include

- using permanent crop covers

- growing crops that contribute large amounts of organic matter (such as those with large fibrous roots)

- using legumes and forages in crop rotations

- adding manure and other organic amendments to the soil

- keeping the crop robust and productive by fertilizing it adequately.

Practices that reduce the loss of organic matter from the soil include conservation tillage, crop residue management, and erosion control (including contour cultivation, crop underseeding, grassing waterways, terracing, strip-cropping, establishing shelterbelts, and building structures for erosion control). Farming systems must be chosen to suit specific soils and locations. 


\title{
Changes in Soil Structure
}

\author{
G.C. Topp, K.C. Wires, D.A. Angers, M.R. Carter, J.L.B. Culley, D.A. Holmstrom, \\ B.D. Kay, G.P. Lafond, D.R. Langille, R.A. McBride, G.T. Patterson, E. Perfect, \\ V. Rasiah, A.V. Rodd, K.T. Webb
}

\section{Highlights}

- Weakened aggregates and soil compaction are the most-recognized forms of structural degradation in Canada's agricultural soils.

- Degradation of soil structure reduces seedling emergence, restricts entry and movement of air and water into and through soil, increases the risk of erosion, and reduces crop yields.

- Soils are particularly vulnerable to structural degradation when they are fine-textured, wet, low in organic matter content, or eroded; intensive tillage, row-cropping, and insufficient crop rotation promote structural degradation.

- A study of soil degradation using the nonlimiting water range method showed that prairie soils are less degraded structurally than eastern soils in Canada.

- Methods that enhance soil structure include conservation tillage, growing forages in crop rotations, crop residue management, continuous cropping (reducing summerfallow), erosion controls (such as cover cropping, underseeding, contour cultivation, terraces, and grassed waterways), and installing subsurface drainage systems.

\section{Introduction}

Soil structure may be thought of in terms of "architecture" and "stability." The size, shape, and arrangement of rooms determines how a building is used and how it stands up under adverse conditions (such as snow loading and earthquakes). In the same way, the size, shape, and arrangement of the pore spaces and solids (clumps composed of sand, silt, and clay) in soil are key factors in soil quality.

Sand, silt, and clay particles in soil are bound together mainly by organic matter to form clumps or aggregates. Soil organic matter and other binding agents stabilize the arrangement of pore spaces and particles. Soils with good structure allow air, water, and nutrients to move through the spaces within and between aggregates. They also retain their arrangements of solids and pore spaces when exposed to the stresses of cultivation, harvesting a crop, and the impact of raindrops, among others. 
The thirsty earth soaks up the rain And drinks, and gapes for drink again The plants suck in the earth, and are With constant drinking fresh and fair.

Abraham Cowley Drinking

\section{Development and effects of soil structure}

Soil structure develops naturally but slowly under the influence of environmental processes, such as wetting-drying and freezing-thawing, and as organic matter (plant and animal residues) is added.

Maintaining good soil structure is essential to sustaining long-term agricultural productivity. But structural quality is difficult both to define and to measure.

Good structure implies that the state and stability of aggregates do not limit a crop's yield potential, that the soil is suitable for maximum root growth and penetration, and that the soil is stable against forces causing soil degradation. Soil structure affects crop growth and yield by influencing many soil and landscape processes, including

- storage of water and nutrients in the soil and their availability to crops

- movement of water and nutrients in and through the soil during infiltration, drainage, and leaching

- aeration for roots and soil microbes

- the soil's resistance to erosion by wind and water

- the soil's resistance to compaction and crusting.

\section{Degradation of soil structure}

Deteriorating soil structure is hard to detect and measure because this property is tied so closely to other factors, such as water flow and aeration in soil. The mostrecognized forms of degradation in soil structure are weakened aggregates and compacted soil (Fig. 6-1).

Soils that have weak and unstable aggregates are the most susceptible to accelerated structural damage. An unstable soil may appear to have a good structure, but its aggregates may break down easily when exposed to rain, or cultivation, or both. The breakdown of aggregates at the surface of fine-textured soils can result in the formation of a hard surface crust. This crust can prevent seedlings from emerging and can block larger soil pores, thereby restricting the entry of water and air into the soil.

Soil compaction happens when soil particles are pressed together, reducing the pore space between them (which increases the soil's bulk density). Soil can be compacted in many ways; the main cause is repeated passes of heavy machinery over wet soil during tillage and harvesting. Fine-textured soils (clayey and silty) in humid climates are the most susceptible to compaction. The risk increases by growing row crops, such as

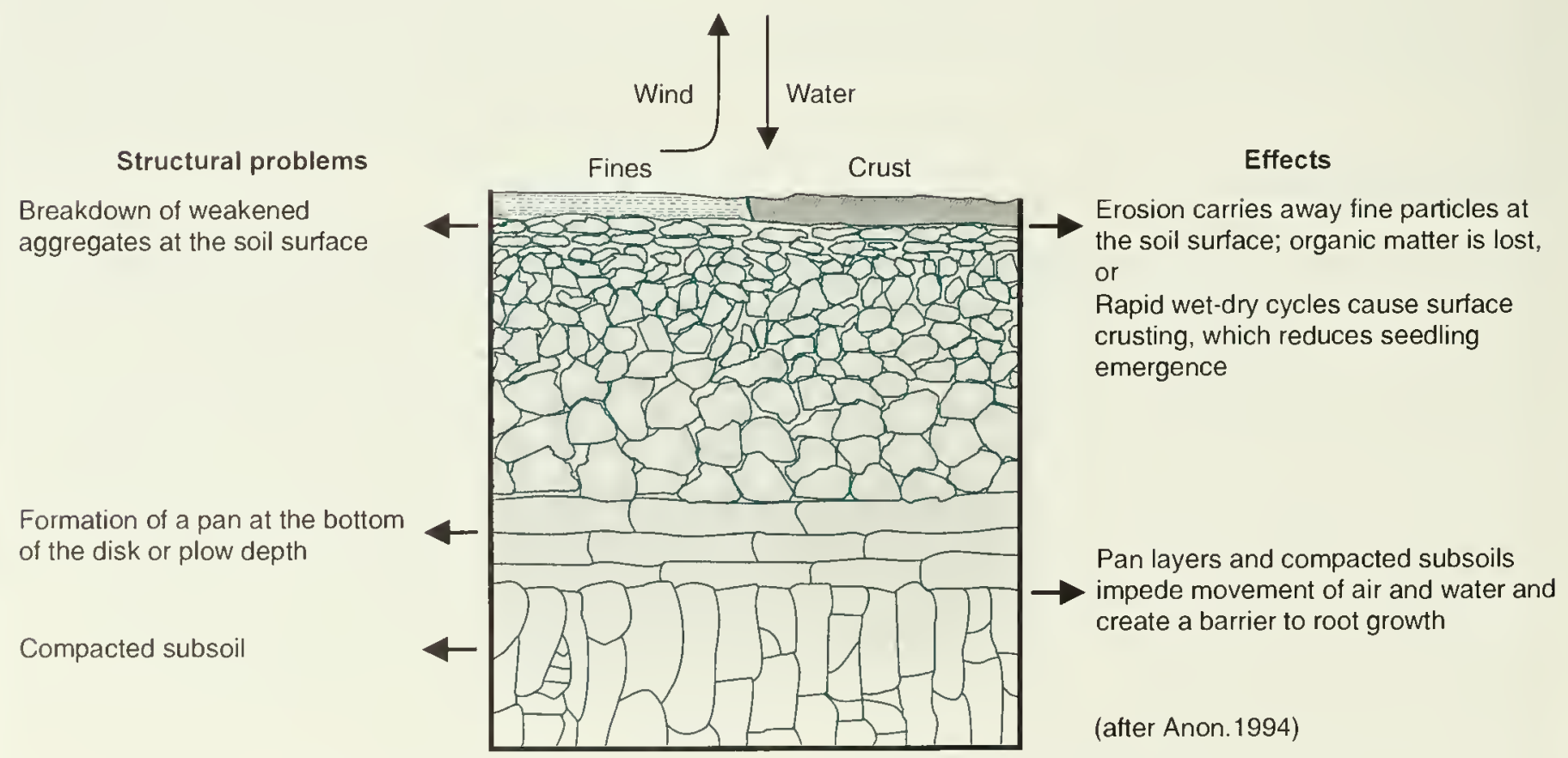

Figure 6-1 Structural problems throughout the soil profile and effects of degradation. 
corn, soybeans, potatoes, and vegetables, because intensive tillage and harvesting often take place when the soil is wet.

The loss of a stable soil structure generally reduces crop yield through its detrimental effects on a wide variety of crop growth factors. For example,

- reduced seedling emergence reduces the crop stand

- the loss of large pores decreases the oxygen supply to crop roots, restricting their growth and increasing the probability of root diseases

- reduced entry of water into the soil limits the water available for crop growth.

Deteriorating soil structure also increases the risk of soil erosion. Fine soil particles created by the breakdown of aggregates at the soil surface are especially vulnerable to being carried away (eroded) by wind and surface runoff. Furthermore, because less water soaks into a compacted soil, surface runoff increases and compounds the effects of erosion. Degraded soils are prone to further degradation at a quicker rate (Fig. 6-2).

\section{Current issues of structural degradation}

\section{Compacted soil}

A 1986 Science Council of Canada study estimated that soil compaction reduces crop yields in Canada by $10 \%$ and costs producers more than $\$ 130$ million each year.
The estimated loss is greatest in Quebec, where $20 \%$ of land under monoculture rowcropping (continuous cultivation of only one type of row crop) is compacted. The fertile and productive St. Lawrence lowlands are especially affected by compaction.

Soil compaction is also a problem in other parts of the country. It is widespread in the medium- and fine-textured soils of the Fraser Valley of British Columbia as a result of relatively high rainfall, high water tables, and intensive cultivation of row crops.

In southwestern Ontario, an estimated $50-70 \%$ of clayey soils have been adversely affected by soil compaction: three-quarters of this land is rated as moderately compacted and one-quarter as severely compacted. In a recent survey of corn growers in Ontario, soil compaction was the problem most frequently identified in soil and water conservation.

The Atlantic Provinces are plagued by naturally compacted subsoils and hardpans (hardened soil layers with greatly reduced porosity), in addition to compaction from farming activities on moist soils. In this region almost one-third of the good cropland has poor soil structure. Soils with poor structure are common in Nova Scotia along the Northumberland shore and in the central part of the province, as well as in most of New Brunswick.

The Prairie Provinces do not have a serious problem with compaction. (Loss estimates for this region were not made by the Science Council study.)

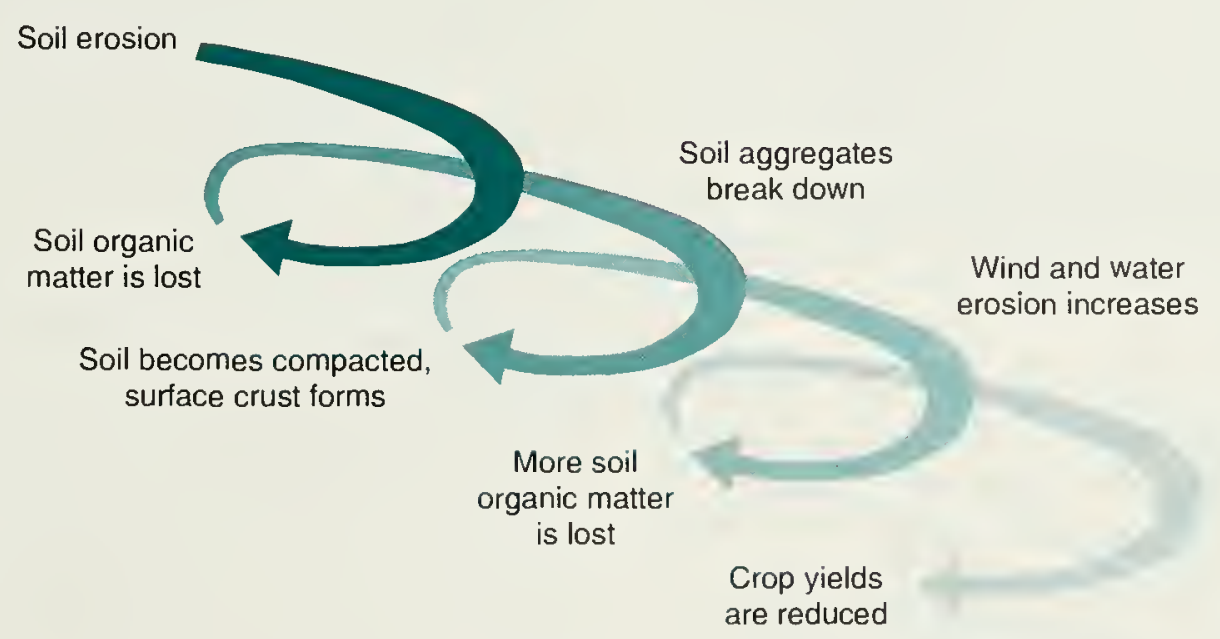

Figure 6-2 The downward-spiralling effect of soil structural degradation. 


\section{Ontario producer tries no-till}

For the last 9 years, no-till has consistently given us higher yields of corn and soybeans on both Brady sandy loam and Huron clay loam soils. Although at least $40 \%$ more water is available in the Brady soil, the Huron soil still produces comparable crop yields, probably because of differences I have noticed in the corn rooting habit in no-till soils.

In the conventionally tilled soil, corn roots grow down to the plow pan, then laterally to fracture lines that were started by field equipment, and then down those fractures to moisture. In the no-till soil, roots seem more often to follow macropores. Thus they have a more general distribution in the soil. Could it be that compaction in the conventionally tilled soil limits crop yield more than the amount of readily available water in notill soil?

Generally, we find that tilled soil experiences more dry-weather cracking than no-till soil. In time, however, no-till soils benefit from more macropore development. The no-till soil is always wetter than the tilled soil. Even so, we found that no-till soil has more load-bearing strength (it suffers less from rutting at planting and harvest time).

Our records show that no-till soil outyielded conventionally tilled soil by $15 \%$ on average. This yield advantage was about equal for corn and soybeans. The greater earthworm activity under no-till indicates that the animal life in the soil is better without tillage too.

(Don Lobb, Producer, Clinton, Ont.)

Soil clods continually hit by metal spikes and blades lose the weak bonds of aggregates, and the soil becomes fluffy and dusty.

Hans Jenny Meeting the Expectations of the Land

\section{Weakened aggregates}

Weakened aggregates produce some of the same visible effects on soil as compacted soils. Although weakened aggregates are widely recognized as a problem of soil structural degradation, estimating their effect is more difficult than for compaction. Separate estimates for these two forms of soil degradation are not yet possible.

\section{Assessing soil structural quality}

\section{British Columbia}

The Fraser Valley is extremely wet, and many soils are susceptible to compaction. However, the suspicion of agricultural workers that compaction is a serious problem in this region has not been confirmed by research. Forage-grass production, for which a five-cut system is common (five crops taken off in a season), is likely the main cause of soil compaction, because machinery traffic in the field is heavy throughout the long growing season, often when soil is wet. Production of vegetables, particularly carrots and potatoes, is also thought to cause soil compaction.

A favoured method to reduce soil compaction is growing a cover crop after the main crop is harvested. In this way, a forage crop can be harvested and then plowed into the soil before planting the next year's main crop.

\section{The Prairie Provinces}

Differences in levels of soil organic matter and soil moisture have resulted in the best natural development of soil structure and stability in the Black soil zone of the prairies. Cooler temperatures and water deficits contribute to poorer soil structure in the Brown soil zone of the southern prairies. Decreases in organic matter associated with the agricultural development since the late 19 th century have resulted in these natural soil structures deteriorating. However, it is widely believed that degraded soil structure does not limit prairie agriculture.

In the semiarid climate of the prairies, most cultivation and seeding takes place when the soil is dry enough to resist compaction by farm implements, except in some poorly drained fine-textured soils. Summerfallowing, used to conserve soil moisture in the driest areas, increases the risk of soil loss, salinization, and structural degradation. Although studies in eastcentral Saskatchewan have shown that crop yields in fallow systems are $12 \%$ higher than in continuous-cropping systems, this short-term benefit is insignificant compared to the damage to soil caused by summerfallow over the long term. Adopting conservation farming practices has markedly decreased summerfallow on cultivated land over the past 20 years (see Figure 8-7), but further reductions are needed. 


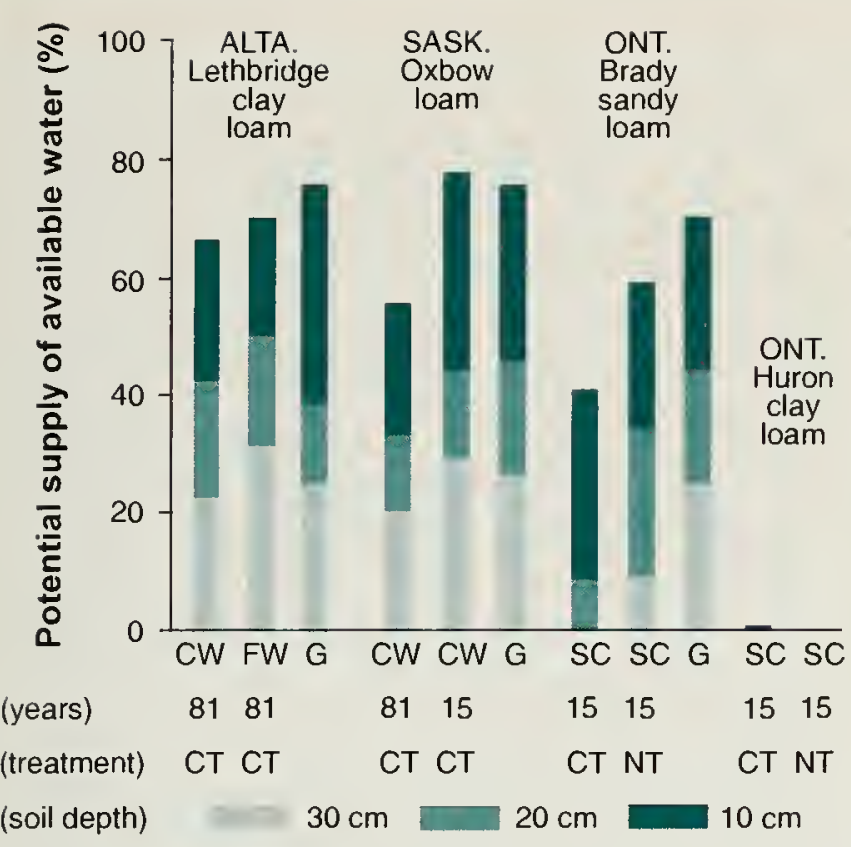

Figure 6-3

The soil's ability to supply water to plants (measured using the NLWR method).

Legend: $\mathrm{CW}=$ continuous wheat, $\mathrm{FW}=$ fallowwheat, $\mathrm{G}=$ grass, $\mathrm{SC}=$ soybean $-\mathrm{corn}, \mathrm{CT}=$ conventional tillage, $\mathrm{NT}=$ no-till.

Studies of soil structure based on measuring the amount of water in soil that is available to plants-the nonliniting water range (NLWR) method-confirmed that prairie soils are less structurally degraded than Ontario soils (Fig. 6-3). All prairie soils in this study were potentially able to supply at least $55 \%$ of available water to crops, compared to much lower values for Ontario soils. Under continuous wheat and fallow-wheat rotations, the clay loam in Alberta showed similar potential to supply available water as did soil under grass. However, soil under grass generally had a higher potential to supply available water in its top layer $(10 \mathrm{~cm})$ than soils tilled conventionally for 81 years.

\section{Ontario}

Few measurements of compaction are available for Ontario's agricultural soils. However, most medium- to fine-textured soils and all low-lying soils in southern Ontario naturailly have imperfect to poor internal drainage, making them vulnerable to compaction during cultivation.
Relatively high precipitation and cool soil temperatures produce wet soils during spring tillage and seeding operations. Fall precipitation often makes soil wet during harvest, particularly for corn. Tile drainage is used in most of southern Ontario's loamy and clayey soils to improve soil moisture conditions.

Soil-compression studies show that soil's friability (crumbly texture) and load-bearing capacity are best when the soil water content is at or below the plastic limit (the soil water content at which the soil changes from being plastic, or pliant, to being brittle). Field traffic and tillage of agricultural soils should be restricted to these times (Fig. 6-4).

A study that identified areas in southwestern Ontario that are susceptible to traffic and tillage-induced soil compaction found that the risk of compaction is greatest for soils that are medium-textured (loamy) and imperfectly to poorly drained. Fine-textured soils were often sufficiently compacted to begin with (probably as a result of natural processes, such as intense drying cycles and glacial pressure) that corn production did not cause further compaction.

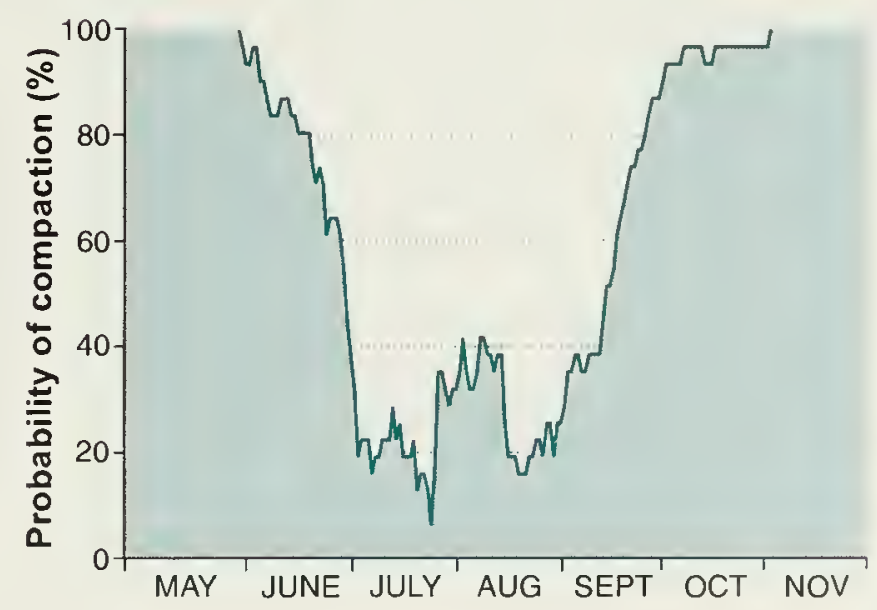

Figure 6-4

Seasonal risk of compaction of soil at a depth of $12.5 \mathrm{~cm}$.

The risk of soil compaction caused by farm machinery is greatest when soil is wet. Ideally, machinery should be put on the field only during times of low risk of soil compactionJuly and August. 


\section{Rebuilding soil structure under corn production}

The length of time required for a particular tillage practice or crop rotation to rebuild the optimum soil structure can be predicted if the rate of change of soil structure is known. One way to measure this rate of change is to determine the half-life of the soil structure. The half-life for structural improvement is the time required for a cropping or tillage practice to increase structural quality to a point halfway between the starting level and the maximum level. The half-life for structural decay is the time required for a cropping or tillage practice to decrease structural quality to a point halfway between the starting level and the minimum.

Studies in southwestern Ontario have determined that the average half-life for structural improvement of soil under forages is 4.5 years, and the average half-life for structural decay under corn production with conventional tillage is 0.2 years. Since the rate of improvement in structural stability is much lower than the rate of decline, most of the improvement gained from 3 years of growing forage on a silt loam is lost within a few months after returning to conventional-till corn production.

Including forages in corn rotations under conventional tillage may therefore do little to enhance soil structure. Tillage and cropping systems that improve or maintain soil structure more continuously should be explored, such as growing forages followed by no-till corn.

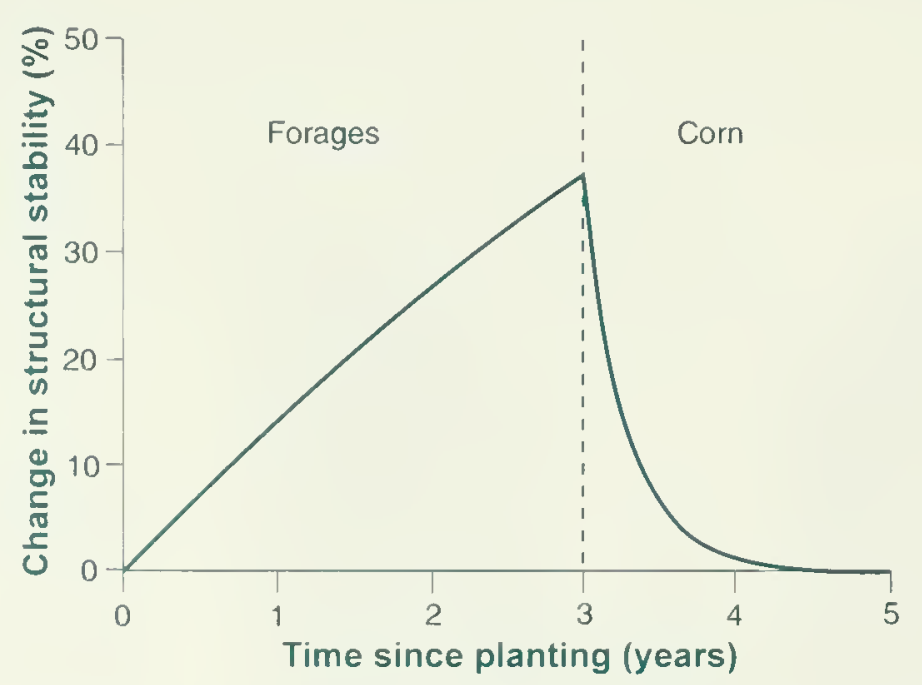

Structural stability of soil under forages and corn.

(B.D. Kay, E. Perfect, and V. Rasiah, University of Guelph, Guelph, Ont.)
Conventional tillage often causes soil structure to deteriorate, especially when used in the monoculture of corn and other row crops. Soil structure studies at Clinton, Ont., using the NLWR method, showed that a sandy loam under a corn-soybean rotation could potentially supply at least $40 \%$ of available water to crops; no-till and grass improved this potential by $20-30 \%$ over conventional tillage (Fig. 6-3). The conventionally tilled soil had almost no potential to supply water at a depth of 30 $\mathrm{cm}$ and a relatively low potential at a depth of $20 \mathrm{~cm}$, because of subsoil compaction. The clay loam at the same site was so structurally degraded that even notill failed to improve the soil's ability to supply available water, but the roots made compensation by growing primarily in the soil cracks and macropores (see box, page 54).

Another study has shown that including forages in corn rotations can improve soil structure. However, under conventional tillage, the structural improvement resulting from forages is quickly lost upon return to corn production (see box, this page). The time needed for structural improvement under forages decreases as the clay content of the soil increases (Table 6-1). This result suggests that clay soils are more responsive than coarser-textured soils to conservation tillage and cropping practices and will show improvements in soil quality more quickly.

\section{Table 6-1}

Time needed to improve the structure of soils planted to forages in southern Ontario

Soil texture Improvement time (years)

Loamy sand 7-9

Silt loam 4-6

Clay 3-5 


\section{Quebec}

Many soils in the St. Lawrence lowlands are poorly drained and are often continuously cropped to corn for many years. The soil is often worked early in the spring and late in the fall when moisture conditions make it particularly susceptible to compaction by farm machinery. More than $80 \%$ of soils under monoculture of annual crops in this region are structurally degraded; compaction affects about $20 \%$ of these soils.

A 1990 survey showed that cultivated clay soils had a higher bulk density than soils under grass, and two independent studies estimated that yield reduction caused by soil compaction was $10 \%$ for corn and $25 \%$ for hay. Light-textured soils that are continuously cropped to potatoes or cereals are also susceptible to structural degradation and surface crusting.

Conservation tillage, along with proper crop rotations and additions of organic matter, increases levels of organic matter in the surface layer and improves soil structure. For example, applying solid cattle manure every 2 years to a poorly structured soil cropped to corn for silage improved its content of organic matter, structural stability, and porosity (Table 6-2).

Despite the importance of conservation farming techniques to maintaining good soil structure, a recent survey indicated that fewer than $10 \%$ of Quebec farmers have adopted these practices. However, some farmers use ridge tillage, and many dairy farmers rotate suitable crops and regularly apply manure to maintain levels of soil organic matter.

\section{New Brunswick}

Soil structural degradation is a serious problem in land under potato and vegetable production in northeastern New Brunswick, where its damaging effects are second only to those of water erosion. Compaction, the most common type of soil degradation in this region, is the result of machinery traffic on soils that have been pulverized by tillage and harvesting operations. Because of the cool, humid climate and short growing season, producers often work the soil in early spring and late fall, when soils are wet.

Potato-grain and potato-potato-grain rotations are common, which return small quantities of organic matter to the soil. Erosion on land under up- and down-slope cultivation has also accelerated loss of soil organic matter. Benchmark studies have shown that soil under potatoes typically has a very weakly structured or structureless top layer $(0-15 \mathrm{~cm}$ deep) over a

Table 6-2 Soil structural properties of a silty clay loam in Quebec after solid cattle manure was applied every 2 years for 10 years

\begin{tabular}{cccc}
\hline $\begin{array}{c}\text { Manure application } \\
\text { rate } \\
\text { (tonnes/ha) }\end{array}$ & $\begin{array}{c}\text { Organic matter } \\
\text { content } \\
(\%)\end{array}$ & $\begin{array}{c}\text { Aggregate size } \\
(\mathrm{mm})\end{array}$ & $\begin{array}{c}\text { Porosity } \\
(\%)\end{array}$ \\
\hline 0 & 3.2 & 1.3 & 51 \\
20 & 4.0 & 1.6 & 52 \\
40 & 4.3 & 1.5 & 54 \\
60 & 4.9 & 1.7 & 55 \\
80 & 5.4 & 1.7 & 56 \\
100 & 5.5 & 1.8 & 56
\end{tabular}


more-compacted, platy subsurface layer (15-25 cm deep). The compacted subsurface layer restricts both root growth and the down-ward movement of water. Earthworms, which improve soil structure, are scarce in soil under potatoes because of disturbances by intensive tillage, low returns of organic matter to the soil, and heavy application of pesticides.

\section{Nova Scotia}

Soils in Nova Scotia are inherently weakly structured, low in soil organic matter and nutrients, and acidic. Poor soil structure may be evident as compacted subsoils or the presence of naturally occurring hardpans or hard-set layers, or both. The use of heavy machinery on moist, finetextured soils during the wet conditions of early spring and late fall accelerates structural degradation.

The risk of structural degradation is highest in soils under row crops, such as corn, pea, bean, carrot, and other latematuring vegetables. Medium risk of compaction is associated with spring cereals and tree fruits. Crops with a low risk of inducing compaction include winter cereals, forages, and pasture. The Annapolis Valley, predominantly in Kings County and to a lesser extent in Annapolis County, are the areas most at risk of structural degradation caused by the cropping systems combined with the inherent structural quality of the soil.

In 1990, about $6 \%$ of Nova Scotia's farmland was planted to row crops. This amount has remained essentially unchanged since 1981, suggesting that the area at high risk of severe structural deterioration is relatively small.

However, there is increasing interest in improving soil structure, using methods such as planting forages instead of cereals, installing subsurface drainage systems, and modifying machinery to reduce the effects of field traffic. (In areas of low and medium risk for soil structural degradation, there has been a $2 \%$ shift toward planting forages during the past 10 years.)

\section{Prince Edward Island}

The loam to loamy sand soils of Prince Edward Island are all somewhat limited for crop production, mainly because of inherently low fertility and poor soil structure. The large amount of silt and fine sand in the soil results in weak aggregation, which in turn makes it difficult for soil structure to be regenerated and maintained. Also, poor soil structure in the subsoil causes low permeability, which inhibits drainage.

Most of Prince Edward Island's agricultural soils currently have organic matter contents of $2-3 \%$; only about $20 \%$ of potato fields have organic matter levels above $3 \%$ (the level commonly thought needed for good soil quality). Studies have shown that direct drilling of cereals increases organic matter in surface soil ( $0-5 \mathrm{~cm}$ deep) to well over $3 \%$ and increases the mean weight diameter of water-stable aggregates to more than 3 $\mathrm{mm}$. However, direct drilling cannot be used for tuber and root crops, such as potato. Increased organic matter in soil under potatoes must be achieved by rotating crops and returning residues (Table 6-3), practices to which soils in this province respond well.

Yields of spring cereals in humid climates generally decline when the soil's macroporosity (the volume of large pores in the soil) falls below $12 \%$ and the severity of root rot (a disease common where soil aeration is inadequate) increases, as is the case in compacted soils. Excessive compaction in

Table 6-3

\section{Estimated root residue produced by crops in Prince Edward Island}

\begin{tabular}{lc} 
Crop & $\begin{array}{c}\text { Root residue } \\
\text { (tonnes/ha) }\end{array}$ \\
\hline Italian ryegrass & $3.0-5.0$ \\
Winter cereal & $2.5-3.0$ \\
Red clover & $2.2-3.0$ \\
Spring cereal & $1.5-2.0$ \\
Soybean & $0.6-1.0$ \\
Potato & $0.3-0.7$
\end{tabular}


the crop-root zone can usually be corrected by using conservation tillage methods. However, excessive compaction in the subsoil is considered permanent.

\section{Improving the structure of Canada's soils}

Evidence continues to accumulate in all regions of the country showing that conservation farming practices aid in maintaining and improving soil structure.

Appropriate tillage practices are those that disturb the soil least. These include

- using no-till and seed-drilling, where suitable for the crop

- replacing conventional deep tillage (more than $25 \mathrm{~cm}$ ) with shallow tillage $(10 \mathrm{~cm})$

- eliminating secondary tillage by using one-pass tillage systems

- using rotational tillage or crop-specific tillage practices.

Practices that increase the amount of organic matter returned to the soil and improve soil structure include

- continuous cropping (reducing summerfallow)

- managing crop residue to reduce fall tillage and provide soil cover

- green manuring

- growing forages in crop rotations

- planting cover crops to protect the soil after the main crop is harvested

- underseeding grain crops that are grown in rotation with potatoes.

In hilly locations, especially those planted to row crops, contour cultivation and landscape alterations (such as terracing and constructing grassed waterways) reduce soil losses resulting from erosion, which contribute to deteriorating soil structure. The risk of compaction can also be lowered by reducing the pressure of field traffic (including restricting axle loads and using flotation tires and tandem wheels) and by installing subsurface drainage systems,

\section{New technique to describe soil structure}

Characterization of soil structure and its effects on soil quality have been problematic. The two main reasons for this are the fragile, changeable nature of soil structure and the general lack of appropriate measurement techniques and associated theory. The recently developed tension infiltrometer technique holds considerable promise, however, as a means to characterize some of the main attributes of soil structure.

The tension infiltrometer is a device that applies suction to the soil. By regulating the amount of suction, it is possible to control the size range of soil pores that transmit water and solutes. This new technique can provide direct measurements of the effect of soil structure on the rate of percolation of water, fertilizers, and pesticides into and through the soil. It can also be used to monitor changes in soil structure resulting from changes in land management, such as the introduction of no-till or extended crop rotations.

This technique can be used easily and rapidly in the field, producing only minimal disturbance of the soil. Research is underway to test and further develop this technique.

(W.D. Reynolds, AAFC, Ottazu, Ont.)

especially in loamy soils overlying slowly permeable subsoils that retard internal drainage.

\section{Conclusions}

Although too few data are available to characterize the structural condition of Canada's soils, the following generalizations apply:

- in humid regions, soil quality is degraded mainly by compaction

- soils under conventional tillage and monoculture cropping systems are degraded structurally by loss of soil organic matter

- soils under tillage methods that incorporate surface residue are more likely to suffer a decline in structural quality
While the earth remaineth, seed time and harvest, and cold and heat, and summer and winter, and day and night shall not cease.

Genesis 8:22 
- residue incorporation combined with monoculture of crops produces the most serious degradation of soil structure.

Halting the degradation of soil structure requires a shift to conservation farming practices. Until these practices are more widely used, structural quality is expected to decline.
Management practices that will enhance or at least maintain soil structure will vary by region and cropping system. For example, suitable practices might include direct drilling for cereals in Prince Edward Island, no-till for corn in Ontario, and conservation tillage combined with continuous cropping in the prairies. Procedures can be developed to indicate optimal periods for cultivation and harvest to prevent additional soil compaction from agricultural machinery. 


\section{Erosion}

G.J. Wall, E.A. Pringle, G.A. Padbury, H.W. Rees, J. Tajek, L.J.P. van Vliet,

C.T. Stushnoff, R.G. Eilers, and J.-M. Cossette

\section{Highlights}

- Erosion is a natural process, accelerated by farming activity, that removes topsoil, reduces levels of soil organic matter, and contributes to the breakdown of soil structure.

- The risk of wind erosion on bare soil is negligible to low in $37 \%$ of cultivated land in the Prairie Provinces, moderate in 29\%, and high to severe in 36\%. Under 1991 management practices, less than $5 \%$ of the cultivated land is at high-to-severe risk of wind erosion.

- Implementation of soil conservation practices resulted in a 7\% decrease in the risk of wind erosion in the Prairie Provinces between 1981 and 1991; improvement is greatest in sandy areas converted from annual crops to perennial forages.

- The risk of water erosion on bare soil is negligible to low on $63 \%$ of Canada's cultivated land, moderate on 17\%, and high to severe on 20\%; the Maritime Provinces (80\%), British Columbia (75\%), and Ontario (50\%) have the largest areas at high-to-severe risk of water erosion, and the Prairie Provinces have a low risk. Under 1991 management practices, 5\% of the cultivated land in Ontario and 2\% in the Prairie Provinces is at high-to-severe risk of water erosion.

- Implementation of soil conservation practices has resulted in a decrease of $11 \%$ in the risk of water erosion in Canada; the risk decreased by 17\% in British Columbia, $11 \%$ in the Prairie Provinces, and 16\% in central Canada; the risk increased by $0.5 \%$ in the Maritime Provinces because of increased row-cropping, but this increase did not account for risk reductions where terraces and grassed waterways have been installed.

- Land management practices that help to control erosion include managing residues, extending crop rotations, interseeding, growing winter cover crops, planting shelterbelts, strip-cropping, using contour cultivation, and restructuring the landscape (terraces, diversions, and grassed waterways).

\section{Introduction}

Erosion is a process by which soil is moved from one area to another. In the geological past, huge volumes of land surface materials were moved by glaciers. At present, the main natural agents of erosion are wind and water. Erosion occurs naturally on cropland, forested land, and in urban areas, but this process can be accelerated by human activity (such as agriculture, forestry, and urban development) to levels that cause environmental and economic problems. like any other reservoir this one too can be drained and left empty and useless; let but the winds and the rains strik at the fallowed fields; let but the naked soil be exposed to the elements-how soon and how tragic the loss.

J.A. Toogood Our Soil and Water 
Have you mark'd but the fall $o^{\prime}$ the snow Before the soil have smutch'd it?

Ben Jonson Celebration of Charis
Erosion removes organic matter from the soil (see Chapter 5) and contributes to the breakdown of soil structure (see Chapter 6). These losses in turn affect soil fertility, the movement of water into and from the soil surface, and crop yields. Yields from severely eroded soils may be $50-100 \%$ lower than those from stable soil in the same field.

\section{Current issues of erosion in Canada}

Soil conservation programs throughout the country have greatly increased Canadians' awareness of erosion and the practices that are effective in controlling it. Issues that are currently important in dealing with the problem of erosion include

- soil conservation planning

- rehabilitation of degraded soils

- rural water quality.

For decades, soil conservation simply meant controlling erosion, mainly because this process resulted in visible changes in the landscape and in soil productivity. Erosion is now understood to be only one factor affecting soil health. A systems approach to soil conservation planning addresses erosion problems along with other aspects of soil health, including productivity, and environmental and economic issues.

Erosion can occur in one part of a field while not affecting other parts. The challenge now is to develop cost-effective field methods for applying soil amendments, such as fertilizers, at variable rates that match the soil's needs.

Sediments that are carried off agricultural land by water can silt up drainage ditches and severely alter aquatic habitats. Nutrients and pesticides that are transported with the eroded soil reduce the water quality of ponds, streams, and lakes; often their altered ecology makes them unsuitable for recreation or even as a source of irrigation water. Controlling soil, nutrient, and pesticide losses from agricultural land is an important component in protecting the quality of both surface water and groundwater.

\section{Factors affecting soil erosion}

Several factors related to soil, landscape, and climate affect erosion, including

- soil texture

- soil structure

- surface relief

- soil protection by plants or plant residues

- rainfall

- wind force.

Erosion works on loosely held soil particles at the soil surface. Silty and very fine sandy soils are particularly vulnerable to erosion. Poorly structured soils whose aggregates (clumps) have been broken down into fine particles by tillage and other forces are also easily eroded. This is particularly true of compacted soils, which are unable to absorb water easily and are thus prone to surface runoff and soil loss.

Surface relief (shape and slope) affects the direction and rate of erosion. It also affects the location of soil deposition, because eroded soil tends to accumulate at the base of slopes and in depressions.

Exposed soils suffer greater erosion than soils well protected by standing plants or plant residues. Plants hold soil in place with their roots and also contribute organic matter to the soil, thus improving its structure and its ability to resist erosion. The above-ground portion of the plant breaks the force of wind and rainfall energy. Crop residues also protect the soil by forming a barrier between the soil's surface and the agents of erosion.

Climate affects erosion mainly through the moisture conditions of the soil and specific climatic events (wind and rainstorms). Soils are most vulnerable to wind erosion when the soil surface dries out rapidly during periods of low or no rainfall, such as the drought during the "dirty thirties" in the prairies or in early spring when the soil is not protected by vegetation. Wind speed and the length of time the wind blows are major factors in wind erosion.

Rainfall and runoff energy are the driving forces behind water erosion (the energy 
from a single raindrop causes splash erosion that can move soil many metres downslope). Both the amount of rainfall and its distribution during the year are important factors that control the rate of water erosion. For example, regions where high rainfall occurs during crop-planting periods are more prone to erosion than regions where the same amount of rainfall occurs later in the growing season, by which time the crop canopy protects the soil.

\section{Signs of erosion}

Sometimes erosion is spotted easily in the field. Common signs of wind erosion include

- dust clouds (Fig. 7-1A)

- accumulation of soil along fencelines and snowbanks

- a drifted appearance of the soil surface.

Some common signs of water erosion are

- small rills and channels on the soil surface

- soil deposited at the base of slopes (Fig. 7-1B)

- sediment in streams and reservoirs (Fig. 7-1C)

- pedestals of soil supporting small stones and pieces of plant debris (erosion washes away the surrounding soil; Fig. 7-1D).

Erosion is not always readily visible in the field, because farming activity often masks its signs. For example, plowing can break up the small surface channels created by water erosion. Sheet erosion, a type of water erosion that removes a thin layer of soil uniformly across the soil surface, is often barely visible. As erosion progresses, however, more-serious signs appear, such as

- persistent large scars in the field, such as large gullies (Fig. 7-1E)

- change of soil colour as dark-coloured organic matter is removed and lightercoloured subsoils are exposed

- poorer crop growth (Fig. 7-1B).

\section{Tillage erosion}

Wind and water are the natural agents of erosion. Generally accepted theory indicates that water erosion should increase with distance downslope. However, in areas like the hummocky till plains of the prairies as well as southwestern Ontario, where more than $70 \%$ of the land is classed as rolling uplands, severe soil losses are often observed on upper slopes of cultivated agricultural land. In many cases, crop yields from these areas are $40-50 \%$ lower than those from other areas of the same field. In extreme cases, topsoil losses on these knolls may be so great that the crop will not grow.

This observation led researchers at the University of Guelph to examine the cause of this soil loss. Their findings showed that tillage erosion (soil movement by tillage equipment) is a major cause of the severe soil loss on rolling or hummocky landscapes.

Results of tillage erosion studies show that many common tillage implements, including moldboard plows, chisel plows, discs, and cultivators, cause soil to move downslope from convex upper-slope positions. Soil displaced by tillage does not move as readily into streams and rivers as that displaced by water erosion and therefore does not have the same environmental effects off the farm; nevertheless the effect of tillage erosion on soil health is substantial. Annual soil loss resulting from tillage at one study site was estimated at more than 45 tonnes per hectare, well above the tolerable annual limit of 5 tonnes per hectare.

The effects of tillage on soil movement are determined by characteristics of both tillage and landscape. Tillage factors include tillage depth, tractor speed, the length and width of the tillage implement, and the tillage tool's shape and arrangement. Important features of the landscape include the curve and gradient of the slope; maximum tillage erosion losses occur on convex-shaped slopes. Other soil properties such as bulk density, soil moisture, and the soil's ability to resist displacement also affect the amount of tillage erosion that may occur.

Studies are ongoing to improve our understanding of the processes that result in tillage erosion and the methods that can be used to reduce its damaging effects. At present, these methods include reducing tillage frequency and intensity, using smaller-sized tillage implements, and varying the direction of tillage within a field. 

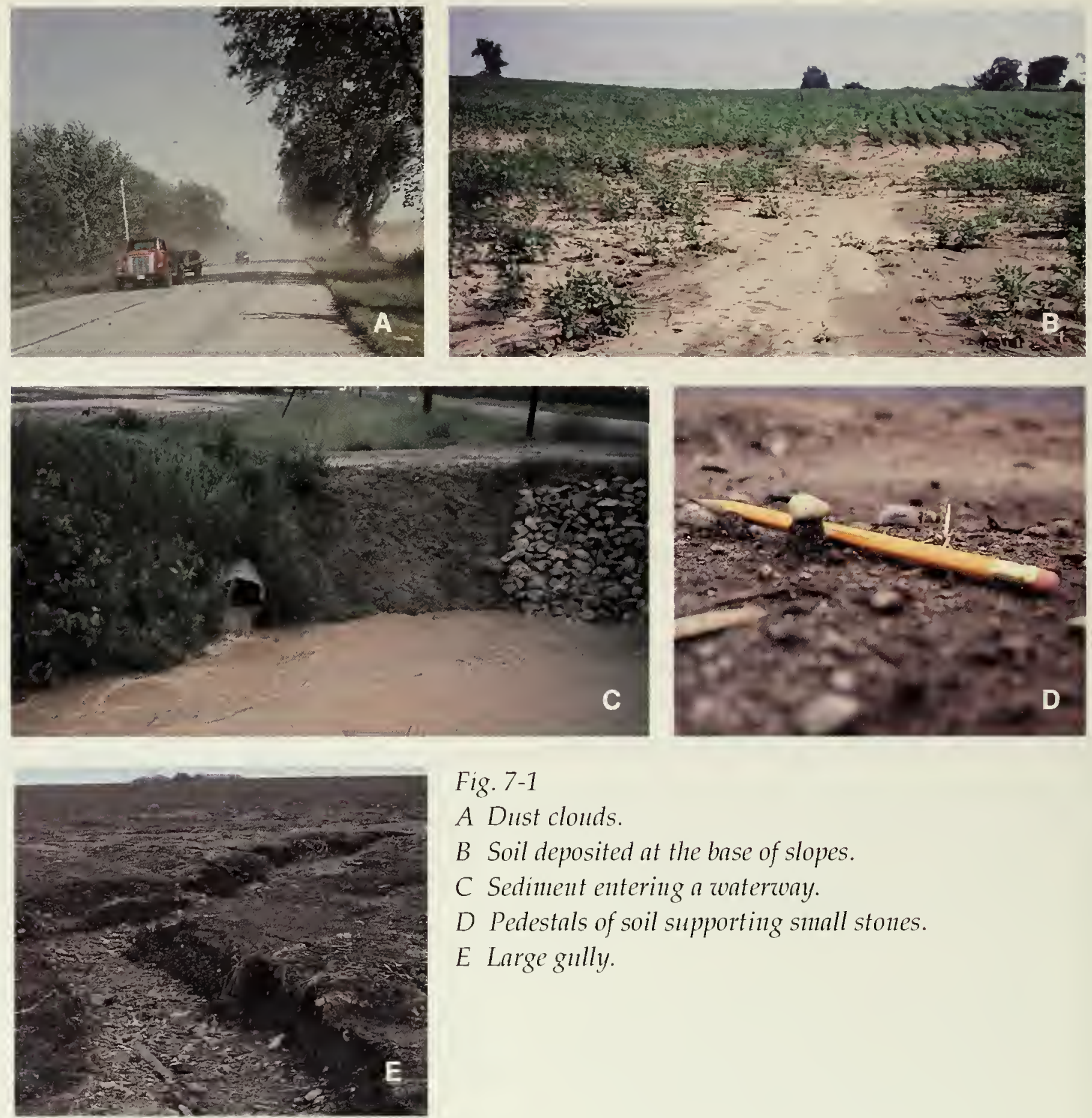

Fig. 7-1

A Dust clouds.

$B$ Soil deposited at the base of slopes.

C Sedinnent entering a waterway.

$D$ Pedestals of soil supporting small stones.

E Large gilly.

\section{Controlling erosion}

Although many conventional farming practices have accelerated erosion, other practices related to cropping, tillage, and water management are effective in reducing it. They do this in three main ways: 1) by maintaining a protective cover on the soil, 2) by creating a barrier to the erosive agent, or 3) by modifying the landscape to control runoff amounts and rates. Methods that maintain soil coverage include

- growing forage crops in rotations or as permanent cover

- growing winter cover crops

- interseeding

- managing crop residues (Fig. 7-2A).
Methods that provide a physical barrier to wind or water reduce erosion by altering the path and reducing the force of the erosive agent. These methods include

- planting shelterbelts (windbreaks; see box, page 66)

- strip-cropping (alternating tilled crops in narrow strips across a long slope; Fig. 7-2B)

- tilling to produce aggregates, or clods, on the soil surface

- contour cultivation (cultivating with the contour of the land, rather than up- and down-slope). 

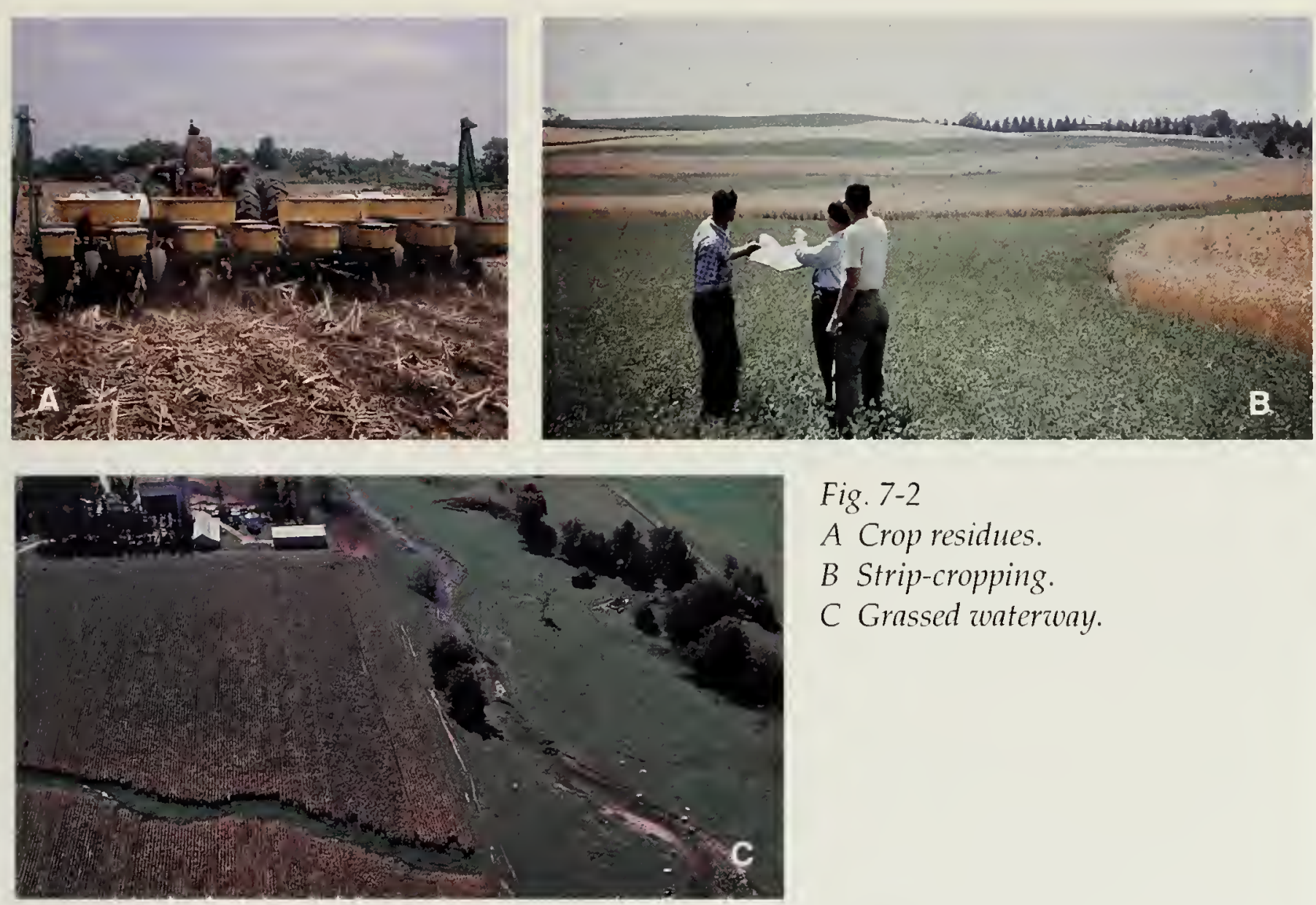

Fig. 7-2

A Crop residues.

$B$ Strip-cropping.

C Grassed waterway.

Sometimes erosion will continue to be a problem unless the grade of the land is changed. Diversions (small earth dikes), terraces (steps that alter the length and steepness of the slope), and land shaping are examples of landscape alterations that can be used to reduce soil erosion. Another method to control runoff is the construction of grassed waterways, which involves grading a main route for runoff and grassing it (Fig. 7-2C). These control methods are costly and are feasible only for high-value crops.

Including forage crops in crop rotations was reported in the 1991 Census of Agriculture as the most commonly used method to control erosion in Canada (Table 7-1). This method is used mainly in humid

Table 7-1 Erosion control practices in Canada, 1991 (percentage of farmers reporting)

\begin{tabular}{lcccccc} 
Province & Forages & $\begin{array}{c}\text { Winter } \\
\text { cover } \\
\text { crops }\end{array}$ & $\begin{array}{c}\text { Grassed } \\
\text { waterways }\end{array}$ & $\begin{array}{c}\text { Strip- } \\
\text { cropping }\end{array}$ & $\begin{array}{c}\text { Contour } \\
\text { cultivation }\end{array}$ & $\begin{array}{c}\text { Wind } \\
\text { breaks }\end{array}$ \\
\hline British Columbia & 23 & 11 & 10 & 2 & 5 & 13 \\
Alberta & 43 & 7 & 17 & 10 & 11 & 29 \\
Saskatchewan & 22 & 6 & 12 & 21 & 18 & 35 \\
Manitoba & 35 & 7 & 12 & 5 & 13 & 37 \\
Ontario & 60 & 20 & 15 & 4 & 7 & 21 \\
Quebec & 52 & 4 & 4 & 3 & 4 & 8 \\
New Brunswick & 44 & 10 & 9 & 5 & 8 & 8 \\
Nova Scotia & 34 & 12 & 8 & 3 & 8 & 7 \\
Prince Edward Island & 72 & 9 & 11 & 4 & 10 & 16 \\
Newfoundland & 17 & 7 & 4 & 1 & 7 & 12 \\
Canada & 42 & 10 & 13 & 9 & 10 & 15
\end{tabular}

Source: Dumanski et al. 1994. 


\section{Shelterbelts on the prairies}

Shelterbelts are commonly used on the prairies to break the force of the wind across the wide, open fields. The percentage of producers on the prairies who reported using shelterbelts in 1991 was more than twice that in the country as a whole. Over the years, encouragement to plant these erosion controls has come largely from the Shelterbelt Centre, in operation since 1902. In its first year, the centre distributed about 1 million seedlings. Now it distributes about 7 million seedlings a year.

During the dry years of the 1930s, major shelterbelt plantings were established at Lyleton, Man.; Conquest and Aneroid, Sask.; and Porter Lake, Alta. By 1964, the Conquest project covered 705 square kilometres, and 1600 kilometres of shelterbelt had been planted using about 7 million seedlings. The main species planted were caragana, green ash, Manitoba maple, and American elm.

During the 1960s and 1970s, shelterbelt planting dropped off, although two new major projects were begun near Carberry, Man. (1968) and Leader, Sask. (1978). By the 1980s, awareness of the need for soil conservation had heightened, and many new shelterbelt associations were formed. From 1989 to 1992, three federal-provincial programs were in operation, the CanadaAlberta Soil Conservation Initiative in Alberta, Save Our Soils in Saskatchewan, and Farming for Tomorrow in Manitoba. These programs resulted in a large increase in the number of field shelterbelts planted.

During the 1990s, the need for a more diversified agricultural sector has resulted in shelterbelts being used for more than wind control. Agroforestry is now promoted, including the production of fruit, maple syrup, and wood products. The benefits of field shelterbelts to special crops is also under study. At present, about $40 \%$ of the stock distributed is for multipurpose use and to enhance wildlife habitat.

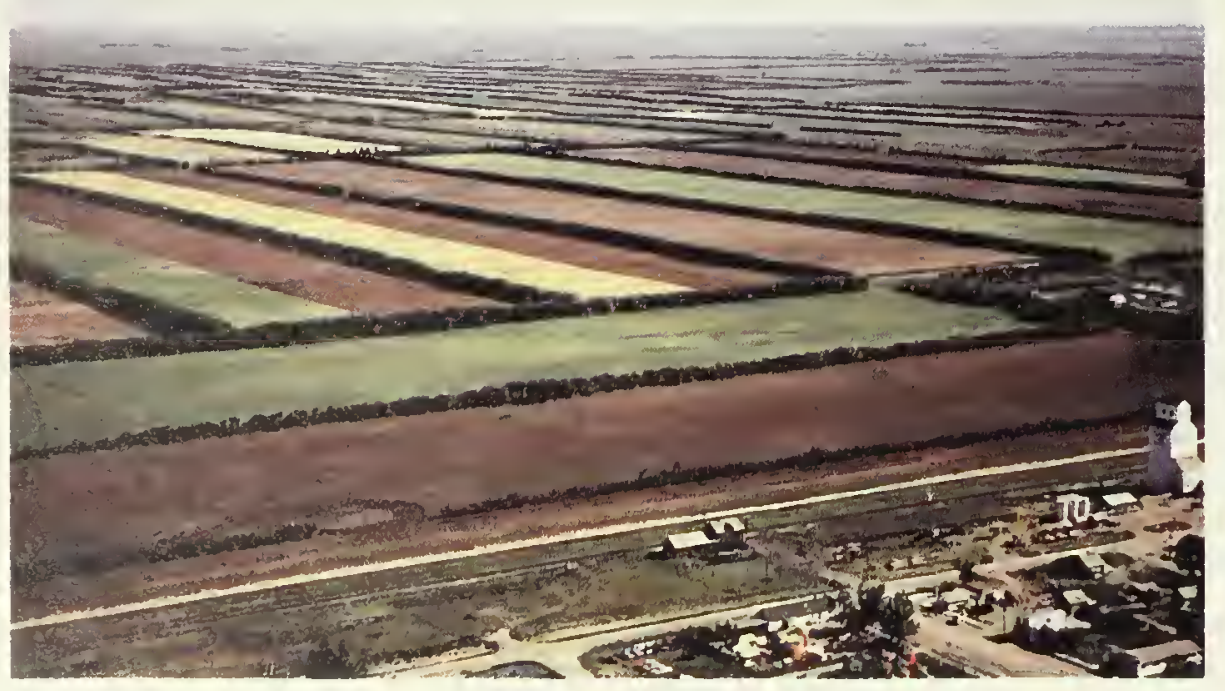

Shelterbelts near Conquest, Sask. regions, where forages grow well, and in areas where there is a livestock industry, because forages are used as livestock feed. In the prairie region, many high-risk areas have been planted to permanent cover. Shelterbelts, or windbreaks, are also used on the prairies, where the flat terrain, minimal natural brush protection, large fields, and frequency of high winds make cropland especially vulnerable to wind erosion. Ontario farms report the highest use of winter cover crops, such as fall rye and winter wheat, which are grown to protect the soil during the normally barren fall and spring months, when erosion can be a serious problem. Strip-cropping and contour cultivation are mainly used in the Prairie Provinces.

Crop residue management is growing in popularity as a way of controlling erosion. Conventional tillage buries crop residues in the soil to prepare a "clean" seedbed for the next crop. Conservation tillage leaves much of the crop residue on the soil surface, where it protects against erosion. No-till, a method by which crops are planted directly into the residue of the previous crop, offers the maximum residue cover of soil.

\section{Assessment of erosion}

It is possible to measure the extent and severity of erosion fairly accurately on a small plot of land, such as an experimental site. It is more difficult to assess erosion over large areas. However, our understanding of the relationships between soil, climate, and landscape can be used to predict which soils and which areas are naturally susceptible to erosion, as well as those that are at risk of erosion caused by land use and management practices. Soils that are at risk of erosion because of both their natural constitution and the system under which they are managed face the greatest threat to their health. 


\section{Inherent erosion risk}

Many natural features of soil, landscape, and climate affect soil erosion. Assessing the natural susceptibility of soils to erosion assumes that the soils are bare (without vegetation) and that they are not under conservation practices.

\section{Wind erosion}

The risk of soil erosion by wind on agricultural land is a concern in many regions of Canada. Vulnerable areas include the sandy soils along the Fraser River in southern British Columbia, the tobacco lands in southern Ontario, the Organic soils of southern Quebec, and the coastal areas of the Atlantic Provinces. However, wind erosion is by far the most extensive and damaging in the Prairie Provinces, where the climate is dry and large expanses of fields lie unprotected under fallow.

Estimates of the relative risk of wind erosion on bare, unprotected soil across the prairies show that slightly more than onethird of this region is at negligible-to-low risk of wind erosion; an equal portion of the land is at high-to-severe risk (Table 7-2).

\section{Water erosion}

The risk of soil erosion by water is a concern in all Canada's agricultural regions. Fine-textured, erodible soils are exposed to erosion by rainfall and runoff in many areas, including

- the Peace and Fraser River basins of British Columbia

\section{Modelling erosion}

In the broadest sense, a model is something that represents something else. Miniature airplanes and road maps are examples of models. In a similar way, mathematical models or equations are often used to represent processes such as soil erosion. Such models summarize how researchers think a process works, and predict what will happen if certain factors in the equation change.

Predicting wind and water erosion events rests on our ability to "outguess nature." Such predictions are difficult because soil conditions and wind velocities vary locally, and future wind and rainfall distribution is uncertain.

The wind erosion equation, developed in part from the pioneering work of Dr. W.S. Chepil at the Swift Current Research Station in the 1930s and 1940s, was the first mathematical model used to predict wind erosion. First published by the US Department of Agriculture in 1965, this equation forms the basis for most of the wind analysis carried out for this report.

Researchers in the United States and Canada are currently working on a new wind erosion model-the Wind Erosion Research Model — which attempts to simulate actual wind erosion processes and to predict daily the variables associated with soil and vegetation that control soil erodibility. It then uses long-term weather records to predict the likelihood and severity of an erosion event. Cooperative research on the new model is currently underway at Agriculture and Agri-Food Canada's research stations at Lethbridge, Alta., and Melfort, Sask.

Table 7-2 Inherent (bare soil) risk of wind erosion on the cultivated land of the Prairie Provinces

- sloping summerfallowed land in the

Prairie Provinces

- rolling upland landscapes of Ontario and Quebec

- shallow and fragile soils in the Maritime Provinces.

\begin{tabular}{lcccc}
\multicolumn{4}{c}{ Prairie Provinces } & \multicolumn{2}{c}{ Cultivated land $(\%)$} \\
Risk class & Alberta & Saskatchewan & Manitoba & Prairies \\
\hline Negligible & 7 & 4 & 8 & 6 \\
Low & 39 & 23 & 37 & 31 \\
Moderate & 24 & 34 & 19 & 29 \\
High & 27 & 33 & 30 & 30 \\
Severe & 4 & 7 & 5 & 6 \\
\hline
\end{tabular}


Table 7-3 Inherent (bare soil) risk of water erosion on Canada's cultivated land

\author{
Cultivated land (\%)
}

Risk class B.C. Alta. Sask. Man. Ont. Que. N.B. N.S. P.E.I. Canada

\begin{tabular}{lrrrrrrrrrr}
\hline Negligible & 5 & 39 & 51 & 35 & 12 & 18 & 0 & 3 & 1 & 40 \\
Low & 8 & 16 & 26 & 41 & 11 & 21 & 4 & 6 & 7 & 23 \\
Moderate & 13 & 17 & 19 & 6 & 24 & 14 & 16 & 4 & 11 & 17 \\
High & 3 & 10 & 3 & 4 & 25 & 4 & 13 & 3 & 37 & 7 \\
Severe & 72 & 18 & 1 & 14 & 27 & 43 & 67 & 84 & 44 & 13
\end{tabular}

The risk of water erosion is greatest on land under intensive cultivation. Land used to produce cash crops in the Maritime Provinces, Ontario, and British Columbia is especially vulnerable.

A national summary (Table 7-3) shows that about $63 \%$ of cultivated land in Canada is at negligible-to-low risk of water erosion, and about $20 \%$ is at high-to-severe risk. The Maritime Provinces are at the highest risk of water erosion (more than $80 \%$ of the cultivated land is in the high-to-severe risk categories), followed by British Columbia (75\%) and Central Canada (about 50\%). The Prairie Provinces are at a much lower risk of water erosion because of their relatively flat terrain and low rainfall.

\section{Effects of land use and management practices}

It is important to keep in mind that both the wind and water erosion risk assessments previously discussed pertain to bare, unprotected soils. Assessment of the actual erosion risk must also consider the land cover, as well as cropping and tillage practices.

In this assessment of erosion risk, we used the 1991 Census of Agriculture, other questionnaires, and information about soils from the Soil Landscapes of Canada to calculate the extent of the various risk classes of wind and water erosion. Actual erosion risk was assessed by taking the inherent erosion risk and adjusting it downward, based on the effectiveness of the cropping and tillage practices in reducing the risk. Wind erosion risk is reported for the Prairie Provinces; water erosion risk is reported for the Prairie Provinces and Ontario.

\section{Wind erosion}

Under 1991 management practices, less than $5 \%$ of cultivated land in the Prairie Provinces was at high-to-severe risk of wind erosion (Fig. 7-3). Most of the land in the highest risk class is sandy and has a high inherent erosion risk. Soils in the moderate risk class are generally sandy loams, although some clayey soils in the southern regions are also included in this class. Otherwise, the risk generally diminishes from the south to north, a reflection of lower wind speeds, cooler temperatures, and higher precipitation in the north. The trends toward less summerfallow and more perennial forage crops, combined with higher crop yields and increased crop residues, also contribute to a lower wind erosion risk in the northern areas.

We estimate that the tolerable annual limit for soil loss in the prairies is exceeded on about 15\% (5 million hectares) of the cultivated land in the Prairie Provinces. This area covers about 750000 hectares in the high-to-severe erosion class and the remainder in the moderate class. About $75 \%$ of the land exceeding the tolerable limit occurs in the Brown and Dark Brown soil zones of southern Alberta and Saskatchewan. 


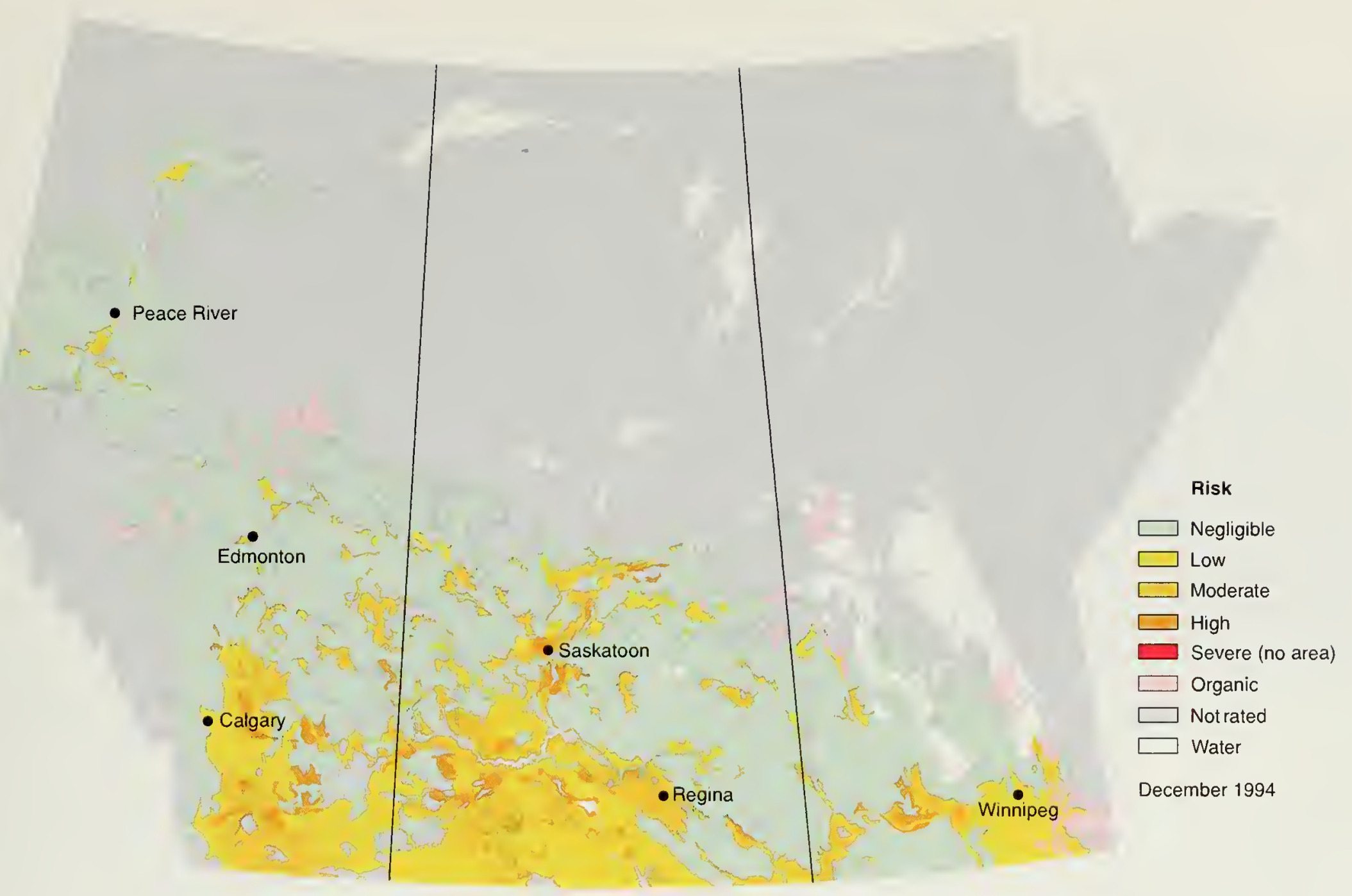

Figure 7-3 The risk of wind erosion in the Prairie Provinces under 1991 management practices (based on 1991 Census of Agriculture).

\section{Water erosion}

We assessed the risk of water erosion in the Prairie Provinces and Ontario, where 90\% of Canada's cultivated land is found. The risk of water erosion on cultivated land is shown in Figure 7-4 for the Prairie Provinces and in Figure 7-5 for Ontario. The lowest risk class contains soils that are at risk of erosion at a rate that is tolerable for sustainable crop production under the most common management practices. The other risk classes represent conditions where soil and water conservation practices are needed for sustainable crop production.

About $95 \%$ of cultivated land in the Prairie Provinces is at tolerable risk of water erosion. The moderate-to-high risk on the remaining land is the result of steep slopes, where conservation management practices are needed to control erosion. About $2 \%$ of cultivated land is at high-to-severe risk of water erosion.

About $60 \%$ of Ontario's cultivated land requires further implementation of conservation management practices; about $25 \%$ is at risk of low rates of erosion and about $10 \%$ is at risk of moderate rates of erosion. Five percent of Ontario soils are at risk of high-to-severe rates of erosion.

\section{Changes in erosion risk}

Reports from the 1980s indicated that soil erosion, left unchecked, poses a threat to the future of sustainable agriculture in Canada. To determine if conservation practices have resulted in reduced risk of erosion since that time, we examined changes in the actual soil erosion risk between 1981 and 1991. 


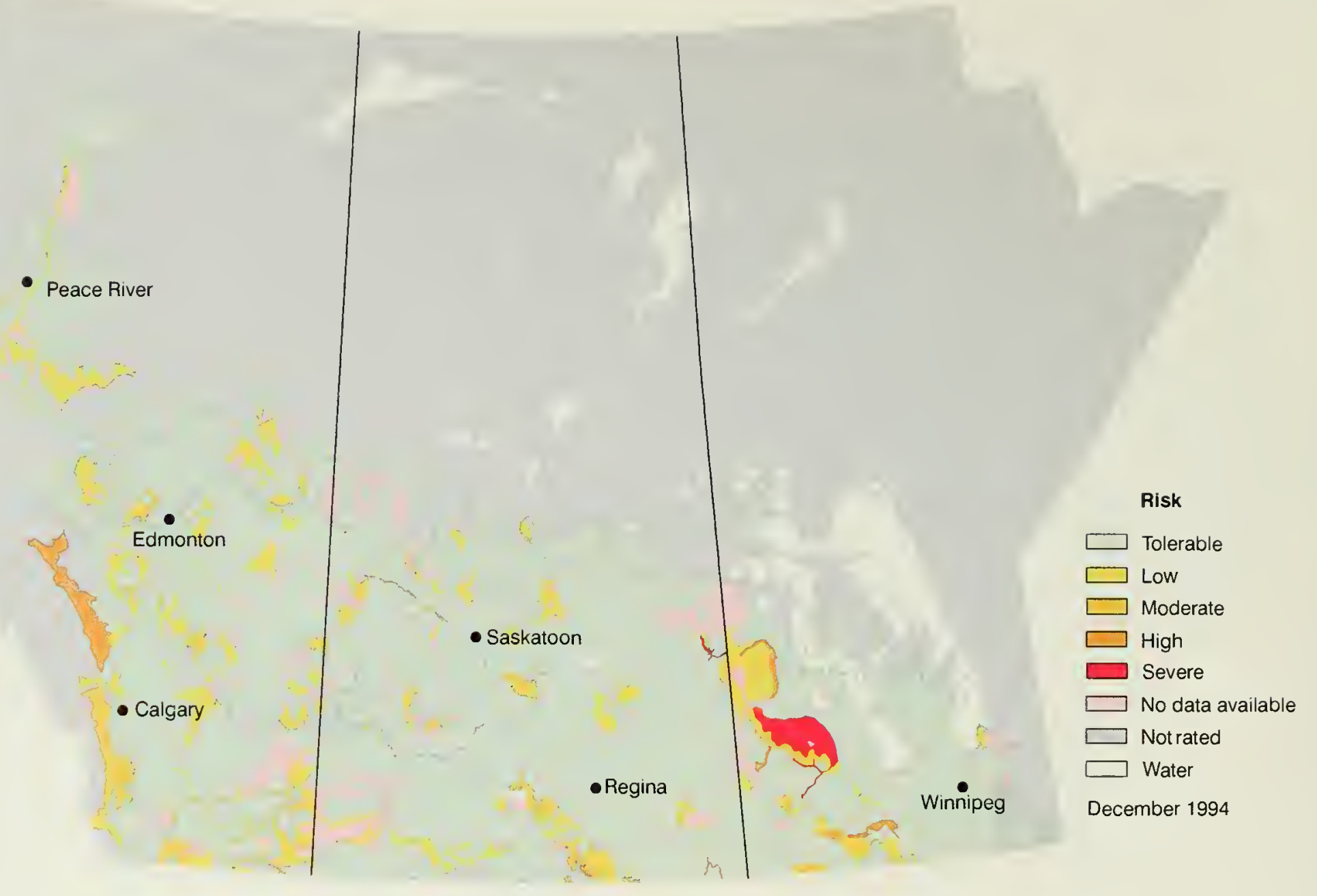

Figure 7-4 The risk of water erosion in the Prairie Provinces under 1991 management practices (based on 1991 Census of Agriculture).

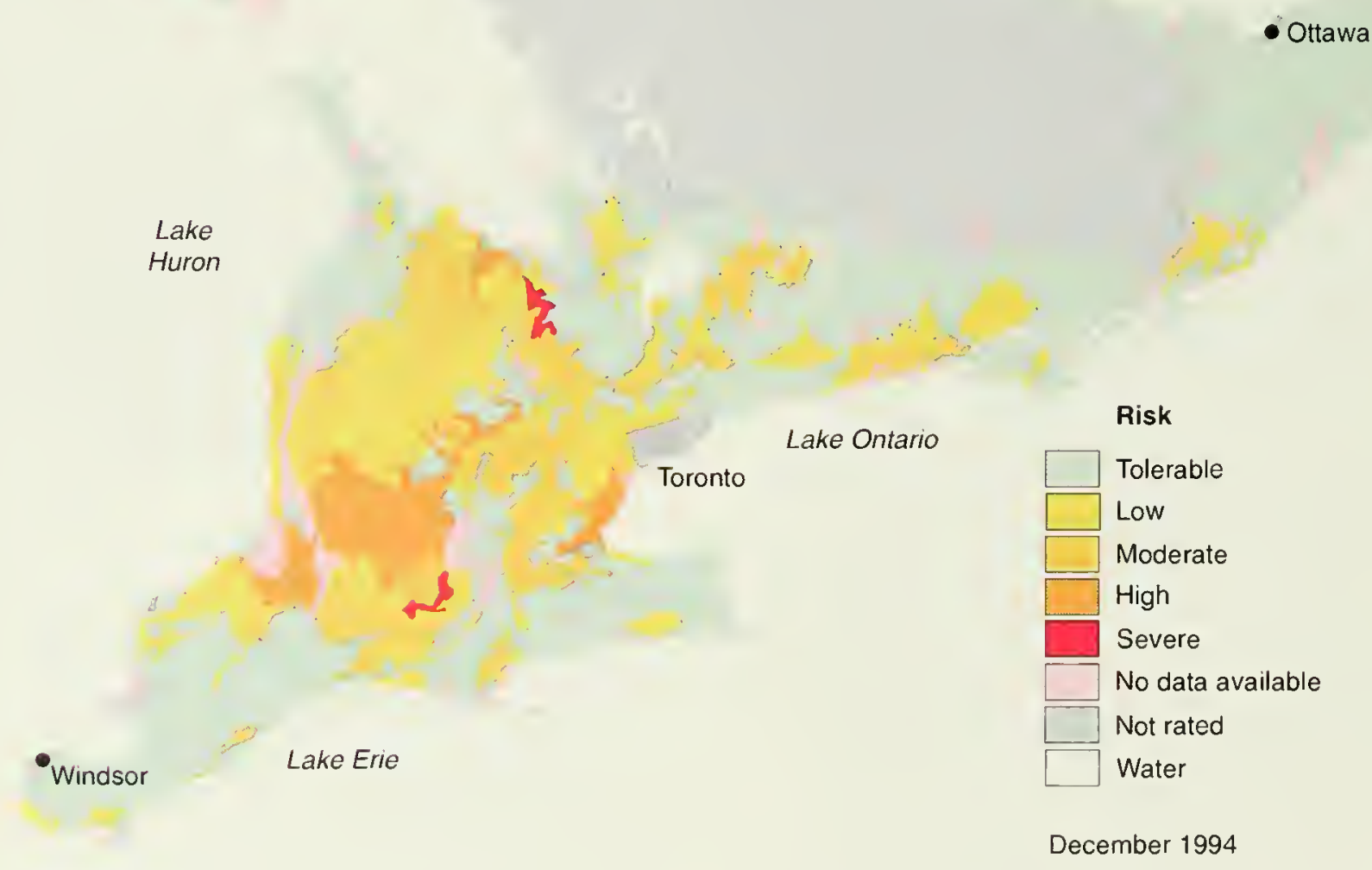

Figure 7-5 The risk of water erosion in southern Ontario under 1991 management practices (based on 1991 Census of Agriculture). 


\section{Wind erosion}

The risk of wind erosion in the prairies decreased by about $7 \%$ between 1981 and 1991 (Fig. 7-6). The increased use of conservation tillage accounts for about twothirds of the decrease; the remainder is the result of changes in cropping systems, especially the significant reduction in summerfallow (see box, page 73).

In the arid regions of Saskatchewan and Alberta, adopting conservation tillage systems has reduced the wind erosion risk by about $5 \%$, whereas the change in cropping systems has had only a minimal effect. Replacing cereals by oilseeds and specialty crops may have increased the wind-erosion risk slightly in some areas. On the other hand, a significant shift from annual crops to perennial forage in some sandy areas has reduced the wind-erosion risk by as much as $20-30 \%$. Wind erosion has been reduced slightly more in the Black, Dark Gray, and Gray soil zones than in the southern prairies, mainly because of

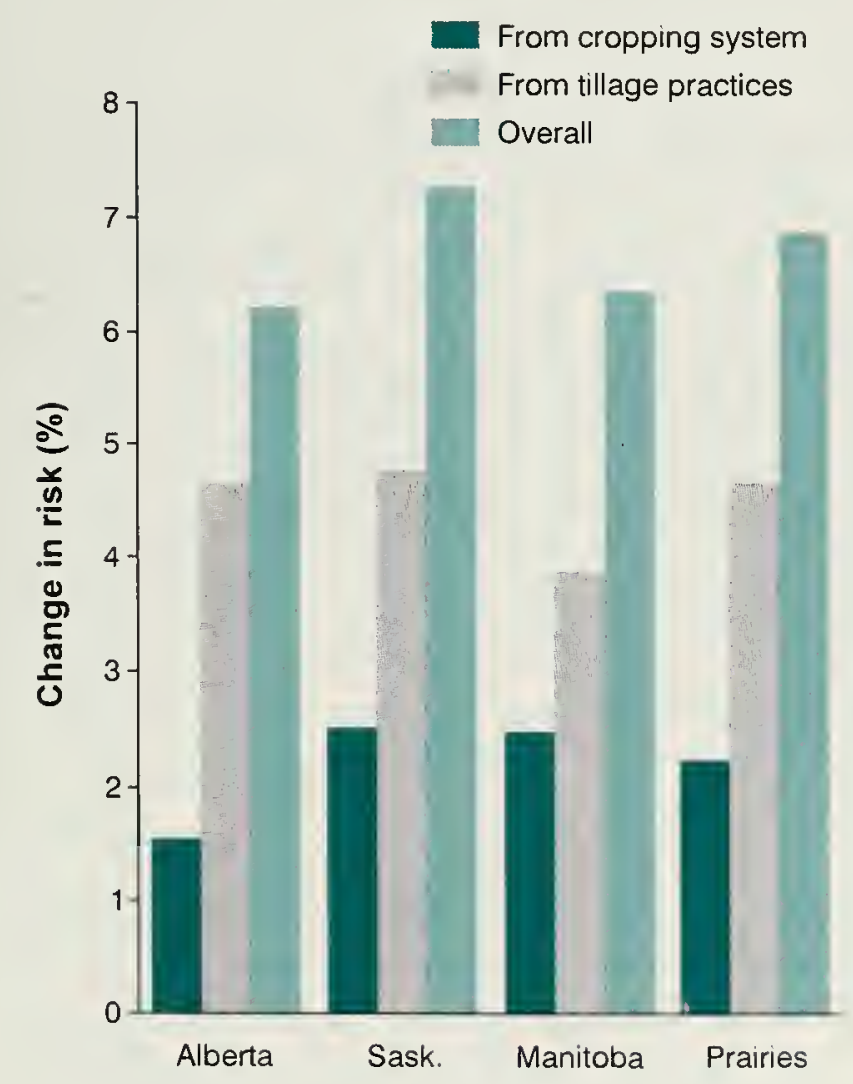

Figure 7-6

Reduction in the risk of wind erosion in the Prairie Provinces between 1981 and 1991.

\section{Measuring wind erosion}

The new wind erosion prediction system, recently developed by scientists in the US Department of Agriculture, has provided an opportunity for the first time in

Canada for researchers to measure actual wind erosion losses based on erosion events. At an experimental site near Lethbridge, Alta., researchers measured soil losses of up to 30 tonnes per hectare from a single wind erosion event and about 122 tonnes per hectare over a 7-month fallow period.

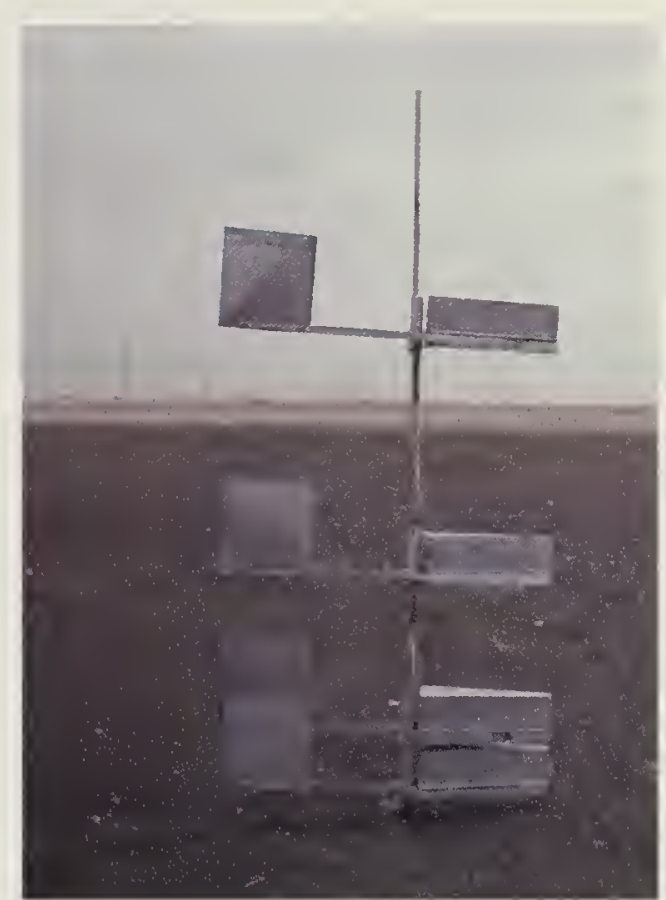

Dust sampler used to measure soil losses in the field.
Although the site was tilled excessively to promote erosion, the fact that the soil type (clay loam) was not particularly susceptible to erosion and that it had been previously under notill for 6 years shows the suscepti-bility of the land in this region to wind erosion if protective measures are not taken. Based on the fastest rate of natural soil renewal for cultivated land and assuming no further erosion, it would take about 15 years to restore the lost topsoil.

Soil losses during wind erosion events, Lethbridge, Alta.

\begin{tabular}{|c|c|c|c|}
\hline Date & $\begin{array}{l}\text { Duration } \\
\text { of wind } \\
\text { (h) }\end{array}$ & $\begin{array}{c}\text { Maximum } \\
\text { wind speed } \\
(\mathrm{km} / \mathrm{h})\end{array}$ & $\begin{array}{c}\text { Soil loss } \\
\text { (tonnes } \\
\text { /ha) }\end{array}$ \\
\hline
\end{tabular}

1991

6 December

$58 \quad 23$

9 December

55

10 December

56

11 December

57

16 December

53

6

1992

3 April

4 April

5 April

9 April

13 April

18 April

7
3
8
2
1
10

$\begin{array}{lr}58 & 30 \\ 50 & 6 \\ 47 & 5 \\ 43 & 1 \\ 51 & 2 \\ 55 & 12\end{array}$

(F.J. Larney, AAFC, Lethbridge, Alta., and G.A. Padbury, AAFC, Saskatoon, Sask.) 
a marked reduction in fallow and some replacement of annual crops with forages in these zones.

The number of producers using conservation tillage and reduced summerfallow is increasing significantly in the prairies. Therefore, it is reasonable to expect that the risk of wind erosion has been further reduced by an estimated 5-10\% since 1991.

\section{Water erosion}

The risk of water erosion in Canada decreased by $11 \%$ between 1981 and 1991 as a result of the implementation of conservation farming practices. Conservation tillage $(6 \%)$ and changes in cropping practices $(5 \%)$ contributed about equally to this improvement. On a regional basis, the decrease in water-erosion risk was $11 \%$ in the Prairie Provinces and 16\% in central Canada. Water-erosion risk increased by $0.5 \%$ in the Maritime Provinces. Reductions in erosion risk are shown by province in Table 7-4.
Regional differences in soil losses arise because of the diversity of cropping systems, the varying suitability of specific conservation practices for those cropping systems, and the cost of erosion controls. For example, large-scale production of potatoes places much of the Maritime Provinces at high risk of water erosion. This risk increases as more cultivated land is devoted to this crop. Some conservation tillage systems, however beneficial in other cropping systems, are unsuitable for potatoes, which require hilling. Appropriate conservation measures for potato production include chisel plowing, crossslope or contour cultivation, terracing, and extended rotations.

Furthermore, because of the scale of analysis and the difficulty in obtaining necessary data, calculating the effects of management practices on erosion did not take into account the benefits of devices for erosion control such as terraces and grassed waterways. Between 1981 and 1991, about 1500 hectares under potato production in Prince Edward Island and about 3000

Table 7-4 Reduction in actual water erosion risk per hectare from 1981 to 1991

Erosion reduction per hectare (\%)

Cultivated land
in 1991
(million ha)

$\begin{array}{cc}\begin{array}{c}\text { Resulting from } \\ \text { cropping }\end{array} & \begin{array}{c}\text { Resulting from } \\ \text { tillage } \\ \text { practice }\end{array} \\ \text { practice }\end{array}$

Total in 1991

British Columbia

$$
0.61
$$

Alberta

11.06

Saskatchewan

19.17

Manitoba

5.06

3.48

1.65

0.12

0.16

0.11

Nova Scotia

41.42

Canada

7
5
5
6
10
3
2
-9
-3

10 17 13 
hectares in New Brunswick were protected by variable-grade diversion terraces, grassed waterways, or strip-cropping. These methods reduced soil losses under potato crops by as much as $90 \%$ compared with traditional up- and down-slope cultivation (see Chapter 4).

Nova Scotia shows no change in potential soil loss, because the benefits gained from conservation tillage were offset by the increased production of berries, grapes, and vegetables. Soil losses resulting from water erosion were reduced by more than $10 \%$ in British Columbia, Alberta, Manitoba, and Ontario, which account for nearly $50 \%$ of Canada's cultivated land.

\section{Changes in Ontario and the Prairie Provinces}

We combined Census of Agriculture information on land use and management practices in 1981 and 1991 with soil and landscape data from the provincial soillandscape maps to show where implementing soil conservation measures has been most effective in the Prairie Provinces and southern Ontario. The change in the risk of water erosion resulting from improved cropping and tillage practices during this period is shown for the Prairie Provinces in Figure 7-7 and for southern Ontario in Figure 7-8.

The water erosion risk remains at tolerable levels for much of the Prairie Provinces. However, parts of western Manitoba and Alberta continue to have some areas exceeding tolerable levels of water erosion risk. The implementation of erosion control practices resulting in reduced erosion risk is particularly evident on sloping land in western Alberta.

In southern Ontario, there are tolerable rates of water erosion on much of the level to gently sloping and marginal agricultural lands. However, water erosion on much of the sloping land that is intensively cultivated in south-central Ontario still exceeds tolerable rates.

\section{Prairie cropping practices}

Crop selection has a significant effect on soil's susceptibility to erosion. The risk of erosion may increase on soils under some crops, such as oilseeds and specialty crops that are grown in rows. On the other hand, the risk may decrease when soils are cropped to perennial forages or summerfallow is reduced. The following graphs show changes between 1981 and 1991 in the proportion of important crops grown on the prairies.

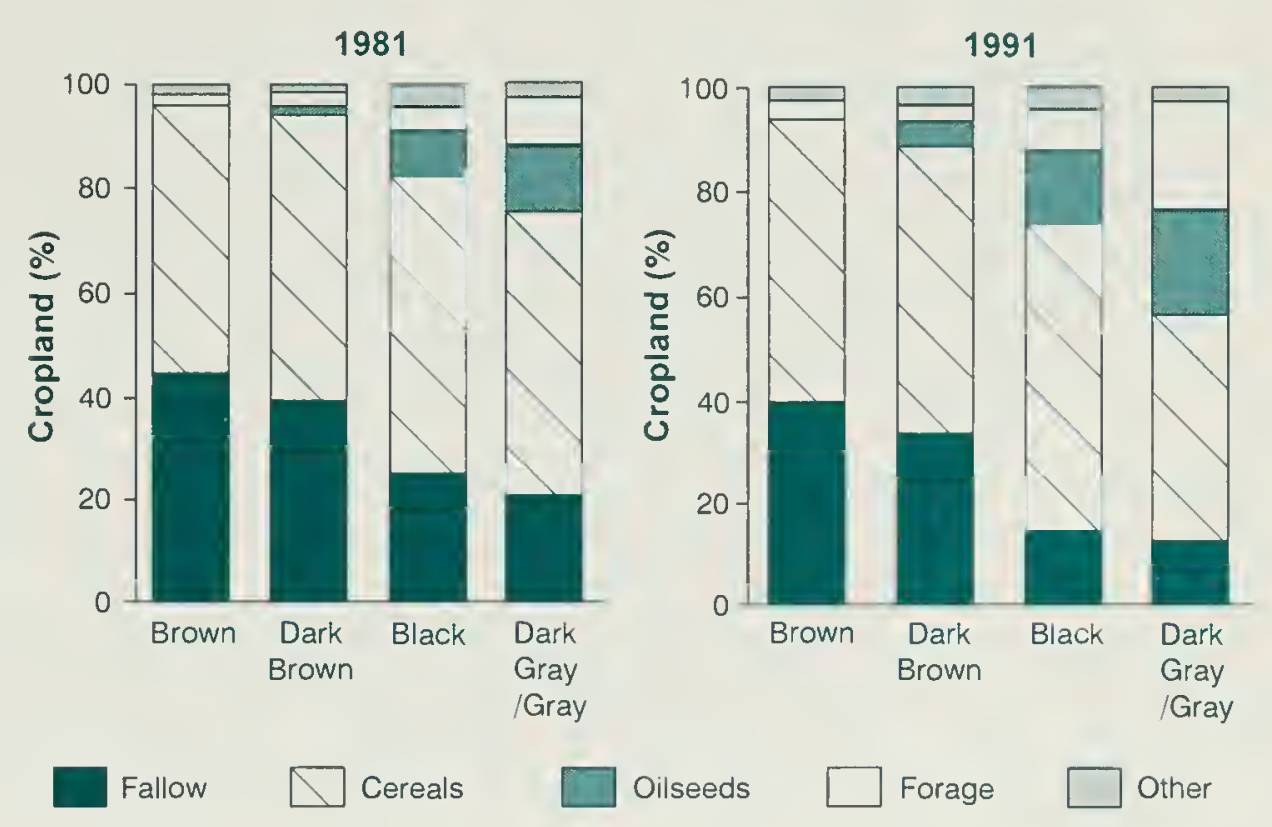

Cropping practices on the prairies.

(G.A. Padbury, AAFC, Snskntoon, Sask.)

\section{Program development}

Awareness of the erosion problem in Canada has increased significantly over the past decade. Many government programs have been, and continue to be, developed to assist producers in erosion control. National and provincial governments, frequently working together, have provided technical and financial assistance for implementing appropriate management practices and have offered financial assistance to purchase equipment or build erosion control structures. Although some 
Wall et al.

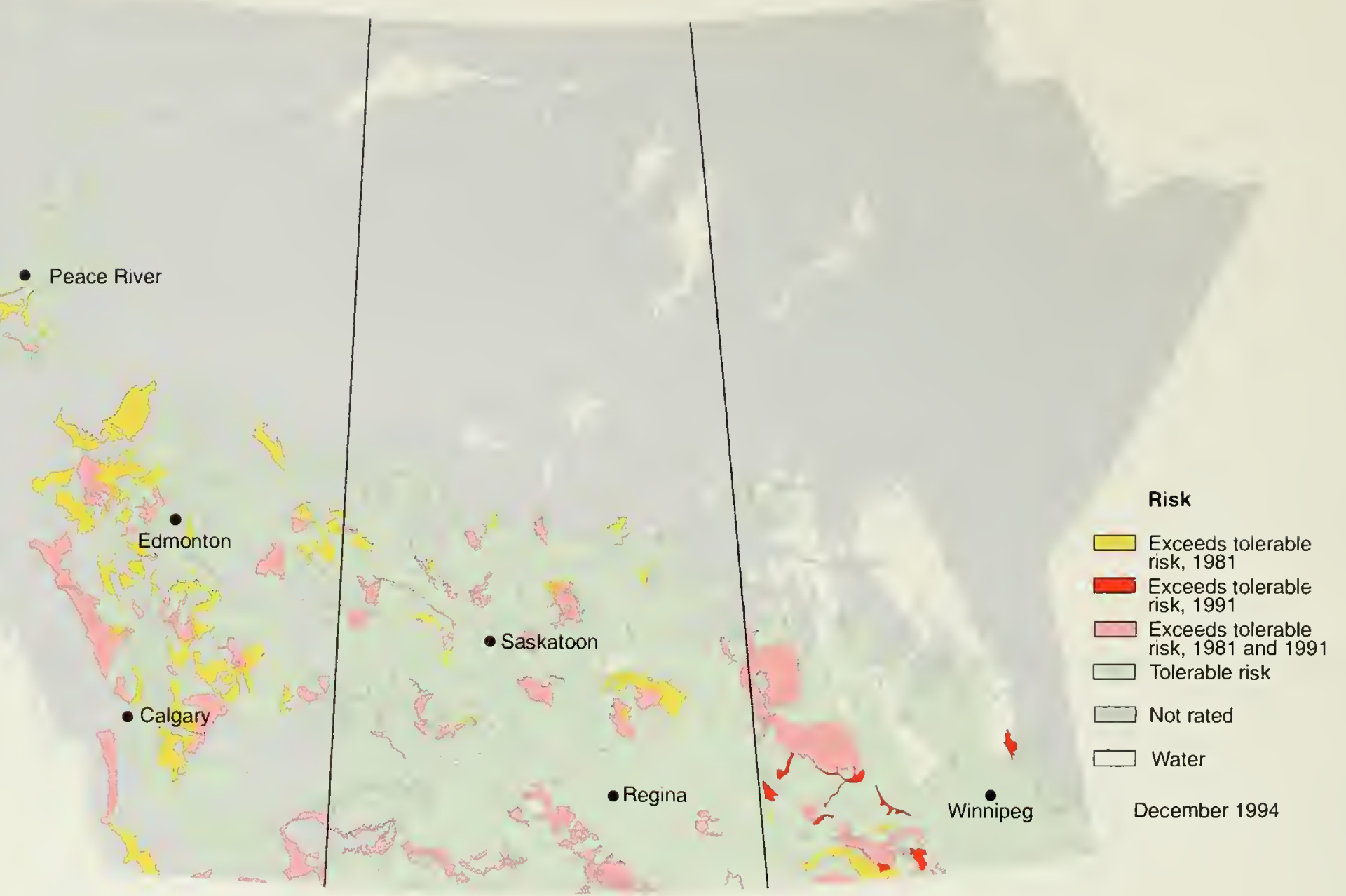

Figure 7-7 Changes in the risk of water erosion in the Prairie Provinces between 1981 and 1991.

- Ottawa

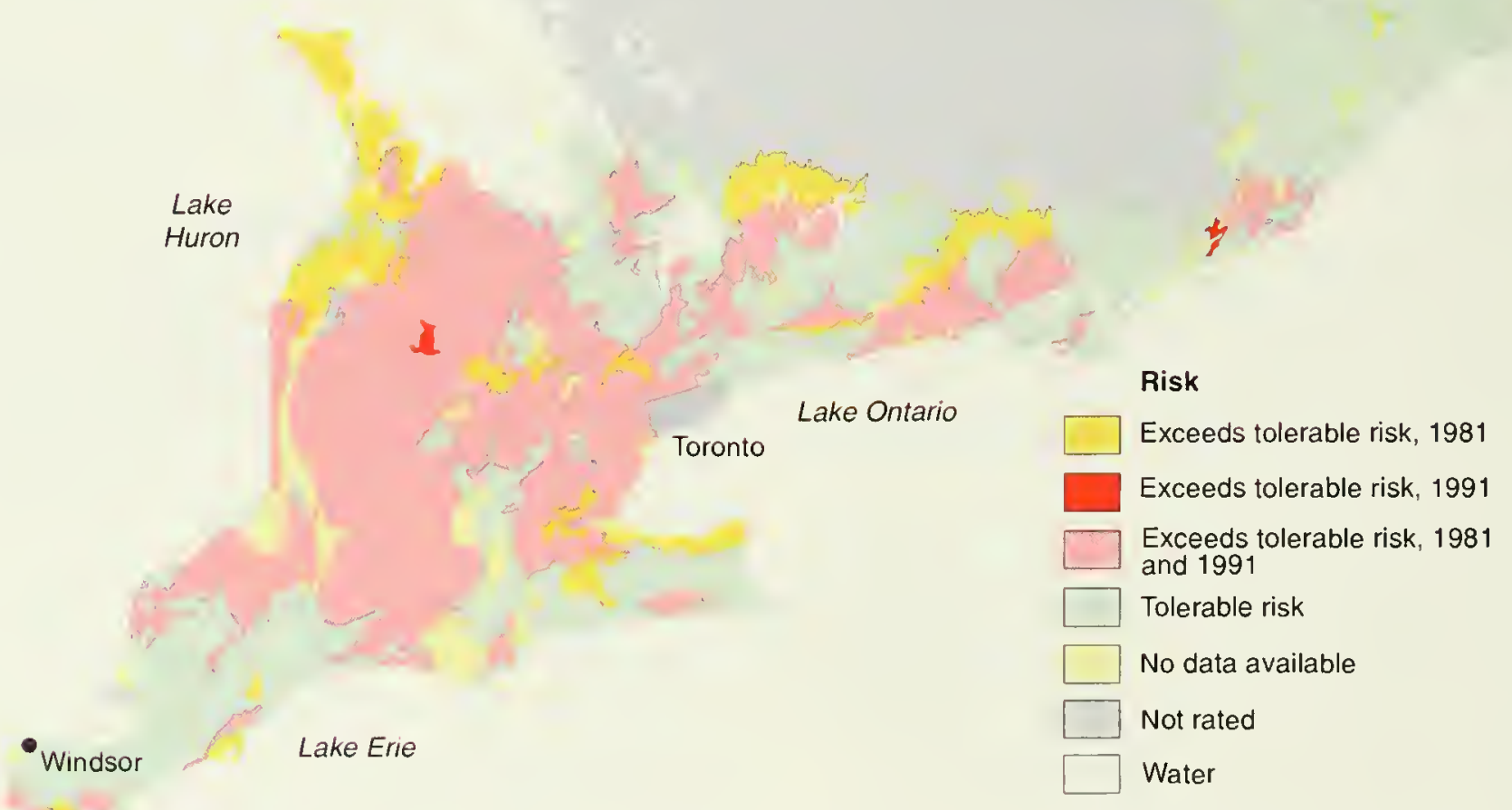

December 1994

Figure 7-8 Changes in the risk of water erosion in southern Ontario between 1981 and 1991. 
erosion control programs have been in place for many years as components of general federal-provincial agreements or provincial programs, it was not until the National Soil Conservation Program (NSCP) began in 1989 that efforts were focussed nationally on soil conservation and thus on soil erosion. Conservation activities initiated by the NSCP have been continued under Green Plan programs. Other soil programs that address erosion include

- the Permanent Cover Program in the Prairies Provinces

- the Soil and Water Environmental Enhancement Program (SWEEP) in Ontario

- programs of the Eastern Canada Soil and Water Conservation Centre (Grand Falls, N.B.) for Atlantic Canada.

\section{Producer response to programs}

As a result of these programs and other erosion-related activities carried out by interest groups and governments, thousands of farmers are better-informed about soil erosion issues and have implemented conservation measures on large areas of cultivated land in Canada. For example,

- The Permanent Cover Program in the Prairie Provinces has resulted in 500000 hectares of marginal land being converted to permanent cover.

- In 1991, 13\% of Canadian farms reported the use of windbreaks totalling $84000 \mathrm{~km}$.

- Direct seeding is used on more than 0.6 million hectares of land in Alberta.

- The Land Stewardship Program II in Ontario resulted in soil and water conservation practices being implemented on 1.1 million hectares of land, exceeding the program's goals.

The trends of increased use of conservation farming practices and reduced soil losses resulting from erosion are expected to

\section{PFRA -60 years of soil conservation}

The Prairie Farm Rehabilitation Administration (PFRA) has been in the business of conserving soil for 60 years. Created under the Prairie Farm Rehabilitation Act of 1935, PFRA was a component of federal emergency measures that responded to the severe drought and soil-drifting conditions of that time on the prairies.

In its early years, PFRA's soil conservation program was carried out by Experimental Farm personnel who expanded their role from research to demonstrate and promote techniques they had developed. After 1946, PFRA's conservation work was confined to its tree nursery and community pastures programs. During the 1950s, a wetter weather cycle and expanding markets resulted in a greater emphasis on crop production at the expense of soil health. Drier weather conditions and the absence of ground cover on many fields resulted in severe soil drifting in the late 1970 s and early 1980s.

In 1981, PFRA began to expand its role in soil conservation and, 2 years later, produced a status report on the soil resource, entitled Land degradation and soil conservation issues on the Canadian prairies. As a result of growing concern about the condition of soils, soil conservation was included in the Economic and Regional Development Agreements signed in 1984. PFRA's soil conservation activities included delivering field services (technical and financial) to producers, investi-gating regional soil degradation, and educating the public about the issues. These activities continued into the early 1990s under the National Soil Conservation Program.

More recently, PFRA has been the lead federal agency to deliver agricultural Green Plan agreements. Activities are aimed at supporting sustainable agriculture by protecting the soil resource, water quality, and wildlife habitat. PFRA community pastures continue to protect about 810000 hectares of fragile land, providing grazing for 210000 cattle and other livestock. About $80 \%$ of this pastureland is native range, which makes an important contribution to wildlife habitat and to prairie biodiversity.

(Glen Shawe and Malcolm Black, PFRA, Regina, Sask.) continue. How quickly further improvements are seen depends on producers' experience and confidence in soil conservation technology and the availability of this technology. 


\section{Conclusions}

Protection against soil erosion can be achieved through the use of erosion controls related to changes in cropping, tillage, and water-management practices. Implementation of such erosion controls has resulted in about a 10\% decrease in the risk of both wind and water erosion in Canada during the past 10 years.
Continued reduction in the risk of soil erosion will help to maintain and improve soil quality in Canada. The quality of surface water on, and downstream from, agricultural lands will also improve as soil and associated agrochemicals are kept on the farm and out of the streams. 


\title{
Salinization of soil
}

\author{
R.G. Eilers, W.D. Eilers, W.W. Pettapiece, and G. Lelyk
}

\section{Highlights}

- Salinization is the process by which salts accumulate in the soil; soil salinity hinders the growth of crops by limiting their ability to take up water.

- A new map of soil salinity in the Prairie Provinces shows that most prairie farmland $(62 \%)$ has less than $1 \%$ of its area affected by salinity; $36 \%$ has $1-15 \%$ of its lands affected; and $2 \%$ has more than $15 \%$ of its lands affected.

- A salinity risk study, based on a newly developed salinity risk index, shows that most prairie farmland (61\% in Manitoba, 59\% in Saskatchewan, and $80 \%$ in Alberta) has a low chance of increasing salinity under current farming practices.

- One-fifth of Manitoba's farmland had less risk of salinization in 1991 than in 1981, probably because of the return of marginal land to permanent cover and increase in continuous cropping.

- Conservation farming practices that help to control soil salinity include reducing summerfallow, extending crop rotations, using conservation tillage, adding organic matter to the soil, and planting salt-tolerant crops.

\section{Introduction}

Many prairie soils contain naturally high levels of water-soluble salts, including the sulfates of sodium, calcium, and magnesium. These salts are the product of chemical action on minerals in the upper layers of the glacial till that underlies the soils in this region. Through the natural process of salinization, they can be concentrated in surface soil, resulting in a condition known as soil salinity.

Soil salinity is a state in which soil contains enough dissolved salts in the plant-root zone to hinder plant growth. This condition is mainly controlled by the presence and movement of water in the soil. Any process that affects the soil-water balance, including the geology, hydrology (water movement), climate (especially long-term trends in precipitation), plant cover, and farming practices of an area may change the level of soil salinity.

\section{Current issues of soil salinity in Canada}

Saline soils are present in many areas throughout the southern Prairie Provinces. Moderate to severe salinity, persisting more or less visibly in the landscape, reduces the annual yields of most cereal and oilseed
When Hun Attila's Asian warriors moved westward, he cowed his enemies by threatening to throw salt on their lands.

Hans Jenny

The Making and

Unmaking of a Fertile Soil in Meeting the Expectations of the Land 


\section{Benchmark sites}

Seasonal and annual monitoring of soil salinity is carried out at research and demonstration sites across the Prairie Provinces, including seven benchmark sites established under the National Soil Conservation Program (see Chapter 4). These sites have different geologic, hydrologic, and climatic conditions and represent the major agricultural landscapes affected by salinity. Land at the benchmark sites is used mainly for growing annual crops. Early monitoring results indicate that salinity varies more during a season than from year to year. In the 4 years since the benchmark program began, no change has been apparent in overall salinity status at the sites.

(R.G. Eilers, AAFC, Winnipeg, Man.)

crops by about $50 \%$. Researchers have tried many times over the years to record the type, extent, severity, and rate of change of soil salinity on the prairies, but these assessments differed in approach and produced varying estimates of saline lands. In this chapter we report the first attempt to describe salinity in the Prairie Provinces in a standard way and to provide a base line against which to compare future measurements of salinity. The aims of the assessment were

- to estimate the current extent and severity of soil salinity

- to assess the risk that soil salinity levels will increase under current agricultural land use and management practices, and to assess changes in this risk in the past 10 years.

\section{Location and signs of salinization}

Salinization takes place where the following conditions occur together:

- the presence of soluble salts in the soil

- a high water table

- a high rate of evaporation (water evaporates from the soil surface faster than it is received through precipitation).
Precipitation

(in excess of crop use)

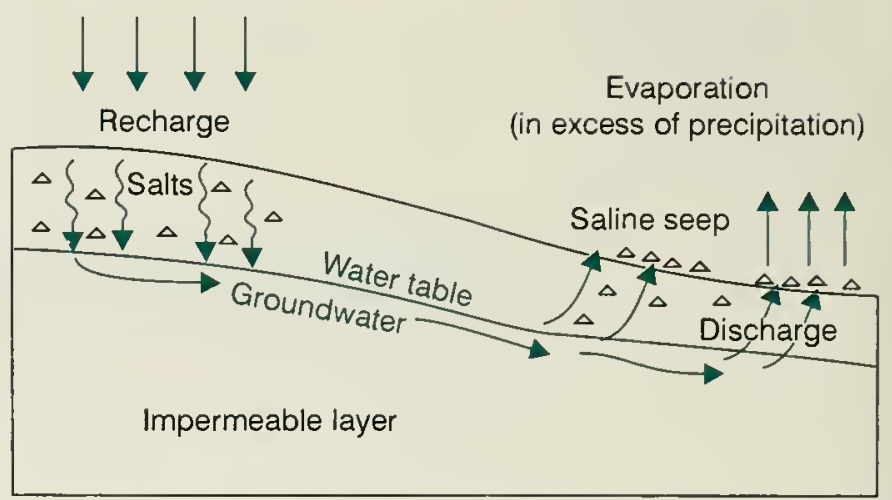

Figure 8-1

Soil salinization at the base of a hillslope. Precipitation is received in the recharge area. Water penetrates the soil and, if not taken up by plants, enters the groundwater. Groundwater dissolves and carries salts into the discharge area. There, the incoming groundwater causes the water table to rise until it reaches the capillary zone, through which the water is drawn to the soil surface by capillary ("sponging") action. Evaporation of the water results in salt accumulation.

These features often exist in depressions and drainage courses, at the base of hillslopes (Fig. 8-1), and in flat, low-lying areas surrounding sloughs and shallow water bodies. Soil salinity can be widespread in areas receiving regional discharge of groundwater.

\section{Signs of soil salinity}

It may be possible to identify saline soils before they become seriously affected. The early signs of soil salinity include

- a surge in crop growth, producing high yields

- increased soil wetness, to the point that the area becomes inaccessible

- the growth of salt-tolerant weeds (such as kochia, Kochia scoparia (L.) Schrad.) among the crop.

As salt levels in the soil increase, the signs become more obvious. They include

- irregular crop growth patterns and lack of plant vigour (Fig. 8-2A)

- white surface-crusting (Fig. 8-2B) 

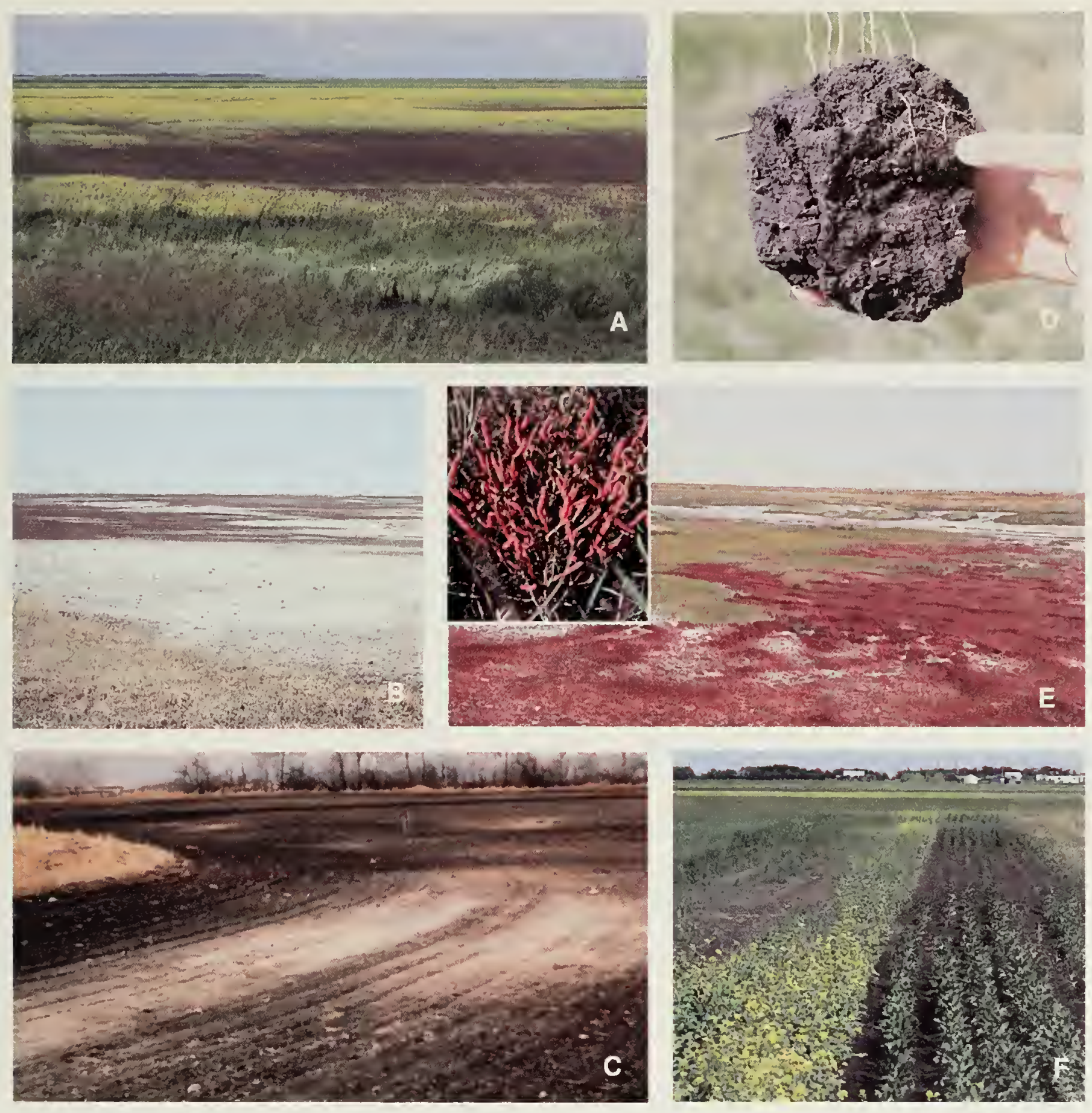

Fig. 8-2

A Irregular crop growth on saline soil.

$B$ White crust of salt on the soil surface.

C Broken-ring pattern of salts around a stough.
$D$ Salt streaks within the soil.

E Red samplive (inset) growing on saline soit.

F Crop-tolerance testing on saline soil.
- broken-ring pattern of salts adjacent to a water body Fig. 8-2C)

- white spots and streaks in the soil, even where no surface crusting shows (Fig. 8-2D)

- presence of naturally growing, salttolerant vegetation, such as red samphire (Salicornia rubra Nels., Fig. 8-2E).

\section{Effects of salinization}

High levels of salt in the soil have the same effect as drought by making water less available for uptake by plant roots. This effect is caused by the difference in salt concentrations between the plant and the soil (the osmotic gradient created between soil and plant prevents water from being 


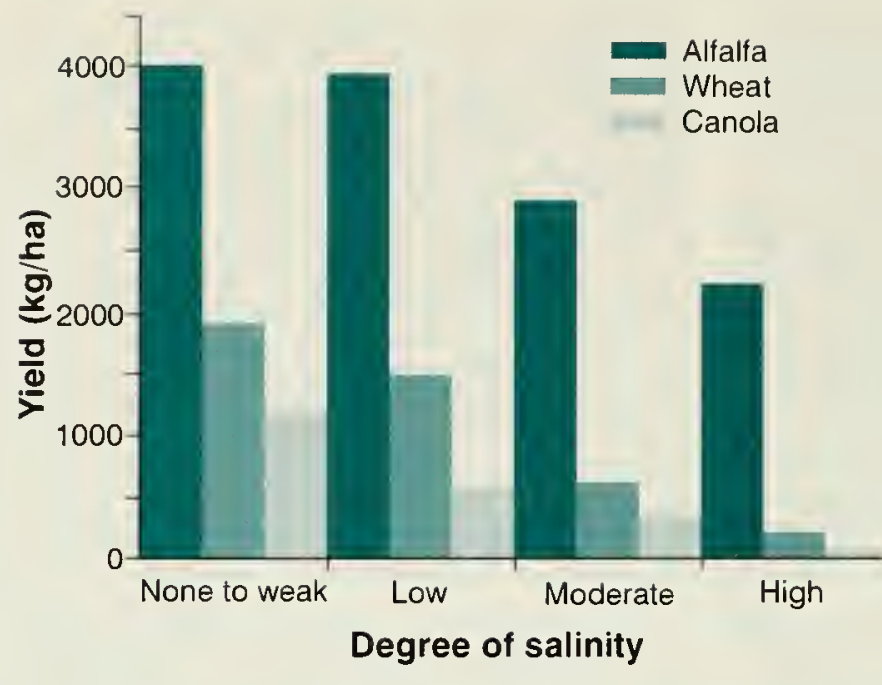

Figure 8-3

Effect of soil salinity on crop yield.

absorbed by the roots and, if great enough, will cause water to be drawn out of the plant). Depending on the degree of salinity, this effect reduces the soil's ability to produce crops and lowers annual crop yields (Fig. 8-3).

Because few plants grow well on saline soils, the farmer's cropping options are limited. Crop-tolerance testing, which measures the ability of a crop to grow in saline soil, is used to identify crops that are less affected by soil salinity (Fig. 8-2F) and to plan appropriate cropping strategies for saline soils.

Salinization also degrades the quality of shallow groundwater and surface waters such as ponds, sloughs, and dugouts. Evaporation may concentrate salt in these waters to levels that pose a risk to the health of livestock and wildlife. Highly saline waters are hazardous to freshwater fish populations and are avoided by waterfowl.

\section{Status of soil salinity}

\section{Mapping the extent of soil salinity}

In 1990, researchers from Agriculture

Canada assessed the extent of moderate to severe salinity in each of the Prairie

Provinces. Existing information from salinity maps was compiled, evaluated by experts, and verified in the field by soil specialists from the prairie region. A map was then drawn, showing the estimated location and extent of salinized soils in the Prairie Provinces (Fig. 8-4).

Most $(62 \%)$ of the farmland in the prairies has a low extent of salinity (less than $1 \%$ of lands affected). Low-salinity areas usually have well-drained soils and are found generally

- on major uplands (Cypress Hills, Sask.; Turtle Mountain, Man.)

- over rapidly drained sandy soils (Great Sand Hills, Sask.)

- next to deep river channels that help to drain the soil in the neighbouring land

- in northern areas, where soils formed under forest vegetation in moist conditions.

About $36 \%$ of agricultural soils on the prairies is moderately affected by salinity (1-15\% of lands affected). These are mainly medium-textured soils that occur next to small wetlands or prairie sloughs and in drainage courses and depressions.

Areas with a greater extent of saline soils are fairly small and scattered throughout the southern region. These areas often receive regional groundwater discharge (underground water that comes up to the land surface), such as those found on nearly level plains at the base of prominent uplands (Hand Hills, Alta.; Moose Mountain, Sask.; and Turtle Mountain, Man.) or on nearly level plains where the discharge is by major aquifers (geologic materials containing large amounts of free water) and where drainage is limited (Quill Lakes, Sask. and Red River basin, Man.).

\section{Risk of salinity}

Many people think that farming practices are the main cause of soil salinity in western Canada. It is true that growing crops can redistribute water in a landscape (by changing vegetation, water infiltration into the soil, and runoff), which in turn can aggravate the natural salinization of soil. But agriculture is only one influence among many-soils usually become saline because of natural physical and environmental factors alone. 


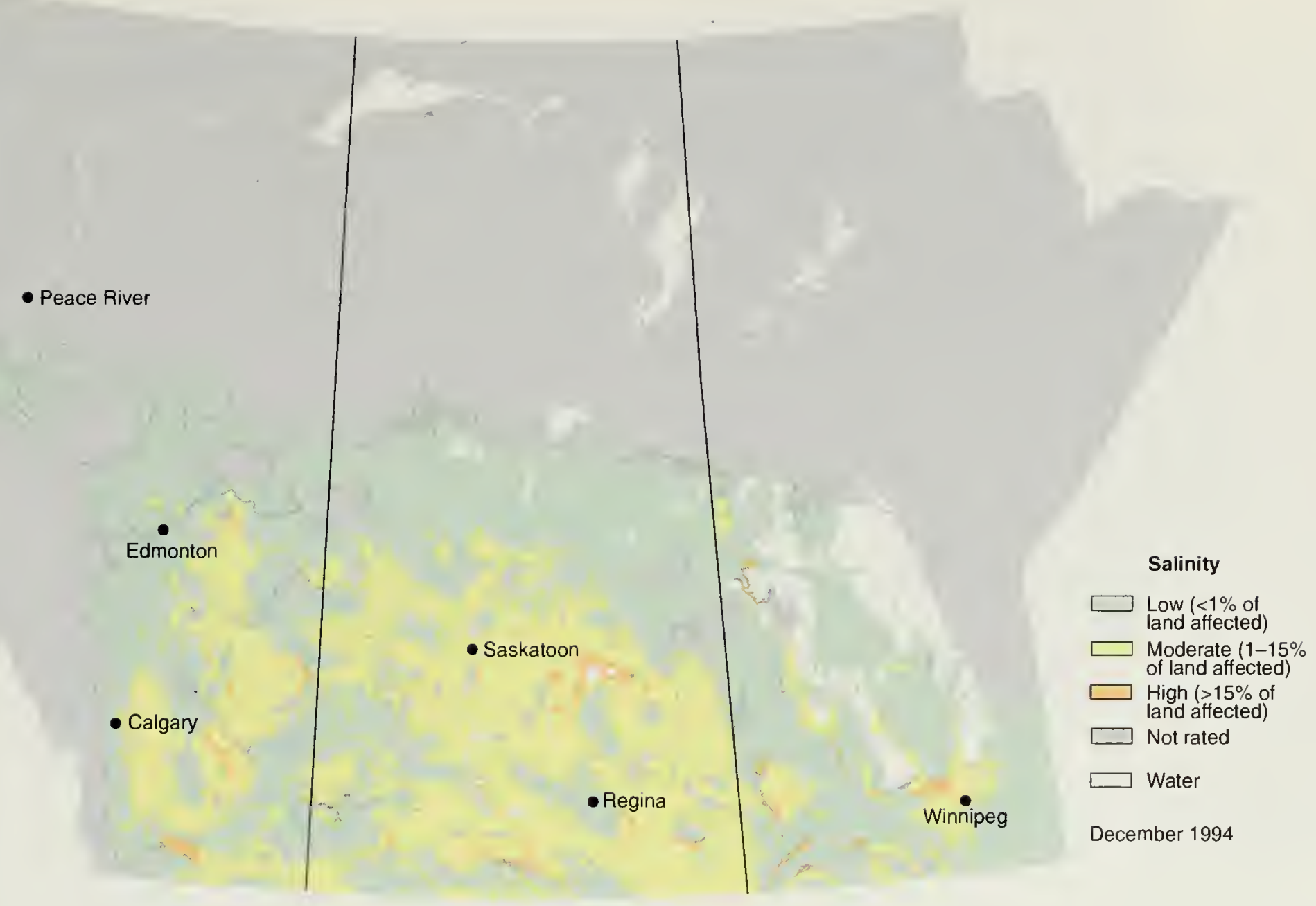

Figure 8-4 Surface salinity in prairie agricultural soils, 1991.

Factors that control the occurrence, extent, and level of soil salinity fall into two main groups:

1) long-term factors, which stay more or less the same, including

- parent materials of the soil

- topography

- soil drainage

- groundwater hydrology

- long-term regional climate;

2) short-term factors, which are likely to change, including

- precipitation

- evaporation

- land use

- farming practices.

Changes in any of these factors can affect soil salinity and may be used to predict salinity levels in a given area.

\section{Salinity risk index}

We developed a salinity risk index (SRI) that measures the chance that an area has a certain level of salinity and used it to determine whether farming practices cause soil salinity to increase. This index will be validated and refined as the factors affecting soil salinity become more fully understood.

Under 1991 cropping patterns (as indicated by the 1991 Census of Agriculture), there is little or no risk of a change in salinity levels in about $61 \%$ of the agricultural land in Manitoba, 59\% in Saskatchewan, and 80\% in Alberta (Fig. 8-5 and Table 8-1). These lands may already be under management that controls salinity (such as permanent cover or minimal summerfallow). On the other hand, the remaining farmland in these provinces has a moderate-to-high risk of increasing salinity under 1991 cropping 


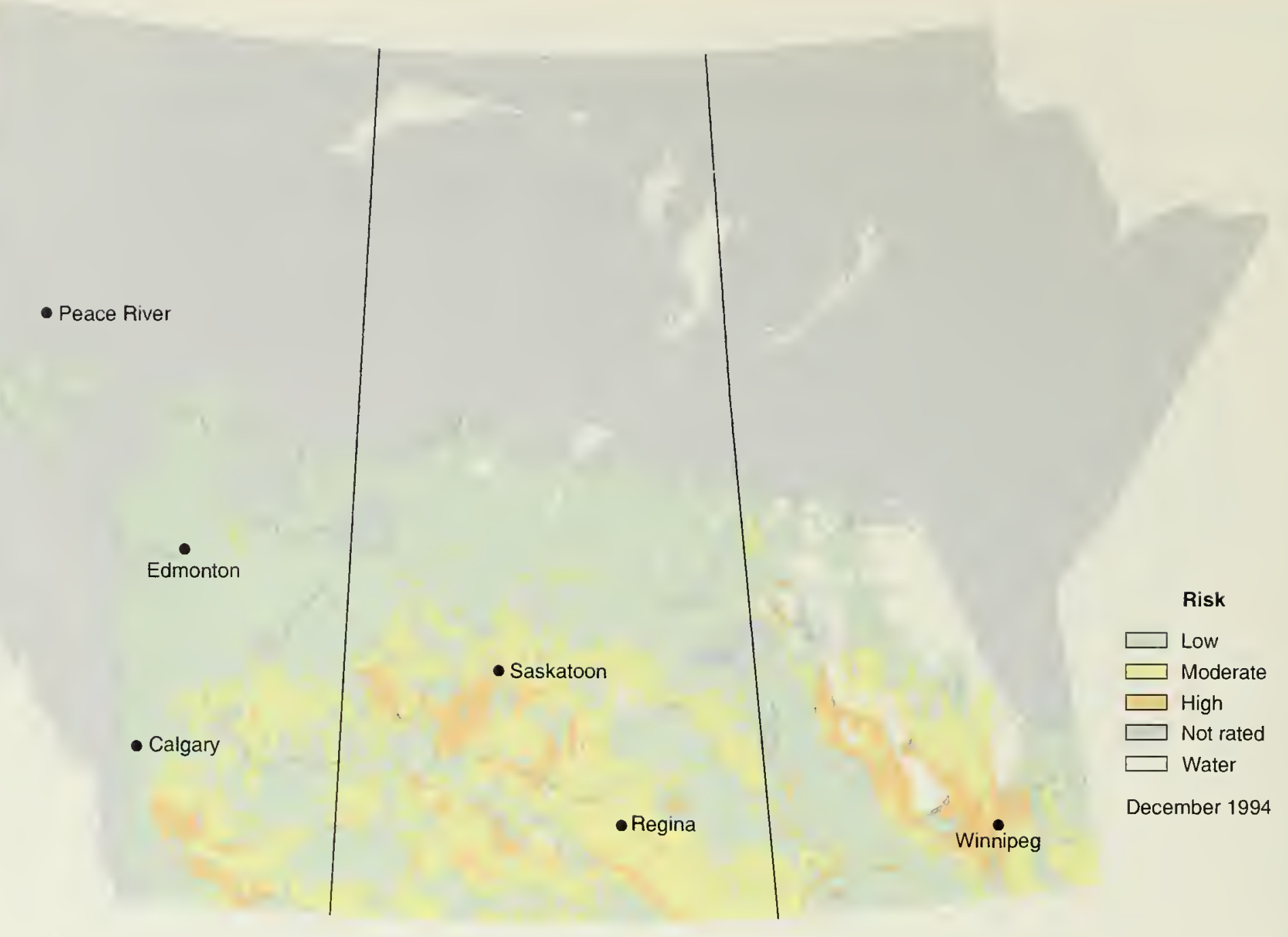

Figure 8-5 Risk of salinization in prairie agricultural soils, 1991.

Table 8-1 Land at risk of increasing salinity (\%), assessed using a salinity risk index (SRI)

\begin{tabular}{lcccc}
\hline Degree of risk & Prairie region & Manitoba & Saskatchewan & Alberta \\
\hline Low & 66 & 61 & 59 & 80 \\
Moderate & 27 & 25 & 34 & 17 \\
High & 7 & 14 & 7 & 3 \\
\hline
\end{tabular}

patterns. This does not mean that salinity has increased on these lands, rather that there is a considerable risk that it could increase under 1991 farming practices.

\section{Changes in salinity risk}

The SRI can be used to make comparisons between years. We compared risk values for Manitoba in 1991 to those in 1981 and mapped the change in risk-class during this 10-year period (Fig. 8-6; similar assessments for Saskatchewan and Alberta are under way). The risk of changing salinity is summarized in Table 8-2. Most of the area $(80 \%)$ showed no significant change in risk in 1991 as a result of land use, possibly because Manitoba has a relatively small share of farmland in summerfallow and because there has been little change in the area under permanent cover. Change in land use has lowered the risk of salinization 
Table 8-2

Changes in salinity risk class of Manitoba's saline lands based on the change in land use between 1981 and 1991

$\begin{array}{ll}\text { Change in } & \text { Share of } \\ \text { salinity risk } & \text { land (\%) }\end{array}$

No change, change by less than 1 class $\quad 80$

Risk decreased by 1 class

Risk increased by 1 class

in $19 \%$ of the lands, most of which are located between Lake Manitoba and Lake Winnipeg. The decrease in salinity risk is probably explained by cultivated land being converted back to permanent cover and by an increase in continuous cropping. Four small areas showed a greater risk of salinity in 1991 than in 1981 because of a change in land use. Changes shown in Table 8-2 do not constitute a trend-they are the results of comparing data from two points in time.

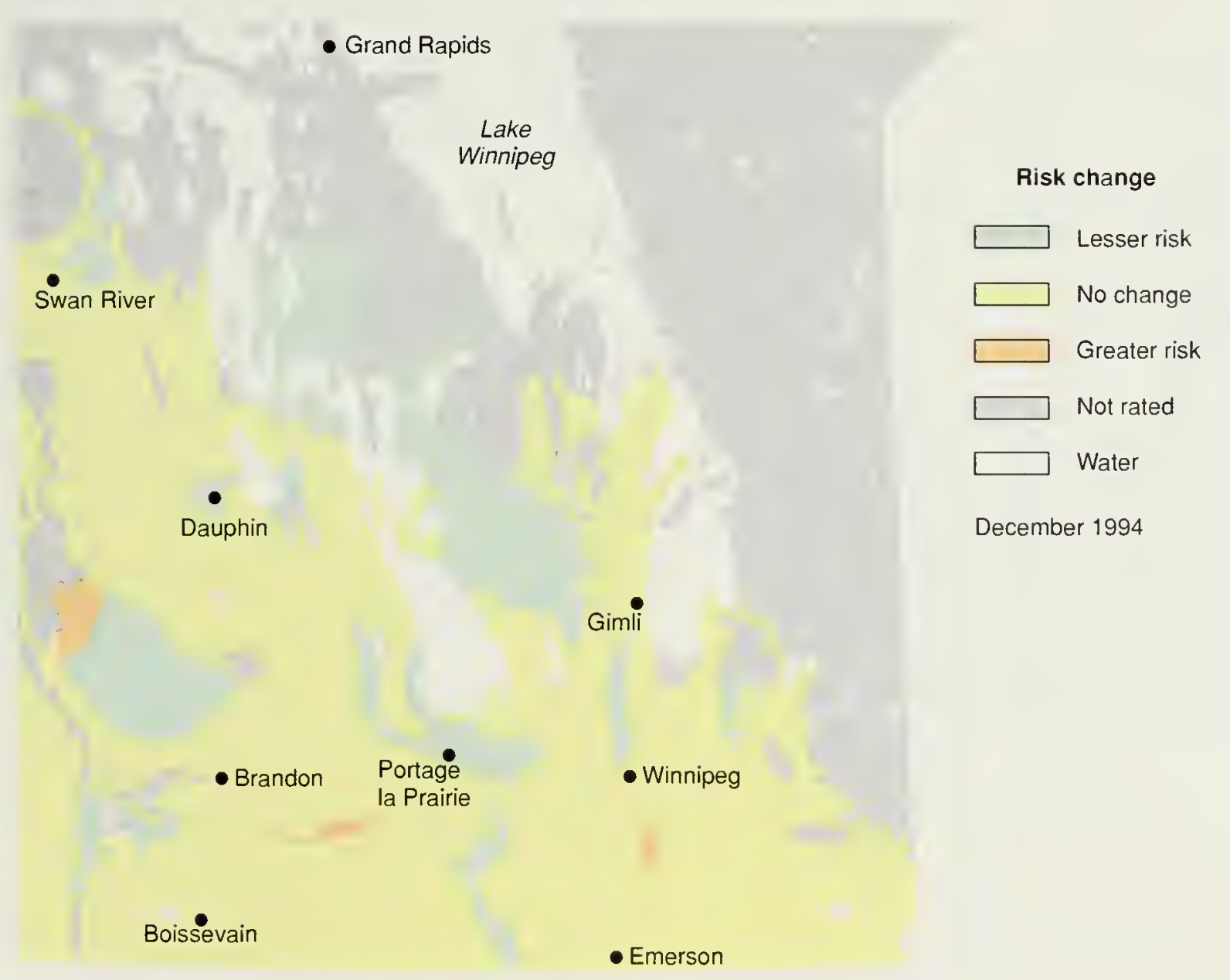

\section{Developing the salinity risk index}

The salinity risk index (SRI) is used to rank individual land areas according to the chance that the salinity level will change within each area. In developing this index, the long-term factors that affect salinity were considered constant, because they change so slowly. Although climate, a short-term factor, varies seasonally and from year to year, in this assessment climatic factors (precipitation and evaporation) were considered constant for the short term by using an average aridity value (precipitation minus evaporation). Land use, combined with farming practices, was therefore the only factor to change over time.

The following factors were used to produce the salinity risk index:

- current extent of salinity (derived from existing salinity maps)

- slope of the land (representing topography)

- soil drainage

- aridity (representing precipitation and evaporation)

- surface cover (representing land use and land management practices).

These factors were assigned relative risk values and then combined to produce an SRI value for each land area. These values were then grouped into relative risk classes and mapped (Fig. 8-5).

(R.G. Eilers, AAFC, Winnipeg, Man.)
Figure 8-6

Change in risk of salinization in Manitoba's agricultural soils between 1981 and 1991. 


\section{Reducing soil moisture}

It is a puzzle of nature that the prairies, a region that often suffers from drought conditions, should also have areas where too much water in the soil gives rise to soil salinity. Growing crops that reduce soil moisture in these areas is one effective method of controlling this condition.

Alfalfa is a perennial forage crop that sends its roots deep down into the soil (more than 5 metres). The accompanying graph shows that alfalfa reduces the amount of water available for plant uptake by twice as much as continuous cropping and by four times as much as a crop-fallow system. Growing alfalfa on saline and adjacent soils can lower the water table enough after about 5 years that an annual crop (such as a cereal) may be reintroduced into the rotation. However, several years of alfalfa must be grown in the rotation to maintain the benefits in these areas.

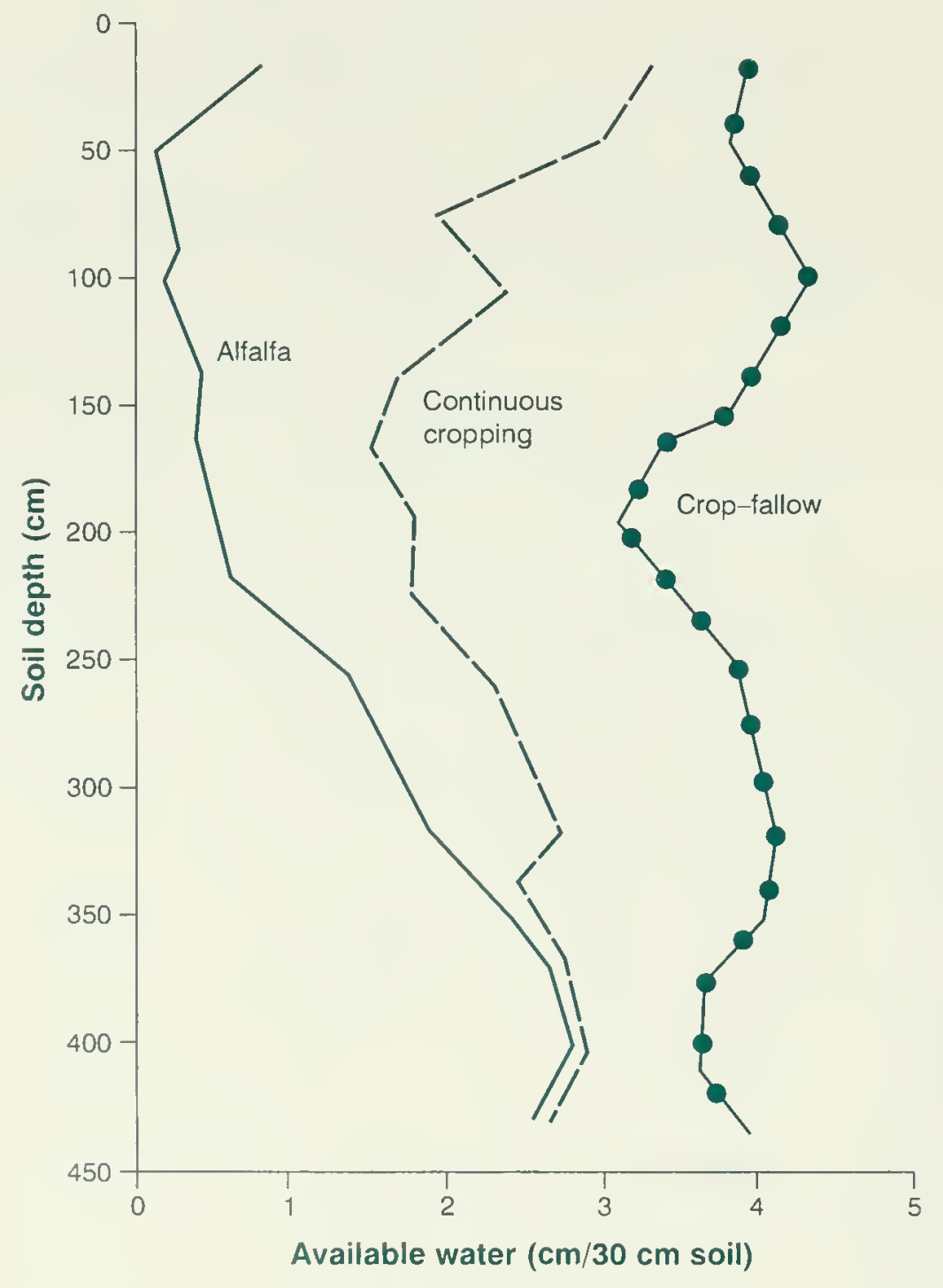

Available soil moisture under various cropping systems (source: Anon. 1991).

\section{Trends in land use}

Summerfallow is commonly considered a major cause of increasing salinization of soils. The share of farmland and cultivated land occupied by summerfallow declined in all three Prairie Provinces from 1971 to 1991 (Fig. 8-7). We can reasonably expect that, over this period, the risk of salinization attributed to summerfallow also declined; further research using the SRI is planned.
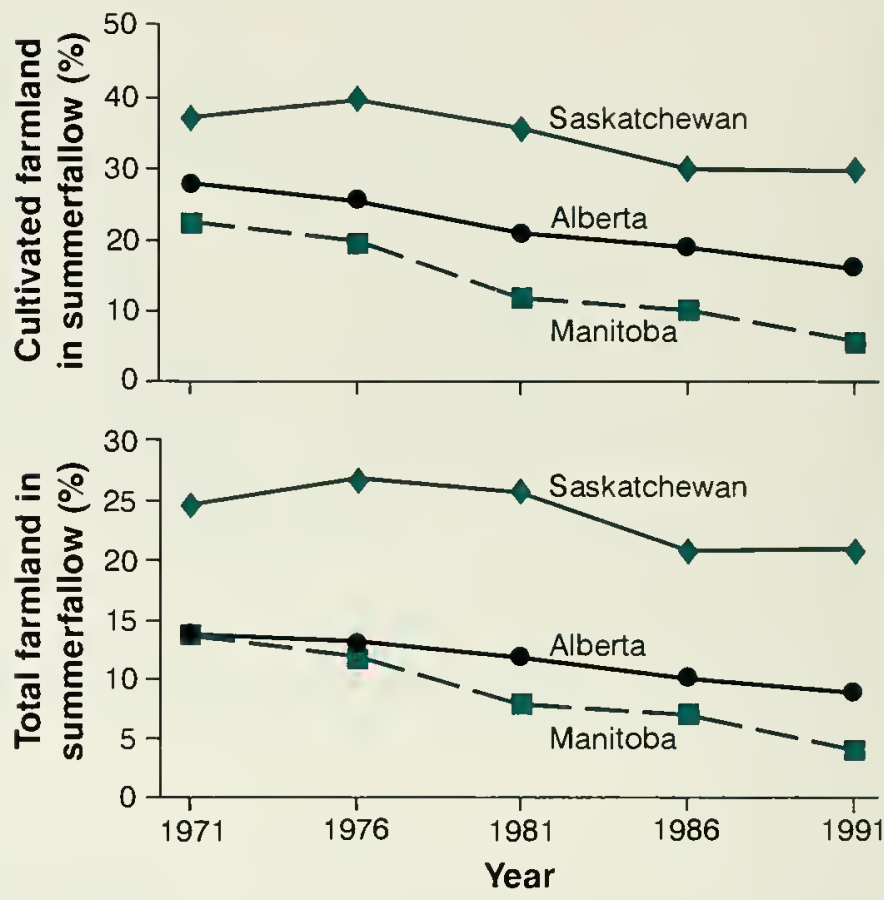

Figure 8-7

Prairie farmland in summerfallow.

\section{Solutions to the salinity problem}

Improving the management and use of salinized land requires an attitude shift on the part of policy makers, planners, and producers. Reducing the severity and extent of soil salinity is primarily a problem of water management. Good water management involves both preventing water received in the recharge areas from percolating into ground water, and maintaining the water table in the discharge area at a low, safe level. 
Saline lands are sensitive and respond differently to various management practices. The choice of farming practices to restore salinized land must be based on the severity and extent of salinity and on the features of the salinized site. In general, control measures should take a biological approach involving cropping and tillage systems. Expensive mechanical controls, such as subsurface drainage systems, should be reserved for severely affected areas.

\section{Recharge management}

Water can be prevented from infiltrating the soil in recharge areas by diverting surface water to downslope ponds. This water is relatively salt-free and can be used for other purposes. Water that enters the soil can be prevented from percolating into the groundwater by being taken up by plants. Perennial plants and forages, especially alfalfa, are useful for this purpose because they have a longer growing season and take up more water over a greater soil depth than annual plants (see box, on previous page). As a result, they prevent the buildup of groundwater, lower the water table, and dry out the subsoil. Forages have the added benefit of increasing soil organic matter and improving soil structure, which reduces the risk of soil erosion.

\section{Discharge management}

The following management practices are useful in controlling salinity levels in the discharge area:

- growing salt-tolerant crops (see box, this page) in areas of moderate or lower risk where the extent or severity of salinity is manageable

- reducing summerfallow by cropping continuously (in areas of low salinity) or converting to permanent soil cover by salt-tolerant crops (in high-risk areas of extensive, severe salinity)

- reducing deep tillage by adopting conservation tillage, including no-till

\section{Salt tolerance of common crops}

Degree of salinity tolerated

$\begin{array}{lll}\begin{array}{ll}\text { Nonsaline to } \\ \text { weakly saline }\end{array} & \text { Moderately } & \text { Strongly to very } \\ \text { strongly saline }\end{array}$

Annual field crops

$\begin{array}{lll}\begin{array}{ll}\text { Soybean } \\ \text { Field bean }\end{array} & \text { Canola } & \text { Barley may produce } \\ \text { Fababean } & \text { Mlax } & \text { some crop but this } \\ \text { Pea } & \text { Wheard } & \text { land is best-suited } \\ \text { Corn } & \text { Fall rye }^{1} & \text { forage crops } \\ & \text { Oat } & \\ & \text { Sunflower } & \\ & \text { Barley }{ }^{1} & \\ & \text { Sugar beet } & \end{array}$

Forage crops

$\begin{array}{lll}\text { Red clover } & \text { Reed canarygrass } & \\ \text { Alsike clover } & \text { Meadow fescue } & \text { Altai wild ryegrass } \\ \text { Timothy } & \text { Intermediate wheatgrass } & \text { Russian wild ryegrass } \\ & \text { Crested wheatgrass } & \text { Slender wheatgrass }{ }^{1} \\ & \text { Bromegrass } & \text { Tall wheatgrass }{ }^{2} \\ & \text { Alfalfa } & \\ & \text { Sweetclover } & \end{array}$

1 Crops that are intolerant of flooding, which is common in some saline areas.

2 Under dry conditions, slender wheatgrass is more tolerant than tall wheatgrass.

(R.G. Eilers, AAFC, Winnipeg, Man.)

(deep tillage may bring salts up to the topsoil from deeper soil horizons)

- planting forage crops or trees next to water bodies to aid in absorbing water from the soil

- returning manure and crop residues to the soil (increased organic matter improves the ability of soil to retain water, preventing it from moving into groundwater)

- managing snow so that it is evenly distributed in the field and does not cause ponding in the spring (see box, next page)

- installing artificial drainage systems in local areas

- eliminating seepage from irrigation canals, dugouts, and ponds. 


\section{Snow-trapping}

Southwestern Saskatchewan is typically very hot and dry. Successful crop production in this environment requires that producers adopt practices that promote efficient and maximum use of all available water supplies, especially as they move away from conventionally tilled fallow-wheat systems to extended crop rotations under reduced tillage management.

One source of water that has the potential for more efficient use is snowfall, which makes up $30 \%$ of the precipitation received in this region. A 10-year study at Agriculture and Agri-Food Canada's research station at Swift Current showed that tall strips of cereal stubble trap more snow than short or standing stubble and ensure its even distribution throughout the field. This practice minimizes surface ponding, which reduces the risk of salinization. Tall stubble trap strips are created at harvest by a deflector or clipper device mounted on the swather or by a direct-cut header.

The benefits of snow trapping were greatest in years with a dry growing season, when yield increases were as much as 6.3 bushels per hectare. After making adjustments for the cost of constructing the trap strips, the average net profit resulting from this method was \$10-33 per hectare, depending on the price of wheat and the rate of fertilizer application. Because of its low cost and economic benefits during most years, this technology is a good option for producers using extended cropping systems in dry areas.

(Con Campbell, AAFC, Szwift Current, Sask.)

\section{Agency programs}

Over the past 10 years, a number of government and nongovernment programs have been introduced to minimize the risk of soil degradation on marginal lands and to better maintain natural habitats. These programs have helped to reduce the spread of salinity by
- raising awareness of the causes of soil salinity

- offering on-farm diagnostic services to determine actual soil salinity levels

- promoting practices that reduce soil disturbance and evaporation from the soil

- encouraging people to convert marginal land to permanent cover or to wildlife habitat.

Examples of these programs include the Permanent Cover Program of the Prairie Farm Rehabilitation Administration, the Canada-Alberta Environmentally Sustainable Agriculture Agreement, and the Prairie Care Program of Ducks Unlimited.

\section{Conclusions}

Soil salinity is a continuing problem in some prairie soils and an important consideration in maintaining and improving their health. Management practices that are effective in controlling the extent and degree of soil salinity relate to water management-reducing the amount of water entering the groundwater under recharge areas and maintaining the water table in discharge areas.

The adoption of appropriate conservation farming methods has resulted in the decreased risk of salinization during the past 10 years. Under current farming practices, most prairie farmland has less than $1 \%$ of its area affected by salinity. Lands more seriously affected by this condition benefit from increased use of conservation farming methods. 


\title{
Contamination of Agricultural Soils
}

\author{
M.D. Webber and S.S. Singh
}

\section{Highlights}

- Pesticide contamination of agricultural soil is not a serious problem in Canada; occasional locally elevated levels of some pesticides are thought to reflect use during the previous growing season or prior to bans of persistent pesticides in the mid 1970s.

- Nonpesticide organic contaminants cause little soil contamination; those detected degrade readily in soils and are not thought to pose a risk to agriculture or the environment.

- Heavy metals are the inorganic soil contaminants of greatest concern; they enter agricultural soils mainly through atmospheric deposition and application of soil amendments (fertilizers, animal manures, and sewage sludge); levels of heavy metals in soils must be controlled, possibly on the basis of the cation exchange capacity of the soil (its ability to retain heavy metal ions).

- Land application of sewage sludge, which contains valuable organic material and plant nutrients, is a beneficial method of sludge management; levels of contaminants, especially heavy metals, in sludge and soil receiving sludge must be regulated.

\section{Introduction}

Some soils contain naturally high levels of potentially toxic substances (selenium, lead, and so on) resulting from weathering of minerals. However, much soil contamination is the result of human activity, including the entry of industrial wastes into soil through atmospheric deposition or application of agrochemicals and sewage waste to the land.

Contaminants have the potential to reduce soil quality for agricultural production. They may be divided into two groups: 1) organic contaminants, which contain carbon, and 2) inorganic contaminants, which do not contain carbon. The organic contaminants of greatest concern are industrial in origin and include agricultural pesticides. The most important inorganic contaminants are heavy metals, which derive mainly from industrial processes although they may occur naturally in soil.

Many potential contaminants are necessary for agricultural production but become hazardous when they occur in excess in the soil. For example, small amounts of copper, molybdenum, and selenium are needed for proper plant and animal growth, but large amounts can be toxic. Similarly, pesticides enhance agricultural production but can pose a risk to human and animal health 
Modern agriculture coasts on the sunlight trapped by floras long extinct; we pump it, process it, transport it over the countryside as chemicals, and inject it into our wasting fields as chemotherapy.

Wes Jackson Altars of Unhewn Stone and environmental quality. Most chlorinated organic pesticides (such as DDT, chlordane, aldrin, and dieldrin) have been banned from use in Canadian agriculture because they persist in the environment and negatively affect foodchains.

In this chapter we present information about the levels of organic and inorganic contaminants in agricultural soils. We also discuss land application of municipal sewage sludge in relation to soil contamination.

\section{Organic contaminants}

Organic contaminants include many industrially derived compounds. Some of these compounds, such as agricultural pesticides, are intentionally applied to soil. Others, such as polynuclear aromatic hydrocarbons, polychlorinated biphenyls, and polychlorinated dibenzo- $p$-dioxins and furans, enter the soil accidentally. Analysis of organic contaminants requires specialized techniques and equipment and is costly.
Prior to our study, information about the levels of organic contaminants in Canada's agricultural soils was limited (data existed for certain pesticides at experimental sites). To provide more information, we analyzed soils (mainly topsoil) from eight national benchmark sites used to monitor soil quality (sites 5, 9, 12, 13, 18, 19, 20, and 21; see Chapter 4, Fig. 4-1) and from six intensively cropped farms in southern Ontario for 122 organic contaminants (grouped in Table 91). This analysis does not provide information about changes in the levels of organic soil contaminants over time, but it does provide baseline data against which to make comparisons in the future.

\section{Pesticides}

Production and use of organochlorine pesticides, except endosulfan (an insecticide that does not persist in soil), has been banned in Canada since the mid 1970s. We did not expect to find large concentrations of these pesticides in soils. Concentrations of about 10 parts per billion $(\mathrm{ppb})$ are thought to represent background

Table 9-1 Concentrations of some organic contaminants in Canadian agricultural soils, expressed on a dry weight basis

\section{Pesticides}

Organochlorines: $<35$ ppb, except total DDT $(<70 \mathrm{ppm})$

Organophosphorous compounds: $<25 \mathrm{ppb}$

Neutral herbicides: $<50 \mathrm{ppb}$, except metolachlor $(<120 \mathrm{ppb})$

Phenoxy acid herbicides: $<60 \mathrm{ppb}$ Carbamate herbicides: $<0.15$ ppm

\section{Nonpesticide compounds}

Total polychlorinated biphenyls: $<0.2 \mathrm{ppm}$

Polynuclear aromatic hydrocarbons: $<0.05 \mathrm{ppm}$, except naphthalene $(<1.2 \mathrm{ppm})$

Haloethers: <0.14 ppm

Chlorinated benzenes: $<0.06$ ppm

Nitrosamines: $<0.06 \mathrm{ppm}$

Phthalate esters: $<1$ ppm, except dibutyl phthalate and bis(2-ethylhexyl) phthalate ( $<3.1 \mathrm{ppm}$ )

Phenols and cresols: $<0.19$ ppm except phenol $(<1$ ppm) and pentachlorophenol (<0.4 ppm)

Heterocyclic nitrogenous and other compounds: $<0.2 \mathrm{ppm}$

$<=$ less than; $\mathrm{ppm}=$ parts per million; $\mathrm{ppb}=$ parts per billion

Source: Webber 1994. 
levels (concentrations in soils with no history of organochlorine pesticide use).

With minor exceptions, concentrations of organochlorine pesticides were less than 10 $\mathrm{ppb}$ in all soils analyzed. Endrin levels marginally exceeded $10 \mathrm{ppb}$ in topsoil from the benchmark sites in Prince Edward Island and New Brunswick and in subsurface soil from the benchmark site in Quebec. Dieldrin marginally exceeded 10 $\mathrm{ppb}$ in the topsoil of four southern Ontario sites. Total endosulfan was found at levels of about $80 \mathrm{ppb}$ in topsoil from two southern Ontario sites and the Prince Edward Island benchmark site. Total DDT exceeded $100 \mathrm{ppb}$ in topsoil from the Prince Edward Island and New Brunswick sites and from three southern Ontario sites. Soil from one Ontario site had total DDT in excess of 70 parts per million (ppm).

The larger concentrations of total endosulfan in three soils probably resulted from use of Thiodan during the growing season in which the samples were taken. Dieldrin concentrations of more than $10 \mathrm{ppb}$ in the intensively cropped soils probably reflect heavy use of this insecticide in past crop production. High total concentrations of DDT probably result from use of this insecticide prior to the mid 1970s. One soil with a total DDT concentration of more than 70 ppm has supported an apple orchard since the 1930s; this level is not unusual for topsoil under this land use (see box).

Fonofos was the only organophosphorous pesticide observed, and concentrations were similar in all study soils. We measured concentrations of up to $100 \mathrm{ppb}$, which are consistent with its use in fieldcrop production, particularly to control corn rootworm species.

We detected no neutral, phenoxy acid, or carbamate herbicides in most of the soils analyzed. Persistence of these herbicides in soil is not a significant agricultural or environmental concern. Metolachlor, used to control grasses in row crops, was detected in two southern Ontario topsoils at $118 \mathrm{ppb}$. Trifluralin, used to control annual grasses and broadleaf weeds in

\section{Orchard soils}

Throughout this century, a great variety of substances containing metals, organochlorine compounds, and organophosphorus compounds have been used to control agricultural pests, including those that affect tree-fruit production. A survey of Ontario orchards in the early 1970s found elevated levels of many contaminants in their soils.

Contaminant levels in orchard soils compared to field-cropped soil

\begin{tabular}{lccc} 
Land use & Lead & Arsenic & Total DDT \\
\hline Apple orchard & 247 & 40 & 43 \\
Sweet cherry orchard & 109 & 30 & 2 \\
Sour cherry orchard & 71 & 23 & 2 \\
Field crop & 14 & 6 & -
\end{tabular}

Concentrations of persistent organochlorine pesticides other than DDT were less than one part per million (1 ppm). Only trace amounts of two organophosphorus compounds (ethion and parathion) were observed.

(M.D. Webber, Wastewater Technology Centre, Burlington, Ont.)

beans, canola, and other crops, was measured in soils from the Alberta and Manitoba benchmark sites at 145 and 167 $\mathrm{ppb}$. Triallate, used to control wild oat in a variety of crops, was measured in the Alberta soil at $48 \mathrm{ppb}$. Phenoxy acid herbicides were measured at concentrations that were usually below $25 \mathrm{ppb}$ but sometimes reached $60 \mathrm{ppb}$.

\section{Nonpesticide compounds}

We found little contamination of agricultural soils by nonpesticide compounds (Table 9-1) in either benchmark or southern Ontario soils. It is unlikely that the nonpesticide compounds observed are significant agricultural or environmental concerns. Except for polychlorinated biphenyls, the compounds (naphthalene, phthalate esters, phenol, and pentachlorophenol) that exceeded the method detection 
The chemicals to which life is asked to make its adjustment are... the synthetic creations of man's inventive mind,

brewed in his

laboratories, and having no counterparts in nature.

Rachel Carson Silent Spring limits (MDL; the smallest concentration of a substance that can be measured accurately by a certain analytical method) are known to degrade rapidly in soils.

Total polychlorinated biphenyls exceeded the MDL of $100 \mathrm{ppb}$ in six soils but did not exceed $250 \mathrm{ppb}$. Napthalene, a polynuclear aromatic hydrocarbon, exceeded the MDL of $50 \mathrm{ppb}$ in 13 soils, and a concentration of $1.2 \mathrm{ppm}$ was found in one soil. Phthalate ester concentrations frequently exceeded the MDLs but only three values for dibutyl phthalate and two values for bis(2-ethylhexyl) phthalate exceeded 1 ppm (the greatest concentration was $3.1 \mathrm{ppm}$ of dibutyl phthalate). Phthalate esters, which make plastics flexible, are commonly present in the environment, and it is possible that these compounds observed resulted from contamination of the soil samples during collection, preparation, and analysis. Phenol concentrations in 21 soils exceeded the $20 \mathrm{ppb}$ MDL and in five soils exceeded $150 \mathrm{ppb}$, but none exceeded 1 ppm. Pentachlorophenol was reported in eight soils but did not exceed $360 \mathrm{ppb}$. Phenol is a breakdown product of many materials, including pesticides and organic matter, and pentachlorophenol is a widely used wood preservative. Phthalate ester, naphthalene, phenol, and pentachlorophenol concentrations in the soils appeared to be unrelated to position in the soil profile (topsoil or subsurface) or to sampling position on slopes (upper, middle, or lower).

\section{Inorganic contaminants}

In general, inorganic contaminants enter soil as a result of human activities. The heavy metals arsenic, cadmium, chromium, cobalt, copper, lead, mercury, molybdenum, nickel, selenium, and zinc are the most hazardous of these substances. Although many of these heavy metals are needed in small quantities by plants and animals (Table 9-2), they may enter soils in great enough quantities to pose risks to the health of plants, animals, and humans. Heavy metals are persistent, and their negative effects in soil are longlasting. For this reason, their levels in soils must be controlled.

Table 9-2 Heavy metals in plant and animal functions

\begin{tabular}{|c|c|c|c|c|}
\hline \multirow[t]{2}{*}{ Element } & \multicolumn{2}{|c|}{ Essential or beneficial to } & \multicolumn{2}{|c|}{ Potential toxicity to } \\
\hline & Plants & Animals & Plants & Animals \\
\hline Arsenic (As) & No & Yes & Yes & Yes \\
\hline Cadmium (Cd) & No & No & Yes & Yes \\
\hline Chromium (Cr) & No & Yes & Yes & DU \\
\hline Cobalt (Co) & Yes & Yes & Yes & Yes \\
\hline Copper $(\mathrm{Cu})$ & Yes & Yes & Yes & Yes $^{b}$ \\
\hline Lead $(\mathrm{Pb})$ & No & No & Yes & Yes \\
\hline Mercury (Hg) & No & No & DUa & Yes \\
\hline Molybdenum (Mo) & Yes & Yes & DU & Yes $^{\mathrm{b}}(5-20 \mathrm{ppm})$ \\
\hline Nickel (Ni) & No & Yes & Yes & Yes \\
\hline Selenium (Se) & Yes & Yes & Yes & Yes (4 ppm) \\
\hline Zinc (Zn) & Yes & Yes & DU & DU \\
\hline
\end{tabular}

a $D U=$ Critical data on limits unavailable

b Toxic to ruminants (sheep, cattle).

After Adriano 1986. 


\section{Background levels}

To assess the quantities of heavy metals that enter soil as a result of human activity, we need to know background levels of these substances in soil. In the natural soil environment, the main source of metals is the parent material from which soils are derived. Occasionally, heavy metals become locally concentrated by natural processes. For example, high levels of boron, cadmium, and selenium may occur naturally in discharge and saline seep areas in the prairies. The range of metal concentrations in Canadian topsoils is considerable (Fig. 9-1).

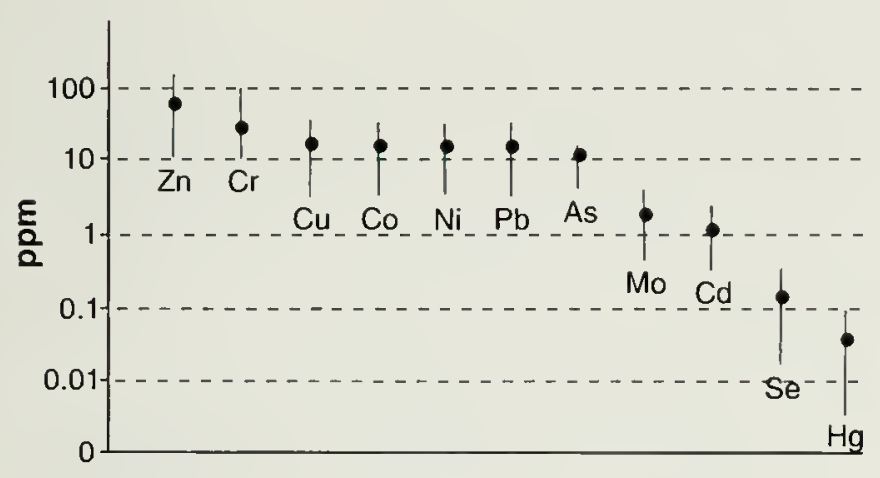

Figure 9-1

\section{Concentrations (average and range) of heavy metals in Canadian topsoil.}

(Sources: For As and Mo: means from Ont. Min. of Environment and Energy 1994, ranges from KabataPendias and Pendias 1992. For Cd: Giroux et al. 1992. For remaining metals: McKeague and Wolynetz 1980.)

\section{Human sources of heavy metals}

Heavy metals enter soil as a result of mining, metallurgy, use of fossil fuels, and application of soil amendments. Heavy metal concentrations for various soil amendments are shown in Table 9-3. Higher concentrations of heavy metals in phosphate fertilizers are related to their aquatic biological origin; high levels in animal manures may be related to feed additives; high levels in sewage sludge reflect the composition of domestic and industrial discharge. There is concern that heavy metals may be absorbed by crops and subsequently enter the human food chain.

\section{Cadmium in soil}

Cadmium is the heavy metal of greatest concern in agricultural soils. It is not required for the growth and development of either plants or animals and can be toxic to both. In animals, it accumulates in the liver and kidneys and can cause kidney damage.

Cadmium is loosely held by soil constituents and is readily available to plants. Thus, increased concentrations in soil result in increased concentrations in crops. Cadmium accumulation in plant materials varies with crop type and plant part. In general, broadleaf plants accumulate more cadmium than grasses, and plant leaves and stems accu-mulate more than seeds. Broad-leaved vegetables, such as lettuce and Swiss chard, accumulate more cadmium than most other plants.

Current concentrations of cadmium in human and animal diets are considered near the maximum acceptable levels. Consequently, Canadian guidelines and regulations have been introduced to allow only minor increases in soil cadmium. These guidelines allow waste recycling to land (such as sewage-sludge application), while maintaining the quality of food products needed for domestic and international markets.

\section{Limiting heavy metals in soils}

Recent studies in Quebec have shown that concentrations of heavy metals in soils vary with soil texture. They are greatest in clay, followed by clay loam, loam, and sand. For example, average concentrations of zinc and copper in soils of these textures are shown in Figure 9-2.

Heavy metal concentrations in soils are also related to soil order. Gleysols and Luvisols have the highest concentrations, followed by Brunisols and Podzols. Average concentrations of zinc and copper in these soil orders are shown in Figure 9-3. 
Table 9-3 Heavy metal concentrations in soil amendments, expressed in ppm on a dry weight basis

\begin{tabular}{lcrrrrrr}
\hline Soil amendment & $\mathrm{Cd}$ & $\mathrm{Co}$ & $\mathrm{Cr}$ & $\mathrm{Cu}$ & $\mathrm{Ni}$ & $\mathrm{Pb}$ & $\mathrm{Zn}$ \\
\hline Triple superphosphate (0-46-0) & 9 & 5 & 92 & 3 & 36 & 3 & 108 \\
Urea (46-0-0) & $<0.1$ & $<1$ & $<3$ & $<0.4$ & $<1$ & $<3$ & $<1$ \\
Potassium chloride (0-0-60) & $<0.1$ & 2 & $<3$ & $<0.6$ & 4 & 3 & $<1$ \\
Agricultural lime & $<0.1$ & $<1$ & $<3$ & $<0.2$ & 5 & $<3$ & $<2$ \\
Cow manure & 1 & 6 & 56 & 62 & 29 & 16 & 71 \\
Sewage sludge & 5 & 5 & 350 & 660 & 35 & 90 & 800
\end{tabular}

$<=$ less than.

After Freedman and Hutchinson 1981, except ${ }^{\text {a }}$ Webber and Nichols 1995.

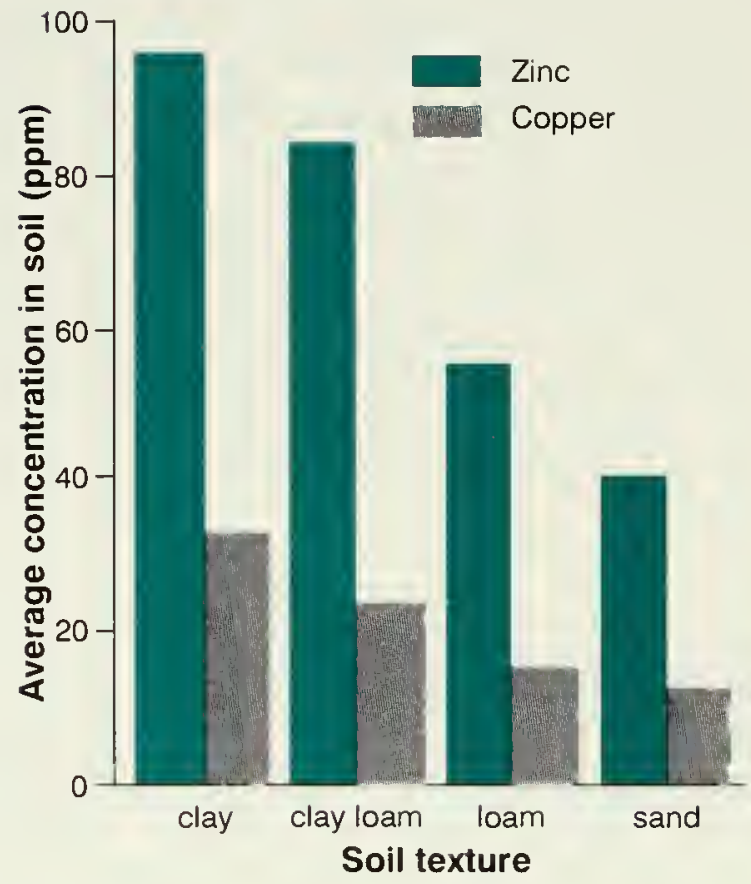

Figure 9-2

Concentrations (ppm) of zinc and copper in Quebec soils of various textures.

(After Giroux et al. 1992.)
However, this observation may also be related to soil texture because Gleysols and Luvisols generally have the highest clay content, followed by Brunisols and Podzols.

Quebec researchers suggest that the maximum heavy metal concentration in soils be based on the cation exchange capacity of the soil, which is a measure of the soil's ability to retain heavy metal ions. The cation exchange capacity increases with increasing clay content of the soil. Thus, they recommend higher maximum heavy metal concentrations for finetextured soils, such as clay and clay loam, than for coarse-textured soils, such as sand (Table 9-4).

Table 9-4 Recommended maximum concentrations (ppm) of heavy metals in soils based on their cation exchange capacities (CEC)

\begin{tabular}{lcccccccc} 
CEC $^{a}$ & $\mathrm{Cu}$ & $\mathrm{Co}$ & $\mathrm{Hg}$ & $\mathrm{Cd}$ & $\mathrm{Cr}$ & $\mathrm{Zn}$ & $\mathrm{Pb}$ & $\mathrm{Ni}$ \\
\hline $\mathrm{CEC}>15$ & 50 & 34 & 0.14 & 2.4 & 120 & 160 & 70 & 60 \\
$\mathrm{CEC}<15$ & 25 & 17 & 0.07 & 1.2 & 60 & 80 & 35 & 30
\end{tabular}




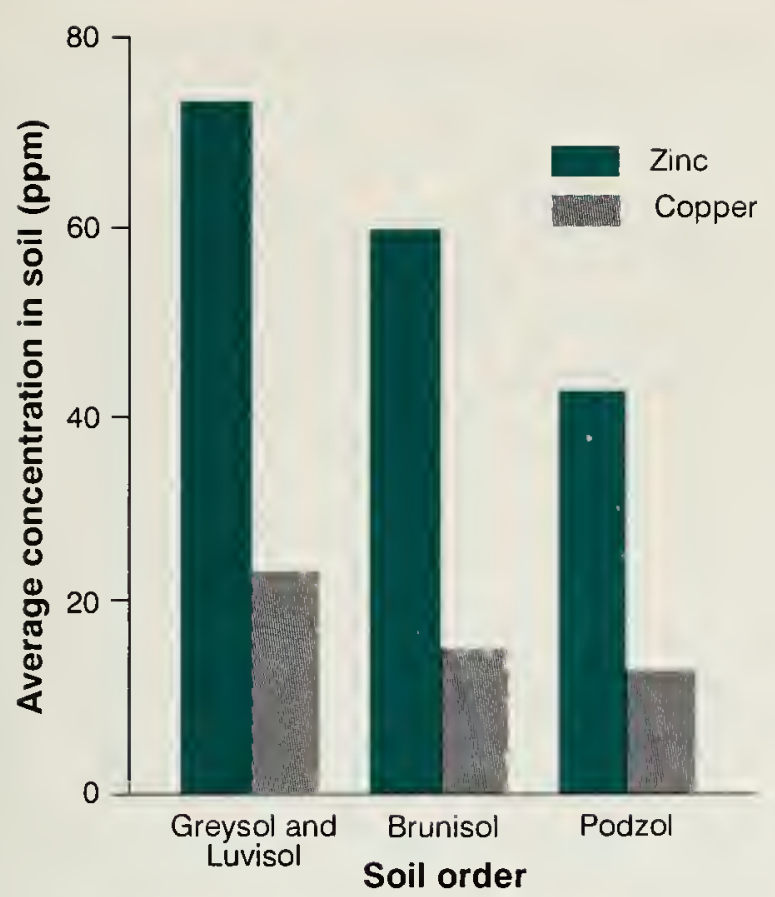

Figure 9-3

Concentrations of zinc and copper in three types of soil in Quebec.

(After Giroux et al. 1992.)

\section{Land application of sewage sludge}

Sludge is the solid waste resulting from the treatment of domestic and industrial effluents (liquid wastes) that are released into sewers. It may contain metals and organic contaminants at widely varying concentrations, depending on the nature and amount of industry and the enforcement of guidelines for effluent quality. Municipal sludge is applied widely to agricultural land in Canada. This process uses about one-third (120 000 tonnes, dry weight annually) of all the sludge produced in Canada and about one-fifth (60000 tonnes, dry weight annually) of that produced in Ontario. This method of sludge disposal is often the most environmentally acceptable and economic. It is also desirable because it recycles organic matter and valuable nutrients, particularly nitrogen and phosphorus, back to the soil. However, there is concern that heavy metals and other contaminants in sludge will accumulate in the soil, reducing its quality for agriculture.

\section{Sludge application in Ontario}

The Regional Municipality of Halton is located west of Toronto, Ont. Seven wastewater treatment plants serve a population of 250000 and annually produce 200000 cubic metres of municipal sludge.

Although there is considerable industry in Burlington, Oakville, and Milton, three cities in the region, careful adherence to sewer-use bylaws has ensured that all sludge meets the Guidelines for Sewage Sludge Utilization on Agricultural Lands in Ontario. Thus, the sludge can be applied as a soil amendment to agricultural land in this region.

Liquid sludge (containing about $2.5 \%$ solids) is supplied free of charge to the farming community. It is moved by tank truck to application sites, where it is transferred to an application vehicle and injected into the soil at a depth of about 10 centimetres. Sludge injection avoids unsightliness, smell, runoff, and nitrogen loss by volatilization of ammonia; it has received widespread approval of producers and the general public. Rates of application are based on crop nitrogen requirements, and crop yields with sludge application are equal to or greater than those with commericial fertilizer. No detrimental increases in metal contents of sludge-treated soils and crops have been observed, but continued vigilance is required to ensure that heavy metals do not accumulate to unsafe levels.

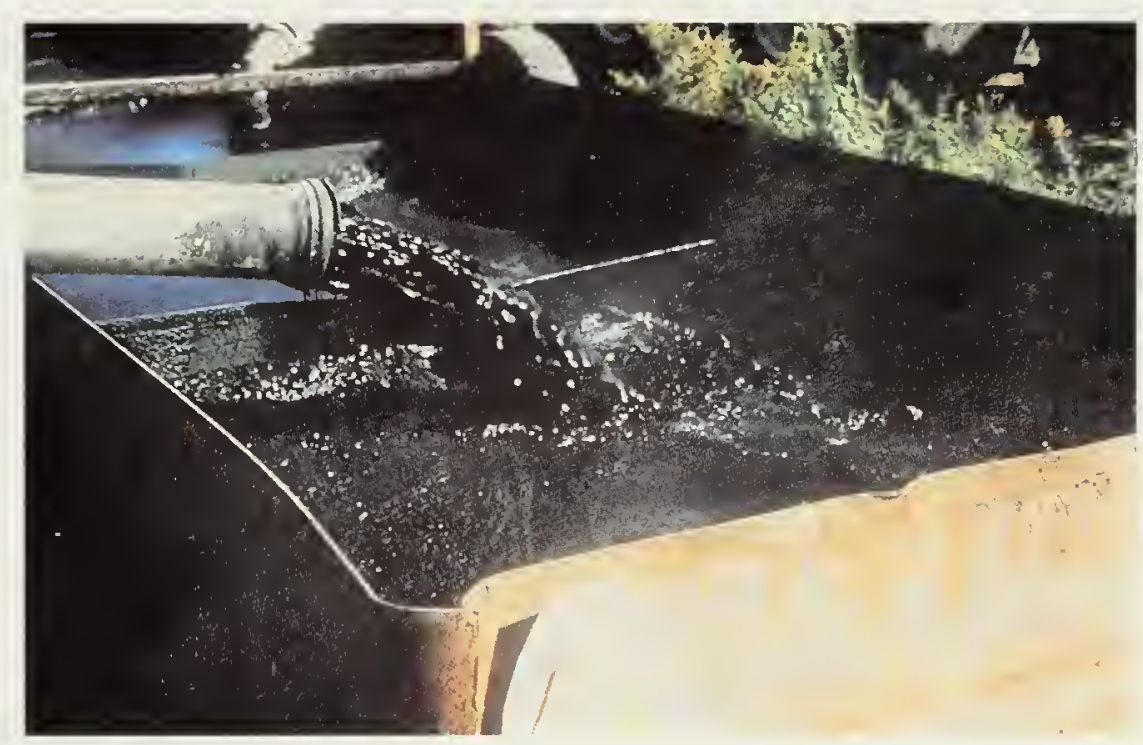

Stabilized sludge ready for land application.

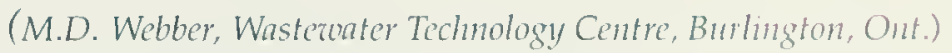


Table 9-5 Heavy metal concentrations in Canadian sludges and soils, expressed in ppm on a dry weight basis

\begin{tabular}{|c|c|c|c|c|}
\hline Metal & $\begin{array}{l}\text { Typical } \\
\text { sludge:soil } \\
\text { metal ratios }\end{array}$ & $\begin{array}{l}\text { Average metal } \\
\text { concentrations in } \\
\text { uncontaminated } \\
\text { soils }^{b}\end{array}$ & $\begin{array}{l}\text { Average metal } \\
\text { concentrations in } \\
10 \text { heavily sludged } \\
\text { Ontario soilsc }\end{array}$ & $\begin{array}{l}\text { Maximum } \\
\text { permissible metal } \\
\text { concentration in } \\
\text { sludged soils }^{b}\end{array}$ \\
\hline As & 0.3 & 7 & na & 14 \\
\hline $\mathrm{Cd}$ & 7 & 0.8 & 1.1 & 1.6 \\
\hline $\mathrm{Cr}$ & 23 & 15 & na & 120 \\
\hline Co & 0.9 & 5 & na & 20 \\
\hline $\mathrm{Cu}$ & 27 & 25 & 41 & 100 \\
\hline $\mathrm{Pb}$ & 6 & 15 & 38 & 60 \\
\hline $\mathrm{Hg}$ & 33 & 0.1 & na & 0.5 \\
\hline Mo & 7 & 2 & 19 (1 sample only) & 4 \\
\hline $\mathrm{Ni}$ & 2 & 16 & 27 & 32 \\
\hline Se & 7 & 0.4 & na & 1.6 \\
\hline $\mathrm{Zn}$ & 15 & 55 & 190 & 220 \\
\hline
\end{tabular}

na = not available.

Sources: a Average concentration in sludges (Webber and Nichols 1995) divided by average concentration in soils (column 3).

b Ontario Ministry of Agriculture and Food and Ontario Ministry of Environment 1992.

c Webber et al. 1983.

\section{Metal contaminants}

Applying sludge to land increases metal concentrations in soil (Table 9-5). Considerable information exists concerning the fate and effects of metals in soil, and criteria have been developed to protect soil quality. For example, in Ontario, metal limits have been defined for sludge and soil, and maximum permissible sludge loadings (the maximum amount of sludge that can be applied safely to soil) are regulated depending upon the metal concentrations in both materials.

\section{Organic contaminants}

Organic contaminants are difficult and expensive to measure in municipal sludges, so less information is available for them than for metal contaminants. However, a recent analysis of Canadian municipal sludges showed that organic contaminants are found in low concentrations (Table 9-6)
Under current restrictions of sludge application (in Ontario, about 40 tonnes of dry sludge may be applied per hectare over 15 years), it is unlikely that applying sludge will result in significant buildup of organic contaminants in agricultural soils. The limited information on levels of organic contaminants in sludge-treated soils (Table 9-7) supports this expectation.

Guidelines for organic contaminant levels in sludge have not been developed in Canada, with one exception. Quebec defines a maximum permissible total polychlorinated biphenyl concentration in sludge of $10 \mathrm{ppm}$ for use on agricultural land; sludges with more than $3 \mathrm{ppm}$ polychlorinated biphenyls must be injected into the soil to avoid direct ingestion by animals. In Ontario, guidelines have been proposed to clean up ind ustrially contaminated soil for agricultural and other uses. Using these guidelines along with information about organic contaminant levels in Canadian sludges, the maximum amount of 
Table 9-6 Average concentrations of organic contaminants in Canadian municipal sludges, expressed on a dry weight basis

- Volatile organic contaminants: many ND; most others $\leq 2 \mathrm{ppm}$; a few petroleum derivatives $>2$ but $<10$ ppm; toluene in three sludges $<45$ ppm

- Polynuclear aromatic hydrocarbons: most $<1$ ppm; a few $<5$ ppm; elevated but $<20$ ppm in one sludge with large contribution from steel mill

- Haloethers: ND

- Chlorinated benzenes: ND except 1,2-diclorobenzene $<0.5$ ppm and 1,4-diclorobenzene $<3$ ppm

- Nitrosamines: ND

- Phthalate esters: $<15$ ppm except bis(2-ethylhexyl) phthalate $<250$ ppm

- Phenols and cresols: many ND; others $<1$ ppm except phenol $<10$ ppm

- Heterocyclic nitrogenous and other compounds: many ND; nitrobenzene $<5$ ppm

- Organochlorine pesticides: ND except $<0.1$ ppm gamma BHC, hexachlorobenzene, methoxychlor and DDT in a few sludges

- Total polychlorinated biphenyls: $<250 \mathrm{ppb}$

- Polychlorinated dibenzo- $p$-dioxins and furans: $\leq 36 \mathrm{ppb}$ total dioxins and furans; $\leq 120 \mathrm{ppt}$ total TEQ

$\mathrm{ND}=$ not detected; $\leq=$ less than or equal to; $\mathrm{ppt}=$ parts per trillion.

TEQ, toxic equivalents as 2,3,7,8-tetrachlorodibenzo-p-dioxin using International Toxic Equivalency Factors.

Source: Webber and Nichols 1995.

sludge that may be applied to agricultural land can be calculated. The main concern when developing guidelines for sludge loading is the potential for contaminants in the sludge to build up in soil and enter the food chain.

The following contaminants are of particular interest:

- Benzo- $a$-pyrene, a polynuclear aromatic hydrocarbon, is carcinogenic (causes cancer) and resists degradation; the maximum permissible loading to agricultural soil must be low (in Ontario, about 2 kilograms per hectare).

- Fluorene, a polynuclear aromatic hydrocarbon, is not carcinogenic and is much less resistant to decomposition than benzo- $a$-pyrene; its maximum permissible loading may be much larger than for benzo-a-pyrene.

- 2-Methyl naphthalene, a polynuclear aromatic hydrocarbon, is neither carcinogenic nor resistant to degradation but imparts a foul odour to water; it may not be added to soil overlying groundwater for human use.

- Dioxins and furans are highly toxic, carcinogenic, and very resistant to degradation; they are much more limiting for sludge use in agriculture than benzo-a-pyrene.

- Polychlorinated biphenyls are very resistant to degradation and are thought to be carcinogenic; they occur in smaller concentrations in sludge and are less limiting for land application than benzoa-pyrene.

- Bis(2-ethylhexyl) phthalate and toluene; concentrations in sludge may be large, but because these compounds degrade rapidly in soil, they are less limiting for land application than benzo- $a$-pyrene.

- Endosulfan, an organochlorine pesticide, is used widely in crop production; small amounts in sludge are unlikely to limit land application. 
Table 9-7 Some organic contaminant concentrations in sludge-treated Ontario soils expressed on a dry weight basis

\begin{tabular}{|c|c|c|c|}
\hline Soils & $\begin{array}{l}\text { Polynuclear } \\
\text { aromatic } \\
\text { hydrocarbons }\end{array}$ & $\begin{array}{l}\text { Organochlorine } \\
\text { pesticides }\end{array}$ & $\begin{array}{l}\text { Total } \\
\text { polychlorinated } \\
\text { biphenyls }\end{array}$ \\
\hline
\end{tabular}

$\begin{aligned} & \text { Agricultural soils } \\ & \text { receiving up to about } \\ & 25 \text { tonnes sludge } \\ & \text { (dry weight) per hectare }\end{aligned} \quad<50 \mathrm{ppb}^{\mathrm{a}}$
$\begin{aligned} & \text { Sludge disposal site } \\ & \text { receiving large } \\ & \text { quantity of sludge }\end{aligned} \quad<500 \mathrm{ppb}$

\section{Suitability for agriculture}

Sewage sludge contains organic matter and plant nutrients that are beneficial to soil health and crop production. Applying sewage sludge to agricultural land fits well with the current concepts of resource recycling and sustainable agriculture. However, sewage sludge contains contaminants that may decrease the quality of agricultural soils. Even though the quality of sewage sludge has improved in recent years (because of better measures for pollution control), careful control of contaminant levels in soils receiving sludge is needed.

Canadian guidelines for sewage sludge regulate the amount of heavy metals added to agricultural soils. Work is currently under way to assess the need to regulate the amount of organic contaminants that can safely be added to soil.

\section{Conclusions}

Contamination of Canadian agricultural soils with pesticide and nonpesticide contaminants is not a serious problem. Currently used pesticides are not persistent in soil, and insignificant amounts are observed. But contamination of soil by heavy metals is a concern because metals are persistent and may affect plant, animal, and human health.

Application to agricultural soils is a beneficial method of managing sewage sludge, but adding contaminants to soil in this, and other, waste materials must be controlled. Currently, heavy metals are regulated and organic contaminant regulation is under review. 


\title{
Agrochemical Entry into Groundwater
}

\author{
W.D. Reynolds, C.A. Campbell, C. Chang, C.M. Cho, J.H. Ewanek, \\ R.G. Kachanoski, J.A. MacLeod, P.H. Milburn, R.R. Simard, G.R.B. Webster, \\ and B.J. Zebarth
}

\section{Highlights}

- Low-level nonpoint-source entry of agrochemicals into groundwater poses a significant risk because of its extent and the difficulty in controlling it.

- Aquifers in south coastal British Columbia underlie areas of high rainfall and intensive agriculture and often contain nitrate levels above the safe limit.

- The Prairie Provinces are at low risk of agrochemical contamination; point-source contamination of domestic wells occasionally occurs, as does groundwater contamination in areas receiving large amounts of manure or irrigation water.

- Nitrate from fertilizer and bacteria from manure are the main contaminants of groundwater in central Canada. Pesticides, including atrazine (persisting from use in intensive corn-cropping in the past), are often present in groundwater, almost always at levels well below safe limits.

- In the Maritime Provinces, groundwater contamination occurs mainly in areas where potatoes and corn are produced intensively. Leaching of nitrate can be a serious problem, although levels seem to be steady. Pesticides, when detected, are almost always at levels well below the safe limits.

- Entry of agrochemicals into groundwater can be reduced by improved farming methods; these include using catch crops and crop rotations and applying nutrients, pesticides, and irrigation water more efficiently.

\section{Introduction}

Groundwater is subsurface water that occurs below the water table in geological materials such as soils, sand and gravel deposits, and bedrock formations. Geological materials that are extensive and permeable enough to yield a steady supply of groundwater to one or more wells are called aquifers. Groundwater pumped from aquifers supplies drinking water to more than six million Canadians ( $26 \%$ of the population). It also contributes substantially to rivers and streams in many parts of Canada. Consequently, groundwater is an important resource that must be protected from the entry of harmful substances including potentially harmful agrochemicals.
And our water, the universal solvent, present in the air, in the soil, in plants, animals and man. Without it life could not endure.

J.A. Toogood Our Soil and Water 


\section{Pesticide use in Canada}

Pesticides are chemicals that kill or control unwanted plants or animals (pests), which, if left unchecked, reduce crop yield or crop quality, or both. Although biocides (natural pesticides) exist, the agriculture industry currently uses synthetic pesticides almost exclusively to protect crops. Common pesticides include

- herbicides (control plants, mainly weeds)

- insecticides (control insects)

- fungicides (control fungi and molds)

- nematocides (control nematodes)

- rodenticides (control rodents)

- miticides (control mites).

Canada's primary food industry generates $\$ 20$ billion in revenues annually. This income would be drastically reduced if pesticides were not used regularly and extensively in Canada's main agricultural regions. Until alternative pest-control programs are effective, the $\$ 190$ million spent annually in Canada on pesticides (mostly herbicides and insecticides) is an economic necessity.

(W.D. Reynolds, AAFC, Ottawa, Ont.)

The main agrochemicals are fertilizers and pesticides. Crop yields would be unacceptably low in many parts of Canada if fertilizers and pesticides were not used regularly. However, pesticides, some components of fertilizer, such as nitrate, and the bacteria in manure are harmful to humans and animals if present at high enough levels in drinking water.

Another important agrochemical is naturally occurring nitrate, produced in the soil by the breakdown of organic matter (decomposed plant and animal residues). Although this nitrate is known to enter groundwater in some situations, our focus is mainly on agrochemicals that are applied to the land. We do not deal with contamination of either surface water or groundwater resulting from salinization, sewage effluent, and the use of sewage water for irrigation.

\section{Agrochemical occurrence in drinking water}

Because agriculture is often carried out on large areas of land situated above important aquifers, there is a risk that agrochemicals will enter drinking water. For example, agrochemicals can seep into individual wells because of accidental spills, poor well construction, or improper practices in storing and handling pesticides. This type of high-level point-source entry (Fig. 10-1) is localized and fairly easy to control by education and regulation.

Another way in which agrochemicals enter groundwater is by low-level nonpoint-source entry (Fig. 10-1). This type of entry occurs over large areas, such as agricultural regions and watersheds. It is mainly caused by the slow downward movement of agrochemicals through the soil profile and into the groundwater.

Low-level nonpoint-source leaching of agrochemicals does not always occur in agricultural areas and, when it does occur, often produces levels of agrochemicals in groundwater that are below the current Canadian safe limits for drinking water. However, this type of agrochemical entry into groundwater is usually of greater concern than high-level point-source entry because

- it can be widespread

- it is more difficult to control, because neither the sources nor the leaching behaviour of the agrochemicals are well understood

- it can occur even where agricultural practices are designed to minimize soil and water degradation

- there is evidence that it may be increasing in some areas of intensive agriculture

- the public may have concerns about long-term exposure to even low levels of agrochemicals. 
Low-level nonpoint-source entry into aquifers

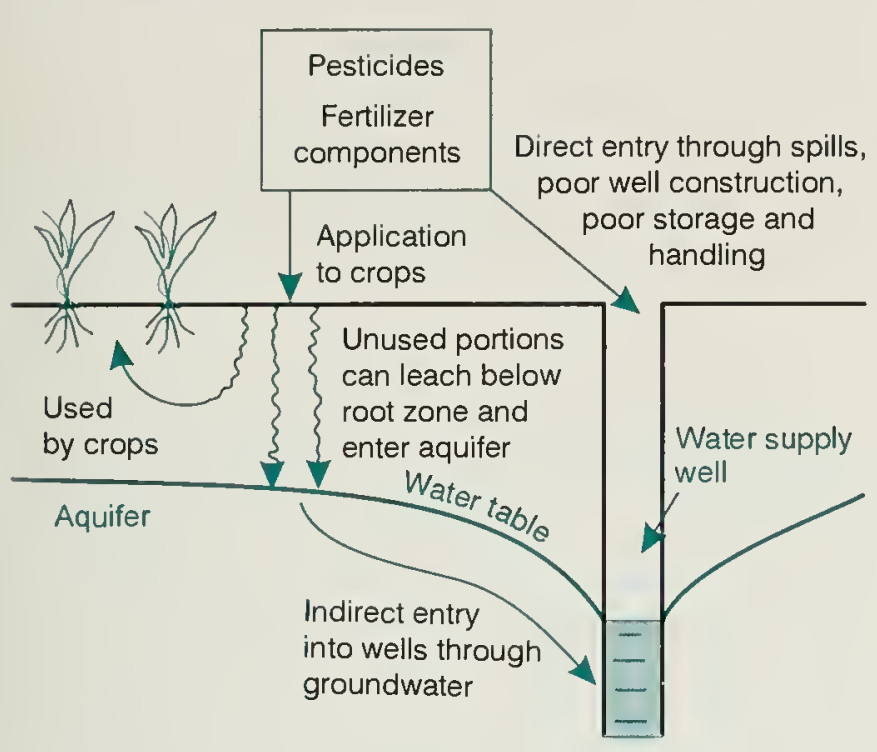

Figure 10-1 Agrochemical entry into groundwater.

\section{Controlling agrochemical entry in to groundwater}

Important factors that control the amount and rate of leaching of agrochemicals through the soil profile and into groundwater include

- type and intensity of agriculture practised

- weather

- land and crop management practices

- type and amount of agrochemicals used

- soil characteristics.

These factors often interact in complex ways. The entry of agrochemicals into groundwater over a particular area depends on which factors are relevant and how they interact at that location.

\section{Type and intensity of agriculture}

Agrochemical leaching into groundwater often occurs in regions where intense cropping results in substantial use of chemicals, and where concentrated production of livestock results in high rates of manure being applied to the soil. In both situations, excess agrochemicals can leach through the soil profile. Leaching, especially of nitrate, can also occur in relatively low-intensity dryland farming where frequent summerfallowing is used. Summerfallowing can cause excess water and unused nitrate to build up in the soil profile. The excess water may then percolate downward and carry the unused nitrate into the groundwater zone.

\section{Weather}

The amount and timing of precipitation are the main elements of weather that influence agrochemical leaching. Rainfall infiltrating the soil in excess of what crops can use may percolate deep into the soil profile, carrying agrochemicals with it. Most agrochemical leaching takes place during spring and fall, when rainfall is high and use of water by crops is low. The humid regions of Canada are much more prone to agrochemical leaching than the dry regions.

\section{Management practices}

Fertilizers, manures, or pesticides may leach into the groundwater when these agrochemicals are applied to the land in excess of crop requirements, and when they are applied at times when the crop cannot use them effectively (early spring or late fall, when crop growth is slow). Excess irrigation water, acting like excess rainfall, can carry agrochemicals deep into the soil profile. The production of crops (such as vegetables) that require high levels of fertilizer, or pesticides, or both, increases the potential for agrochemical leaching into groundwater.

\section{Type and amount of agrochemicals}

Some agrochemicals are highly leachable. Because they are slow to break down and are held loosely by the soil, they can move down through the soil profile much faster than a nonleachable substance. A moderately toxic, leachable agrochemical often poses a greater threat to groundwater resources than a highly toxic, nonleachable one. The herbicide atrazine and nitrate fertilizer are only mildly toxic to humans, 


\section{Pesticide leaching potential}

The potential for a pesticide to leach into groundwater resources can be estimated using its ground water ubiquity score (GUS). The GUS value is determined from how easily the pesticide is transported deeper into the soil profile by downwardpercolating water and from how fast the pesticide is broken down into harmless by-products by soil microorganisms and chemical reactions.

High GUS values indicate highly leachable pesticides (those with a high potential for leaching into groundwater), low GUS values indicate nonleachable pesticides (those with a low potential for leaching), and intermediate GUS values indicate moderately leachable pesticides (those with a moderate potential for leaching). The accompanying chart ranks several common commercial pesticides according to their GUS values.

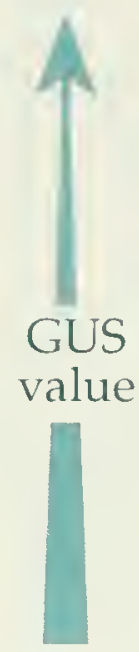

but both are leachable and have been used extensively for a long time over large areas of land. The potential for widespread leaching of atrazine or nitrate into groundwater is high in some of Canada's prime agricultural regions.

\section{Soil characteristics}

Agrochemical leaching tends to increase with increasing soil permeability (a soil's ability to allow the passage of fluids, such as water) and decreasing soil dissipation capacity (a soil's ability to adsorb, or hang on to, and degrade chemical compounds). Coarse sandy soils and fine soils with many

cracks, worm holes, and root channels usually have a higher permeability, or lower dissipation capacity, or both, than clay soils and soils with few large pores. Sandy soils therefore usually pose a greater risk for agrochemical entry into groundwater than do clay soils.

\section{Current status and trends}

Groundwater monitoring has not been carried out long enough, nor in enough detail, in Canada to give a complete national picture of the current status and trends for agrochemicals entering groundwater resources. However, we have enough information to develop an overall impression of the situation for Canada's main agricultural regions.

\section{British Columbia}

Aquifers are an important source of water for municipal, domestic, and agricultural use in the arable valleys of British Columbia. The aquifers in the interior plateau and most of the Peace River area are considered to be at low risk for agrochemical entry because of low rainfall and generally low-intensity agriculture. In southern British Columbia, however, some aquifers are at moderate-to-high risk for agrochemical entry because of

- intensive production of livestock, or crops, or both

- the use of summer irrigation

- the predominance of coarse, sandy soils.

The aquifers in the lower mainland are particularly vulnerable because this area also receives heavy winter rainfall. Significant amounts of agrochemicals (mainly nitrate) have already been detected in the groundwater of several aquifers in the Fraser and Okanagan valleys.

A major concern is the Abbotsford-Sumas aquifer in the lower Fraser Valley, which extends over about 100 square kilometres on both sides of the Canada-United States border. It is one of the most important sources of water in the area for both 
countries, making agrochemical contamination an international concern. This aquifer is highly susceptible to the entry of agrochemicals because of extensive use of high-nitrogen poultry manure on raspberry and forage crops, combined with climatic and soil conditions that promote leaching.

Nitrate concentrations have increased steadily in large parts of the aquifer over the past 20 years and are often greater than the Canadian safe limit for nitrate-nitrogen of 10 milligrams per litre of water, set out by the 1987 Canadian Water Quality Guidelines. Chlorinated hydrocarbon fumigants are also present in some parts of the aquifer, but at concentrations below provincially established safe limits. Concentrations of these pesticides in the aquifer are expected to decline over time because of their removal from the market.

Significant nitrate leaching into groundwater may also occur in an important aquifer near the town of Osoyoos in the lower Okanagan Valley. About 17\% of wells sampled in 1986 and 33\% of those sampled in 1987 contained nitrate-nitrogen levels higher than the safe limit. Fertilizer used in intensive, irrigated tree-fruit production is likely the main source of the nitrate.

\section{The Prairies}

Nonpoint-source entry of agrochemicals into groundwater appears to be rare in the dry prairie of southern Alberta and Saskatchewan. In that area agriculture is mainly low intensity (grain farming and low-density grazing of cattle) and the climate is dry-water use by plants usually equals or exceeds the rainfall.

Much of Alberta's groundwater is obtained from deep-bedrock aquifers that are not directly linked to the soil surface. Thus, only about $4-5 \%$ of domestic wells have nitrate levels above the safe limit.

In Saskatchewan, 7-17\% of domestic wells have nitrate levels above the safe limit. It is now believed, however, that most of this contamination is from point sources (feedlots, spills, and leakage of surface

\section{Nitrate contamination}

The main sources of nitrogen in the soil are natural soil organic matter (decomposed plant and animal material), animal manures, and commercial fertilizers. Nitrogen becomes available for crop use when it is in the water-soluble forms-ammonium and nitrate. Nitrate not used by the crop can be leached below the root zone into groundwater aquifers, where it may reach levels that are harmful to humans and animals.

Nitrate, while relatively nontoxic itself, can be converted in the digestive tracts of human infants and ruminant animals (like cattle and sheep) to nitrite, which is toxic. When nitrite is absorbed into the bloodstream from the digestive tract, it impairs the ability of hemoglobin to transport oxygen, producing a condition of oxygen starvation called methemo-globinemia. Human infants are particularly susceptible to this condition because their upper gastrointestinal tracts are less acidic, allowing for greater conversion of nitrate to nitrite. Most documented cases of methemoglobinemia that have been traced to contaminated drinking water have involved nitrate-nitrogen levels of more than 40 milligrams per litre-more than four times the current safe limit in Environment Canada's Canadian Water Quality Guidelines. water into shallow wells) and from naturally occurring nitrate.

Although most of the Prairie ecozone is thought to be at low risk of contamination by agrochemicals, their entry into the subsoil and groundwater can be significant under certain conditions. For example, applying feedlot cattle manure on the land at the maximum recommended rates has resulted in substantial soil and groundwater contamination by nitrate at some locations in Alberta. Nitrate-nitrogen levels can be more than 1 tonne per hectare in nonirrigated, continuously cropped soils and as high as 500-600 milligrams per litre in the shallow groundwater under irrigated soils (Fig. 10-2). Pesticides (mainly herbicides) have also been found at 


\section{Canadian Water Quality Guidelines}

The Canadian Water Quality Guidelines consist of a set of recommended "safe limits" for various polluting substances in raw (untreated) drinking water, recreational water, water used for agricultural and industrial purposes, and water supporting aquatic life. They are designed to protect and enhance the quality of water in Canada. The guidelines apply only to inland surface waters and groundwaters and not to estuarine and marine waters.

The guidelines for drinking water quality recommend maximum acceptable levels for various physical, chemical, radiological, and microbiological substances. Drinking water that contains these substances in concentrations greater than the limits is either potentially capable of producing negative health effects or aesthetically objectionable. The drinking water guidelines for several conmon agrochemicals are given below.

\section{Canadian Water Quality Guidelines for} Selected Agrochemicals

\begin{tabular}{lc} 
Agrochemical & Recommended safe limit \\
\hline $\begin{array}{l}\text { Pesticide } \\
\text { atrazine } \\
\text { chlorothalonil } \\
\text { cyanazine }\end{array}$ & 5 \\
diazinon & no recommendation \\
diclofop-methyl & 10 \\
dinoseb & 14 \\
EPTC & 9 \\
glyphosate & no recommendation \\
linuron & no recommendation \\
metolachlor & 280 \\
metribuzin & no recommendation \\
simazine & 50 \\
Nitrate-nitrogen & 80 \\
Bacteria & 10 \\
\hline
\end{tabular}

Source: Canadian Water Quality Guidelines.

The Canadian Water Quality Guidelines are used by provincial, territorial, and federal agencies to assess water quality problems and to manage competing uses of water resources. The guidelines are based on the best scientific information available at the time and are subject to periodic adjustments as new information becomes available.

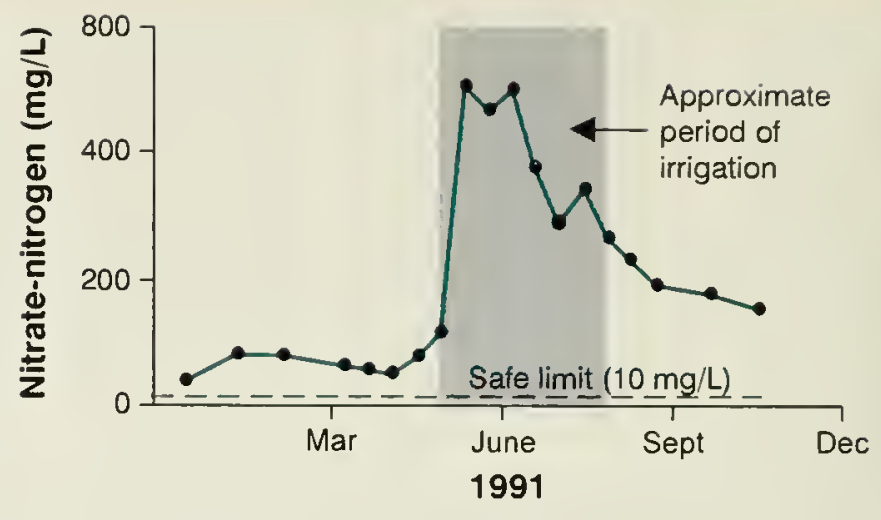

Figure 10-2

Groundwater contamination under soil receiving manure at one irrigated site in Alberta

Applying feedlot cattle manure to the land at the maximum recommended annual rate of 60 tonnes per hectare has led to serious contamination. Nitrate-nitrogen concentrations exceeded the safe limit of $\mathbf{1 0}$ milligrams per litre all year, rising dramatically during irrigation.

concentrations ranging from trace to higher than the safe limit in the groundwater below irrigated soils.

Experiments in Saskatchewan have shown that significant nitrate-nitrogen leaching can occur

- when land is frequently summerfallowed (summerfallowing may allow excess water and nitrate to accumulate in the soil and then percolate below the root zone)

- when crops are overfertilized, leaving excess nitrate in the soil (especially when fertilizer rates are based on general crop and soil characteristics rather than on soil and plant tissue tests)

- in some cases, where crops are underfertilized (poor crop growth results in low nitrogen use by plants and excess water in the soil profile)

- when frequent irrigation is used (tiledrainage water from some irrigated fields contains nitrate levels above the safe limit, as well as trace amounts of herbicides). 


\section{Parkland and boreal transition}

In Manitoba, information on the effects of agricultural activities on groundwater quality is limited. Available data suggest that agrochemical entry into groundwater is generally low where low-intensity agriculture is practised and where soils are clayey. In southern Manitoba, however, intensive agriculture is practised. The resulting rapid increase in the use of fertilizer and manure during the last 20 years has caused certain agrochemicals to accumulate under some fields.

A 1992-1993 survey in southern Manitoba found elevated levels of nitrate in the subsoils of fields that were heavily fertilized, or manured, or both, and were cropped to cereal grains or horticultural crops. Although this nitrate does not appear to have entered the groundwater significantly so far, the potential for it to do so in the future is high.

Also of concern in southern Manitoba are aquifers beneath the upper and lower Assiniboine delta. These major sources of drinking and irrigation water for the region underlie sandy and coarse loamy soils that support intensive agriculture, which often uses irrigation. A recent study at one site found nitrate levels above the safe limit in the ground water below a highly fertilized wheat crop; the extent of this contamination is not known. Analysis of water samples collected in 1991-1993 from a few of the wells used for monitoring groundwater and from wells used to supply irrigation water suggests that pesticides have not contaminated these aquifers.

\section{Central Canada}

Many locales in central Canada's prime agricultural regions have diverse combinations of intensive agriculture, wet climate, highly permeable soils, shallow soils, and high water tables. As a result, the risk of agrochemicals leaching into groundwater in those areas is considered to be high.
In southern Ontario, the main agrochemicals entering ground water are nitrate and the herbicide atrazine, along with bacteria. Nitrate contamination results mainly from a combination of fertilizer use, natural nitrate in the soil, and nitrogen compounds in rainwater. Bacterial contamination results from applying large amounts of liquid manure from large-scale livestock operations (mainly hog, beef, poultry, and dairy facilities). Atrazine occurs mainly as a result of intensive continuous corn cropping in the past; studies in eastern Ontario have shown that atrazine can persist in shallow groundwater for more than 5 years after its use is discontinued.

A 1992 groundwater survey of 900 rural water-supply wells in southern Ontario found that $37 \%$ of the wells contained nitrate, bacteria, herbicides, or all three, above safe limits; $15 \%$ had nitrate-nitrogen levels above the safe limit; $32 \%$ exceeded the safe limit for coliform bacteria; and 12\% had detectable levels of pesticides (mainly atrazine), but only two of the wells $(0.2 \%)$ had pesticide concentrations above safe limits. The incidence of groundwater contamination was widely scattered (Fig. 10-3) and was not related to crop type or cropping practice. However, bacteria contamination occurred more often where manure was applied regularly; nitrate contamination was more frequent under highly permeable soils and in shallow groundwater.

Data for groundwater quality in Quebec is inadequate to give a good picture of the extent and degree of agrochemical contamination in the agricultural areas of this province. Limited surveys in the St. Lawrence lowlands and the île d'Orleans area found that significant contamination by nitrate and bacteria can occur in areas of intensive potato, vegetable, hog, and poultry production. A 1978-1980 survey of domestic wells in potato-producing areas found that $6 \%$ of wells contained nitratenitrogen levels above the safe limit. In the île d'Orleans area, $83 \%$ of 35 sampled wells contained bacteria levels above the safe
While there is a certain public mystique about groundwater and its purity, the farm community understands groundwater better than most; rural residents depend more on groundwater than any other segment of society.

George R. Hallberg From Hoes to Herbicides: Agriculture and Groundwater Quality 
A
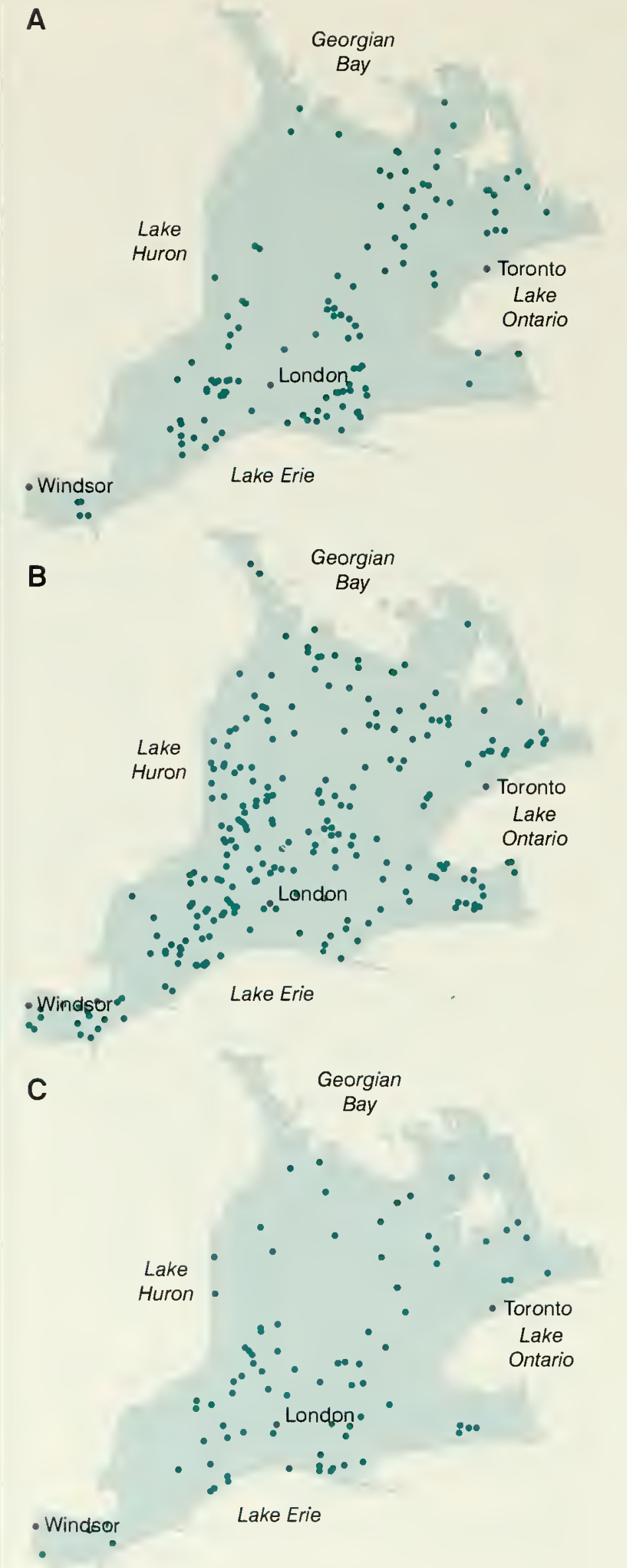

Figure 10-3

Distribution of farm wells in southwestern Ontario containing agrochemicals.

A) Wells with nitrate levels exceeding the safe limit for nitrate-nitrogen of $\mathbf{1 0}$ milligrams per litre; $B$ ) with bacteria levels exceeding the safe limit for coliform colonies of 5 per 100 millilitres; C) with detectable levels of pesticides. limit for drinking water, probably because of point-source contamination (inadequate waste treatment and surface run-off into improperly sealed wells). The herbicides aldicarb and atrazine were also detected in about $31 \%$ of the wells sampled in the Île d'Orleans area but at concentrations well below the current safe limits. As with Ontario, the incidence of nitratecontaminated groundwater appears to be widely scattered and more prevalent under highly permeable soils and in shallow ground water.

\section{Atlantic Canada}

Agrochemical entry into groundwater in Atlantic Canada occurs mainly in areas producing potatoes and corn intensively, because

- these crops are well fertilized to ensure high yields

- potatoes grow best on coarse, highly permeable soils

- high rainfall in spring and fall causes much leaching.

Average nitrate-nitrogen concentrations in the groundwater in potato-growing areas range from 4 to 10 milligrams per litre. Within this range, average concentrations relate directly to the share of land cropped to potatoes, but evidence suggests that the amount of nonpoint-source nitrate leaching into groundwater is holding steady over time. Certain leachable pesticides used in potato production, such as metribuzin and dinoseb, are also found in the groundwater but usually at concentrations that are only a small fraction of the safe limit values. Nonleachable pesticides, such as chlorothalonil, are detected only occasionally in groundwater, usually at trace levels.

In a recent survey of farm wells in Kings County, Nova Scotia, where most of the province's potatoes and corn are grown, $41 \%$ had detectable levels of pesticides (none exceeded safe limits), 9\% contained bacteria above the guideline levels, and $13 \%$ exceeded the safe limit for nitrate. All pesticides detected were attributed to 
nonpoint sources, and atrazine occurred most frequently. Elevated concentrations of bacteria were attributed to point sources, and high nitrate levels came from point, nonpoint, and unknown sources.

Production of grass (hay and haylage) is the Atlantic Province's most common agricultural land use. It appears to contribute only low-to-moderate amounts of nitrate to groundwater.

\section{Reducing agrochemical entry into groundwater}

As agricultural activity becomes more intense, some degree of agrochemical entry into groundwater is unavoidable. The challenge is to develop ways to reduce agrochemical entry. The methods will vary to suit the wide diversity of climate, soils, and agricultural activity in Canada's agricultural areas. The most promising options for achieving this task are outlined below.

\section{Catch crops and crop rotations}

The use of catch crops (usually a lower-value crop that is planted in the fall after the main higher-value crop has been harvested) and certain crop rotations can substantially reduce the amount of nitrate leaching into the subsoil, or groundwater, or both. Catch crops use leftover nitrogen and water in the soil, both during the fall after the main crop has been harvested and in the following spring before the main crop is planted. Certain crop rotations reduce nitrate leaching by establishing a situation of mutual benefit. Any leguminous crop in the rotation takes up nitrogen left over from the previous crop and at the same time adds slow-release nitrogen to the soil through its root system. Succeeding crops in the rotation then use the slow-release nitrogen during the growing season, reducing the amount of chemical fertilizer required.

For example, in Atlantic Canada, winter wheat, oilseed radish, and winter rye are effective catch crops for use in potato

\section{Nitrate leaching in potato production}

Optimum potato production requires high rates of nitrogen fertilization and the use of sandy soils that are prone to nitrate leaching. As a result, tile-drainage water leaving potato fields often contains substantially higher levels of nitrate than water draining from fields planted to other crops. The nitrate levels in tile-drainage water from potato fields often exceeds the safe limit for nitrate-nitrogen in drinking water of 10 milligrams per litre.

Nitrate-nitrogen level in tile-drainage water

\begin{tabular}{llc}
\hline Crop & Location & $\begin{array}{c}\text { Nitrate-nitrogen } \\
\text { concentration } \\
\text { (milligrams per litre) }\end{array}$ \\
\hline Potatoes & New Brunswick & \\
Pasture & and P.E.I. & $15-20$ \\
Corn silage & New Brunswick & $1-3$ \\
Grass & New Brunswick & 5 \\
& New Brunswick & 5 \\
\hline
\end{tabular}

Potatoes are the primary cash crop in Prince Edward Island, generating about $\$ 100$ million in revenues annually and occupying about $48 \%$ of the improved cropland (not all this land is seeded to potatoes every year). Because this province relies on groundwater for $100 \%$ of its drinking water, potential contamination of groundwater by nitrate from potato production is of great concern.

(P.H. Milburn, AAFC, Fredericton, N.B. and J.A. MacLeod, AAFC, Charlottetown, P.E.I.)

production. Studies in Prince Edward Island have shown that oilseed radish and winter rye remove unused nitrogen from potato land at about 100 kilograms per hectare. In Saskatchewan, rotating wheat crops with legumes, such as lentil, and fallseeded crops, such as winter rye, has resulted in less nitrate leaching below the root zone than with the more traditional summerfallow-spring wheat rotation or continuous spring wheat cropping (Fig. 104). The lentil crop allows lower rates of chemical fertilization by providing natural, slow-release nitrogen to the soil, which is 


\section{Essential crop nutrients}

All plants, including crops, require many nutrients for proper growth and development. Macronutrients are nutrients needed in large quantities (carbon, hydrogen, oxygen, nitrogen, phosphorus, potassium, calcium, magnesium, sulfur). Micromutrients are those needed in small quantities (iron, manganese, molybdenum, boron, copper, zinc, chlorine).

Crops get carbon, hydrogen, and oxygen from air and water. The other nutrients come from the soil. To get economic crop yields, farmers must often add extra nitrogen, phosphorus, and potassium (beyond what exists naturally in the soil) in the form of commercial fertilizers and manure. The portion of these chemicals that is not used by crops may leach through the soil profile and into groundwater supplies used for drinking water. Phosphorus and potassium are not toxic, but nitrate levels in groundwater can reach toxic levels when certain soil types, weather conditions, and agricultural practices prevail.

(W.D. Reynolds, AAFC, Ottazua, Ont.)

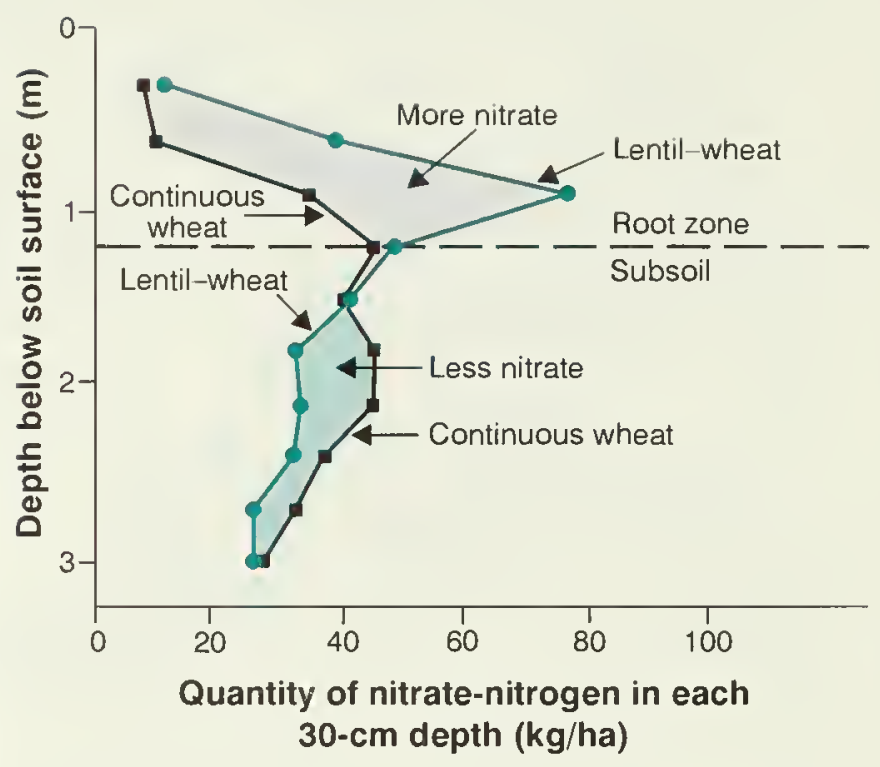

Figure 10-4

Nitrate in soils under two cropping systems.

In a 12-year study at Swift Current, Sask., a lentil-wheat rotation resulted in more nitrate in the root zone and less nitrate leached into the subsoil than with continuous wheat. Both systems were fertilized each year according to soil test recommendations. used by the succeeding wheat crop before leaching occurs. The winter rye crop grows in the fall before freeze-up and starts growing again earlier in the spring than the traditional spring wheat, using the leftover nitrate in the soil before it leaches.

\section{Timing, rates, and procedures for applying agrochemicals}

Entry of nitrate from commercial fertilizer and manure into surface water and groundwater is the main water-quality problem related to agricultural activity. Although the entry of pesticides into groundwater is currently very low throughout Canada, they still need to be used carefully. Increasing efficiency in the use of nutrients, pesticides, and irrigation water by crops can reduce the potential for nitrate and pesticide leaching.

\section{Nutrients}

Ways to improve nutrient use by crops include the following:

- properly accounting for all major sources of nitrogen, including that which occurs naturally in soil and the amounts supplied by plowing under greenmanure crops and crop residues and by adding livestock manure

- improving the estimates of each crop's needs and applying agrochemicals only in amounts that the crop can use (for example, nitrogen fertilization rates can be based on soil and plant tissue tests, Fig. 10-5)

- timing agrochemical applications to match times of maximum crop need, while avoiding times of major leaching

- improving ways of applying agrochemicals

- setting goals for crop yield that are both economically and environmentally sustainable

- using crops that prevent build-up of unused nitrate after the growing season.

The potential for manure to cause nitrate and bacterial contamination is reduced if dry manure is spread on dry and completely 


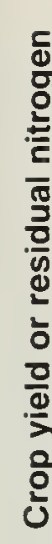

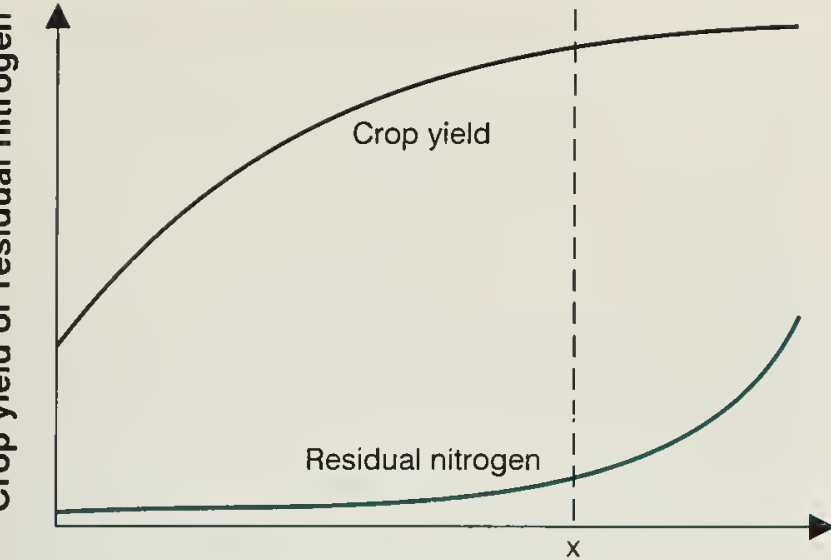

Rate of nitrogen fertilization
Figure 10-5

Crop yield and residual soil nitrogen. Crop yield and the amount of nitrogen unused by plants and left in the soil after harvest both increase as the rate of nitrogen fertilization increases. Point $x$ (dashed line) indicates the point beyond which residual nitrogen can potentially contaminate groundwater. Fortunately, this point falls close to the rate of fertilization producing maximum economic return. Thus, fertilizing crops according to results of soil or plant tissue tests, or both, should achieve maximum economic return and minimum nitrate leaching.

thawed soils and then tilled into the soil soon afterward. In some areas, it is possible to inject liquid manure directly into the root zone, using a tractor-drawn injection implement, rather than spraying it onto the soil surface. This method prevents manure run-off from the soil surface, and at the same time the injector teeth reduce manure leaching below the rool zone by breaking up large cracks and worm holes in the soil.

\section{Pesticides}

Although it is hard to predict the behaviour and transport of pesticides under field conditions, the following management practices can reduce their entry into the groundwater:

- selecting suitable pesticides and applying them at the recommended rates

- timing pesticide applications and applying them appropriately to reduce drift and evaporation
- reducing pesticide use by adopting integrated pest management strategies (pest control that combines use of crop rotations, cultivation, and biological and chemical pest controls).

\section{Irrigation}

Crop use of irrigation water can be made more efficient by

- basing the amount and timing of irrigation on measurements of the amount of soil water still available in the crop-root zone, which prevents excess water being applied

- avoiding soaking by flood or heavy irrigation, which can cause water carrying agrochemicals to leach quickly below the root zone through cracks, worm holes, and root channels.

\section{Improved feed technology and pesticides}

Progress is being made in developing animal feed (especially poultry ration) that increases the use of nitrogen by the animal and reduces the nitrogen content of the manure. Many of the persistent leachable pesticides, such as atrazine, are gradually being phased out and replaced by lesspersistent nonleachable ones. Also, new pesticide products are being developed that pose less risk to the environment because they are toxic only to the targeted pests and not to other plants and animals.

\section{Regulation of agrochemical use}

Federal and provincial governments are developing strategies and guidelines for regulating manure handling and pesticide use. For example, British Columbia's Code of Agricultural Practice for Waste Management requires farmers to store and use livestock manure according to environmental guidelines. In many provinces, farmers must pass a course on pesticide safety that teaches proper handling procedures and application rates. Some provinces are developing strategies for reducing pesticide use by $50 \%$ or more within the next few years.
The impact of modern agricultural practices on water is similar throughout the industrial world. ... In all cases the solution lies in the management and control of the inputs used in agricultural production ... There is a need to focus on causes rather than symptoms.

Canadian Agricultural Research Council Agricultural Impacts on Water Quality: Canadian Perspectives 


\section{Great Lakes Action Plan (GLAP)}

Under the Great Lakes Water Quality Agreement between Canada and the United States, Agriculture and Agri-Food Canada funded GLAP-a 5-year, \$5-million research study: 1) to increase our understanding of how agrochemicals affect the environment, especially in the Great Lakes basin, and 2) to develop and refine farming practices to conserve, improve, and sustain the quality of soil, water, and air. Some findings of the research follow.

\section{Pesticides}

- The pesticides atrazine and metolachlor move off rolling farmland mainly in surface runoff. They are dissolved in the water, not attached to eroded sediments. Losses are highest when rainstorms closely follow application and may reach $10 \%$ after a severe storm. Pesticide levels in runoff sometimes exceed the safe limit for up to 1 month after application.

- On level farmland with cracking soil (rich in clay and silt), pesticides are transported to tile drains mainly through large soil pores (cracks, worm holes, and old root channels). Transport is greatest immediately after application, especially when followed by a heavy rain. The large pores do not appear to cause significant pesticide transport below the tile line.

- Wetlands and marshes rimming the Great Lakes appear to be able to filter out and retain much of the pesticide that enters from farm runoff. Some bacteria in wetland sediments degrade atrazine rapidly.

\section{Manure and nitrate}

- Bacteria and nitrate from manure can move rapidly through large soil pores and can enter tile-drainage water and shallow groundwater. Serious contamination can occur when liquid manure is applied at high rates directly to the land surface. The risk is greatest immediately after application especially when closely followed by a heavy rain.

- Leaching of nitrate from fertilizer and manure into the subsoil occurs mainly during the nongrowing season (spring, fall, and winter), when crops are not present to intercept and use it. Tile drainage can reduce nitrate (and atrazine) leaching by up to $50 \%$.

(W.D. Reynolds, AAFC, Ottazen, Ont.)

\section{Research and monitoring programs}

Extensive agrochemical research and monitoring programs are maintained by fecieral and provincial governments, universities, and the agrochemical industry. The recently completed Soil and Water Environmental Enhancement Program (SWEEP), Great Lakes Action Plan (GLAP), and National Soil Conservation Program (NSCP) are examples of government initiatives that include extensive research on how agrochemicals behave in the environment. Ongoing federal and provincial Green Plan programs also include agrochemical studies. These programs are working to answer the following questions about agrochemical entry into groundwater:

- Where does it occur?

- Are present levels harmful?

- Where is it likely to occur, now and in the future?

- How does it occur? (understanding the leaching process)

- Is it increasing, decreasing, or remaining stable over time?

- How can levels be maintained that are both safe and compatible with sustained high-intensity agricultural production?

\section{Conclusions}

Current research and monitoring programs are not sufficient to obtain a comprehensive knowledge of the extent and degree of nonpoint-source agrochemical contamination of Canada's groundwater resources. However, information from various locations in the major areas of intensive agriculture allows an overall assessment.

Nitrate associated with agricultural activities is present in nearly all groundwater underlying the main agricultural regions of Canada. Nitrate levels in groundwater supplies are below the safe limit in most regions of Canada, but in some areas of intensive agriculture they are increasing and have already exceeded the safe limit. The main sources of nitrate are 


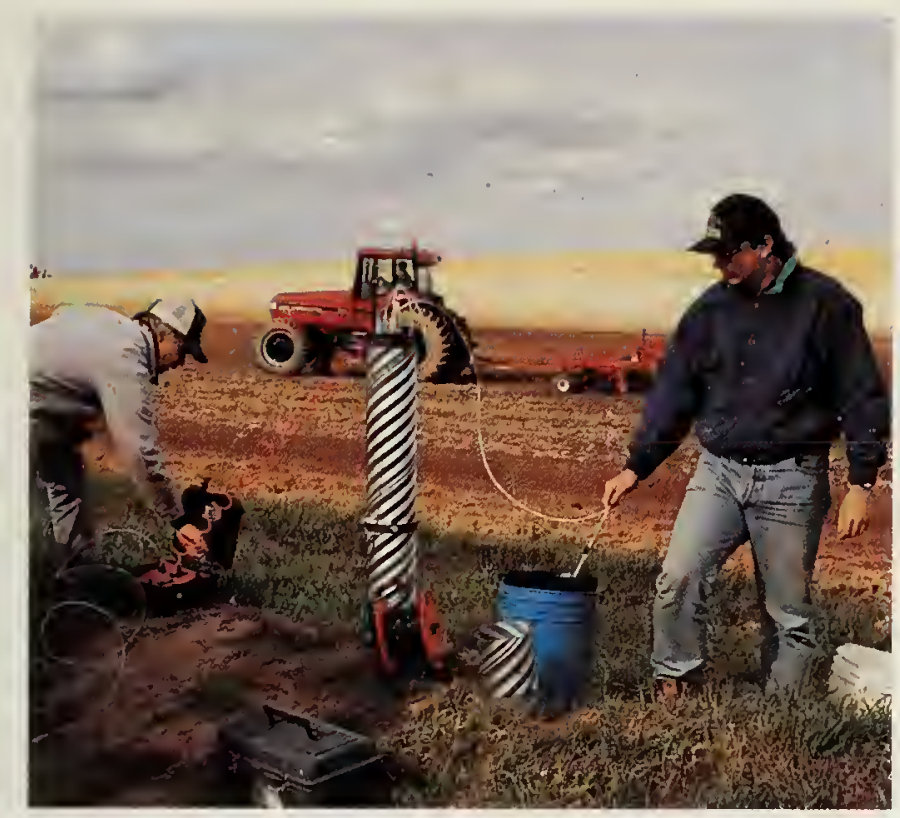

Monitoring a well for groundwater quality in land under potato production in Atlantic Canada.

commercial fertilizers, livestock manures, and nitrate occurring naturally in the soil profile. Pesticides are also found in the groundwater of Canada's agricultural regions, but generally at levels that are well below safe limits. Pesticide levels in groundwater generally appear to be decreasing as less persistent and less leachable pesticides are developed and as application methods are improved.

Bacterial contamination of groundwater in southern Ontario and Quebec is scattered but widespread, probably resulting from heavy application of liquid manure.

Federal, provincial, university, and private agencies are studying ways to minimize the entry of nonpoint-source agrochemicals into ground water resources. Important developments include the use of catch crops and crop rotations to reduce the use of pesticides and to intercept unused agrochemicals in the soil; improved technologies for applying agrochemicals and irrigation water; new animal feeds that reduce the nitrogen content of manure; and new pesticide products that are less leachable, less persistent, and more targeted to specific pests. Entry of agrochemicals into ground water must be regulated so that concentrations do not exceed safe limits and are environmentally acceptable. Continued monitoring, research on agrochemical leaching processes, and development of improved methods for agrochemical use are needed in Canada.
Once polluted, ground water is difficult, if not impossible, to clean up, since it contains few decomposing microbes and is not exposed to sunlight, strong water flow, or any of the other natural purification processes that cleanse surface water.

Eugene P. Odum Ecology and Our Endangered Life Support Systems 


\title{
Summary
}

\author{
L.J. Gregorich and D.F. Acton
}

\section{Introduction}

Soil health is indisputably a major factor in our ability to sustain agricultural activities in Canada and to safeguard the environment. This report defines soil health in terms of agriculture and presents key results of research undertaken in the past decade to increase our understanding of the factors affecting soil health, to monitor indicators of soil health, and to identify and refine farming practices that help to maintain and improve soil health. It also gives a picture, although an incomplete one, of the health of Canada's agricultural soils today.

Apart from small areas of agricultural expansion, Canada has reached the limit of land suitable for crop production. Thus, agricultural productivity will be maintained mainly through wise use of present resources-preserving the area and the quality of land currently in agricultural use.

\section{Current and future trends in soil health}

The use of conservation farming methods has increased over the past 10 years. As a result, some agricultural soils are improving in quality and becoming less susceptible to erosion and other damaging forces. For example, levels of soil organic matter have increased in some areas, the risk of erosion has decreased nearly everywhere in the country, and the risk of salinization has decreased in the Prairie Provinces. However, this general improvement is a small one overall, and does not apply to all soils. On the other hand, it provides proof that the health of our agricultural soils can indeed be maintained and even improved with the right care.
Three general trends emerge from this assessment of soil health:

- Soil health will continue to decline in areas of intensive cropping and marginal land where conservation farming methods are not used.

- Soil health is holding steady or improving in regions where conservation practices have been tailored to local problems of soil degradation.

- Declines in soil health occur rapidly, often most dramatically in the first 10 years following conversion of virgin land to agriculture; improvements in soil health take place slowly and at greater cost than maintenance.
Obviously, agriculture involves the rearranging of nature to bring it more in line with human desires, but it does not require exploiting, mining, or destroying the natural world.

Don Worster Good Faming and the Public Good in Meeting the Expectations of the Land 
Because of the wide diversity of landscape, inherent soil quality, and farming systems in Canada, more specific trends in soil health are best observed and interpreted at the regional level.

\section{British Columbia}

Mild climate and adequate rainfall permit a long growing season in southern British Columbia. Deteriorating soil quality in this region is mainly related to cropping intensity, particularly of high-value specialty crops, and the associated machinery traffic and use of agrochemicals. Agrochemical entry into groundwater is a serious problem where farmland overlies shallow aquifers. Table S-1 presents important findings on soil health in this region.

\section{Prairie Provinces}

In the Prairie Provinces a large area of soils are inherently of good quality, and this region has generally suffered comparatively less soil degradation than other regions of the country. Many agricultural soils are subject to the stresses of a dry climate and are susceptible to certain degradative processes, particularly wind erosion and salinization. The reduced risk of wind erosion over the past 10 years is attributed to reduced use of summerfallow and increased use of conservation tillage and other erosion controls, such as permanent cover and shelterbelts. The risk of salinity attributed to agricultural practices has decreased in some areas, apparently because of the use of salinity controls (permanent cover, extended

\section{Table S-1 Aspects of soil health in British Columbia}
Soil structure
- Soils in Fraser Valley susceptible to compaction; more study needed
- Farm machinery traffic in forage-grass and vegetable production, especially when soil wet, likely main cause of compaction

Water erosion

Agrochemicals in groundwater

- Based on analysis of Alberta portion of Peace River region, few soils in B.C. portion of region at high risk of wind erosion

- $75 \%$ of cultivated land at high-to-severe inherent (bare soil) risk of water erosion

- Conservation practices resulted in 17\% reduction in this risk since 1981

- Aquifers in southern B.C. at moderate-to-high risk of agrochemical contamination, particularly in areas of high rainfall (lower mainland)

- Abbotsford-Sumas aquifer in lower Fraser Valley highly susceptible to agrochemical contamination; nitrate contamination mainly from heavy field application of manure from local highdensity poultry and livestock production

- Fertilizers used in irrigated tree-fruit production are main source of nitrate in aquifers in Okanagan Valley

- Nitrate levels greater than Canadian safe limit for drinking water are found in groundwater supplies of Fraser and Okanagan valleys 
rotations). Conservation practices have resulted in stabilized levels of soil organic matter in some areas. Further improvements in soil quality are expected as more farmers adopt these methods. Important aspects of soil health in this region are presented in Table S-2.

\section{Central Canada}

Many soils in central Canada are under the stress of intense cultivation; cropping intensity (defined as cultivation of more than $70 \%$ of total farmland) has increased by $3 \%$ in southern Ontario over the past 10

\section{Table S-2 Aspects of soil health in the Prairie Provinces}

Soil organic matter

Soil structure

Soil salinity

Agrochemicals in groundwater
- Earlier estimates of 50-70\% losses of soil organic matter since virgin land first cultivated appear high; recent studies indicate losses of $15-30 \%$ in uneroded soils

- Organic matter levels stabilized in much of this region; levels can be increased by adding organic matter (manure, crop residues, etc.) to soil, adequately fertilizing crop, and continuous cropping (reducing summerfallow)

- Organic matter levels decline quickly in eroded soils, dropping to $20 \%$ of original levels or lower over time

- Compaction not a major concern, because most field operations take place when soil dry

- Summerfallowing contributes to loss of soil organic matter, in turn affecting soil structure; soil structure may improve as summerfallowing reduced

- Most prairie farmland (62\%) with less than $1 \%$ of area affected by salinity; $36 \%$ with $1-15 \%$ of lands affected; $2 \%$ with more than $15 \%$ of lands affected

- Under 1991 cropping practices, most prairie farmland (61\% in Manitoba, 59\% in Saskatchewan, and 80\% in Alberta) at low risk of increasing salinity

- In Manitoba, $80 \%$ of agricultural land with no change in risk of salinization between 1981 and 1991; 19\% with decreased risk (probably because of conversion of land to permanent cover and to extending length of crop rotations); less than $1 \%$ with increased risk

- Nonpoint source contamination of groundwater generally no problem

- Summerfallowing, overfertilization (and, in some cases, underfertilization), and applying manure at high rates can result in significant nitrate leaching

- Irrigation of some soils results in nitrate and pesticide entry into groundwater

- Nitrate levels above safe limit detected in Assiniboine delta aquifers in Manitoba underlying sandy and sandy loarn soils supporting intensive agriculture (often with irrigation) 
The energy contained in nature-in the earth and its waters, in the atom, in sunshine-will not avail us if we fail to activate the most precious vital energy:

the moral-spiritual energy inherent in man; in the inner recesses of his being; in his mysterious, uncompromising, unfathomable, and divinely inspired soul.

Daniel Hillel Out of the Earth: Civilization and the Life of the Soil

Table S-2 concluded

Water erosion

- $5 \%$ of cultivated land at risk of water erosion losses exceeding tolerable limit

- Risk of water erosion reduced between 1981 and 1991 by $13 \%$ in Alberta, 8\% in Saskatchewan, 15\% in Manitoba

Wind erosion

- About $36 \%$ of cultivated land at high-to-severe inherent (bare soil) risk of wind erosion in Prairie Provinces combined (46\% in Alberta, 27\% in Saskatchewan, 45\% in Manitoba)

- Risk of wind erosion decreased by 7\% between 1981 and 1991, mainly because of reduced summerfallow (especially in arid areas), also because of increased conservation tillage

- Conversion from annual crops to perennial forages reduced risk of wind erosion by $20-30 \%$ in some areas of sandy soils

years. Large areas have low levels of soil organic matter, and soil health is expected to decline further if conservation practices are not adopted. Areas of intensive cropping, row-cropping, and monocultures are particularly vulnerable to continuing degradation. Extended crop rotations, conservation tillage, and organic matter added to the soil have all resulted in improved soil health in some areas. The large livestock industry in this region creates the need for manure disposal; manure is a beneficial soil amendment, but future management of this resource must consider its potential to contaminate groundwater with nitrate and bacteria. Aspects of soil health in this region are highlighted in Table S-3.

Table S-3 Aspects of soil health in central Canada

Soil organic matter

Soil structure
- Loss of soil organic matter since beginning of cultivation 15-30\%, with most loss within first 10 years of cultivation

- No-till increases organic matter at soil surface compared to soil tilled conventionally with moldboard plow

- Adequate fertilization contributes to higher organic matter levels in soils cropped to corn, especially under rotation with other crops

- Adding manure reduces loss of soil organic matter on eroded soils

- Conventional tillage, decreased soil organic matter, and monoculture corn production cause soil structure to deteriorate in southern Ontario and Quebec's St. Lawrence lowlands; conservation tillage and rotation of corn with forages improves it 
Table S-3 concluded

- Field traffic and tillage operations today not causing greater compaction of clay soils than previous natural processes

- Sandy soils continuously cropped to potatoes or cereals in Quebec susceptible to structural deterioration and surface crusting

Water erosion

- About $52 \%$ of cultivated land in Ontario and $47 \%$ in Quebec at high-to-severe inherent (bare soil) risk of water erosion

- About $40 \%$ of Ontario's cultivated land needs further implementation of conservation management practices

- Risk of water erosion reduced between 1981 and 1991 by $21 \%$ in Ontario and 6\% in Quebec using conservation practices

Agrochemicals in groundwater
- Many locales at high risk of agrochemical leaching into groundwater because of combinations of intensive agriculture, wet climate, highly permeable soils, shallow soils, and high water tables

- Nitrate contamination of groundwater in southern Ontario related to fertilizer use; bacterial contamination to use of liquid manure; atrazine contamination to intensive, continuous corn production in past

- Survey of southern Ontario wells found 15\% with nitrate levels above safe limit, $32 \%$ with bacteria levels above safe limit, $12 \%$ containing detectable levels of atrazine

- Nitrate and bacteria contamination of groundwater can be significant in areas where potatoes, vegetables, hogs, and poultry produced intensively in St. Lawrence lowlands and Île d'Orleans region of Quebec

\section{Atlantic Provinces}

In the Atlantic Provinces, poor inherent soil quality combined with intensive agricultural activity has resulted in severe soil degradation in many areas. Row-cropping and short rotations have contributed to this condition. On the other hand, soil organic matter levels have increased in areas where rotations have been extended and forage crops have been plowed into the soil. As producers adopt these methods along with practices that control erosion, soil health should continue to improve. Important findings on soil health in this region are given in Table S-4.

\section{Current and future trends in water quality}

The chief effect of agriculture on water quality is the entry of nitrate into groundwater and surface waters. Nitrate is found in virtually all groundwaters in the agricultural regions of Canada. Its main sources, apart from naturally occurring nitrate, are fertilizers and manure. Regions that currently have significant problems with nitrate entering groundwater are southwestern British Columbia and scattered locations throughout southern Ontario, Quebec, and the Maritime Provinces. The future of water quality as it relates to nitrate contamination is mainly a 
Table S-4 Aspects of soil health in the Atlantic Provinces

Soil organic matter

Soil structure

Water erosion

Agrochemicals in groundwater
- Loss of soil organic matter 15-30\% since cultivation began

- Evidence that soil organic matter levels being maintained or increased; many soils under potato production now with higher levels of soil organic matter, in part because of longer crop rotations

- Benchmark studies in New Brunswick show that erosion controls (grassed waterway and terraces) reduced loss of organic matter in soil under potato production by $5 \%$ over 3 years; under conservation practices, soil lost through erosion less than $10 \%$ of that lost under conventional practices

- Soils inherently weakly structured throughout region

- Soil structure damaged by heavy machinery traffic on moist, fine-textured soils during late-spring seeding and late-fall harvesting

- Risk of structural degradation highest under row crops, moderate under spring cereals and fruit trees, and low under winter cereals, forages, and pasture

- About $80 \%$ of cultivated land in New Brunswick, $87 \%$ in Nova Scotia, and $81 \%$ in Prince Edward Island at high-to-severe risk of water erosion

- Risk of water erosion reduced between 1981 and 1991 by 6\% in New Brunswick, mainly because of conservation tillage. Risk remained the same over this period in Nova Scotia and increased slightly $(0.6 \%)$ in Prince Edward Island, mainly because of increased area under row crops (potatoes)

- Agrochemical leaching of concern in all areas where shallow, permeable soils and high rainfall combined; agrochemical leaching low to moderate under forages (a major land use) and low under pastures

- Significant nitrate contamination of groundwater underlying land under potato production and other intensive row-cropping - Several pesticides detected in groundwater, but always at levels less than safe limits for drinking water

- Bacterial levels above safe limit, resulting from point-source contamination, found in many domestic wells 
matter of controlling the amount of nitrate applied to soil. Trends in water quality will be determined by producers' willingness and ability to match the rate and timing of manure and fertilizer application to crop needs, as well as by the ability of soils to retain nutrients (determined by levels of soil organic matter). Contamination of water by bacteria derived from manure is expected to decrease as producers use refined methods of storing and applying this soil amendment.

Water contamination by pesticides is less serious now than 10-20 years ago, because the pesticides in current use are generally less persistent and more specialized. However, pesticides are present in waters of some areas of the country (aquifers in southern British Columbia and domestic wells in southern Ontario, Quebec, and the Maritime Provinces), and the long-term effects of these substances are usually unknown. Public concern about the potential health hazards of water contamination is expected to encourage the trend toward decreased use of agricultural pesticides and increased use of nonchemical pest controls.

\section{Methods for improving soil quality}

Although soil degradation has taken place since cultivation first began, the problem became urgent in the prairies during the 1930s and seriously affected the rest of the country by the 1970 s. The high value placed on maximum crop yields created pressures on producers to increase production by using more mechanization, fossil fuels, and agrochemicals. High crop yields often came at the expense of soil health.

In the past decade, the problem of soil degradation has received considerable attention and is now better understood. Research and regular monitoring continue to improve our understanding of the processes that degrade soil. But soil health will not be maintained or improved unless corrective action is taken. This corrective action must involve both stopping practices that degrade soil health and starting practices that enhance it.

Conventional tillage pulverizes soil, breaking down soil structure and increasing the risk of wind and water erosion. Tillage machinery causes tillage erosion and compaction of the soil. Some traditional cultivation practices also result in deteriorating soil health, because they promote erosion and the loss of soil organic matter. These include

- up- and down-slope cultivation

- intensive row-cropping

- monoculture

- fallowing.

Practices that enhance soil health do so by building up and protecting soil organic matter and soil structure. These practices include

- conservation tillage, including no-till

- residue management

- contour cultivation on hilly land

- application of organic amendments, such as manure, compost, and sewage sludge

- reducing fallow by extending crop rotations or cropping continuously

- including legumes and forages in crop rotations

- water management

- erosion controls, including growing forages in rotation, interseeding, planting shelterbelts, strip-cropping, and restructuring the landscape (such as with terraces, grassed waterways, diversions).

\section{Trends in management practices}

Most agricultural soil degradation is the result of inappropriate farming techniques. It stands to reason then that soil degradation can be abated by changing these techniques. The management practices needed to improve soil health not only exist but are already being used in many parts of Canada. Future trends in soil quality will
Ultimately, the fate of the soil system depends on society's willingness to intervene in the marketplace and to forego some of the short-term benefits that accrue from "mining" the soil so that soil quality and fertility can be maintained over the long term.

E. Odum

Ecology and Our Endangered Life Support Systems 
depend on how quickly these practices are adopted by producers who are still using conventional farming methods.

In 1991 the Census of Agriculture required producers to report on land management practices for the first time. Agriculture and Agri-Food Canada staff used this information to assess the use of these practices at the national and regional levels. This assessment can be used as a baseline for determining changes in land management practices in the future.

Conservation tillage generally improves soil health by reducing the mechanical disturbance of soil, protecting the soil surface with residue cover, and adding more organic matter to the soil. In 1991, conservation tillage (including no-till) was used on one-third of Canada's cultivated land. This type of tillage is increasing in popularity, especially in the Prairie Provinces, where there is a great need to reduce the effects of wind erosion, and in Ontario (Table S-5). Conservation tillage is used mainly on large farms that grow cereal crops and grain corn. It is used least in the Atlantic Provinces. Conventional tillage continues to be used in areas where manure must be tilled into the soil.

The $30 \%$ reduction in the area of fallowed land in the past 20 years (see Chapter 2 , Table 2-1) has contributed to the decreasing risk of erosion. The shift toward continuous cropping and extended rotations on this land has resulted in greater returns of organic matter to the soil.

Growing legumes and forages in rotation with other crops helps to prevent erosion and builds up soil organic matter. In 1991, forages were grown on $42 \%$ of Canada's farms, mainly in the humid regions of the country (see Chapter 7, Table 7-1).

\section{Improving soil quality in the future}

Promotion of conservation farming in the past 10 years has tended to focus on individual management practices, such as conservation tillage. However, because each area of land has its own unique characteristics, not all conservation

Table S-5 Tillage practices used to prepare land for seeding in Canada, 1991

\begin{tabular}{|c|c|c|c|c|}
\hline \multirow[b]{2}{*}{ Province } & \multirow[b]{2}{*}{$\begin{array}{c}\text { Area of } \\
\text { land seeded } \\
\text { (1000 hectares) }\end{array}$} & \multicolumn{3}{|c|}{ Seeded land } \\
\hline & & $\begin{array}{c}\text { Conventional } \\
\text { tillage } \\
(\%)\end{array}$ & $\begin{array}{c}\text { Conservation } \\
\text { tillage } \\
(\%)\end{array}$ & $\begin{array}{c}\text { No-til } \\
(\%)\end{array}$ \\
\hline British Columbia & 241 & 83 & 12 & 5 \\
\hline Alberta & 7965 & 73 & 24 & 3 \\
\hline Saskatchewan & 13035 & 64 & 26 & 10 \\
\hline Manitoba & 4220 & 66 & 29 & 5 \\
\hline Ontario & 2510 & 78 & 18 & 4 \\
\hline Quebec & 850 & 85 & 12 & 3 \\
\hline New Brunswick & 60 & 85 & 13 & 2 \\
\hline Nova Scotia & 30 & 88 & 8 & 4 \\
\hline Prince Edward Island & 110 & 91 & 8 & 8 \\
\hline Newfoundland & 2 & 84 & 8 & 8 \\
\hline Canada & 29030 & 67 & 24 & 7 \\
\hline
\end{tabular}

Source: Dumanski et al. 1994. 
practices are suitable for all areas. For example, conventional tillage is superior to conservation tillage in some areas where the soil benefits from being broken up occasionally. Furthermore, conservation practices are usually most beneficial when used in combination, such as conservation tillage plus continuous cropping with an extended rotation. This means that a soil management program must be site-specific, or tailored to the needs of a specific soil. This is best done at the farm level.

\section{Farming systems}

Management practices should be combined in farming systems (overall plans to manage cropping and soils) that are aimed at keeping soils healthy and productive. These systems require the usual decisions about the variety, pattern, and sequence of crops; tillage methods; and levels of inputs, including agrochemicals and organic amendments. But these decisions are made with the understanding that they affect soil health and the broader environment, along with productivity. Systems also include a "producer factor," which assesses the level of skill, management ability, education, and commitment to conservation shown by the producer.

To hasten the adoption of conservation farming practices, policies and programs that encourage poor farming systems should be replaced by those that support beneficial ones. This shift in policy will require careful study of the factors that cause producers to select certain farming practices over others. It will also place an emphasis on finding better ways to transfer technology, ensuring that producers are knowledgeable about the factors that affect soil health, as well as about the farming methods that promote soil health.

Producers usually implement conservation farming only when they are convinced of its economic benefits. However, many of them are accustomed to evaluating farm economy only in the short term, based on markets and costs. Conversion to

\section{An integrated farm system plan}

An integrated farm system plan begins with an inventory of farm resources and practices. It then answers such questions as:

- Does the producer participate in any government agricultural programs?

- Where does the producer get information on which to base decisions about farming practices?

- Are there resources available that are not currently being used (such as a manure supply from a nearby livestock operation)?

- What are the barriers, if any, to using conservation practices?

Once a general picture of the farm enterprise emerges, moredetailed information about soil health and farming practices can be added. For example, the following questions may be asked:

- What is the condition of the soil? Are there any locations of particular soil degradation?

- Are there ways to improve the efficiency of input use?

- Would alternative cropping or tillage strategies, or both, be beneficial?

(After Batie and Cox 1994)

conservation farming is made more easily when producers realize that continued use of conventional methods will inevitably result in further soil degradation and declining profitability.

\section{New policy for sustainable agriculture}

Agricuitural policy has typically focussed on high production and has viewed agriculture as a closed system. The concept of sustainable agriculture creates a need for new policy that acknowledges the environmental effects of agriculture and promotes resource conservation along with productivity. This new policy should have the following objectives:

- to recognize agriculture as a human activity that affects both the local and the broader environment
A carefully defined objective tells us where we are going, what the value is of getting there, and what is the probability of success. It is the measure of our achievement. ... Next we have to determine the cost, make the commitment to pay it and then commit ourselves to keeping our commitment. Now we are ready to do battle.

Chris Maser The Redefined Forest 


\section{Sustainable land management}

Sustainable land management means managing the land in a way that keeps it productive without depleting resources or harming the environment. This kind of management requires a change in thinking and a change in habits. Land should be thought of as a bank. If we think that the land is an unlimited resource that we can continuously "withdraw" from, our account will eventually be used up. If instead we are wise stewards and invest back into the land, our account will balance and will continue to give us a good return in the future.

Agriculture and Agri-Food Canada is committed to the principles of sustainable land management. New policies and technologies are being developed to support a land management system built on five pillars:

- productivity-maintaining or improving agricultural production and services

- stability-reducing the level of production risk

- protection-conserving natural resources and preventing degradation of soil and water

- viability-making good economic sense

- acceptability-maintaining social acceptance.

(J. Dumanski, AAFC, Ottazua, Ont.)

- to maintain and improve agricultural soil health as an essential step in maintaining and improving environmental health and ensuring long-term farm profitability

- to maintain and improve soil health by promoting practices that build soil organic matter and otherwise protect soil structure

- to foster increased understanding of the factors affecting soil health and the means to maintain and improve it through continued research and monitoring programs

- to conserve agricultural lands and soils by curtailing their nonagricultural uses and by protecting against soil losses resulting from erosion

- to promote practices that conserve resources, including

- recycling organic wastes (such as manure, compost, wood chips, and sewage sludge)

- reducing the use of fossil fuels and agrochemicals and making their use more efficient

- conserving water quality (mainly by minimizing off-farm movement of soil and agrochemicals)

- to support producers during their transition to conservation-farming systems.

Built on the foundation of these objectives, the goal of policy should be to diminish the degradation of agricultural soil and the broader environment and to maintain soil health by targeting programs to problem areas and problem farms. It is the task of policy-makers to use the findings of ongoing research and monitoring programs to design policy that reaches this goal effectively and quickly. 


\section{Glossary}

Acidic Having a low $\mathrm{pH}$ value (less than 7); the opposite of alkaline.

Actual erosion risk Risk of erosion, accounting for soil cover, land use, and management practices.

Aggregate Sand, silt, and clay particles in soil bound together mainly by organic matter to form a clump.

Aggregation Bonding together of soil particles to form an aggregate.

Agri-environmental indicator Measure of change either in the state of environmental resources used or affected by agriculture, or in the farming activities that affect the state of these resources.

Agrochemical Chemical used in crop production.

Agro-ecosystem Ecosystem under agricultural management; an open, dynamic system that is connected to other ecosystems through the transfer of energy and materials.

Alluvial plain Level or gently sloping, flat or undulating surface formed from material deposited on recent floodplains by running water.

Alkaline Having a high $\mathrm{pH}$ value (greater than 7); also basic; the opposite of acidic.
Alternative agriculture School of thought in agriculture that sees people as one component in a large ecological system in which their needs must balance the earth's ability to produce without depletion or degradation.

Amendment Substance, such as manure and compost, that is added to soil to make it more productive.

Aquifer Geological bed or stratum that is far-reaching and porous enough to yield a supply of groundwater to one or more large wells or springs.

Aridity Dryness.

Background level Concentration of a substance in soil due to natural processes alone, where there is no history of application of this substance.

Baseline data set First set of measurements made at a site.

Benchmark site Locale at which certain soil properties and processes can be measured in a standard way at regular intervals.

Biocide Natural pesticide.

Black soils Chernozemic soils characterized by a very dark surface, a brownish B horizon, and usually a calcareous $\mathrm{C}$ horizon. 
Brown soils Chernozemic soils characterized by a brown surface, lighter brown B horizon, and usually a calcareous $\mathrm{C}$ horizon.

Brunisolic soils Order of soils that occur under a wide variety of climatic and vegetative conditions, all having $\mathrm{Bm}$ or Btj horizons.

Bulk density Mass of dry soil per unit bulk volume.

Carbon cycle Route by which carbon is fixed by photosynthesis, added to soil as plant and animal remains, then released from soil through decomposition and mineralization.

Capillary zone Zone through which water is drawn from a water table toward the soil surface by capillary action.

Catch crop Usually a lower-value crop that is planted either between the rows of a main crop or in the fall after the main higher-value crop has been harvested to take up excess nutrients, such as nitrogen, in the soil.

Cation Positively charged ion.

\section{Cation exchange capacity Capacity of a} soil to retain and supply exchangeable cations, including nutrients.

Chemical rooting conditions Chemical characteristics of soil that control root growth.

Chernozemic soils Order of soils developed under cool, subarid-tosubhumid grasslands, characterized by a mineral surface horizon darkened by accumulating organic matter.

Coarse-textured soil Soil, such as sand and sandy loam, composed of coarse particles; also light-textured soil.

Colluvium Mixed material deposited mainly by gravity at the base of slopes or cliffs.
Compost Organic residues, usually with soil added, that have been piled, mixed, moistened, and allowed to decompose; used as a soil amendment.

\section{Computer simulation model Mathe-} matical model, processed on a computer, that is used to describe various soil processes and to predict how these processes will change if certain variables are altered.

Conservation tillage Methods of tillage that maintain a cover of crop residues on the soil surface and either reduce the amount of tilling (reduced tillage or minimal tillage) or eliminate it altogether (no-till).

Contamination Presence of a substance in soil or water at a concentration above the safe limit.

Continuous cropping Growing crops every growing season (no fallow years).

Contour cultivation Cultivation along the contour of the land, rather than upand down-slope.

Conventional tillage Practice of tilling the land to improve it for agricultural purposes; includes plowing and cultivating for seeding and for weed control.

Crop residue Plant material remaining after harvesting, including leaves, stalks, roots.

Crop rotation Growing at least two crop varieties in sequence, such as soybean-corn or alfalfa-alfalfawheat.

Cropland Total area on which field crops, fruits, vegetables, nursery products, and sod are grown.

Crop-tolerance testing Tests to detect a crop's ability to grow in a certain soil.

Crop yield Quality and quantity of a crop harvested. 
Cropping intensity Share of farmland devoted to cultivation.

Cultivated land Land tilled and used to produce crops; includes land left fallow.

Dark Brown soils Chernozemic soils characterized by a dark brown surface, a lighter brownish $B$ horizon, and usually a calcareous C horizon.

Dark Gray soils Chernozemic soils characterized by a dark gray surface, a brownish $B$ horizon, and usually a calcareous $\mathrm{C}$ horizon.

Database Collection of data.

Decomposition Process by which organic and inorganic residues (plant and animal remains) are broken down.

Discharge area Area in which groundwater comes to the soil surface.

Dissipation capacity Soil's ability to adsorb, or hang on to, and degrade chemical compounds.

Diversion Rerouting of part of or all the water in a stream to a different course by means of small earth dikes and dams.

Ecozone Area having distinct climate, vegetation, geology, and soils.

Effluent Liquid waste discharged by industries and other producers into sewage systems and waterways.

Environmental buffer Soil serving to relieve stress on other parts of the environment, such as by detoxifying chemical contaminants.

Erodibility Measure of a soil's susceptibility to erosion.

Erosion, soil Movement of soil from one location to another mainly by wind and water, and also by tillage.

Erosion control Methods used to reduce soil losses resulting from erosion.
Extended rotation Cropping sequence that is lengthened by adding additional crop varieties to the sequence.

Farm stewardship Orderly management of a farm, including responsibility for efficient use of natural resources and care for the environment.

Farming system Overall plan to manage cropping and soils that combines a variety of management practices.

Farmland All land for crops, grazing and pasture, summerfallow, buildings and barnyards, bush, slough, and marshes.

Fertility, soil Measure of the amount of nutrients in the soil available for plant growth.

Fertilization Application of plant nutrients to the soil in the form of commercial fertilizers, animal manure, green manure, and other amendments.

Fines Very small particles in soil; silt and clay fraction.

Fine-textured soils Soils, such as clay and clay loam, composed of small particles; also heavy-textured soil.

Fluvial Relating to flowing water.

Forage Crops, such as alfalfa, that are either grazed or cut for animal feed.

Friability Describes the degree to which a soil can be crumbled.

Gleysolic soils Order of soils developed under wet conditions and characterized by reduced iron and other elements, gray colors, and prominent mottling.

Grassed waterway Grassed strip of land that serves as a channel for runoff; a method of controlling erosion.

Gray soils Luvisolic soils characterized by a light-coloured surface, a brownish B horizon, and usually a calcareous Chorizon. 
Green manure Any plant material that is plowed into the soil while still green to serve as a natural fertilizer or amendment.

Groundwater Subsurface water, the upper surface of which forms the water table in geological materials such as soils, sand and gravel deposits, and bedrock formations; it is free to move by gravity.

Groundwater discharge Groundwater that comes up to the surface.

Growing degree days Measure of heat energy available for crop production.

Gully Channel cut into the soil surface by severe but intermittent water erosion and deep enough to interfere with tillage operations.

GUS value Groundwater ubiquity score (GUS) determined from how easily a pesticide is carried into the soil by downward-percolating water and from how fast it is broken down into harmless by-products by soil microorganisms and chemical reactions.

Half-life Time taken for one-half the amount of a chemical material or soil property to be degraded, transformed, or eliminated.

Hardpan Hardened soil layer at or beneath the surface, having greatly reduced porosity.

Heavy metals Metal elements, such as arsenic, cadmium, chromium, cobalt, copper, lead, mercury, molybdenum, nickel, selenium, and zinc, which are known to contaminate some soils.

Horizon See soil horizon.

Hummocky Uneven, hilly.

Humus Well-decomposed organic portion of the soil forming a dark brown, porous, spongy material with a pleasant, earthy smell.
Hydraulic conductivity Describes the ability of soil to transmit water through soil pores; expresses permeability.

Hydrologic Relating to water.

Hydrologic cycle Route by which water passes naturally from water vapour in the atmosphere through precipitation onto land or water and back into the atmosphere by means of evaporation and transpiration; also water cycle.

Improved cropland Sum of cropland, summerfallow, and improved pasture.

Improved pasture Area improved by seeding, draining, irrigating, fertilizing, brush or weed control, not including areas where hay, silage, or seeds are harvested.

Index of inherent soil quality (ISQ) Measure to assess inherent soil quality based on broad-scale soil, landscape, and climatic information.

Index of soil quality susceptibility (SQS) Identifies agricultural areas that are at risk of declining soil quality because of various land use and management practices.

Indicator Factor indicating or helping to define the state of a larger system.

Inherent erosion risk Risk of erosion on bare soil.

Inherent soil quality Natural quality of a soil as affected by parent materials and the way in which the soil developed.

Inorganic contaminant Soil contaminant that does not contain carbon, such as heavy metals.

Integrated pest management (IPM) Control of pests using a combination of crop rotations, cultivation, and biological and chemical pest controls. 
Interseeding Companion planting; seeding a secondary crop along with the primary crop to provide soil cover after the primary crop is harvested; also underseeding.

Irrigation Artificial watering of land using water channels, pipes, or sprayers.

Lacustrine Relating to lakes.

Land use Way in which land is used, such as for pasture, orchards, and producing field crops.

Leachable Percolates easily down through the soil profile; refers to soluble substances.

Leaching Removal of materials in solution by water percolating through the soil profile.

Luvisolic soils Order of soils developed under forest in a moderate-to-cool climate, in which silicate clay removed from part of the $A$ horizon has accumulated in part of the $B$ horizon.

Macronutrient One of several chemical elements needed in large amounts for proper growth and development of plants (carbon, hydrogen, oxygen, nitrogen, phosphorus, potassium, calcium, magnesium, sulfur); compare micronutrient.

Macroporosity Volume of large pores in the soil.

Marine Relating to the sea.

Methemoglobinemia State of oxygen starvation produced, especially in babies, when nitrite is absorbed into the bloodstream from the digestive tract; it impairs the ability of hemoglobin to transport oxygen.

Method detection limit (MDL) Smallest concentration of a substance that can be measured accurately by a certain analytical method.
Microbial oxidation Process in which soil microorganisms "burn up" organic matter in the soil during their normal metabolism.

Microorganisms Microscopic plants and animals present in the soil and active in decomposition.

Micronutrient One of several chemical elements (trace elements) needed in small amounts for proper growth and development of plants (iron, manganese, molybdenum, boron, copper, zinc, chlorine); compare macronutrient.

Mineralization Conversion of an organic to an inorganic substance as a result of microbial decomposition.

Mixed farm Farm that grows food or cash crops, feed crops, and livestock.

Monoculture Cultivation of a single plant species over a wide area for many years.

Monoculture row-cropping Cultivation of only one type of row crop for many years.

Morainal Relating to material deposited by glacial ice.

Mottling Mixed gray and orange colouration arising from reduced iron effects.

Nonlimiting water range Measure of the amount of water in soil that is available to plants.

Nitrate Predominant form of dissolved nitrogen in soil and groundwater and the principal source of nitrogen for higher plants.

No-till Tillage practice involving direct seeding, which does not break the soil surface.

Nonpoint-source entry Entry of agrochemicals into groundwater over a large land area, usually by leaching through the soil profile. 
Nonrenewable resources Natural resources that cannot be replaced on a human time-scale once they have been used up (such as fossil fuels).

Nutrient retention Holding onto nutrients.

Organic contaminant Soil contaminant that contains carbon.

Organic matter Decomposed plant and animal residues.

Organic soil Soil containing a high level of organic matter.

Osmotic gradient Difference in salt concentrations between two solutions that controls the movement of water. Water moves from the solution with a lower concentration to that with a higher concentration of salt.

Pan Layer in the soil that is strongly compacted, hardened, or high in clay content.

Pedestal Column of soil supporting stones and plant debris; evidence of water erosion.

Penetrometer Instrument used for measuring soil strength by penetrating with a small cone.

Permanent crop cover Perennial crop, such as a forage, that protects the soil throughout the year.

Permeability Describes the ease with which gases, such as air, or fluids, such as water, can pass through a soil.

Pest Organism that is a nuisance to humans or injures crops and animals upon which people depend for food, fibre, and shelter.

Pesticide Chemical that kills or controls pests; includes herbicide, insecticide, fungicide, nematocide, rodenticide, and miticide.

Physical rooting conditions Physical characteristics, such as waterholding capacity and porosity, that control root growth.
Plastic limit Soil water content at which the soil changes from a semisolid to a plastic state.

Podzolic soils Order of soils formed under coniferous forests, generally from coarse parent materials, and containing a $\mathrm{B}$ horizon high in iron and aluminum.

Point-source entry Localized entry of agrochemicals into drinking water, such as by accidental spills and manure leakage into domestic wells.

Policy Principles and courses of action adopted by government to fulfil certain objectives, such as sustainable agriculture.

Pore space Space in a soil not occupied by soil particles.

Recharge area Place where water percolates through the soil into the groundwater.

Residue management Maintaining a cover of crop residues on the soil surface.

Rill Small water channel on the soil surface, caused by water erosion.

Root rot Plant disease characterized by decay of the roots.

Runoff Portion of the total precipitation that enters surface streams rather than infiltrating the soil.

Safe limit Concentration of a substance, such as bacteria, pesticides, or nitrate, in drinking water above which the substance may pose a risk to human or animal health.

Saline seep Intermittent or continuous saline discharge at or near the soil surface under dryland conditions, which reduces or eliminates crop growth

Salinity Amount of soluble salts in a soil.

Salinity risk index Measure of the chance that an area has a certain level of salinity. 
Salinization Natural process by which salts accumulate in the soil.

Sediment Soil particles that are moved and deposited by wind, water, or gravity.

Seedbed Soil prepared for seeding.

Seed-drilling Seeding by means of an implement that plants seeds in holes or furrows and covers them with soil.

Sewage sludge Solid and semisolid waste resulting from the treatment of domestic and industrial effluents that are released into sewers.

Sheet erosion Removal of a fairly uniform layer of soil from the land surface by runoff water.

Shelterbelt Line of trees or bushes planted at the border of a field to break the force of the wind; also windbreak.

Sludge loading Maximum amount of sewage sludge that can be safely applied to soil.

Soil archive Collection of soil samples.

Soil compaction Pressing together of soil particles, reducing the pore space between them.

Soil contaminant Chemical substance present in the soil above safe limits.

Soil cover Vegetation, including crops, and crop residues left on the soil surface.

Soil degradation General process by which soil declines in quality and is thus made less fit for a specific purpose, such as crop production.

Soil health Soil's fitness to support crop growth without resulting in soil degradation or otherwise harming the environment; also soil quality.

Soil horizon Distinct layer of soil in the soil profile; primary horizons usually labelled A, B, or C.
Soil organic matter Constituent of soil that includes plant and animal remains in various stages of decomposition, cells and tissues of soil organisms, and substances produced by the soil microbes.

Soil pores Spaces between soil particles.

Soil porosity Amount of space in a soil not occupied by solid particles.

Soil profile Vertical section of a soil that displays all the soil horizons.

Soil quality Soil's fitness to support crop growth without resulting in soil degradation or otherwise harming the environment; also soil health.

Soil quality index Measure of a soil's health at one point in time; a "report card" of soil health.

Soil quality indicator Property, function, or condition of soil that is useful in describing soil quality.

Soil structure Physical properties of a soil relating to the arrangement and stability of soil particles and pores.

Soil texture Relative proportions of sand, silt, and clay in a soil.

Splash erosion Displacement of soil by falling droplets of water.

Strip-cropping Alternating tilled crops in narrow strips across a long slope.

Subsoil Layers of soil found below the original level of plowing between the topsoil and parent material.

Subsurface drainage Artificial drainage systems, such as tiles, installed below the soil surface to relieve wet soil conditions.

Summerfallow Land that is not cropped for at least 1 year.

Surface relief Elevations and depressions on the land surface. 
Surface water Water occurring on the surface of the land, such as streams, rivers, ponds, lakes, and oceans.

Sustainable agriculture Way of farming that maintains the land's ability to produce over time.

Terrace Steplike surface that breaks the continuity of a slope.

Threshold values Points at which a change in soil quality is likely to occur.

Tillage Mechanical preparation of the soil for seeding, for fallow, or for weed control.

Tillage erosion Displacement of soil by the action of tillage.

Tilth Physical condition of the soil as it relates to ease of tillage and fitness as a seedbed.
Toxic Poisonous to plants, animals, or humans.

Transfer technology Convey useful scientific and technological findings to user groups.

Water contaminant Substance in water at a concentration above the safe limit, entering the surface water through runoff or the groundwater through leaching.

Water table Upper surface of the groundwater, found at a depth where the pressure in the water equals atmospheric pressure.

Winter cover-cropping Maintaining soil cover throughout the nongrowing season by planting a cover crop during the fall. 


\section{Additional Reading}

\section{Introduction}

Parr, J.F., R.I. Papendick, S.B. Hornick, and R.E. Meyer. 1992. Soil quality: attributes and relationship to alternative and sustainable agriculture. Journal of Alternative Agriculture 7:5-11.

\section{Chapter 1 Understanding soil health}

Doran, J.W. and T.B. Parkin. 1994. Defining and assessing soil quality. Pages 3-21 in J.W. Doran, D.C. Coleman, D.F. Bezdicek, and B.A. Stewart (eds.) Defining soil quality for a sustainable environment. SSSA Special Publication No. 35, 244 pp.

Chapter 3 A geographical framezork for assessing soil quality

Canadian Global Change Program. 1995. Looking ahead: long-term ecological research and monitoring in Canada. Report of the long-term ecosystem and monitoring panel of the Canadian Global Change Program, Royal Society of Canada. Technical Report Series No. 95-1, (in press).

Hillel, D. 1991. Out of the earth: civilization and the life of the soil. University of California Press, Berkeley, Calif. $321 \mathrm{pp}$.
Chapter 4 Benchmark sites for monitoring agricultural soil quality

Parr, J.F., R.I. Papendick, S.B. Hornick, and R.E. Meyer. 1992. Soil quality: attributes and relationship to alternative and sustainable agriculture. Journal of Alternative Agriculture 7:5-11.

Wang, C., B.D. Walker, H.W. Rees, L.M. Kozak, M.C. Nolin, W. Michalyna, K.T. Webb, D.A. Holmstrom, D. King, E.A. Kenney, and E.F. Woodrow. 1994. Benchmark sites for monitoring agricultural soil quality in Canada. Centre for Land and Biological Resources Research, Agriculture and Agri-Food Canada, Ottawa, Ont. Soil Quality Evaluation Program Technical Report 1,76 pp.

\section{Chapter 5 Changes in soil organic matter}

Campbell, C.A., R.P. Zentner, H.H. Janzen, and K.E. Bowren. 1990. Crop rotation studies on the Canadian prairies. Research Branch, Agriculture Canada. Publication 1841/E. 133 pp.

Carter, M.R. 1994. A review of conservation tillage strategies for humid temperate regions. Soil \& Tillage Research 31(4):289-301.

Dumanski, J., D.R. Coote, G. Luciuk, and C. Lok. 1986. Soil conservation in Canada. Journal of Soil and Water Conservation 41:204-210. 
Gregorich, E.G., M.R. Carter, D.A. Angers, C.M. Monreal, and B.H. Ellert. 1994.

Towards a minimum data set to assess soil organic matter quality in agricultural soils. Canadian Journal of Soil Science 74:367-385.

Power, J.F. 1994. Understanding the basics: Understanding the nutrient cycling process. Pages 16-23 in Nutrient management. Special Supplement to Journal of Soil and Water Conservation 49(2).

Reganold, J.P., R.I. Papendick, and J.F. Parr. 1990. Sustainable agriculture.

Scientific American June:112-120.

Swift, M.J., O.W. Heal, and J.M. Anderson. 1979. Decomposition in terrestrial ecosystems. University of California Press, Berkeley, Calif. 372 pp.

Tarnocai, C. 1994. Amount of organic carbon in Canadian soils. Pages 67-82 in Transactions of 15th world congress of soil science, vol. 6a, Commission V: Symposia. Acapulco, Mexico. International Society of Soil Science.

\section{Chapter 6 Changes in soil structure}

Anon. 1986. A growing concern: Soil degradation in Canada. Science Council of Canada, Ottawa, Ont. 24 pp.

Anon. 1988. Assessment of soil compaction and structural degradation in the lowland clay soils. Report of the Soil and Water Environmental Enhancement Program (Technology

Evaluation and Development subprogram). CAN-AG Enterprises and Agriculture and Agri-Food Canada, Ottawa, Ont. 70 pp.

Anon. 1994. Best management practices: Soil management. Ontario Ministry of Agriculture, Food and Rural Affairs, Toronto, Ont., and Agriculture and Agri-Food Canada, Ottawa, Ont. 68 pp.

Carter, M.R. 1994. A review of conservation tillage strategies for humid temperate regions. Soil \& Tillage Research 31:289-301.
Kay, B.D. 1990. Rates of change of soil structure under different cropping systems. Pages 1-52 in B.A. Stewart (ed.) Advances in soil science. Springer-Verlag, New York, N.Y.

Lafond, G.P., Heather Loeppky, and D.A. Derksen. 1992. The effects of tillage systems and crop rotations on soil water conservation, seedling establishment and crop yield. Canadian Journal of Plant Science 72:103-115.

Larney, F.J., C.W. Lindwall, R.C. Izaurralde, and A.P Moulin. 1994. Tillage systems for soil and water conservation on the Canadian prairie. Pages 305-328 in M.R. Carter (ed.) Conservation tillage in temperate agroecosystems. Lewis Publ., Boca Raton, Fla.

Tabi, M., L. Tardif, D. Carrier, G. Laflamme, and M. Rompré. 1990. Inventaire des problèmes de dégradation des sols agricoles du Québec. Rapport synthèse. Min. de l'Agriculture, des Pêcheries et de l'Alimentation du Québec, Québec. 71 pp.

Topp, G.C., Y.T. Galganov, K.C. Wires, and J.L.B. Culley. 1994. Non-limiting water range (NLWR): An approach for assessing soil structure. Soil Quality Evaluation Program, Technical Report 2. Agriculture and Agri-Food Canada, Ottawa, Ont. $36 \mathrm{pp}$.

Vyn, T.J., K. Janovicek, and M.R. Carter. 1994. Tillage requirements for annual crop production in eastern Canada. Pages 47-71 in M.R. Carter (ed.) Conservation tillage in temperate agroecosystems. Lewis Publ., Boca Raton, Fla.

\section{Chapter 7 Erosion}

Anon. 1994. (Series) Best management practices: Field crop production, 133 pp.; Soil management, 68 pp.; Water management, $93 \mathrm{pp}$. Ontario Ministry of Agriculture, Food and Rural Affairs, Toronto, Ont., and Agriculture and Agri-Food Canada, Ottawa, Ont 
Canada Soil Inventory. 1989-. Water erosion risk-(by province). Land Resource Research Centre, Research Branch, Ottawa, Ont. Agriculture Canada Publication (each a kit folder including 10-page booklet and map).

Canada Soil Inventory. 1989-. Wind erosion risk-(by province). Land Resource Research Centre, Research Branch, Agriculture Canada, Ottawa, Ont. Agriculture Canada Publication (Alberta and Manitoba each a kit folder including 10-page booklet and map; Saskatchewan map only).

Great Lakes Advisory Committee, G.J. Wall, Chair. 1994. Great Lakes Water Quality Program-Summary of achievements. 1989-1994. Pest Management Research Centre, Research Branch, Agriculture and Agri-Food Canada, London, Ont. 6-page brochure.

Standing Senate Committee on Agriculture, Fisheries and Forestry, Hon. H.O. Sparrow, Chair. 1984. Soil at riskCanada's eroding future. Senate of Canada, Ottawa, Ont. 129 pp.

Dumanski, J., L.J. Gregorich, V. Kirkwood, M.A. Cann, J.L.B. Culley, and D.R. Coote. 1994. The status of land management practices on agricultural land in Canada. Centre for Land and Biological Resources Research, Agriculture and Agri-Food Canada, Technical Bulletin 1994-3E, 46 pp.

\section{Chapter 8 Salinization of Soil}

Anon. 1973. Irrigation, drainage and salinity. An international source book. FAO/UNESCO, Rome, Italy. 510 pp.

Anon. 1982. Soil salinity. Proceedings of the first annual western provincial conference rationalization of water and soil research and management, Lethbridge, Alta. Government of Alberta. 379 pp.

Anon. 1991. Dryland saline seep control. Alberta Agriculture and Agriculture Canada. 12 pp.

Anon. 1992. Dryland salinity investigations procedures manual. Conservation and Development Branch, Alberta Agriculture and PFRA, Agriculture and Agri-Food Canada. 110 pp.

Henry, J.L., W.R.A. Harron, and D. Flaten. 1987. The nature and management of salt-affected land in Saskatchewan. Soils and Crops Branch, Saskatchewan Agriculture. Agdex 518. $23 \mathrm{pp}$.

Holms, H.M. and J.L. Henry. 1982. Understanding salt-affected soils. Plant Industry Branch, Saskatchewan Agriculture. 14 pp.

Steppuhn, H. and D. Curtin (eds.). 1992. Salinity and sustainable agriculture. Research Branch, Agriculture Canada. Swift Current Research Station, Swift Current, Sask. Prairie Salinity Publication No. 1. 192 pp.

\section{Chapter 9 Contamination of Agricultural} Soils

Adriano, D.C. 1986. Trace elements in the terrestrial environment. SpringerVerlag, New York, N.Y.

Freedman, B. and T.C. Hutchinson. 1981. Sources of metal and elemental contamination of terrestrial environments. Pages 35-94 in N.W. Lepp (ed.) Effect of heavy metal pollution on plants. Applied Science Publishers, New York, N.Y.

Garrett, R.G. 1994. The distribution of cadmium in A horizon soils in the prairies of Canada and adjoining United States. Pages 73-82 in Current Research 1994-B. Geological Survey of Canada.

Giroux, M., M. Rompré, D. Carrier, P. Audesse, et M. Lemieux. 1992. Caractérisation de la teneur en métaux lourds totaux et disponibles des soil du Québec. Agrosol 5(2): 46-55.

Kabata-Pendias, A. and H. Pendias. 1992. Trace elements in soils and plants. CRC Press, Boca Raton, Fla.

McKeague, J.A. and M.S. Wolynetz. 1980. Background levels of minor elements in some Canadian soils. Geoderma 24:299-307. 
Ontario Ministry of Agriculture and Food and Ontario Ministry of the Environment. 1992. Guidelines for sewage sludge utilization on agricultural lands. Sludge and Waste Utilization Committee, OMAF and OME, Toronto, Ont. 32 pp.

Ontario Ministry of Environment and Energy. 1994. Proposed guidelines for the cleanup of contaminated sites in Ontario. Toronto, Ont. 74 pp.

Webber, M.D., H.D. Monteith, and D.G.M Corneau. 1983. Assessment of heavy metals and PCBs at sludge application sites. Journal of Water Pollution Control Federation 55:187-195.

Webber, M.D. 1994. Industrial organic compounds in selected Canadian municipal sludges and agricultural soils. Report prepared for Agriculture and Agri-Food Canada, Ottawa, Ont., October 1994. 100 pp.

Webber, M.D. and J.A. Nichols. 1995. Organic and metal contaminants in Canadian municipal sludges and a sludge compost. Wastewater Technology Centre, Burlington, Ont. 169 pp.

\section{Chapter 10 Agrochenical entry into groundivater}

CCREM (Canadian Council of Resource and Environment Ministers). 1987. Canadian water quality guidelines. Task Force on Water Quality Guidelines, Environment Canada, Ottawa, Ont. (and subsequent appendixes 1989-).

Environment Canada, Conservation and Protection. 1990. Fact Sheet No. 5: Groundwater - nature's hidden treasure. Inland Waters Directorate, Environment Canada, Ottawa, Ont. $12 \mathrm{pp}$.
Hargrove, W.L. (ed.). 1991. Cover crops for clean water. Soil and Water Conservation Society, Ankeny, Iowa. 198 pp.

Henry, J.L. and W.A. Meneley. 1993. Fertilizers and groundwater nitrate. I Review of literature. II Nitrates in western Canadian ground water. Western Canada Fertilizer Association, Surrey, B.C. 55 pp.

MacRae, B. 1991. Backgrounder: The characterization and identification of potentially leachable pesticides and areas vulnerable to groundwater contamination by pesticides in Canada. Pesticides Directorate, Agriculture Canada, Ottawa, Ont. 35 pp. + appendixes.

Milburn, P., W. Nicholaichuk, and C. Topp (eds.). 1992. Agricultural inpacts on water quality: Canadian perspectives. Canadian Agricultural Research Council, Ottawa, Ont. 207 pp.

Millette, J.A. and M. Torreiter. 1992. Nonpoint source contamination of groundwater in the Great Lakes basin: a review. Centre for Land and Biological Resources Research, Agriculture Canada, Ottawa, Ont. $21 \mathrm{pp}$.

\section{Stmminary}

Batie, S.S. and C.A. Cox. 1994. Soil and water quality: an agenda for agriculture. A summary. Journal of Soil and Water Conservation 49(5):456-462.

Dumanski, J., L.J. Gregorich, V. Kirkwood, M.A. Cann, J.L.B. Culley, and D.R. Coote. 1994. The status of land management practices on agricultural land in Canada. Centre for Land and Biological Resources Research, Agriculture and Agri-Food Canada, Technical Bulletin 1994-3E, $46 \mathrm{pp}$. 


\section{Authors' Affiliations}

D.F. Acton

CLBRR/LRD, Research Branch, Agriculture and Agri-Food Canada

Saskatchewan Land Resource Unit, 5c26 Agriculture Building

University of Saskatchewan, 51 Campus Drive

Saskatoon, SK S7N 5A8

L.J. Gregorich

59 Hackett Street, Ottawa, ON K1V 0P6

\section{Chapter 3}

K.B. MacDonald

CLBRR Land Resource Unit, Research Branch, Agriculture and Agri-Food Canada

Land Resource Division, 70 Fountain Street

Guelph, ON N1H 3N6

W.R. Fraser (AAFC, Winnipeg, Man.)

G.W. Lelyk (AAFC, Winnipeg, Man.)

F. Wang (AAFC, Guelph, Ont.)

Chapter 4

C. Wang

CLBRR/LRD, Research Branch, Agriculture and Agri-Food Canada

K.W. Neatby Building, Central Experimental Farm

Ottawa, ON K1A 0C6

L.J. Gregorich (Ottawa, Ont.)

D.A. Holmstrom (AAFC, Charlottetown, P.E.I.)

E.A. Kenney (AAFC, Vancouver, B.C.)

D.J. King (AAFC, Guelph, Ont.)

L.M. Kozak (AAFC, Saskatoon, Sask.)

W. Michalyna (AAFC, Winnipeg, Man.)

M.C. Nolin (AAFC, Sainte-Foy, Que.)

H.W. Rees (AAFC, Fredericton, N.B.)

B.D. Walker (AAFC, Edmonton, Alta.)

K.T. Webb (AAFC, Truro, N.S.)

E.F. Woodrow (AAFC, Mount Pearl, Nfld.) 
Chapter 5

E.G. Gregorich

CLBRR/LRD, Research Branch, Agriculture and Agri-Food Canada

K.W. Neatby Building, Central Experimental Farm

Ottawa, ON K1A 0C6

D.A. Angers (AAFC, Sainte-Foy, Que.)

C.A. Campbell (AAFC, Swift Current, Sask.)

M.R. Carter (AAFC, Charlottetown, P.E.I.)

D.F. Drury (AAFC, Harrow, Ont.)

B.H. Ellert (AAFC, Lethbridge, Alta.)

P. Groenevelt (University of Guelph, Guelph, Ont.)

D.A. Holmstrom (AAFC, Charlottetown, P.E.I.)

C.M. Monreal (AAFC, Ottawa, Ont.)

H.W. Rees (AAFC, Fredericton, N.B.)

R.P. Voroney (University of Guelph, Guelph, Ont.)

T.J. Vyn (University of Guelph, Guelph, Ont.)

Chapter 6

G.C. Topp

CLBRR/LRD, Research Branch, Agriculture and Agri-Food Canada

K.W. Neatby Building, Central Experimental Farm

Ottawa, ON K1A 0C6

M.R. Carter (AAFC, Charlottetown, P.E.I.)

J.L.B. Culley (AAFC, Saskatoon, Sask.)

D.A. Holmstrom (AAFC, Charlottetown, P.E.I.)

B.D. Kay (University of Guelph, Guelph, Ont.)

G.P. Lafond (AAFC, Indian Head, Sask.)

D.R. Langille (AAFC, Truro, N.S.)

R.A. McBride (University of Guelph, Guelph, Ont.)

G.T. Patterson (AAFC, Truro, N.S.)

E. Perfect (University of Guelph, Guelph, Ont.)

V. Rasiah (University of Guelph, Guelph, Ont.)

A.V. Rodd (AAFC, Kentville, N.S.)

K.T. Webb (AAFC, Truro, N.S.)

K.C. Wires (AAFC, Ottawa, Ont.)

Chapter 7

G.J. Wall

CLBRR Land Resource Unit, Research Branch, Agriculture and Agri-Food Canada Land Resource Division, 70 Fountain Street

Guelph, ON N1H 3N6

J.-M. Cossette (AAFC, Sainte-Foy, Que.)

R.G. Eilers (AAFC, Winnipeg, Man.)

G.A. Padbury (AAFC, Saskatoon, Sask.)

E.A. Pringle (AAFC, Guelph, Ont.)

H.W. Rees (AAFC, Fredericton, N.B.) 
J. Tajek (AAFC, Edmonton, Alta.)

L.J.P. van Vliet (AAFC, Vancouver, B.C.)

Chapter 8

R.G. Eilers

CLBRR Land Resource Unit, Research Branch, Agriculture and Agri-Food Canada Ellis Building, University of Manitoba

Winnipeg, MB R3T 2N2

W.D. Eilers (AAFC, Saskatoon, Sask.)

G.W. Lelyk (AAFC, Winnipeg, Man.)

W.W. Pettapiece (AAFC, Edmonton, Alta.)

Chapter 9

M.D. Webber

Wastewater Technology Centre

867 Lakeshore Road, P.O. Box 5068 Burlington, ON L7R 4L7

S.S. Singh (AAFC, Ottawa, Ont.)

Chapter 10

W.D. Reynolds

CLBRR/LRD, Research Branch, Agriculture and Agri-Food Canada

K.W. Neatby Building, Central Experimental Farm

Ottawa, ON K1A 0C6

C.A. Campbell (AAFC, Swift Current, Sask.)

C. Chang (AAFC, Lethbridge, Alta.)

C.M. Cho (University of Manitoba, Winnipeg, Man.)

J.H. Ewanek (Manitoba Agriculture, Selkirk, Man.)

R.G. Kachanoski (University of Guelph, Guelph, Ont.)

J.A. McLeod (AAFC, Charlottetown, P.E.I.)

P.H. Milburn (AAFC, Fredericton, N.B.)

R.R. Simard (AAFC, Sainte-Foy, Que.) 


\section{Acknowledgments}

The authors thank the following individuals who provided reviews:

Introduction/Understanding soil health/ Development and effects of farming in Canada: J.F. Dormaar (AAFC, Lethbridge, Alta.), R.L. Halstead (retired, formerly AAFC, Ottawa, Ont.), and W.W. Pettapiece (AAFC, Edmonton, Alta.).

Development and effects of farming in Canada: The author makes extensive use of material in Sustainability in Canadian agriculture (Anderson, D.W., C.J. Roppel, and R.M. Gray 1991), a report prepared for the Science Council of Canada and presented to the House of Commons Standing Committee on Agriculture.

A geographical framezork for assessing soil quality: R. McBride (University of Guelph, Guelph, Ont.) and T. Wright (Prairie Farm Rehabilitation Administration, Regina, Sask.).

Benchmark sites for monitoring agricultural soil health: J. Millette and S. Nelson (both of AAFC, Ottawa, Ont.).
Changes in soil organic matter: H.H. Janzen (AAFC, Lethbridge, Alta.) and A.J. McKeague (retired, formerly AAFC, Ottawa, Ont.).

Changes in soil structure: J. Carron (University of Laval, Sainte-Foy, Que.), E. de Jong (University of Saskatchewan, Saskatoon, Sask.), L.J.P. van Vliet (AAFC, Vancouver, B.C.), and B.J. Zebarth (AAFC, Agassiz, B.C.).

Salinization of soil: D.B. Harker and W. Harron (both of Prairie Farm Rehabilitation Administration, Regina, Sask.) and H.S.A. Vander Pluym (Alberta Agriculture, Food, and Rural Development, Edmonton, Alta.).

Contamination of agricultural soils: S. Clegg (OMAFRA, Guelph, Ont.) and A.J. McKeague (retired, formerly AAFC, Ottawa, Ont.).

Agrochemical entry into groundwater: R.W. Gillham (University of Waterloo, Waterloo, Ont.) and J.L. Henry (University of Saskatchewan, Saskatoon, Sask.).

The authors acknowledge the following organizations that provided reviews for part of, or the whole, manuscript:

Charlottetown Research Centre, Agriculture and Agri-Food Canada

Fredericton Research Centre, Agriculture and Agri-Food Canada
Integrated Management Section, Policy and Planning Branch, Saskatchewan Environment and Public Safety

Irrigation and Resource Management Division, Alberta Agriculture 
Land Resources Branch, New Brunswick Department of Agriculture

Lethbridge Research Centre, Agriculture and Agri-Food Canada

Prairie Farm Rehabilitation Administration, Regina, Saskatchewan.

Resource Management Branch, British Columbia, Ministry of Agriculture,

Fisheries and Food
Service des sols, Ministère de l'Agriculture, des Pecheries et de l'Alimentation du Quebec

Soil and Land Management Division, Newfoundland Department of Fisheries, Food and Agriculture

Sustainable Development Branch, Saskatchewan Agriculture and Food

Swift Current Research Centre, Agriculture and Agri-Food Canada

The following people provided photographs:

Chapters 1 and 2: CLBRR photo collection.

Chapter 4 (box): C. Carter.

Chapter 7: Figs 7-1A to 7-1D, 7-2A and 7-2B

G.J. Wall, AAFC, Guelph, Ont.

Fig 7-1E H.W. Rees, AAFC, Fredericton, N.B.,

Fig 7-2C D.R. Coote, AAFC, Ottawa, Ont.

Box 2 G. Howe, PFRA Shelterbelts Centre, Indian Head, Sask.

The following organizations provided maps:

Map data from Agriculture census, Statistics Canada. Compilation by the Ontario and Saskatchewan Land Resource Units. Printing preparation by CanSIS/ CDR, Research Branch, AAFC, Ottawa, Ont.

Soils of Canada: prepared by Canada Soil Information System (CanSIS), Centre for Land and Biological Resources Research, Research Branch, Agriculture and AgriFood Canada.

The following organizations provided funds:

Environment Canada, State of the Environment Directorate for preparation of the maps in Chapter 3 (arranged through Ian Marshall, Ecozone Analysis Branch).
Chapter 8: R.G. Eilers, AAFC, Winnipeg, Man.

Chapter 9: M.D. Webber, Wastewater Technology Centre, Burlington, Ont.

Chapter 10: W.D. Reynolds, AAFC, Ottawa, Ont.

Terrestrial ecozones of Canada: Ecological Stratification Working Group 1995. A national ecological framework for Canada. Centre for Land and Biological Resources Research, Research Branch, Agriculture and Agri-Food Canada, and Ecozone Analysis Branch, State of the Environment Directorate, Environment Canada. Map prepared by CanSIS.

Canada-Alberta Environmentally Sustainable Agriculture Agreement (CAESA) and Canada-Saskatchewan Agricultural Green Plan Agreement (CSAGPA) for increasing the printrun and distribution of the report. 

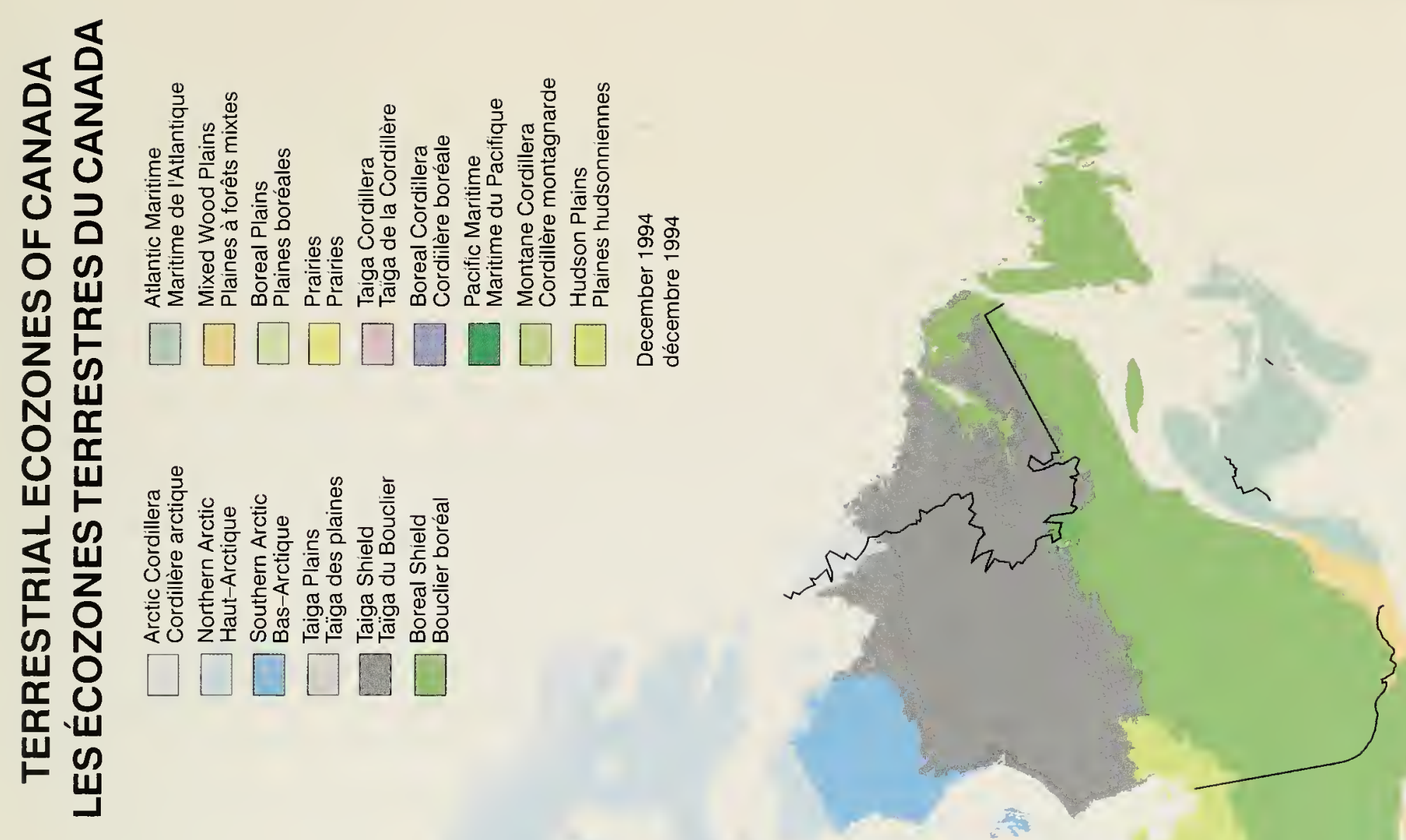


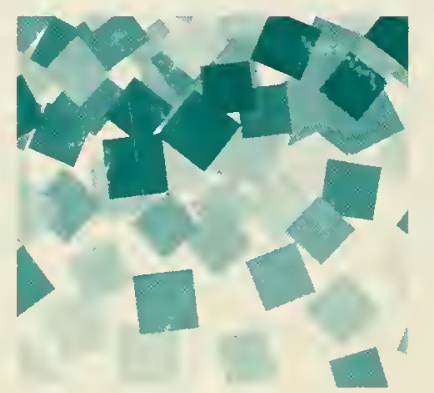

Canadäà 